División de Ciencias Sociales y Humanidades

\title{
El problema semántico de la verosimilitud
}

ICR que para obtener el grado de:

Maestría en Humanidades

Con especialidad en:

Filosofía de las Ciencias y del Lenguaje.

Presenta:

Licenciado Marcos Gabriel Vázquez Dávila

\author{
Asesor: \\ Dr. Armando Cíntora Gómez
}

Sinodales: Dr. David Gaytán Cabrera.

Dr. Jorge Roberto Ornelas Bernal.

9 de diciembre del 2016

Ciudad de México

Esta tesis se realizó con el apoyo de Conacyt. 


\section{ACTA DE EXAMEN DE GRADO}

EL PROBLEMA SEMANTICO DE LA VEROSIMILITUD

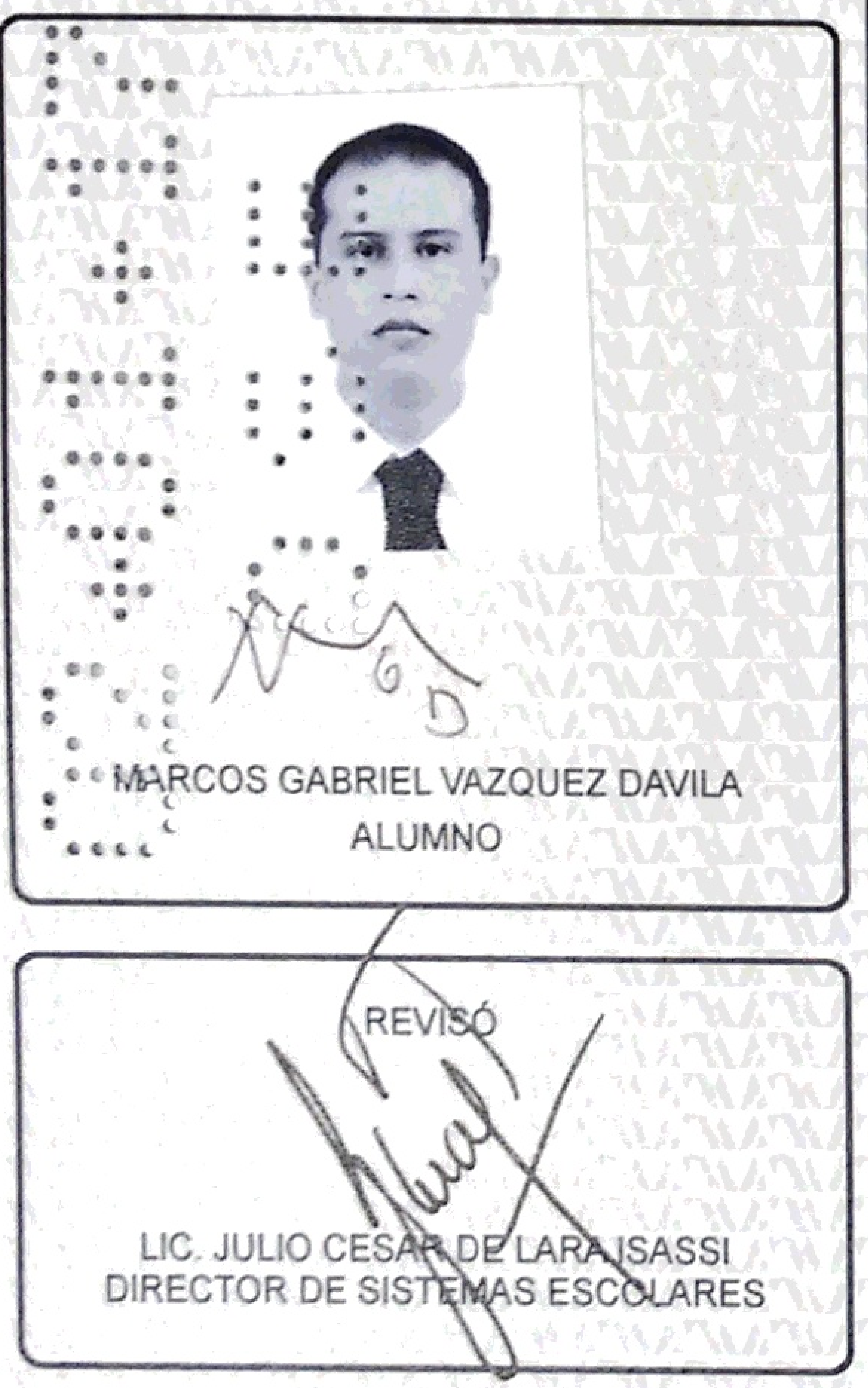

En la Ciudad de México, se presentaron a las 11:00 horas del día 9 del mes de diciembre del año 2016 en la Unidad Iztapalapa de la Universidad Autónoma Metropolitana, los suscritos miembros del jurado:

DR. ARMANDO CINTORA GOMEZ

DR. DAVID GAYTAN CABRERA

DR. JORGE ROBERTO ORNELAS BERNAL
Bajo la Presidencia del primero y con carácter de Secretario el último, se reunieron para proceder al Examen de Grado cuya denominación aparece al margen, para la obtención del grado de:

MAESTRO EN HUMANIDADES (FILOSOFIA)

DE: MARCOS GABRIEL VAZQUEZ DAVILA

$y$ de acuerdo con el artículo 78 fracción III del Reglamento de Estudios Superiores de la Universidad Autónoma Metropolitana, los miembros del jurado resolvieron:

\section{APROBAR}

Acto continuo, el presidente del jurado comunicó al interesado el resultado de la evaluación $y$, en caso aprobatorio, le fue tomada la protesta.
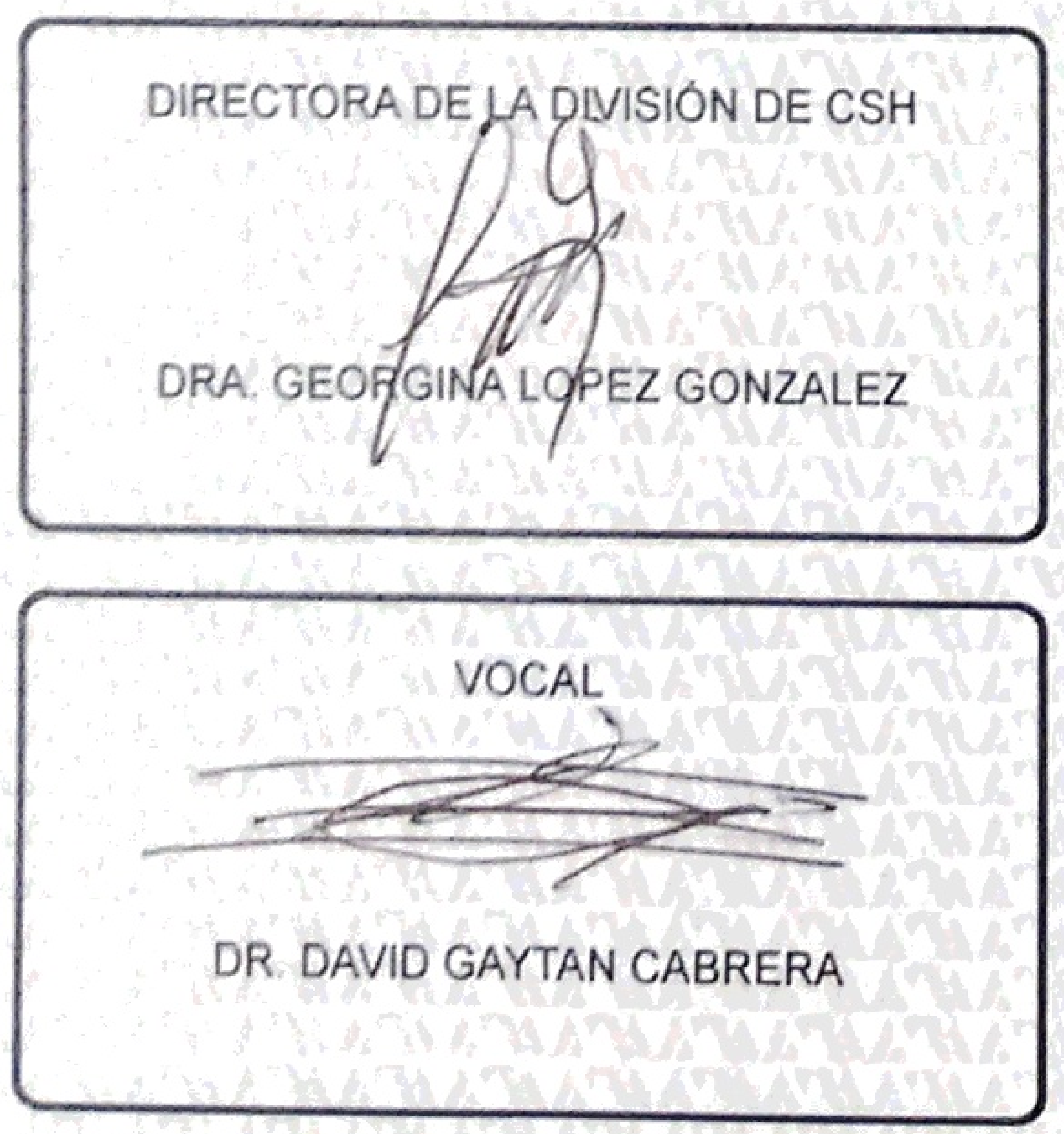
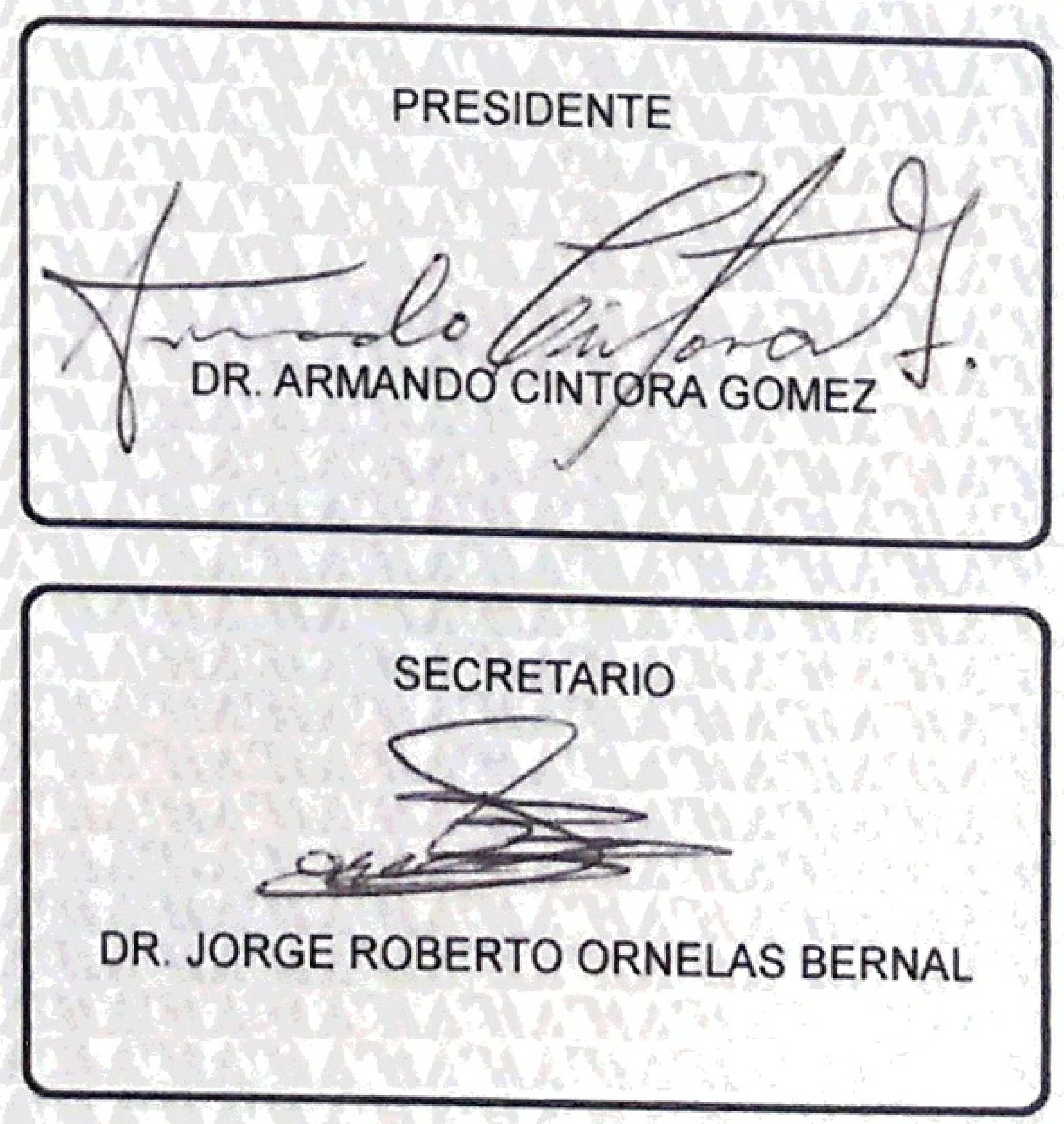


\section{Índice}

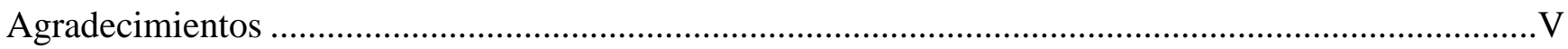

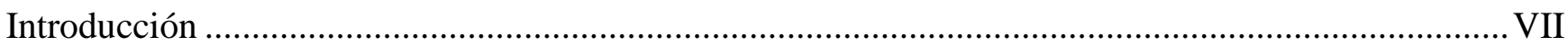

Capítulo I. El debate sobre el realismo científico ................................................................................. 1

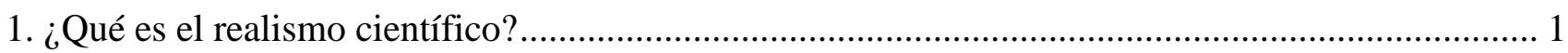

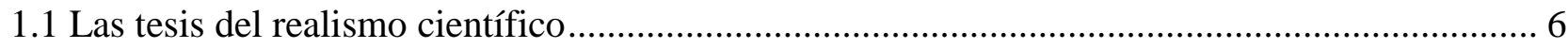

2. Argumentos a favor del realismo científico …………….......................................................

2.1 El realismo científico y el sentido común................................................................................... 9

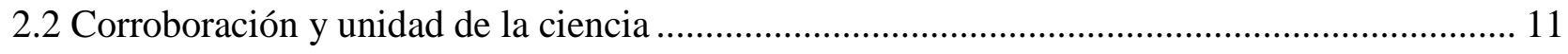

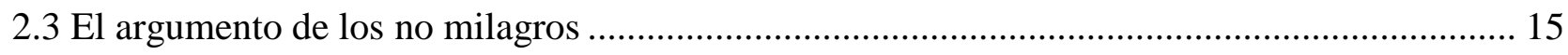

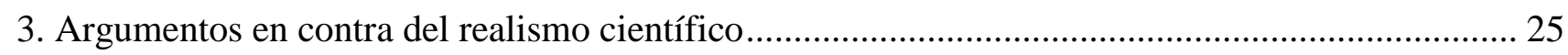

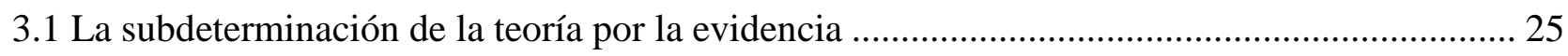

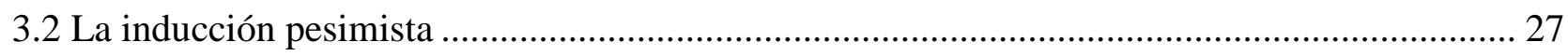

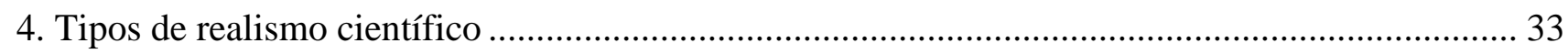

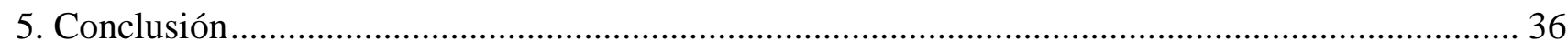

Capítulo II. La verosimilitud: definiciones y problemas ......................................................................... 39

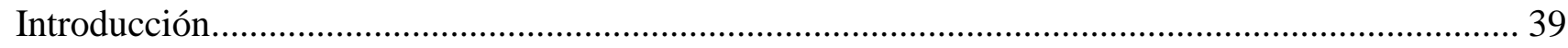

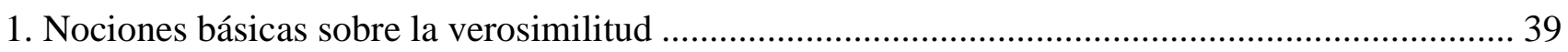

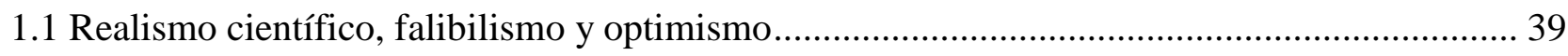

1.2 La intuición del sentido común y la verosimilitud ................................................................... 41

1.3 Verosimilitud, corroboración, probabilidad y grados de justificación ......................................... 43

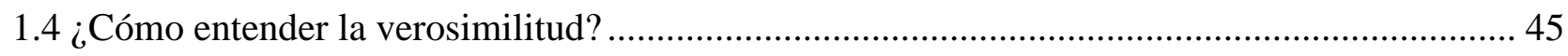

2. Karl Popper y el inicio del proyecto de la verosimilitud................................................................ 49

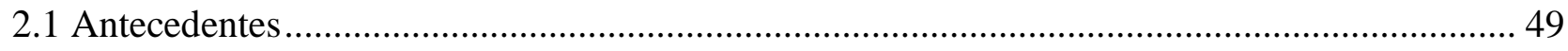

2.2 Teoría de la verdad por correspondencia y la verosimilitud........................................................ 51

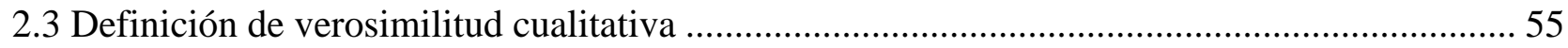




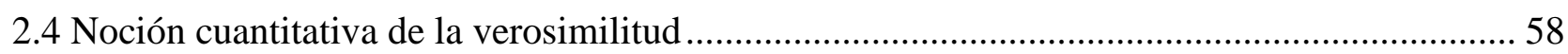

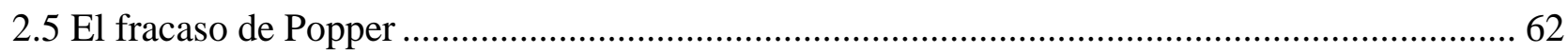

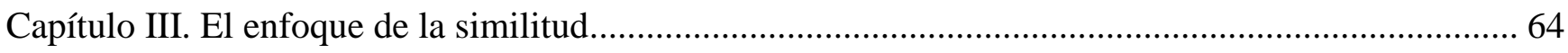

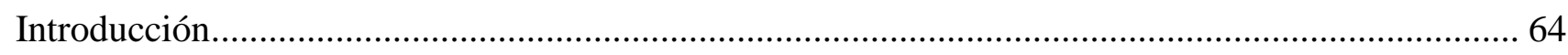

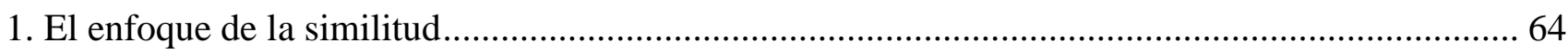

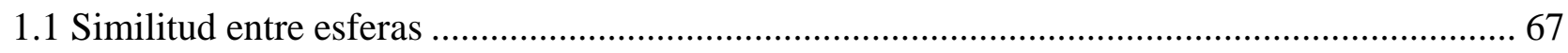

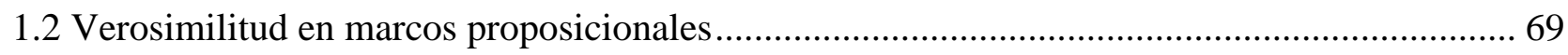

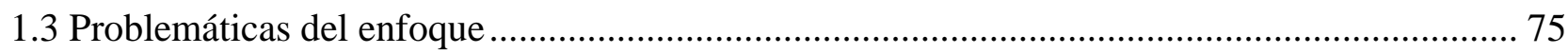

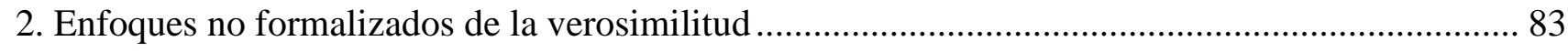

2.1 Verosimilitud en el realismo constructivista de Ronald Giere ....................................... 83

2.2 El enfoque "type-hierarchy" de Aronson, Harré y Way .................................................... 90

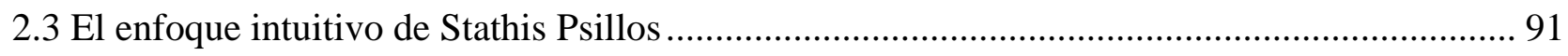

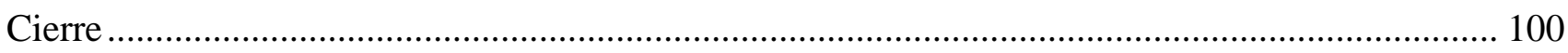

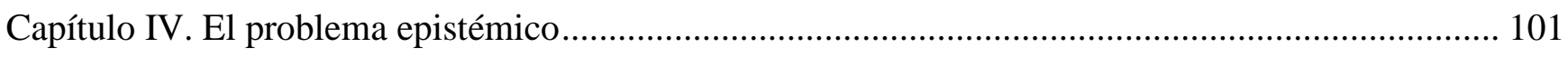

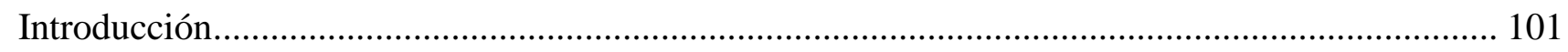

1. Críticas al proyecto de la verosimilitud .................................................................... 103

2. Mediciones de verosimilitud epistémica ...................................................................... 106

2.1 Popper: falsacionismo y corroboración .................................................................. 106

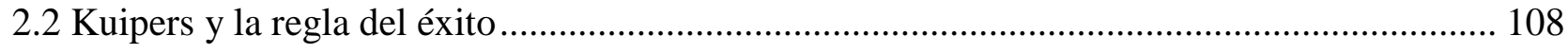

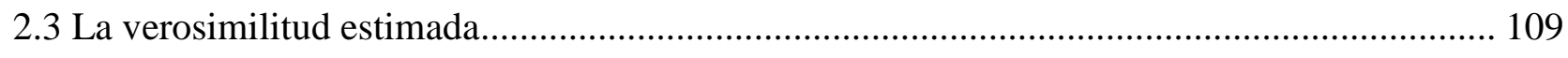

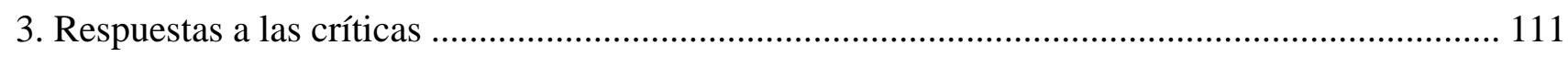

Capítulo V. Verdad aproximada, deflacionismo y modelos ....................................................... 115

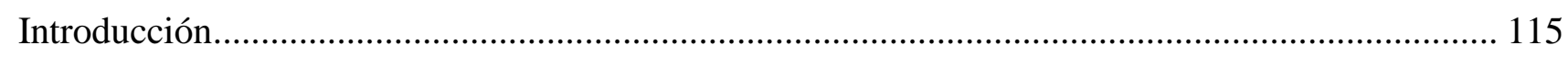

1. Un enfoque minimalista para la aproximación a la verdad ................................................ 115

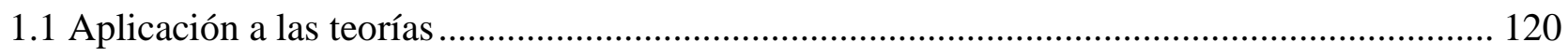

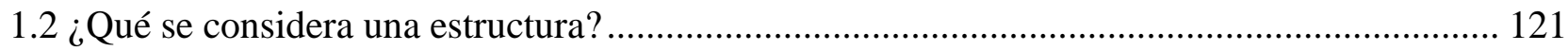




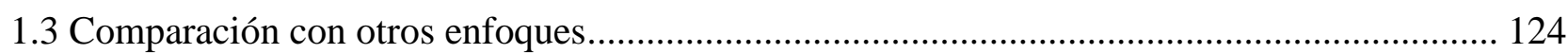

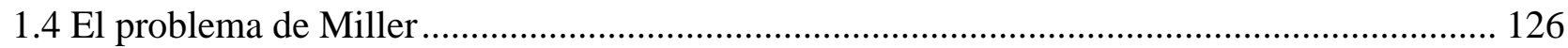

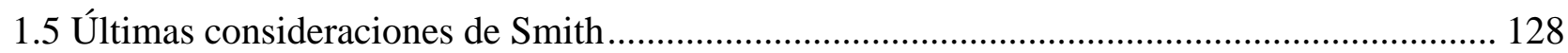

2. Objeciones y algunos detalles sobre la propuesta de Smith ............................................................ 129

2.1 Con este esquema cualquier afirmación sería aproximadamente verdadera ............................ 129

2.2 Similitud y relatividad contextual (la carencia de verosimilitud objetiva).............................. 130

2.3. La visión semántica de las teorías y el realismo................................................................... 132

2.4 La visión semántica de las teorías y la aproximación a la verdad de Smith.............................. 134

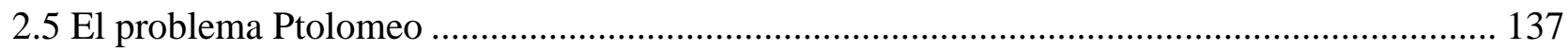

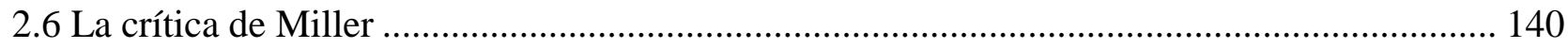

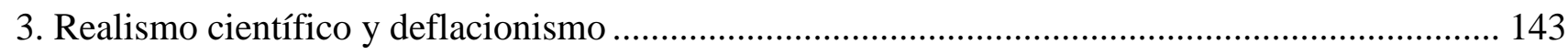

3.1 La teoría de la verdad por correspondencia ........................................................................ 143

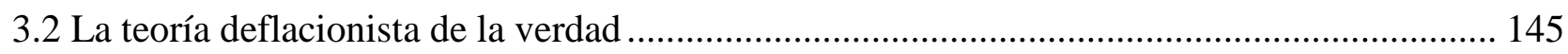

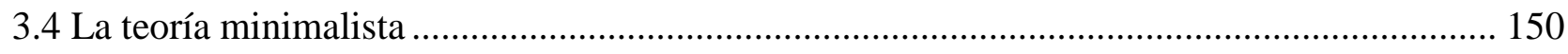

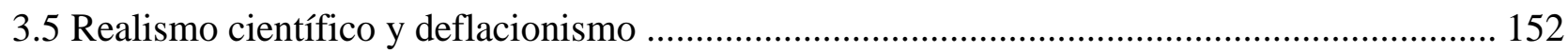

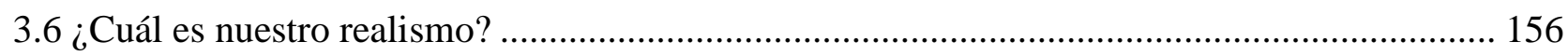

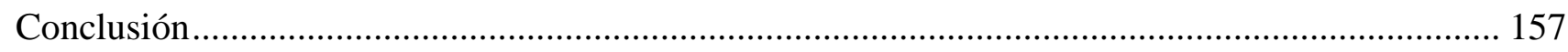

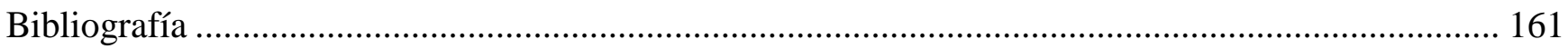




\section{Agradecimientos}

Realizar una lista de agradecimientos es complicado porque siempre se inicia con el temor de omitir a alguien y que haya sido de gran importancia. Si eso sucede, pido disculpa por olvidarme en el momento de realizar este escrito; pero no es por falta de gratitud. Además el orden de aparición no es por su importancia, sino meramente aleatorio.

Quiero comenzar con mencionar a mi familia quienes siempre me han apoyado para salir adelante en lo que me propongo. Mi mamá, mi papá y mi hermana son el pilar principal en mi desarrollo profesional y personal.

También quiero agradecer a las personas con las que compartí aula durante dos años: Antonio Puente, Miguel Agustín Aguilar, Miguel Barrueta, Edgar Avendaño, Osvaldo Rosas, Arturo López, Pablo Chávez y Rodrigo Campos; ellos fueron importantes en el desarrollo de mi proyecto con sus comentarios, preguntas y críticas, además de incrementar mis aprendizaje en otras áreas filosóficas. También extiendo mi gratitud a otros estudiantes del posgrado que cursaban grados superiores: Paloma Hernández, Eduardo Rojas, Marc Jiménez, Miguel García, Victor Cantero, Juan Carlos Squitieri y Lourdes Argonza, a ellos les agradezco sus comentarios y sugerencias, además de las nuevas enseñanzas que obtuve cuando compartimos seminarios.

Asimismo quiero reconocer el gran trabajo que realizó el doctor Armando Cíntora Gómez, quien fungió como asesor en el desarrollo de mi Idónea Comunicación de Resultados, sus comentarios siempre fueron acertados, tuvo la paciencia para saber guiarme y lograr llevar a buen término nuestro trabajo. Además debo mencionar al doctor Jesús Zamora Bonilla quien tuvo a bien enviarme su libro Verdades a medias donde habla ampliamente del tema que abordamos en este trabajo, ese texto fue de gran ayuda para poder entender y exponer las distintas propuestas de los filósofos. Otras dos personas con quienes tengo una gran gratitud son con el doctor David Gaytán y el maestro Alejandro Vázquez del Mercado quienes hicieron sugerencias y revisiones desde el momento en el que estaba planteando mi proyecto de investigación para ingresar a la maestría.

Los aciertos y méritos que tenga esta ICR son atribuibles a los anteriormente mencionados. Los errores y fallas son meramente propios.

Igualmente debo mencionar a los docentes del posgrado en Humanidades división de Filosofía de las Ciencias y del Lenguaje de quienes tuve el honor de aprender en el aula o fuera de ellas: Max Fernández, Godfrey Guillaumín, Jorge Martínez, Yolanda Torres, José de Teresa, Violeta Aréchiga, Enrique Serrano y Silvio Mota Pinto. Gracias por ser la casa abierta al tiempo que me abrió sus puertas. 
A las hermanas Alba e Itzel Sánchez Montenegro quienes fueron una gran ayuda y guía durante mi estancia en la Ciudad de México, de hecho siguen siendo un gran apoyo con respecto a esa ciudad. Gracias a su amistad logré conocer diferentes puntos de la ciudad y que mi experiencia fuera más grata.

A mis amistades de Chihuahua, en especial a quienes estuvieron en contacto durante los dos años que duró la maestría e hicieron que la lejanía no pesara tanto: Eduardo Limas, Yanira Sánchez, Miriam Valenzuela, Julio Aranda, Rossana Vázquez, Alex García, Ana Gutiérrez, Linda Miranda, Elizabeth Silva (quien además realizó la corrección de estilo de este texto), Miguel Flores, Sarahí Espinoza, Jorge Gutiérrez, Nury Sosa, Karina Sánchez, Perla Muela (quien me dio asilo cuando iniciaba la búsqueda de posgrado), Heriberto Ramírez, Eduardo Tapia y Eduardo Morales.

Cabe destacar que mis estudios no hubieran sido posibles sin el apoyo que proporciona Conacyt por medio de las becas que otorga a los estudiantes de posgrado que se encuentran inscritos en el PNPC. Espero que muchos otros estudiantes tengan la oportunidad de ser financiados por este programa para impulsar la formación de investigadores en nuestro país y aumentar la generación del conocimiento en México. Por parte de la UAM Iztapalapa reconozco el gran trabajo de la licenciada Hyldely Garduño quien siempre fue un puente efectivo entre ambas instituciones y los alumnos para que su beca y trámites siempre llegaran a buen término.

Por último a las personas con las que tuve el privilegio de compartir departamento: Vladimir Armendáriz, Alberto Valles, Karely González y Brenda Sánchez, con quienes forgé una gran amistad y disfruté de excelentes momentos.

Por último, a la Universidad Autónoma Metropolitana unidad Iztapalapa, en especial a quienes conforman el posgrado en Humanidades. Gracias por darme la oportunidad de estudiar en sus aulas y en este programa. Gracias por ser la casa abierta al tiempo que me abrió sus puertas. 


\section{Introducción}

La presente idónea comunicación de resultados tiene como tema central a la verosimilitud que se enmarca dentro del debate entre realistas y anti-realistas en la Filosofía de la Ciencia, es decir, el problema central que nos atañe es el qué se quiere decir cuando un realista afirma que una teoría (modelo, afirmación o postulado) científica es aproximadamente verdadera, con ello cabe destacar que nuestro principal interés es la parte semántica, aunque hacemos mención del aspecto epistémico.

La idónea ha sido dividida en cinco capítulos, cada uno de ellos con un objetivo específico a cumplir dentro del proyecto. Por ejemplo, el capítulo primero versa sobre el debate general entre el realismo científico y sus contrapartes, para ello se realiza un análisis sobre en qué consisten esas posturas y cuáles son sus argumentos clásicos para sostenerse, así como los contrargumentos; aquí la finalidad es mostrar que dentro de tal debate se hace mención en repetidas ocasiones de conceptos como “aproximadamente verdadero", "cercano a la verdad", "verosímil”, "parcialmente verdadero" y "verdad aproximada" que requieren una aclaración para poder saber "de qué se está hablando" cuando se sacan a colación en la discusión.

El segundo capítulo se centra en mostrar la génesis teórica e histórica del problema de la verosimilitud, en un primer apartado vemos cómo "emerge" tras la adopción de posturas realistas, optimistas, pero al mismo tiempo falibilistas, aunque podríamos rastrearlo dentro del sentido común; ahí mismo se analizan las maneras en las que se entiende: "aproximado a la verdad" y "parcialmente verdadero", además de su división en dos grandes problemas: epistémico y semántico. Después, en la parte final, se realiza un breve recorrido histórico basado en el análisis de Ilkka Niiniluoto y de Karl Popper sobre cómo es posible que algunos filósofos hayan entendido dicho concepto o si lo abordaron de una manera indirecta, el cual termina en la propuesta del mismo Popper y las razones de su fracaso.

En el capítulo tercero damos su lugar a las diversas propuestas que surgieron tras las críticas a Popper, tanto aquellas que adoptaron un enfoque formal como las que propusieron una definición fuera de la formalización lógica; en ambos casos se señalan las problemáticas con las que se toparon, siendo principalmente la dependencia del lenguaje para los primeros y diferentes tipos de ambigüedad para los segundos.

El problema epistémico hace su aparición en el cuarto capítulo ante las críticas del proyecto "verosimilituridiano" no es útil para evaluar el progreso científico porque deja a un lado los aspectos de justificación, entre otros señalamientos. Ante eso, es necesario mostrar que sí hay interés en ese aspecto dentro de esta vertiente, además de las diferentes respuestas en cuanto a que deberían de servir como una 
herramienta que sugiera reglas para que la práctica científica tenga un mayor éxito en acercarnos a la verdad

Por último, en el capítulo quinto se defiende la propuesta de Peter Smith quien define a la verdad aproximada con un esquema que no aplica igual en todos los casos, para lo cual se debe especificar qué es lo que cuenta como aproximado cuando lo mencionamos, además de que se encuentra dentro de una teoría deflacionista de la verdad. Ahí se revisan los diversos cuestionamientos que se le hacen como los cambios contextuales y su utilidad para el realismo, dado que defiende la visión semántica de las teorías. En dicha parte se concluye que el esquema puede tomarse como correcto, pero lo que consideró para evaluar las teorías de modelado geométrico, la cercanía geométrica, no es suficiente ni adecuado; por lo cual se debe enriquecer con otros aspectos (grados de idealiación, abstracción y las fuerzas participantes). Al final, se hace una defensa sobre que es posible mantenerse como realista a pesar de abrazar una teoría minimalista de la verdad sin que esto cause problemas graves. 


\section{Capítulo I. El debate sobre el realismo científico}

"if you can spray them, then they are real" - Ian Hacking.

En este primer capítulo se dará un panorama breve acerca de lo que es el realismo científico y cuáles son los principales argumentos a favor y en contra del mismo. De antemano, es bien sabido que cualquiera de los diversos puntos que se abordarán son bastante amplios y cualquiera de ellos podría ser un tema para una tesis completa, pero se dará cuenta de ellos para establecer el contexto en el que se desarrolla el problema de la tesis.

En gran parte se toma como base el libro Realismo científico: una introducción al debate actual en la filosofía de la ciencia (1998) de Antonio Diéguez Lucena.

\section{1. ¿Qué es el realismo científico?}

Responder a la pregunta anterior podría parecer fácil en un principio, sin embargo, presenta diversas dificultades, ya que diferentes autores que asumen esa postura han dado varias caracterizaciones del mismo, además, han ido cambiando sus propuestas ante la problemática, es por eso que Philip Kitcher afirma: "realism is a doctrine with many sects" (1993, pág. 127). También podemos sumar aquellas definiciones que han dado los filósofos que se oponen al realismo. La cifra puede ser bastante amplia, por ejemplo, Carman (2005) analiza que cuando menos hay 1111 maneras de ser un realista científico, muchas de las cuales no coinciden con alguna de las que haya sido defendida por alguien en específico, por ello "hace que haya muchas más caracterizaciones de realismo que realistas" (p. 43), por lo tanto, a veces es complicado realizar una caracterización del realismo científico que a su vez dé cuenta de la propuesta y que incluya a, cuando menos, la mayoría de quienes la han planteado.

Aunque el área de la filosofía donde se lleva a cabo el debate es relativamente joven, es decir la filosofía de la ciencia, la disputa entre realistas y anti-realistas es un tema clásico que se encuentra desde los inicios del filosofar. La problemática principal es acerca de la naturaleza de la realidad y la posibilidad (y formas) de adquirir conocimiento de ella.

Si radicalizamos las posturas en sus puntos más alejados se encuentran quienes afirman que el mundo externo es completamente independiente de nosotros y quienes hacen referencia a que es una construcción de nuestras mentes o que sólo existe dentro de la misma, entonces nos topamos con posturas que van desde los realistas ingenuos hasta los idealistas y los constructivistas, con sus respectivos bemoles. En filosofía de la ciencia el problema se acota a un campo un poco más estrecho, la discusión suele centrarse acerca de si podemos asegurar o no la existencia de las entidades no-observables postuladas por las diferentes teorías científicas, es decir, aquellas que, de alguna manera, no se pueden observar a simple vista o "a ojo desnudo". 
Es por ello que Devitt aclara que las doctrinas realistas se encuentran divididas en dos dimensiones: la primera sería el "realismo en general", la de la existencia de las entidades físicas observables que se postulan en el sentido común (árboles, casas, animales, etc.) y la segunda dimensión, aquella que se refiere al realismo científico el cual tiene un compromiso con la existencia de las (algunas, todas, la mayoría) entidades no observables postuladas por las teorías científicas (virus, fotones, átomos, etc.). Esta sería la caracterización del realismo del sentido común: "Most of the observable physical entities of common sense and science exist mind-independently” (Devitt, 2014, pág. 257).

El idealismo es, principalmente, una tesis que va en contra del realismo en general, en ésta se niega el aspecto de la dimensión de la independencia del mundo con nuestra mente, estas entidades se componen por elementos mentales, ideas o datos de los sentidos que no son externos de la mente. Para algunos idealistas las entidades no son objetivas, sino que dependen para su existencia y naturaleza de las actividades cognitivas y las capacidades de nuestra mente, de alguna manera las construimos al ir imponiéndoles nuestros conceptos. Esto explica por qué tenemos diferentes visiones del mundo o que nuestros conceptos sean diferentes nos permite "construir" una realidad distinta entre diferentes personas. Estos serán los puntos que un realista rechazaría, pues afirmarían que, aunque tengamos diferentes concepciones del mundo, la realidad se impondrá y nos hará elegir entre las "mejores" de una manera u otra (Cfr. Devitt, 2014, pág. 256).

El segundo es el "realismo científico", que puede ser caracterizado de la siguiente manera: "Most of the essential unobservables of well-established current scientific theories exist mind-independently" (ídem). Aquí cabe remarcar lo que afirma Devitt, el compromiso con los no-observables no es sobre todos, sino, primeramente, con aquellos que se postulan en las teorías científicas actuales y que tienen ciertas características en específico, además de adoptar una postura falibilista, ya que puede que alguno de ellos esté equivocado, nadie sensato pensaría que en la ciencia actual no se está cometiendo ningún error $^{1}$. Esta estrategia de mostrar cierta cautela no es exclusiva de los filósofos, sino que se considera una extensión de la práctica científica, dado que los científicos tienen diferentes actitudes epistémicas al respecto de sus teorías, en algunos casos se muestran incrédulos de manera absoluta ante teorías que son útiles para realizar predicciones, pero al mismo tiempo se sabe que son falsas; en otros son agnósticos sobre algunas especulaciones interesantes, por último, hay los que muestran un fuerte compromiso puesto que están ampliamente probados y establecidos. Los realistas realizan una maniobra similar, se

\footnotetext{
${ }^{1}$ Esto va en contra de la caracterización realizada por Bass van Fraassen del realismo científico: "Science aims to give us, in its theories, a literally true story of what the world is like; and acceptance of a scientific theory involves the belief that it is true. This is the correct statement of scientific realism" (1980, p. 8), dado que sería muy extraño el caso en el que un realista se comprometa a que las teorías nos ofrecen una descripción completamente verdadera del mundo, sino que se acepta la gran posibilidad de que haya errores.
} 
comprometen con aquellas teorías que están probadas y establecidas, a su vez son críticos hacia otras que no tienen esas características, además, hay situaciones que se postulan no-observables poco relevantes y otros que son esenciales, son estos segundos los que se deben adoptar como "reales": "In brief, realism is a cautious and critical generalization of the commitments of well-established current theories" (ídem). En otras palabras:

Scientific realism is a general theory of (scientific) knowledge. In one of its forms it assumes that the world is independent of our knowledge-gathering activities and that science is the best way to explore it. Science no only produces predictions, it is also about the nature of things, it is metaphysics and engineering theory in one (Feyerabend, 1981, p. 3).

Aquí vale la pena hacer una aclaración entre categorías diferentes, pero emparentadas: lo teórico/no-teórico y lo observable/no-observable. Un término es teórico, dentro de una teoría, cuando sin ella no tendrían sentido, mientras que uno no-teórico son esos que tienen sentido ya sea porque están dentro de otra teoría o no requieren de una teoría para tenerlo. La cuestión observable/inobservable es un poco más complicada, puesto que a veces no existe una frontera clara entre ellos, los primeros son aquellos que podemos observar a "ojo desnudo", mientras que los segundos tenemos mecanismos indirectos para detectarlos (sus consecuencias o algún instrumento): "Hay entidades teóricas para una determinada teoría que, sin embargo, son observables (al menos en un sentido amplio); tal es el caso de los virus, las bacterias etc. Y hay entidades teóricas para una teoría que no son observables, como las partículas subatómicas" (Carman, 2005, pág. 47).

Para el análisis de una teoría entonces habrá que localizar aquellas entidades que sean observable e inobservables (teóricos y no-teóricas, en ambos casos). Por lo tanto, la disputa no es sobre entidades teóricas solamente, sino sobre esas entidades teóricas que en cierto momento son inobservables. El realista intentará defender que cuando menos algunas de esas entidades teóricas no-observables tienen el mismo "estatus de realidad" como lo son las entidades observables (Cfr. Carman, 2005, p. 50).

Quienes se oponen a esta postura afirman que las entidades teóricas inobservables son meramente ficciones útiles que nos ayudan a realizar predicciones o explicar el comportamiento de los fenómenos observables, en otras palabras, dichas entidades no son más que instrumentos que nos ayudan a obtener los resultados buscados, pero no hay ninguna necesidad de comprometerse con su existencia, para pensadores como Quine, en From a Logical Point of View, estas entidades son similares a los dioses de la mitología griega, sólo que estos han sido más efectivos:

As an empiricist, I continue to think of the conceptual scheme of science as a tool, ultimately, for predicting future experience in the light of past experience. Physical objects are conceptually imported into the situation as convenient intermediaries-not by definition in terms of experience, but simply as irreducible posits comparable, epistemologically, to the gods of Homer. For my part I do, qua lay physicist, believe in physical objects and not in Homer's gods; and I consider it a scientific error to believe otherwise. But in point of epistemological footing the physical objects and the gods differ only in degree and not in kind. Both 
sorts of entities enter our conception only as cultural posits. The myth of physical objects is epistemologically superior to most in that it has proved more efficacious than other myths as a device for working a manageable structure into the flux of experience (1963, pág. 44).

Otro aspecto en el que suelen diferir los realistas y anti-realistas son los enunciados sobre los cuales se puede predicar "verdad", los realistas afirmarán que esta propiedad puede aplicar tanto a observables como a inobservables, algunos anti-realistas dirán que sólo para los observables, tal es el caso de Pierre Duhem como lo muestra en el siguiente pasaje de Diéguez:

(Para Pierre Duhem) Los únicos enunciados susceptibles de verdad o falsedad son, según su conocida opinión, los enunciados que expresan «hechos de experiencia». Aquellos otros que son usados en una teoría, pero no expresan hechos, no son ni verdaderos ni falsos, sino «cómodos» o «incómodos» (...) Sujetar estos principios a «suposiciones concernientes a las realidades que se ocultan bajo las apariencias sensibles» es una tarea «estéril y perecedera» (1998, pág. 33).

Aquí es entonces donde se muestra la tensión entre si lo que logra o tiene como objetivo la ciencia es obtener teorías (aproximadamente) verdaderas o simplemente que sean empíricamente adecuadas, es decir, que salven los fenómenos. Feyerabend nos muestra qué actitud tomarían los realistas e instrumentalistas ante una teoría exitosa:

Thus, considering Newton's theory of gravitation, a realist would remark that it teaches us of the existence, in addition to physical objects and their spatiotemporal behavior, of entities of an altogether different kind which cannot be directly seen, heard, or felt, but whoso influence is still noticeable enough, viz. forces. An instrumentalist, on the other hand, will take the position that there are no such entities and that the functional of words like 'gravitation', 'force' and 'gravitational field' is exhausted by their giving an abbreviated description of the spatiotemporal behavior of physical objects. HE may even deny the existence of these objects and regard object words, too, as instruments, usable for the ordering and predicting of sense data (Feyerabend, 1981, pág. 176).

Si revisamos la historia de la ciencia, encontraremos que los científicos en sus prácticas han adoptado ambas posturas con respecto a sus diversas teorías. Tomemos como ejemplo el caso del átomo cuyo primer modelo fue planteado por Dalton en 1803, varios científicos y filósofos de la segunda mitad del siglo XVIII se inclinaban a no comprometerse con su existencia, sino que se podían tomar como meras ficciones útiles: "For Ostwald, molecules, atoms, and ions were only mathematical fictions to explain the operations of energy.” (Holt, 1970, pág. 387), o en el caso del físico y filósofo austriaco Ernest Mach que los consideraba como "herramientas":

Similarly, it would not become physical science to see in its self-created, changeable, economical tools, molecules and atoms, realities behind phenomena, forgetful of the lately acquired sapience of her older sister, philosophy, in substituting a mechanical mythology for the old animistic or metaphysical scheme, and thus creating no end of suppositious problems. The atom must re- main a tool for representing phenomena, like the functions of mathematics (Mach, 1895, págs. 206-207).

Incluso había quienes pensaban que dicha entidad no observable jamás podría ser comprobada:

Hypothesis of Atoms. So far as the assumption of such atoms as we have spoken of serves to express those laws of chemical composition which we have referred to, it is a clear and useful generalization. But if the Atomic Theory be put forwards (and its author, Dr. Dalton, appears to have put it forwards with such an intention,) as asserting that chemical elements are really composed of atoms, that is, of such particles not further divisible, we cannot avoid remarking, that for such a conclusion, chemical research has not afforded, nor can afford, any satisfactory evidence whatever (Whewell, 1840, pág. 406). 
Sin embargo, tras los experimentos de Jean Perrin acerca del movimiento browniano algunos autores cambiaron de parecer (Diéguez da cuenta de Poincaré y Ostwald) como lo vemos en el siguiente pasaje:

In 1908 Ostwald changed his public position on atomism in the foreword to the fourth edition of his widely read textbook, Grundriss der allgemeinen Chemie. In response to Jean Baptiste Perrin's molecular weight determination of Avogadro's number through a statistical study of the Brownian movement in colloids, Ostwald acknowledged a "discontinuity" in the structure of matter (Holt, 1970, pág. 388).

[Dicho por Poincaré] autorizan incluso al científico más cauteloso a hablar de una prueba experimental de la constitución atómica de la materia (...) Las antiguas hipótesis mecanicistas y atomistas- decía- han adquirido en estos últimos tiempos bastante consistencia para dejar casi de aparecernos como hipótesis; los átomos ya no son una ficción cómoda; nos parece, por así decir, que los vemos desde que los sabemos contar. (...) El átomo del químico es ahora una realidad (Citado por Diéguez, 1998, pág. 39).

Aunque Mach y Duhem mantuvieron su visión instrumentalista de los átomos.

Con ello, Diéguez puede concluir que los científicos suelen aceptar las teorías por cuestiones prácticas, sin tomar mucho en cuenta la verdad, pero con el paso del tiempo se dan a la tarea de investigar el éxito de dichas teorías y saber con ello si realmente refieren a entidades existentes o no, y prefieren sustituirlas por las que sí lo hacen. Esto se demuestra por los grandes esfuerzos que han realizados los científicos por confirmar entidades no observables como el neutrino, y más actualmente podríamos decirlo de los bosones. Dividiendo así la práctica científica al respecto de entidades no observables en dos períodos, el primero en el cual son instrumentalistas y utilizan aquello que les permite hacer predicciones y explicaciones sin importarles si existen o no; y el segundo se refiere al momento en el que se dan a la tarea de buscar si realmente dichas entidades existen. Ésta segunda parte es la cual nos da permiso de ser realistas en el caso de nuestras teorías establecidas y altamente confirmadas, tomando en cuenta la actitud que adoptan los científicos sobre ellas, este es uno de los argumentos clásicos del realismo científico.

Existen filósofos que han tomado una postura neutral ante el debate del realismo/anti-realismo, afirmando que sólo es una manera de hablar de ambos bandos, sin adoptar un compromiso sobre la problemática, entre ellos podemos contar a Moritz Schlick (1932) en Positivism and Realism, Alfred Ayer (1959) en Logical Positivism, Thomas Nagel (1961) en The Structure of Science; y Rudolf Carnap (1985) en Fundamentación Lógica de la Física:

es una cuestión que depende de la manera de hablar que se prefiera en un conjunto determinado de circunstancias. Decir que una teoría es un instrumento de confianza- esto es, que se confirmarán las predicciones de sucesos observables deducidas de ella- es esencialmente lo mismo que decir que la teoría es verdadera y que las entidades teóricas, inobservables, de las que habla existen. Así, no hay ninguna incompatibilidad entre las tesis de los instrumentalistas y los realistas (Carnap, 1969, pág. 341).

Aunque esta declaración pareciera que no se está tomando partido, no es más que una muestra del rechazo a la metafísica del neopositivismo, lo cual iría en contra del realismo científico y varios anti-realistas podrían aceptar el fenomenismo positivista. 


\subsection{Las tesis del realismo científico}

Hasta aquí se ha dado a muy grandes rasgos las características principales del realismo científico: la realidad es independiente de nuestra mente $^{2}$, las mejores teorías científicas actuales son (aproximadamente) verdaderas (tesis 1) y sus entidades teóricas no observables (al menos algunas) tienen el mismo estatus ontológico que las observables (Tienen un referente en el mundo - tesis $2^{3}$ ). A continuación, expondremos una lista de tesis que han sostenido los realistas, sin embargo, cabe hacer hincapié en que algunos filósofos pueden no tener compromiso con todas.

Leplin dice que la mayoría de los filósofos son realistas, pero que se encuentran demasiado divididos sobre lo que ello significa, por eso parece que son minoría, cuyas aseveraciones son las siguientes:

1. The best current scientific theories are at least approximately true.

2. The central terms of the best current theories are genuinely referential.

3. The approximate truth of a scientific theory is sufficient explanation of its predictive success.

4. The (approximate) truth of a scientific theory is the only possible explanation of its predictive success.

5. A scientific theory may be approximately true even if referentially unsuccessful.

6. The history of at least the mature sciences shows progressive approximation to a true account of the physical world.

7. The theoretical claims of scientific theories are to be read literally, and so read are definitively true or false.

8. Scientific theories make genuine, existential claims.

9. The predictive success of a theory is evidence for the referential success of its central terms.

10. Science aims at a literally true account of the physical world, and its success is to be reckoned by its progress toward achieving this aim (Leplin, Introduction, 1984, págs. 1-2).

Las tesis 3, 4 y 9 son famosamente conocidas por pertenecer a un argumento que se revisará más adelante denominado como "no-milagros", es decir, que sería un milagro que se tuviese teorías altamente exitosas y que al mismo tiempo fuesen falsas, y que, además esta es la mejor explicación para ello (el énfasis de Leplin en que sea la única posible explicación podría ser bastante fuerte, ya que pueden ser exitosas por otros motivos y no únicamente la verdad). La tesis 5 es para aquellos casos en los cuales no hay referencia de las entidades no observables y aun así la teoría es exitosa, esto quiere decir que cuando menos en algunos puntos la teoría es aproximadamente verdadera. La número 6 y 10 hacen referencia a lo que se denomina como realismo progresivo, la primera afirma que la ciencia ha ido acumulando verdades (o se ha aproximado a la verdad), a esto es lo que el realista cree que es el logro de la ciencia, mientras que la segunda lo toma como un objetivo, la ciencia debe buscar tener cada vez más verdades

\footnotetext{
2 The Metaphysical Thesis: The world has a definite and mind-independent structure (Psillos, The Present State of the Scientific Realism Debate, 2000, pág. 706).

3 The Epistemic Thesis: Mature and predictively successful scientific theories are well-confirmed and approximately true of the world. So, the entities posited by them, or, at any rate, entities very similar to those posited, inhabit the world (ídem).
} 
(o aproximarse más a la verdad). La 7 es la parte semántica del realismo ${ }^{4}$, es decir, la interpretación debe ser en torno a valores de verdad, mientras que la 8 hace referencia a su parte metafísica, es decir, que los enunciados son al respecto de algo que está en el mundo de manera independiente. ${ }^{5}$

Psillos hace notar que hay una posible tensión entre la 6 y 10, tomando en cuenta que el realista muestra dos posturas, una de ellas es la modestia y la otra es ser presuntuoso:

The modest claim is that there is an independent and largely unobservable-by-means-of-the-senses world which science tries to map. The more presumptuous claim is that although this world is independent of human cognitive activity, science can nonetheless succeed in arriving at a more or less faithful representation of it that is of knowing the truth (or at least some truth) about it (Psillos, 2000, pág. 707).

Esto para algunos filósofos puede parecer una especie de combinación incompatible, porque ¿si el mundo es independiente de nuestra habilidades o capacidades para investigarlo y para reconocer la verdad de nuestras teorías acerca de él, entonces cómo es posible que sea cognoscible? El realista cuenta con dos opciones: comprometer la modestia o la presunción.

Popper y Musgrave siguen la estrategia de comprometer la presuntuosidad al tomar al realismo como una tesis acerca del objetivo de la ciencia, sin ocuparse de si este es posible o ya se ha logrado, es decir, toman a la verdad como un ideal regulativo. Algunos problemas con la caracterización axiológica del realismo son: 1) parece ser vacua, pero se hace inmune a argumentos como a la inducción pesimista (que veremos más adelante), dado que no importa el récord de teorías falsas de la ciencia, el objetivo sigue siendo conseguir la verdad; 2) no se especifica si el método científico consigue "verdades", lo cual hace misterioso cómo se logrará el objetivo del realismo; y 3) el entusiasmo de la afirmación realista de que la ciencia es una actividad donde se mueven las fronteras de la ignorancia y el error se pierde (Cfr. Psillos, 2000, pág. 798).

Entonces nos queda como única opción comprometer la modestia, es decir, afirmar que el mundo no es independiente de nosotros de una manera fuerte, por lo tanto, se hace posible que podamos conocerlo. Esto se logra utilizando una noción epistémica de la verdad en el realismo que nos permita

\footnotetext{
${ }^{4}$ The Semantic Thesis: Scientific theories should be taken at face-value. They are truth-conditioned descriptions of their intended domain, both observable and unobservable. Hence, they are capable of being true or false. The theoretical terms featuring in theories have putative factual reference. So, if scientific theories are true, the unobservable entities they posit populate the world (ídem).

${ }^{5}$ Richard Boyd lo pone en términos resumidos pero muy similares:

1. Theoretical terms in scientific theories (i.e., nonobservational terms) should be thought of as putatively referring expressions; that is, scientific theories should be interpreted "realistically."

2. Scientific theories, interpreted realistically, are confirmable and in fact are often confirmed as approximately true by ordinary scientific evidence interpreted in accordance with ordinary methodological standards.

3. The historical progress of mature sciences is largely a matter of successively more accurate approximations to the truth about both observable and unobservable phenomena. Later theories typically built upon the (observational and theoretical) knowledge embodied in previous theories.

4. The reality which scientific theories describe is largely independent of our thoughts or theoretical commitments. (Boyd, The Current Status of Scientific Realism, 1984, págs. 41-42)
} 
tener a nuestro alcance cognitivo a la verdad y al mundo. Aquí el tema en discusión es acerca del tipo de teoría de la verdad que se debe adoptar y cuáles serán los criterios de justificación que se pedirán (el reto que no sean muy seculares para evitar el relativismo, ni muy teológicas que los vuelva inaccesibles para los seres humanos), generalmente se piensa que es la teoría de la verdad por correspondencia, sin embargo, hay quienes discrepan que esta tenga que ser necesariamente:

Realism does not strictly entail any doctrine of truth at all. It follows that a person could, without inconsistency, be a Realist without having any notion of truth in his theory. Nor is there an obviously true proposition which, together with Realism, entails any explanatory - hence non-deflationary - doctrine of truth (Devitt, 1997, pág. 41).

No obstante, quedan bastantes sospechas de si es posible prescindir de una teoría de la verdad por correspondencia y sustituirla por una deflacionista, y aun así el realista pueda seguir sosteniendo que sus teorías hablan de lo que sucede en el mundo externo. ${ }^{6}$

Una de las preguntas acerca del realismo científico es si debemos considerarlo como una hipótesis empírica, es decir, como las otras hipótesis que plantea la ciencia y si es posible contrastarla empíricamente por medio de los datos obtenidos mediante la historia de la ciencia, la sociología de la ciencia, la psicología de la ciencia, etc.

Para Putnam hay dos aspectos de carácter empírico del realismo: la primera es que podría ser falso y la segunda es que los hechos pueden ser relevantes a favor o en contra del mismo, por estas razones piensa que "realism is like an empirical hypothesis" (Putnam, Meaning and the Moral Sciences., 1978, pág. 78), pero no quiere decir que sea una hipótesis empírica, ni que tampoco pertenezca a la ciencia. Aquí debemos destacar que Putnam no dice que sean iguales, sino "parecidas" (like):

Dicho de otro modo, el realismo científico no pertenece a la ciencia empírica. No es propiamente una teoría científica sobre la ciencia, puesto que versa sobre la mejor manera de interpretar nuestros conceptos y teorías científicos, lo cual no es una cuestión empírica. Tal como se lo entienden habitualmente, pertenece a la filosofía de la ciencia; pero como otras muchas doctrinas filosóficas, no carece de consecuencias empíricas que lo pueden presentar con un mayor o menor grado de plausibilidad (Diéguez, 1998, pág. 99).

Otro aspecto que vale la pena aclarar es que el realismo no es acerca de por qué los científicos adoptan una teoría científica, ni el hecho de que ellos adopten una teoría es porque creen literalmente en su verdad, como vimos anteriormente hay diferentes motivos por los cuales un científico puede aceptar y utilizar una teoría, sino que se está hablando específicamente de la relación que tienen algunas teorías con el mundo, o de forma más detalla:

En lo que el realismo insiste, sin embargo, es en que no toda teoría es aceptada sólo por su valor instrumental ni todos los términos teóricos son heurísticos. Para el realismo, en las ciencias maduras es la regla más que la excepción que los términos teóricos pretendan referirse a algo real, en ocasiones a través de un modelo muy idealizado (cualquier modelo es siempre una idealización), y pretendan tener un valor ontológico y no sólo instrumental. En tales casos, la aceptación de la teoría a la que pertenecen suele comportar la creencia en la existencia de las entidades a las que se refieren. Y en cuanto a los términos teóricos que no designan

${ }^{6}$ (Para más detalles sobre dicho debate puede revisarse Psillos, 2000, págs. 709-712). 
directamente entidades supuestamente reales, en la medida en que en el seno de las teorías establecen relaciones entre los restantes términos, y quedan ellos mismos integrados en el conjunto, puede decirse que, de manera indirecta, se refieren a propiedades o relaciones objetivas. Aunque su función sea principalmente instrumental, modelizan aspectos concretos de la realidad que, en lo esencial, se consideran similares al modelo (pág. 77).

A continuación, expondremos cuáles son los argumentos clásicos a favor y en contra del realismo científico y cuáles son sus complicaciones o respuestasi ${ }^{\mathrm{i}}$.

\section{Argumentos a favor del realismo científico}

Así como mencionamos en un inicio las dificultades de dar una conceptualización del realismo científico debido a que existen maneras de representarlo, lo mismo sucede con los argumentos a favor o en contra del mismo, cada autor los plantea según sus necesidades y lo que buscar defender o atacar, por lo tanto, podemos encontrar diferentes argumentos o versiones de los argumentos según sea el tipo de realismo que se encuentre en cuestión.

Sin embargo, hay algunos argumentos que se pueden clasificar como “clásicos” en la discusión y una forma de exponerlos que podríamos denominarla como "estándar" que se ha ido modificando con el paso del tiempo (o los autores). Esos argumentos "clásicos" en sus versiones "estándar" son los que se expondrán a continuación, junto con algunas de sus problemáticas y las respuestas más conocidas que se han dado.

\subsection{El realismo científico y el sentido común}

Uno de los argumentos más comunes a los que suele recurrir el realista es que es una intuición del sentido común, de hecho, para una persona alejada de la ciencia y de la filosofía sería muy extraño que alguien se planteara si la realidad es independiente de ellos o un constructo de nuestra mente. Para Kitcher el anti-realismo es algo con lo que muy pocos "nacen": "Few are born antirealists, and those who achieve antirealism typically do so because it is thrust upon them by arguments they feel unable to answer." (1993, pág. 131), a ello le agrega que "la verdad por correspondencia" es algo que inicia en casa, es decir, que la utilizamos de manera cotidiana.

En nuestra práctica diaria convivimos con objetos y pensamos que ellos existen de manera independiente de nuestra mente y que podemos conocerlos cuando menos parcialmente, tal es el caso de los libros, las mesas, las plumas, las computadoras, etc., los cuales creemos que existen sin necesidad de un observador; además de que hacemos enunciados sobre ellos que consideramos como verdaderos.

Pero no sólo lo hacemos sobre entidades observables, también explicamos y predecimos de manera exitosa el comportamiento de las personas atribuyéndoles sentimientos, emociones, 
pensamientos, etc. ${ }^{7}$ Además solemos creer en otras entidades que no observamos como los programas de las computadoras, cuando andamos enfermos se lo atribuimos a virus y bacterias que en nuestra vida hemos visto, o cuando nos encontramos con ciertas estructuras óseas atribuimos que ahí debió existir un animal aunque no se le parezca a los que existen actualmente.

Diéguez afirma que sucede de manera similar con los científicos, los biólogos creen en los microorganismos que estudian y que el conocimiento que tienen sobre ellos es verdadero, lo mismo sucede con los genes, las moléculas de $\mathrm{ADN}$, los átomos, las placas tectónicas, etc., aunque quizá los físicos pueden dudar cuando se les pregunta acerca de la teoría cuántica o por partículas subatómicas (Cfr. Pág. 90). Esto se puede observar en las siguientes palabras de Karl Popper: "Common sense is unquestioningly on the side of realism” (1972, pág. 38), además agrega el carácter indemostrable e irrefutable que tiene el realismo y sus contrarios, lo reafirma párrafos más delante:

(I) Perhaps the strongest argument consists of a combination of two: (a) that realism is part of common sense, and (b) that all the alleged arguments against it are not only philosophical in the most derogatory sense of this term, but are at the same time based upon an uncritically accepted part of common sense (...) (pág. 39)

Como hemos mencionado, para una persona que no se dedique a la filosofía sería muy extraño que pensase como un anti-realista, los argumentos le parecerán sofisterías o un intento de engaño, puesto que la existencia de objetos fuera de su mente la considera muy obvia e irrebatible, incluso si no los puede observar. McMullin hace el salto de la persona común a los científicos cuando hace el análisis del razonamiento utilizado por Galileo para determinar la existencia de montañas en la Luna, al cual le llama "retroducción”, es decir, conocimiento abductivo:

Scientists are likely to treat with incredulity the suggestion that constructs such as these are no more than convenient ways of organizing the data obtained from sophisticated instruments, or that their enduring success ought not lead us to believe that the world actually contains entities corresponding to them. The near-invincible belief of scientists is that we come to discover more and more of the entities of which the world is composed through the constructs around which scientific theory is built (McMullin, 1984, págs. 89).

Diéguez suma a este a argumento otro que está hermanado, consiste en tomar al realismo como un presupuesto de la investigación científica, un principio más que un resultado, algo que se exige por los fines de la investigación y porque da muy buenos resultados y utiliza la siguiente cita de Mario Bunge:

[El científico] diseña y ejecuta experimentos en los que modifica deliberadamente propiedades, monta o desmonta sistemas, controla o provoca procesos, etc. En todo momento da por sentado que lo que estudia

\footnotetext{
${ }^{7}$ The correspondence theory of truth is often held to involve extravagant metaphysics, but, I claim, its roots lie in our everyday practices. We explain and predict the behavior of our fellows by attributing to them states with propositional content (for celebration of this theme, see Dennett 1987). We explain and predict the differential successes of our fellows in coping with the world by supposing that there are relations between the elements of their representations and independent objects. Those with correct beliefs about spatial relations can navigate their way more successfully than those who have faulty beliefs, and they can do so because their beliefs correspond to the ways in which the constituents of the local environment are arranged. Simple psychological ideas form part of the explanation of everyday behavior. Simple semantical ideas, added to those simple psychological ideas, explain the consequences of behavior. (Kitcher, 1993, págs. 130-131)
} 
existe (o al menos puede existir) y cambia legalmente, y que lo que diseña está compuesto por cosas que existen independientemente de su voluntad y que se comportan conforme a leyes objetivas antes que caprichosamente (Citado por Diéguez, 1998, págs. 91-92).

A este tipo de razonamiento se adhieren filósofos como Popper y Rescher.

De ser así, los científicos pensarían que su quehacer es un conocimiento acerca del mundo, luego no se puede negar la existencia de entidades a las cuales refieren los términos teóricos y que podemos alcanzar conocimiento sobre ellas. Si el realismo estuviere equivocado, se perdería el sentido de la ciencia y adoptar el anti-realismo nos llevaría a una parálisis (para Diéguez esto sucedió con la escuela de Copenhague de la teoría cuántica).

Aunque ambos argumentos parecen bastante persuasivos, pero en realidad no son muy fuertes. Si uno revisa la historia de la ciencia se dará cuenta que muchas de las investigaciones van precisamente en contra del sentido común, para cualquier observador sin conocimiento científico le parecería bastante razonable que la tierra gira alrededor del sol, o para una persona medianamente educada podría parecerle implausible la teoría cuántica. El problema con el sentido común es su variabilidad, lo que antes era de sentido común, ahora ya no lo es: "el sentido común no es más que la ciencia periciclada" (pág. 92), incluso puede variar no sólo por épocas, sino por lugares.

El argumento acerca de la actitud de los científicos como realistas es bastante cuestionable, ya que encontramos en varios períodos a científicos que no utilizan el realismo como un presupuesto, como se mencionó anteriormente al respecto de que había escepticismo en cuanto a la existencia del átomo, pero se inclinaban a utilizarlo como una ficción útil que les permitía hacer predicciones exitosas sin tener ningún compromiso ontológico al respecto.

\subsection{Corroboración y unidad de la ciencia}

Un argumento todavía más interesante que los anteriores surgió en la década de 1980, el cual se centra en un realismo que está más comprometido con las entidades no observables que con la verdad de las teorías, además que le da un mayor peso a la intervención de los científicos en el mundo, es decir, a la práctica, que a la representación o construcción de teorías sobre la realidad, al menos esto es a lo que se refiere Ian Hacking (1983) en las primeras páginas de Representing and Intervening, donde menciona que Nancy Cartwright (1983) sigue el mismo camino en How the Laws of Physics Lies. En este caso estamos frente a un argumento que toma al realismo como un resultado de la experimentación en lugar de un presupuesto para la misma.

Hacking nos cuenta la manera de cómo se hizo realista, y esto fue mediante una charla con uno de sus amigos:

For my part I never thought twice about scientific realism until a friend told me about an ongoing experiment to detect the existence of fractional electric charges. These are called quarks. Now it is not the quarks that 
made me a realist, but rather electrons. Allow me to tell the story. It ought not to be a simple story, but a realistic one, one that connects with day to day scientific research (1983, pág. 23).

A continuación, se da a la tarea de explicar el experimento que básicamente consiste en variar la carga de energía de las bolas de niobio mediante el proceso de rociarle un spray con positrones para aumentar la carga o de electrones para disminuirla, lo cual lo llevó a concluir: "From that day forth I've been a scientific realist. So far as I'm concerned, if you can spray them then they are real" (ídem), Diéguez tiene a bien relacionar esta frase con otra que utiliza Landé: "Las cosas reales son susceptibles de darles un puntapié" (Citado por Diéguez, 1998, pág. 94).

Este giro que da Hacking en cuanto a poner atención en la intervención más que en la representación fue un cambio a la filosofía de la ciencia tradicional que venía enfocándose más en las teorías que en la práctica científica. Para él, la realidad está relacionada con la causación y lo que nosotros pensamos sobre la realidad se va formando gracias a las capacidades que tenemos para cambiar (intervenir) en el mundo: "We shall count as real what we can use to intervene in the world to affect something else, or what the world use to affect us" (Hacking, 1983, pág. 146).

El argumento adquiere más fuerza cuando son varias las consecuencias causales que se pueden obtener de manera exitosa o cuando conseguimos crear diferentes modos de detección de la entidad teórica mediante el uso de artefactos que detecten su existencia. Si varios experimentos independientes nos llevan al mismo resultado, entonces nos sugiere que la existencia de esa entidad inobservable es real y esa es la "mejor explicación" (abordaremos este tema en el siguiente apartado) de dicha coincidencia. Como lo dice en “Do We See through a Microscope?": "It would be a preposterous coincidence if, time and again, two completely different physical processes produced identical visual configurations which were, however, artefacts of the physical processes rather than real structures in the cell” (Hacking, 1985, págs. 144-145).

Las debilidades de este argumento, para Diéguez, son: 1) tiene un alcance muy limitado, pues sólo apoya al realismo ontológico, al cual pocos anti-realistas cuestionan; y 2) tal como sucede con el argumentum baculinum que se utilizaba contra los escépticos (golpearlos para que creyeran en la realidad exterior), da pocos resultados para convencer a los oponentes.

El anti-realista puede responder que las técnicas de detección fueron construidas o calibradas con el objetivo de reproducir esos resultados; mediante hacer énfasis en las similitudes y descartar las diferencias; y, por lo tanto, la coincidencia no lo es tanto o cuando menos no es sorprendente, porque el experimento se planteó para que así sucediera o el aparato se construyó con esos propósitos, esto lo afirma van Fraassen en "Empiricism in the Philosophy of Science” (1985, págs. 297-298). 
Para van Fraassen el hecho de que dos artefactos nos lleven a un mismo resultado no nos garantiza que podamos hacer una inferencia sobre la realidad de la estructura inobservable que se está analizando. Hacking intenta encontrar un ejemplo más instructivo y da "The Argument of the Grid", aunque el nuevo ejemplo sea más sorprendente esto no significa que tenga más fuerza probatoria, no nos permite decir que observado a través del microscopio es verídico porque hicimos el artefacto para que fuera de esa manera, puesto que la premisa que lo implica está bajo disputa:

To add that agnosticism on this point requires belief in a Cartesian demon of the microscope reveals only the unstated premise that the persistent similarities in the relevant phenomena require, must have, a true explanation. But reliance on that premise is exactly what the previous section denied (ídem).

Existe una ambigüedad cuando se intenta dar argumentos de causa común para apoyar el realismo científico:

Wesley Salmon has discussed this sort of example consistently in terms of the notion of common cause: "two correlated events (-type) have a common cause when, in a significant proportion of the correlated pairs, the histories can be traced back to an intersection of a third event (-type), bearing certain relations to the first two (ídem).

Y da como ejemplo la correlación entre los fumadores consuetudinarios y el cáncer de pulmón lo cual se estableció como una explicación de causa común al analizar que en el pasado aquellas personas que tenían cáncer de pulmón eran quienes tenían el hábito de fumar, lo mismo sucede con los ejemplos de Hacking, y esto se debe a que:

We see observable causes $C_{1} \ldots, C_{n}$ all of a certain sort producing similar observable effects $E_{1}, \ldots, E_{n}$; then we attribute a similar but unobservable cause $\mathrm{C}$ to a further observable effect $\mathrm{E}$ by analogy. And what is the status of (pág. 299).

Con ello podemos ver que Diéguez estaba en lo correcto, el argumento de la corroboración no es útil para convencer al anti-realista de la existencia de las entidades no observables, ellos pueden mantener su agnosticismo y afirmar que las entidades no observables deben tratarse como si existieran dado su éxito predictivo, pero no hay razón para comprometerse con su existencia real.

Otro de los argumentos más conocidos del realismo científico es el denominado como "principio de la unidad de la ciencia" que ha sido defendido por Richard Boyd ${ }^{8}$, C. S. Hooker y Hilary Putnam en sus primeros años. El cual consiste básicamente en que hay casos en los cuales se unen dos teorías independientes, a veces provienen de disciplinas muy diferentes, y esto logra explicar o predecir fenómenos que antes no hubiera sido posible si se les hubiera tomado aisladamente. Para el realista que esto suceda es gracias a la verdad de las teorías, de otra manera no sería posible.

\footnotetext{
${ }^{8}$ There is a point regarding the use of auxiliary hypotheses that can be made the basis for a very strong defense of scientific realism. The use of auxiliary hypotheses, like other applications of what positivists called the "unity of science" principle, depends upon judgments of univocality regarding different occurrences of the same theoretical terms. It is possible to argue that only a realist conception of the semantics and epistemology of science can account for the role of such univocality judgments in contributing to the reliability of scientific methodology. But this argument is not anticipated in the standard rebuttals to empiricist anti- realism (Boyd, 1984, pág. 51).
} 
Si tenemos dos teorías, p y q que las consideramos como verdaderas cada una por separado, será lógico que su conjunción $\mathrm{p}^{\wedge} \mathrm{q}$ sea también verdadera (las tablas de verdad así lo indican) ${ }^{910}$. Esto es algo que el instrumentalista no puede explicar ya que p puede conducir a predicciones válidas o ser adecuada empíricamente, lo mismo sucede con q, pero nada nos indica que su conjunción vaya a producir nuevas predicciones válidas y sigan siendo empíricamente adecuadas, incluso podrían ser rivales o incompatibles ${ }^{11}$ :

The conjunction argument is this: Scientists regularly, and surely rationally, conjoin two theories to derive consequences unavailable in other. This practice is understandable if the theories are taken to be true, since, if $\mathrm{A}$ is true and $\mathrm{B}$ is true, then $(\mathrm{A} \& \mathrm{~B})$ is true. But the conjunction of empirically adequate theories need not be empirically adequate, or even, consistent. Hence, the justification of this practice as rational requires a realistic understanding of theories (Hooker, 1985, pág. 174).

Lo que un anti-realista puede responder, lo que de hecho hace van Fraassen, es que, aunque el científico crea que $\mathrm{p}^{\wedge} \mathrm{q}$ es verdadera porque q es verdadera y $\mathrm{p}$ también lo es, cuando el científico hace la conjunción antes se pregunta si ésta sigue siendo empíricamente adecuada. Cuando deciden unir las teorías para utilizarlas de manera conjunta la razón es porque no son en realidad completamente independientes. Si carecieran de algún tipo de solapamiento fenoménico entre ellas, algún modelo en común, por ejemplo, no tendría caso llevar a cabo la unión. Esto es lo que podría explicar la adecuación empírica de la conjunción.

Para van Fraassen decir que una teoría es verdadera es afirmar que cada una de sus partes lo es también, mientras que la adecuación empírica es una propiedad global: "There is no characteristic of statements such that, if all propositions of a theory individually have that characteristic, then the theory is empirically adequate.” (1980, pág. 84), por lo tanto, no tiene sentido hacer un análisis de la adecuación empírica de cada una de las afirmaciones individuales de una teoría, o solicitar que la adecuación empírica se preserve de las premisas a la conclusión.

\footnotetext{
${ }^{9}$ For the reliability of this principle, the realist offers the explanation that experimental evidence for $\mathrm{T}$ and for $\mathrm{T}$ constitutes evidence for the truth of each of the theories and that the judgments of univocality for theoretical terms which are presupposed in the unity of science principle constitute reliable judgments of sameness of reference for the theoretical terms common to $\mathrm{T}$ and $\mathrm{T}$ '. Thus, under the circumstances envisioned for the application of the unity of science principle, we have evidence that $\mathrm{T}$ and $\mathrm{T}$ are true theories with relevantly the same subject matter, and, thus, we have evidence that their conjunction is true. It is this consideration which justifies us in taking the empirical adequacy of their conjunction to be confirmed (Boyd, 1985, pág. 16).

${ }^{10}$ When a realistically minded scientist - that is to say, a scientist whose practice is realistic, not one whose official "philosophy of science" is realistic - accepts a theory, he accepts it as true (or probably true, or approximately-true, or probably approximately-true). Since he also accepts logic he knows that certain moves preserve truth. For example, if he accepts a theory $T_{1}$ as true and he accepts a theory $T_{2}$ as true, then he knows that $T_{1} \& T_{2}$ - the conjunction of $T_{1}$ and $T_{2}-$ is also true, by logic, and so he accepts $\mathrm{T}_{1} \& \mathrm{~T}_{2}$ (Putnam, 1975, pág. 210).

${ }^{11}$ I have argued elsewhere that some familiar positivist substitutes for the notion of truth (e.g., 'is simple and leads to true predictions') do not have the property that the conjunction of acceptable theories (theories with the property in question) is acceptable. So, acceptability is not preserved by deductive logic." But scientists do regard logical consequences of acceptable theories as acceptable. (In the sense that, if the consequence is unacceptable, then one has to go back and revise one's decision that all the premises were acceptable.) (Putnam, 1978, pág. 102).
} 
Según van Fraassen no hay una forma de proceder tan simple en la práctica científica como la que dibuja Putnam cuando explica el fenómeno de la unidad, esto porque no se puede ser dogmático acerca de la verdad de las teorías, aunque lo creamos de todo corazón. Antes de hacer la conjunción simple, aunque esté convencido de que las teorías en cuestión sean verdaderas, analizará si juntas son empíricamente adecuadas para la nueva área que se está aplicando. La creencia no se sostiene simplemente por el hecho de que la evidencia nos dijo que ambas teorías eran empíricamente adecuadas de manera separada, entonces la creencia de que su conjunción lo será se pone a prueba de manera más rigurosa de como se hizo anteriormente:

In my opinion, practice does not come that near; the preamble about believing $\mathrm{T}$ and $\mathrm{T}^{\prime}$ to be true is missing, and what is about to be put to a more stringent test is the hypothesis that ( $\mathrm{T}$ and $\left.\mathrm{T}^{\prime}\right)$ is empirically adequate. This hypothesis is significant only, of course, if it is at least logically possible, that is, if $\mathrm{T}$ and $\mathrm{T}^{\prime}$ have models in common - a theoretical question which should surely be taken seriously before any joint application is attempted (1980, págs. 85-86).

Aquí surge una pregunta interesante: ¿por qué los científicos deberían querer una sola teoría que pueda cubrir fenómenos de dominios dispares en lugar de tener una diferente para cada dominio? Un realista diría que, si una teoría es verdadera, entonces se podrá extender a toda la naturaleza, ¿pero es posible que se tengan muchas teorías que más o menos se solapen en sus dominios de aplicación, que sean empíricamente adecuadas y que no se puedan combinar en una sola imagen? Van Fraassen responde que tal situación no es factible ya que las teorías en algún momento necesitarán explicar un fenómeno que sólo será posible hacerlo en conjunto, pero en la práctica se utilizan una especie de "mini-teorías" (un fisiólogo difícilmente verá la necesidad de realizar correcciones resultantes de la teoría de la relatividad).

A pesar de ello piensa que la Filosofía de la Ciencia debe explicar el por qué suceden las uniones entre diferentes teorías para crear una más grande, y dice que esto se da más por medio de un proceso de corrección que de unificación: "But there seems to me no doubt that the aim of empirical adequacy already requires the successive unification of 'mini-theories' into larger ones, and that the process of unification is mainly one of correction and not of conjunction” (pág. 87).

\subsection{El argumento de los no milagros}

El siguiente argumento es sin duda el más utilizado por los realistas científicos, pero también el que ha obtenido una mayor cantidad de críticas por parte de los realistas, se trata del denominado como “argumento de los no milagros" que es una inferencia a la mejor explicación o razonamiento abductivo. Para Jarrett Leplin: “The debate between realism and instrumentalism is at an impasse. (2000, pág. 393), y señala que es precisamente en esta parte donde la tensión es más fuerte. 
Peirce ha sido uno de los filósofos que más ha estudiado dicho tipo de razonamiento y nos explica que está a la par de la inducción y la deducción:

There are in science three fundamentally different kinds of reasoning, Deduction (called by Aristotle \{synagögé\} or \{anagögé\}), Induction (Aristotle's and Plato's \{epagögé\}) and Retroduction (Aristotle's \{apagögé\}, but misunderstood because of corrupt text, and as misunderstood usually translated abduction). Besides these three, Analogy (Aristotle's \{paradeigma\}) combines the characters of Induction and Retroduction (1896 [c], pág. CP 1.65).

Consiste en aquellas situaciones en las cuales no tenemos la evidencia suficiente para poder dar una conclusión de manera deductiva o inductiva, pero es necesario dar una explicación a un hecho, entonces hacemos una hipótesis o conjetura acerca de qué es lo más probable que haya causado dicha situación. No se toma como si fuera verdadera, pero sí como la conclusión más posible, que más adelante debería ser probada:

Ultimately, the circumstance that a hypothesis, although it may lead us to expect some facts to be as they are, may in the future lead us to erroneous expectations about other facts, - this circumstance, which anybody must have admitted as soon as it was brought home to him, was brought home to scientific men so forcibly, first in astronomy, and then in other sciences, that it became axiomatical that a hypothesis adopted by abduction could only be adopted on probation, and must be tested (Peirce, 1901, pág. CP 7.202).

Uno de los ejemplos paradigmáticos de razonamiento abductivo en ciencia es el descubrimiento de Neptuno, ya que antes de haber sido observado por Johann Galle, matemáticos como Le Verrier y Adams habían conjeturado su existencia. Esto gracias a que vieron que el movimiento de Urano no era precisamente el que marcaba la teoría de Newton, sino que tenía ciertas “aberraciones”, lo que postularon es que existía un planeta que provocaba mediante su atracción este tipo de movimiento, lo cual se confirmó años más tarde.

Supongamos que hemos llegado a diferentes conclusiones para el mismo fenómeno por medio del razonamiento abductivo, todas ellas son "evidencialmente equivalentes", entonces nos vemos en la necesidad de elegir una de ellas, aquella que consideremos que sea "la mejor" bajo un criterio en específico: es más probable, más elegante, más profunda, más simple, más coordinada, más coherente, etc., entonces parecerá válido que aceptemos dicha hipótesis mientras no cambie la situación de los datos que tenemos. Esto es a lo que Harman bautizó como inferencia a la mejor explicación:

In making this inference one infers, from the fact that a certain hypothesis would explain the evidence to the truth of that hypothesis. In general, there will be several hypotheses which might explain the evidence, so one must be able to reject all such alternative hypotheses before one is warranted in making the inference. Thus, one infers, from the premise that a given hypothesis would provide a "better" explanation for the evidence than would any other hypothesis, to the conclusion that the given hypothesis is true (1965, pág. 89).

Quizá Le Verrier y Adams pensaron en diferentes hipótesis que pudieran explicar los porqués del comportamiento de Urano, sin embargo, la existencia de otro planeta que causara este fenómeno fue el que les pareció como una mejor explicación. Como podemos notar, Neptuno en esos momentos es precisamente un "no-observable", lo cual nos muestra que este tipo de argumentación nos puede ayudar 
a defender la existencia de algunas entidades teóricas inobservables (ya sea por su tamaño, tiempo o distancia), y así poder mostrar que estos tienen una referencia genuina.

Dicha estrategia también es utilizada para defender el realismo en general, no solamente la existencia de algunas entidades no-observables, sino todo el proyecto realista, en especial su parte semántica. Una característica de la ciencia que muy pocos se atreverían a negar es que cada vez es más exitosa, es decir, podemos manejar más fácilmente los fenómenos naturales, tienen una mayor eficacia predictiva y con más exactitud, se han incrementado las aplicaciones prácticas de las teorías. Un instrumentalista diría que ese es precisamente el objetivo de la ciencia, "tener éxito", pero el realista quisiera ir más allá, le gustaría saber las razones por las cuáles se produce ese éxito, intentará responder preguntas como: “¿por qué sirven esas herramientas para manejar el mundo?, ¿por qué, por ejemplo, las teorías de la aerodinámica permiten construir aviones que vuelan?” (Diéguez, 1998, págs. 103-104).

Lo anterior es porque el realista piensa que la ciencia no se conforma únicamente con explicar y manipular lo que podemos observar, sino quiere saber por qué suceden así los fenómenos. La respuesta que suele dar es que el mundo es en realidad como la teoría dice, cuando menos de manera aproximada, ya que sería muy extraño que fuese falsa y aún siguiera siendo tan exitosa (¡sería un milagro!), este argumento ha sido defendido por muchos realistas y formulado de maneras distintas, generalmente suele llamársele el argumento de los no-milagros:

If there are such things, then a natural explanation of the success of these theories is that they are partially true accounts of how they behave. And a natural account of the way in which scientific theories succeed each other - say, the way in which Einstein's Relativity succeeded Newton's Universal Gravitation - is that a partially correct/partially incorrect account of a theoretical object - say, the gravitational field, or the metric structure of space-time, or both - is replaced by a better account of the same object or objects. But if these objects don't really exist at all, then it is a miracle that a theory which speaks of gravitational action at a distance successfully predicts phenomena; it is a miracle that a theory which speaks of curved space-time successfully predicts phenomena; and the fact that the laws of the former theory are derivable 'in the limit' from the laws of the latter theory has no methodological significance (Putnam, 1978, pág. 19). ${ }^{12}$

O formulado de la siguiente manera: "it would be 'a miracle' that theories were so successful if they were not approximately true. Realism does not just have the best explanation of success, it has the only good explanation" (Devitt, 2014, pág. 260) y

The convergence of the sequence of theories that scientific change produces on an unqualifiedly true theory explains the increasing successfulness of science at the level of observation. Richard Boyd (1984) argues similarly that the success of scientific methods is uniquely explained by a realist view of the theories that underwrite those methods (Leplin, 2000, pág. 396).

Cabe destacar que aquí no se está diciendo que sea la "única explicación” del éxito de la ciencia, los anti-realistas pueden tener explicaciones para el éxito, pero lo que se afirma que es la mejor explicación o, como dice Devitt, es la única buena explicación. A veces una teoría puede ser exitosa por

12 Hilary Putnam seems to have inaugurated a new era of interest in realism with his declaration that realism is the only philosophy that does not make the success of science a miracle. (Leplin, 1984, pág. 1). 
otras razones, como el azar; puesto que hay ideas equivocadas que han sido exitosas o nos han dado resultados prácticos, tómese a consideración a los navegantes que podían llevar a cabo un viaje de manera exitosa aún y cuando pensaban que las estrellas estaban fijas y los planetas se movían alrededor de la Tierra.

Diéguez hace la aclaración de que el realista no está afirmando que cuando una teoría sea exitosa necesariamente sea verdadera, por ello el realista no tendría que preocuparse por los argumentos de Laudan acerca de teorías que hoy consideramos falsas, pero que fueron altamente exitosas, lo cual veremos más adelante. Lo que sí es más fuerte es cuando el éxito empírico es prolongado, repetido y novedoso, es decir, la teoría es exitosa en fenómenos o situaciones que no se habían tomado en cuenta, esto nos da una señal de que entre la teoría y la realidad hay algo más que adecuación empírica, como lo menciona Whewell:

La evidencia en favor de nuestra inducción es mayor y tiene más fuerza cuando nos permite explicar y determinar casos de un tipo diferente de aquellos que fueron contemplados en la formación de la hipótesis. De hecho, los casos en los que esto ha ocurrido nos impresionan con la convicción de que la verdad de la hipótesis es cierta. Ningún accidente podría dar lugar a tan extraña coincidencia. Ninguna falsa suposición podría, después de ser ajustada a una clase de fenómenos, representar exactamente una clase diferente cuando la concordancia no fue prevista ni se contó con ella (Citado por Diéguez, 1998, pág. 101).

Cabe destacar que el realista tampoco está diciendo que, si las teorías son exitosas, entonces son verdaderas, sino que la mejor explicación es que son "aproximadamente" verdaderas, siempre dando cabida al falibilismo: "the world is observationally as if S because, approximately, S" (Devitt, 2014, pág. 260). Con ello, el realismo gana mayor fuerza porque tiene un nivel de poder explicativo con el cual no cuentan sus alternativas rivales. Incluso se pueden explicar el éxito temporal de las teorías falsas, mientras que para los instrumentalistas el éxito se convierte en un misterio, como lo dice Smart:

el sistema ptoloméico puede proporcionar casi las mismas predicciones relativas a los movimientos aparentes de los planetas que la hipótesis copernicana. De ahí que el presupuesto de la verdad realista de la hipótesis copernicana explique la utilidad instrumental de la ptoloméica. Tal explicación de la utilidad instrumental de determinadas teorías no sería posible si todas las teorías fuesen consideradas como meramente instrumentales (Citado por Diéguez, 1998, pág. 106).

Debemos aclarar que el argumento de los no milagros se refiere a que la mejor explicación de que una teoría sea exitosa es su aproximación a como realmente es el mundo, sin embargo, no se compromete que cada vez que una teoría sea exitosa necesariamente tiene referentes en el mundo, ni a la inversa, cada vez que una teoría tenga referentes en el mundo, no quiere decir que va a ser exitosa. Entonces se acepta que es posible que existan teorías exitosas, pero sin referencia; teorías con referentes, pero sin éxito y que el éxito no justifica (siempre) su verdad.

Una acusación común que se le suele hacer al argumento de los no milagros es la de cometer la falacia de afirmación del consecuente, es decir, que tiene la siguiente forma: si una teoría es aproximadamente verdadera, entonces será exitosa; esta teoría es exitosa; por lo tanto, esta teoría es 
aproximadamente verdadera. Sin embargo, lo que realmente dice el argumento es que "la mejor explicación" del éxito de la teoría es que sea aproximadamente verdadera, con ello no está queriendo decir que sea una implicación, puesto que explicar e implicar son diferentes.

Por ejemplo, si un día miro por la ventana y veo gran parte de la calle mojada o siento humedad en el clima, pensaré que la mejor explicación de este suceso es que ha llovido; es decir, lo más probable es que sucedió tal fenómeno dadas mis experiencias pasadas, pero no estoy diciendo que necesariamente eso fue lo que sucedió. Posiblemente hubo un problema con las tuberías que provocó una fuga o un derrame en algún depósito en particular. Aquí no estoy afirmando que cada vez que vea la calle mojada es porque llovió, sino que eso es lo más probable que haya pasado (frente a otras hipótesis que puedo tener en mente). Tampoco es de la manera contraria: cada vez que llueve, se moja la calle. Y esto es precisamente lo que sucede con el argumento de los no milagros:

El realista puede conceder a Laudan que éxito no implica verdad. Puede reconocer asimismo que la supuesta verdad de una teoría no tiene por qué conseguir más éxito que la supuesta falsedad de otra. Y con todo ello, el realista puede sin embargo mantener coherentemente que la mejor explicación del éxito prolongado es la verdad porque (dadas ciertas condiciones acompañantes, como la habilidad técnica, los recursos adecuados el tiempo suficiente) es probable tener éxito instrumental con teorías verdaderas (Diéguez, 1998, pág. 109). Lo cual sería complicado que sucediera si las teorías fueran falsas, sobre todo que tengan éxito de manera prolongada y ante fenómenos para las cuales no fueron pensadas, sin embargo, esto podría pasar en algunos casos extraños.

El otro intento de refutación del argumento de los no milagros es decir que se trata de una falacia de circularidad, es decir, que se supone dentro de las premisas lo que se va a concluir; por lo tanto, es una petición de principio. Se supone que la mejor explicación del éxito es que una teoría es verdadera, y luego se llega a esa misma conclusión.

Van Fraassen afirma que creer en una teoría o hipótesis científica que mejor explica un fenómeno es por ser verdadera es en sí misma una hipótesis psicológica, por lo que puede ser sustituida por la creencia de que en realidad pensemos que esa teoría es empíricamente adecuada; ambas hipótesis son equivalentes. Alguien puede mantener cualquiera de los dos de manera consistente y no hay forma de obligar a que se piense que sólo es una de ellas.

Además, plantea, para que el argumento funcione debe tener una premisa adicional, acerca de las regularidades de la realidad observada; mientras que para el anti-realista las regularidades no es necesario explicarlas sin recurrir a entidades más allá de las observables:

The realist asks us to choose between different hypotheses that explain the regularities in certain ways; but his opponent always wishes to choose among hypotheses of the form 'theory $\mathrm{T}_{\mathrm{i}}$ is empirically adequate'. So, the realist will need his special extra premiss that every universal regularity in nature needs an explanation, before the rule will make realists of us all. And that is just the premiss that distinguishes the realist from his opponents (van Fraassen, 1980, pág. 21). 
Diéguez reconstruye el argumento de los no-milagros de la forma como lo piensa van Fraassen de la siguiente manera:

Premisa extra: Toda regularidad necesita explicación [que puede incluir entidades no observables] ${ }^{13}$.

Premisa 1: [Es una regularidad constatable que] las teorías en las ciencias maduras tienen éxito.

Premisa 2: La mejor explicación de ese éxito instrumental de las teorías científicas es suponer que la realidad es de manera aproximada, como dicen las teorías.

[Regla de inferencia abductiva: Si hay una hipótesis que es la que mejor explica una regularidad, conclúyase esa hipótesis].

Luego, la realidad es, de manera aproximada, como dicen las teorías científicas de las ciencias maduras [incluyendo las entidades inobservables] (1998, pág. 111).

Lo que muestra van Fraassen es que al tomar en cuenta la premisa extra se está presuponiendo al realismo, dado que buscar regularidades implica dar por sentado la existencia de las causas inobservables; por lo tanto, se llegaría a una circularidad. Esta necesidad de buscar una estructura inobservable la rastrea en el pensamiento de Reichenbach quien pensaba que si dos eventos sucedían al mismo tiempo entonces deberían tener una causa común (inobservable) y que la explicación científica sería imposible sin dichos $\operatorname{postulados}^{14}$.

Para van Fraassen el anti-realista puede concluir por medio de la inferencia a la mejor explicación que el realismo es empíricamente adecuado, pero no necesariamente que es verdadero, es decir, que la realidad es como si fuera aproximadamente a como dicen las teorías de las ciencias maduras. Esta extraña conclusión puede "jugar" más en contra del anti-realismo que del realismo puesto que es "hacer al fenomenismo parasitario del realismo" (1998, pág. 116). Si el anti-realista acepta la premisa de que la realidad es como las teorías dicen, entonces queda imposibilitado para descalificar el argumento de los no milagros, porque con ello admite que hay buenas hipótesis explicativas que van más allá de lo fenoménico y carece de sentido excluirlo en la regla de inferencia. Por lo tanto, si se aceptan las premisas es difícil negar la conclusión, y así ya no se puede admitir la circularidad.

Recordemos que lo que reclama el anti-realista es una circularidad en las premisas, donde el realista pide que las regularidades deben de ser explicadas con base a la existencia de entidades inobservables y luego concluye que debemos aceptar dichas entidades puesto que hay regularidades en el mundo. Mientras que para el anti-realista no es necesario explicarlas, las toma como hechos brutos de lo observable.

\footnotetext{
${ }^{13}$ I have offered elsewhere (1997: 113-17) a very basic argument: by supposing that the unobservables of science exist, we can give good explanations of the behavior and characteristics of observed entities, behavior and characteristics which would otherwise remain inexplicable (Devitt, 2014, pág. 261).

${ }^{14}$ Reichenbach held it to be a principle of scientific methodology that every statistical correlation (at least, every positive dependence) must be explained through common causes. This means then that the very project of science will necessarily lead to the introduction of unobservable structure behind the phenomena. Scientific explanation will be impossible unless there are unobservable entities; but the aim of science is to provide scientific explanation; therefore, the aim of science can only be served if it is true that there are unobservable entities (van Fraassen, 1980, pág. 26).
} 
Debemos notar que el realista parte de un argumento de posibilidad donde toma en cuenta varias hipótesis y afirma que una de ellas es mejor que las demás, y esa debe ser aceptada como verdadera. Así se diluye la circularidad, pues se parte de algo es posible para luego concluir que es verdadero: "Dicho de otro modo, el argumento de la mejor explicación no presupone la verdad del realismo, sino la posibilidad de que sea verdadero; no lo da desde el principio como admitido, sino sólo como alternativa a considerar" (pág. 117).

El argumento de los no milagros tiene la siguiente estructura: Tenemos el fenómeno P, las posibles explicaciones son X, Y y Z, la mejor explicación es X; por lo tanto, X es (aproximadamente) verdadera. Mientras que el anti-realista piensa que es de la siguiente forma: Tenemos el fenómeno P, la explicación X es verdadera; por consiguiente, $X$ es verdadera; por eso piensa que se trata de un argumento circular, pero en la primera forma vemos que no es así.

Las siguientes objeciones no son específicamente para el argumento de los no-milagros, sino para el uso de abducción y de la inferencia a la mejor explicación que utilizan los realistas para defender sus posturas.

Fine afirma que como las teorías filosóficas sobre la ciencia ponen en entredicho la legitimidad de los modos de inferencia utilizados dentro de la práctica científica, entonces en filosofía de la ciencia deberían limitarse a aquellos modos de inferencia no utilizados dentro de la ciencia; consiguientemente se deben buscar unos que sean más fuertes y menos cuestionables. Lo que responderá el realista es que, en primera, se debe defender la confiabilidad de la abducción en la práctica científica para liberarla de sospecha (en un nivel 1), si eso es posible, entonces podemos utilizarla para defender el realismo (el nivel 2):

But the burden of realism is to defend abduction at level 1, not simply to refute arguments against it. For as realism advocates a positive epistemic status for level 1 conclusions, it is bound to defend the reasoning used to reach those conclusions. Such a defense cannot itself be abductive, for then it would presuppose its own conclusion (Leplin, 2000, pág. 396).

El realista tiene dos estrategias para poder superar este problema. El primero de ellos es mostrar que en la práctica el uso del razonamiento abductivo generalmente es exitoso, sobre todo dentro de la práctica científica, para así establecer que es confiable para utilizarlo en la filosofía de la ciencia. Con esto no se puede convencer a los oponentes del argumento de los no milagros, pero puede decirle porqué es confiable a quienes sí lo emplean, y es posible que pueda convencer a quienes son neutrales en el tema (Cfr. Lipton, 1991, pág. 164).

El otro es justificar de manera inferencial, ya sea por la propia regla o mediante otra regla de inferencia. El primer camino, acusa el anti-realista, nos llevará a lo que se le llama como circularidad porque se está justificando la inferencia a la mejor explicación por medio de ella misma, el segundo tarde 
o temprano nos llevará a esas laderas, puesto que tendríamos que justificar esa otra regla con otra regla ad infinitum o cometer circularidad: "Vicious circularity is an epistemic charge - a viciously circular argument has no epistemic force. It cannot offer reasons to believe the conclusion. It cannot be persuasive" (Psillos, 2011, pág. 25). El reto del realista es demostrar que, aunque estemos frente a una circularidad, no es precisamente viciosa.

Psillos distingue entre dos tipos de circularidad, la primera es de las premisas y la segunda es de la regla. La circularidad de las premisas es siempre viciosa, es decir, cuando la conclusión ya está contenida en las premisas. Este tipo de circularidad no sucede en el argumento de los no-milagros, ni en la justificación de la inferencia a la mejor explicación, puesto que la conclusión no está contenida en las premisas $^{15}$.

La segunda es la denominada como circularidad de la regla o regla circular, la cual Braithwaite la describe de la siguiente manera: "is the circularity involved in the use of a principle of inference being justified by the truth of a proposition which can only be established by the use of the same principle of inference" (ídem), un argumento tiene la siguiente forma: con las premisas $\mathrm{P}_{1}, \ldots, \mathrm{P}_{\mathrm{n}}$ se llega a la conclusión Q mediante la regla R; en este caso en particular Q nos dice que R es confiable: "If anything, NMA is rule-circular (though in an oblique sense). Part (A) yields conclusion (C2), whose content is that the rule by means of which (C1) was arrived at is reliable" (pág. 26). La pregunta pertinente es si este tipo de circularidad es viciosa y si, en caso de serlo, se queda el argumento sin fuerza epistémica.

Psillos afirma que la inferencia a la mejor explicación se encuentra en una situación muy similar a la que tienen otras reglas de inferencia para ser justificadas, dado que para justificar el modus ponens, es necesario utilizarlo a él mismo. Como la situación de la inferencia a la mejor explicación es similar a otras reglas tan básicas como el modus ponens, entonces podemos decir que está en "buena compañía":

The good news is that this is not a conceptual tangle that arises only in the case of IBE. It spills over to more basic forms of ampliative reasoning as well as to

${ }^{15}$ Psillos caracteriza el argumento de la siguiente manera:

(A)

(A1) Scientific methodology is theory-laden.

(A2) These theory-laden methods lead to correct predictions and experimental success (instrumental reliability).

How are we to explain this?

(C1) The best explanation (of the instrumental reliability of scientific methodology) is this: the statements of the theory which assert the specific causal connections or mechanisms in virtue of which methods yield successful predictions are approximately true. 2

(B)

(B1/C1) Theories are approximately true.

(B2) These background scientific theories have themselves been typically arrived at by abductive reasoning.

(C2) Therefore, (it is reasonable to believe that) abductive reasoning is reliable: it tends to generate approximately true theories (2011, págs. 23-24).

Observamos que C2 no está en las premisas de B y C1 no lo está en las premisas de A, así evita caer en la circularidad viciosa de premisas. 
deductive logic. So IBE is in good company. Let's call this 'the good company argument'. (...)

It follows that the rule-circular justification of IBE is in good company — with all basic forms of reasoning (including, of course, enumerative induction) (pág. 27).

Si el anti-realista reconoce otras maneras de inferencia como justificadas, tendrá que decir por qué son diferentes a la inferencia a la mejor explicación, cuáles son las características que tiene la regla que él acepta y de las cuales adolece el otro método de razonamiento ampliativo.

Boyd da una buena estrategia para defender la existencia de entidades inobservables, puesto que el debate contra el escéptico extremo, quien aún duda de que la realidad observable es independiente de nosotros, aún no ha terminado, aunque el anti-realista sí afirma que tenemos conocimiento sobre lo observable. Entonces el realista lo que debe hacer es examinar las justificaciones del anti-realista para conocer lo observable y utilizar el mismo argumento para los inobservables. Además, debe mostrar que el escepticismo sobre inobservables es similar al de los observables. Dado que en la práctica científica se utiliza el razonamiento abductivo para sacar conclusiones acerca de entidades observables, entonces estamos en una buena posición para utilizarlo en la Filosofía de la Ciencia, a menos que el anti-realista pueda justificar esto sin utilizar la abducción, si fracasa en ese intento, entonces es legítimo el uso de la inferencia a la mejor explicación.

Supongamos que el anti-realista utilizase otros métodos ampliativos diferentes a la abducción para superar el escepticismo extremo, tendría que dar una justificación de por qué estas reglas están justificadas y no debemos abandonarlas, podemos aplicar la misma estrategia para nuestro argumento, puesto que no es obvio que la justificación de la abducción sea más complicada que la de los métodos utilizados por el anti-realista (Cfr. Boyd, 1984, págs. 65-75).

Otra estrategia que puede seguir el anti-realista es intentar dar una explicación al éxito de la ciencia y, además, que esta sea mejor que la otorgada por los realistas. Bas van Fraassen da un enfoque darwinista acerca de por qué tenemos teorías exitosas:

In just the same way, I claim that the success of current scientific theories is no miracle. It is not even surprising to the scientific (Darwinist) mind. For any scientific theory is born into a life of fierce competition, a jungle red in tooth and claw. Only the successful theories survive- the ones which in fact latched on to actual regularities in nature (1980, pág. 40).

Sin embargo, su explicación no es satisfactoria porque no está explicando lo mismo que el realista. En efecto, explica por qué mantenemos teorías exitosas, pero no por qué son exitosas. Lo que van Fraassen explica es por qué se aceptan y mantienen las teorías en un momento determinado (porque tienen éxito), pero no explica las razones de su éxito, mucho menos que su éxito sea prolongado o se mantenga ante nuevos fenómenos:

The realist will accept the selection mechanism, but this does not explain everything that inference to truth would explain. (...) If a club only admits members with red hair, that explains why all the members of the 
club have red hair, but it does not explain why Arthur, who is a member of the club, has red hair. That would perhaps require some genetic account. Similarly, van Fraassen's selection account may explain why all the theories we now accept have been observationally successful, but it does not explain why each of then1 has been. It does not explain why a particular theory, which was selected for its observational success, has this feature. The miracle argument, by contrast does explain this, by appealing to an intrinsic feature of the theory, rather than just to the principle by which it was selected (Lipton, 1991, pág. 194).

Fine también tiene una propuesta en la cual afirma que no en el mundo no sólo se manifiestan características observacionales, sino que existe una estructura de fondo que es imposible de conocer, que tiene las propiedades de producir los efectos que serían producidos por la estructura desconocida que la teoría representa. Tenemos, pues, que existe una estructura profunda que no es accesible de manera experiencial, pero que es causalmente responsable de lo que tenemos experiencia, aquello que la teoría intenta representar:

The best that can be said for any representation is that the actual structure produces the observable effects that it would produce were that representation true of it. The explanation of the success of any theory, however great and exceptionless, is that the actual structure of the world operates at the experiential level as if the theory represented it correctly. Whether the theory does represent it correctly is, in principle, undecidable (pág. 26).

Leplin le llama a esta postura "surrealism" (realismo sustituto) el cual es compatible con la parte ontológica del realismo científico, pero difiere ampliamente de la tesis epistémica la cual afirma que se puede conocer tal estructura profunda del mundo:

If an adequate or unimprovable explanation of a theory's success does not require imputing truth to the theory, then a major reason for supposing truth to be discoverable is lost. Certainly, a major motivation for epistemic realism is the conviction that unless there is some truth to a theory, there must be some limit to how successful the theory can be (págs. 26-27).

Es posible que una teoría completamente errónea sobre la estructura profunda del mundo sea exitosa, pero esto necesitaría una gran coincidencia para que la teoría funcionara lo suficientemente bien a pesar de estar completamente equivocada acerca de la estructura profunda. Una cantidad de éxito considerable podría justificarnos para afirmar que la teoría es (aproximadamente) verdadera, aunque siempre con la reserva de ser falible. Para que el éxito no provea tal justificación sería necesario que esto ocurra por probabilidades y no por casualidad, para que sea inexplicable.

Para Leplin el surrealismo tiene lagunas explicativas innecesarias, además es una propuesta que es parasitaria del realismo científico. Al analizar lo que significa la afirmación de que el mundo actúa "como si" la teoría fuese verdadera surgen las siguientes preguntas: ¿Cuáles implicaciones debemos suponer a tal comportamiento que se tiene a un nivel experiencialmente accesible? ¿Las consecuencias deben ser las mismas como las de la verdad de la teoría? ¿Para qué sirven? Asumimos que la experiencia va a llevar a cabo las predicciones de la teoría, si las predicciones de una teoría verdadera no necesitan ser confirmadas, entonces afirmar que el mundo se comporta como si la teoría fuese verdadera no explica por qué las predicciones de la teoría se confirman; no explica el éxito de la teoría. Si la explicación del 
surrealismo acerca del éxito científico quiere competir con la del realismo, debe presuponer que la verdad teórica se manifiesta en la experiencia, es decir, la manera como el realista explica el éxito: "The realist intuition is that if we have latched onto the right theoretical structure, our predictions, based on this structure, will conform to experience. Thus, surrealism is explanatory only in virtue of presupposing realist explanation” (pág. 27).

\section{Argumentos en contra del realismo científico}

Así como hay argumentos clásicos y en diversas formulaciones a favor del realismo científico, también los hay en contra, los cuales principalmente se enfocan en ir atacar alguna de las premisas principales del realista para socavar la validez del proyecto en general. A continuación, se dará una exposición estándar de ellos, así como las estrategias que se siguen para responderlos, con ello no quiero decir que estén completamente resueltos y no se sigan discutiendo en la actualidad.

\subsection{La subdeterminación de la teoría por la evidencia}

Supongamos que un día se encuentra ante un problema o fenómeno en particular e intenta darle una explicación a lo que sucedió, cuenta con una evidencia en específico para poder dar dicha explicación, entonces comienza a hacer especulaciones. Después de un tiempo de estar pensando se da cuenta que hay dos o más explicaciones posibles, y con la evidencia que tiene, ambas son igual de convincentes, no puede decantar por una o por la otra, además tampoco es posible conjuntarlas en una misma explicación porque se volvería inconsistente, a esto se le llama subdeterminación y los métodos ampliativos como la inferencia a la mejor explicación no permitiría legítimamente elegir una de las hipótesis como verdadera, o al menos eso es lo que piensa el anti-realista.

En Filosofía de la Ciencia este argumento anti-realista nace de la doctrina de la equivalencia empírica, si tomamos a $T$ como una teoría que está comprometida con inobservables, entonces diremos que tendrá rivales empíricamente equivalentes (EE), es decir, tienen las mismas consecuencias observacionales; esto implica que $T$ tiene teorías rivales que son apoyadas por toda la evidencia observacional, a lo cual se le llama como la tesis de subdeterminación fuerte $(\mathrm{SU})^{16}$. Si este es el caso, el realista no tiene justificación, puesto que no se sabe cuál debería ser la teoría verdadera y, por lo tanto, cuál debería elegirse (sino que se eligen por otros motivos distintos).

Debemos diferenciar entre las distintas tesis de subdeterminación, ya que existe también aquella que dice que cualquier teoría tiene rivales que es apoyada por la misma evidencia observacional actual, esta es la tesis débil (WE) ${ }^{17}$, la cual Devitt la considera como obviamente verdadera. La tesis SU es más

\footnotetext{
${ }^{16}$ SU: T has rivals that are equally supported by all possible observational evidence for it (Devitt, 1997, pág. 262).

${ }^{17}$ WU: Any theory has rivals that entail the same actual given observational evidence (pág. 259).
} 
fuerte que WE en dos sentidos: 1) SU concierne a una relación ampliativa entre las teorías y la evidencia, no solamente a la parte deductiva y 2) mientras que WE sólo hace referencia a la evidencia actual, SU es más fuerte puesto que afirma que sucede con toda la evidencia posible; con la versión débil sí se puede utilizar métodos ampliativos de manera válida, mientras que si SU es verdadera, los métodos ampliativos no permitirán que se acepte o apoye $T$ sobre otras teorías rivales, dado que no habrá evidencia que permita hacerlo de manera legítima; entonces no se sabrá elegir si se acepta la existencia de los inobservables postulados por $T$ o por cualquier otra teoría que esté en esa subdeterminación.

Existe una estrategia para establecer una teoría rival a $T$ que tenga las mismas consecuencias observacionales, es decir, que sea empíricamente equivalente. Si se tiene a $T$ ' como la teoría que contiene todas las consecuencias verdaderas de $T$. $T$ ' es empíricamente equivalente que $T$, sin embargo, aquí todavía no se tiene subdeterminación, dado que es posible obtener la conjunción de $T$ y $T$ ' de manera consistente. El siguiente paso será crear $T^{*}$ la cual está conformada por $T^{\prime}$ y la negación de $T\left(\mathrm{~T}^{\prime \wedge} \neg \mathrm{T}\right)$, $T^{*}$ es una teoría rival empíricamente equivalente de $T$ y ahora sí es posible la subdeterminación, puesto que no se puede conjuntar $T$ y $T^{*}$ de manera consistente (puesto que caería en contradicción $\mathrm{T}^{\wedge} \mathrm{T}^{\wedge} \neg \mathrm{T}$ ).

Aquí la primera estrategia del realista será la de descalificar a $T^{*}$ como una teoría rival no genuina, por lo tanto, no es interesante para el análisis filosófico ${ }^{18}$ : "We are not interested in bizarre theories (for example, almanac-style lists of observation conditionals), nor are we interested in empirically equivalent theories constructed out of existing (legitimate) theories by cheap tricks." (Hoefer \& Rosenberg, 1994, pág. 603). Laudan y Leplin no consideran a una teoría que es producto de un algoritmo como una rival genuina porque así no se produce una representación del mundo que pueda predecir o explicar el mismo fenómeno empírico, incluso tiene sólo vida parasitaria de la teoría de donde surgió al aplicársele el algoritmo. La versión instrumentalizada de la teoría no puede ser rival porque es una consecuencia lógica de la teoría y nadie se comprometería con ella: "We know of no algorithm for generating genuine theoretical competitors to a given theory" (Laudan \& Leplin, 1991, pág. 457).

Dado lo anterior, el anti-realista tendrá que restringir su argumento de subdeterminación a las teorías que sean rivales genuinos. Ahora deberá afirmar que $T$ tiene rivales genuinos que implica la misma evidencia observacional posible (EE1). Sin embargo, esto no es suficiente para apoyar la tesis de subdeterminación, recordemos lo que afirma la conocida como Tesis Duhem-Quine acerca del holismo confirmacional:

The view that any single hypothesis or theoretical sentence is not conclusively refuted when predictions derived from it turn out to be false, that is, when it is apparently incompatible with observation. Predictions

\footnotetext{
${ }^{18}$ We turn, finally, to the issue of what our response should be in the case that two genuinely different empirically adequate and equivalent theories are possible for our world (Hoefer \& Rosenberg, 1994, pág. 605).
} 
may also rest upon other hypotheses, which serve as background knowledge. We can always revise this background knowledge to save the hypothesis in question. Empirical tests can only be applied to the whole system of hypotheses, not to single theoretical sentences. The unit of empirical significance is the whole of science. The confirmation conditions of a single sentence are determined by the sentence's role in the language or in the theory in which it occurs (Bunnin \& Yu, 2004, pág. 194).

Lo cual nos indica que una teoría no está sola, sino que viene acompañada de una serie de elementos auxiliares con las cuales se presenta de una manera conjunta. Por lo tanto, $T$ y $T$ ' no se enfrentan al mismo problema por sí mismas, sino junto con una cantidad de elementos ya aceptados por la comunidad científica, es posible que $T^{\prime}$ no tenga las mismas implicaciones que $T$ si tomamos en cuenta estos elementos, por lo tanto, esta EEI no sirve para apoyar la subdeterminación y es necesario replantearla.

El anti-realista ahora afirmará que $T$ tiene rivales genuinos si ambas en conjunto con los auxiliares aceptados en cierto momento implican la misma evidencia observacional posible (EE2). Sin embargo, sigue siendo demasiado débil para preocupar al realista. Es posible que $T^{\prime}$ y $T$ sean empíricamente equivalentes si tomamos en cuenta a los auxiliares actuales, pero esos auxiliares pueden cambiar, con ello puede que $T$ o $T^{\prime}$ ya no den cuenta de la misma evidencia, por lo tanto, se puede aplicar de nuevo la estrategia de "sentarse y esperar" para desvanecer a la subdeterminación.

Entonces el anti-realista necesitar fortalecer su tesis y tendrá que plantearla en los siguientes términos: $T$ tiene rivales genuinos si ambas en conjunto con todos los elementos auxiliares posibles dan cuenta de toda la evidencia observacional posible (EE3) y esta es la que realmente puede apoyar a la tesis de subdeterminación. Devitt, al igual que Laudan y Leplin, cree que no hay razones para creer que EE3 pueda suceder. Dado que la dinámica de los auxiliares es muy cambiante, algunos dejan de tomarse en cuenta y otros nuevos se aceptan. Tenemos una gran capacidad de inventar nuevos instrumentos y experimentos para probar a las teorías, con ello se crean nuevos elementos auxiliares como las teorías del instrumento y presupuestos acerca de la situación experimental. Así podemos crear nueva evidencia y nuevos supuestos para los cuales puede que alguna de las teorías ya no pueda explicarlas. Es poco posible que una teoría tenga un rival genuino con todas esas características, más difícil todavía que eso suceda con todas las teorías: "We will seldom, if ever, have a basis for concluding that two genuine rivals are empirically equivalent in the absolute sense required by EE3. There is no known limit to our capacity to generate acceptable auxiliaries" (Devitt, 2014, pág. 264).

Por lo tanto, no hay una tesis sobre la subdeterminación que debería preocuparle demasiado a los realistas más allá de un juego especulativo con muy pocas posibilidades de que suceda.

\subsection{La inducción pesimista}

La siguiente objeción es distinta de la anterior, ya que su enfoque es diferente. Mientras que la subdeterminación era un argumento lógico o de posibilidad lógica, ahora nos toparemos con uno que es 
histórico, con la idea de que el realismo científico carece de apoyo si lo confrontamos con la historia de la ciencia. Es decir, si sometemos al realismo científico a pruebas empíricas, difícilmente se verá respaldado por la evidencia histórica de la ciencia, incluso puede tomarse como una refutación. Eso es lo que sostiene el filósofo Larry Laudan en su célebre A Confutation of Convergent Realism (1981).

Laudan se enfoca principalmente en un tipo de realismo que le llama epistemológico convergente en el cual se afirma lo siguiente:

R1) Scientific theories (at least in the 'mature' sciences) are typically approximately true and more recent theories are closer to the truth than older theories in the same domain;

R2) The observational and theoretical terms within the theories of a mature science genuinely refer (roughly, there are substances in the world that correspond to the ontologies presumed by our best theories);

R3) Successive theories in any mature science will be such that they 'preserve' the theoretical relations and the apparent referents of earlier theories (i.e., earlier theories will be 'limiting cases' of later theories).'

R4) Acceptable new theories do and should explain why their predecessors were successful insofar as they were successful. (...)

R5) Theses (R1) - (R4) entail that ('mature') scientific theories should be successful; indeed, these theses constitute the best, if not the only, explanation for the success of science. The empirical success of science (in the sense of giving detailed explanations and accurate predictions) accordingly provides striking empirical confirmation for realism (Laudan, 1981, págs. 20-21).

Ello se toma en conjunto con el argumento de los no milagros y se concluye que las teorías exitosas son aproximadamente verdaderas y sus términos realmente refieren al mundo, esto último es lo que Laudan va a poner en entre dicho. Donde por éxito se entenderá lo siguiente: "A theory is 'successful' so long as it has worked well, i.e., so long as it has functioned in a variety of explanatory contexts, has led to confirmed predictions and has been of broad explanatory scope” (pág. 23).

Lo primero que muestra es una lista de teorías científicas que actualmente diríamos que realmente refieren, pero que carecieron de éxito, entre ellas están la teoría atómica química en el siglo XVIII, la teoría wegeneriana acerca de las placas tectónicas y las teorías de Dalton o de Bohr sobre el átomo; lo cual nos hace dudar acerca de si una teoría genuinamente referencial tiene que ser necesariamente exitosa, aunque él mismo reconoce que en otros aspectos eran "masivamente falsas", como en la descripción de esos elementos.

Es aún más fuerte cuando la afirmación es a la inversa, es decir, cuando se afirma a que dado el éxito de una teoría podemos inferir que sus términos no observables existen realmente. Pone varios ejemplos de teorías altamente exitosas que actualmente las consideramos como no referenciales, como las teorías del éter del siglo XIX, del cual afirma: "In this connection, it is worth recalling the remark of the great theoretical physicist, J. C. Maxwell, to the effect that the aether was better confirmed than any other theoretical entity in natural philosophy!" (pág. 28); más adelante dará una lista de teorías exitosas, pero que actualmente consideraríamos como no referenciales (Cfr. pág. 33). Y esto tiene como consecuencia que "The realist's claim that he can explain why science is successful is false at least insofar 
as a part of the historical success of science has been success exhibited by theories whose central terms did not refer" (pág. 27).

El siguiente punto es atacar la noción de verdad aproximada o verosimilitud en conjunto con la de éxito. El primer embate es sobre la idea de si una teoría es aproximadamente verdadera, entonces será explicativamente y predictivamente exitosa. Para el realista, si una teoría es aproximadamente verdadera, entonces, deductivamente, será predictivamente y explicativamente exitosa. Laudan primero critica la carencia de una definición clara de lo que quiere decir "aproximadamente verdadero" (ése será precisamente el tema de esta idónea): "Unfortunately, few of the writers of whom I am aware have defined what it means for a statement or theory to be 'approximately true'. Accordingly, it is impossible to say whether the alleged entailment is genuine" (págs. 30-31), pero concede que, aunque existiera tal, o cuando menos con las definiciones con las que disponía en su tiempo, no se sigue que una teoría aproximadamente verdadera será explicativamente exitosa:

Even if the realist had a semantically adequate characterization of approximate or partial truth, and even if that semantics entailed that most of the consequences of an approximately true theory would be true, he would still be without any criterion that would epistemically warrant the ascription of approximate truth to a theory. As it is, the realist seems to be long on intuitions and short on either a semantics or an epistemology of approximate truth (pág. 32).

Laudan hace hincapié en que es urgente que el realista dé una noción clara de lo que es "la verdad aproximada" y la manera con la que se vincula con el éxito, de no hacerlo, varias de sus tesis serán pura palabrería.

Ahora queda ver si es posible sostener la hipótesis de la manera inversa, es decir, el éxito garantiza que una teoría es aproximadamente verdadera. Laudan supone que para un realista una teoría es aproximadamente verdadera si sus términos teóricos centrales refieren:

If there were nothing like genes, then a genetic theory, no matter how well confirmed it was, would not be approximately true. If there were no entities similar to atoms, no atomic theory could be approximately true; if there were no sub-atomic particles, then no quantum theory of chemistry could be approximately true. In short, a necessary condition-especially for a scientific realist-for a theory being close to the truth is that it central explanatory terms genuinely refer (pág. 33).

A continuación, de nuevo menciona la existencia de teorías que son exitosas, pero no consideraríamos como referencialmente genuinas, tales como: las esferas cristalinas de la astronomía antigua y medieval, la teoría de los humores en medicina, la teoría de la electricidad estática como fluido, la geología "catastrófica" (con su compromiso con un diluvio universal de Noé), la teoría química de los flogistos, la teoría calórica del calor, la teoría vibratoria del calor, las teorías de fuerza vital de psicología, etc. y agrega que la lista puede ser extendida ad nauseam con teorías que fueron alguna vez exitosas y bien confirmadas, pero hoy consideramos como falsas: "I daresay that for every highly successful theory in the past of science which we now believe to be a genuinely referring theory, one could find half a dozen 
once successful theories which we now regard as substantially non-referring" (pág. 35), lo cual nos debería hacer dudar acerca de si está justificado pensar que porque una teoría es altamente exitosa, entonces podemos hablar de que es aproximadamente verdadera.

También da ejemplos de casos de teorías genuinamente referenciales y empíricamente exitosas pero que difícilmente diríamos que son aproximadamente verdaderas, tal sería el caso de las teorías geológicas anteriores a 1960 en donde se negaba el movimiento lateral de los continentes. Es decir, esas teorías hablaban de entidades que hasta la fecha consideramos como existentes, además tenían predicciones y explicaciones exitosas; pero en cuanto a la descripción de los mecanismos es difícil pensar que se acercaban a la verdad.

Otro punto a analizar es la validez del realismo retencionistas, dado que si una teoría fue exitosa y se le consideró aproximadamente verdadera, la sucesora debería incluir los elementos que causaron su éxito explicativo cuando menos como casos límites, sin embargo, hay casos donde esto se ve que no ha sucedido (la teoría copernicana no contenía los elementos de la ptoleméica, por ejemplo), sino que se rechaza por completo la teoría anterior; lo cual de nuevo hace dudar de la conexión éxito-verdad: "The point is that some of the most important theoretical innovations have been due to a willingness of scientists to violate the cumulationist or retentionist constraint which realists enjoin 'mature' scientists to follow" (pág. 39). La razón por la cual las teorías sucesoras puede que no contengan consecuencias de la anterior como casos límites es fácil de explicar, dado que, si la primera teoría contenía fórmulas que explicaban una entidad que ahora pensamos como no existente, entonces la siguiente no tiene por qué tomarlos en cuenta (la física relativista no contiene maneras de "medir" el éter como la mecánica clásica, por la simple y sencilla razón que el éter no es considerado como existente) $)^{19}$.

En resumidas cuentas, Laudan siembra severas dudas en las conexiones entre la referencia genuina y la aproximación a la verdad con el éxito (y viceversa), no hay de manera histórica una base que nos permita confiar en dicha inferencia, al contrario, vemos que en muchos casos se encuentran completamente por separado. Lo cual da paso a la siguiente conclusión que le ha llamado inducción pesimista: dado que en el pasado hemos tenido una gran cantidad de teorías con un alto nivel de éxito, pero que actualmente consideramos como falsas o no referenciales; es válido pensar que eso puede sucederles a nuestras mejores teorías actuales a pesar de ser exitosas; por lo tanto, no estamos justificados a sostener que las teorías científicas actuales son aproximadamente verdaderas.

\footnotetext{
${ }^{19}$ Once we see that even in this prima facie most favorable case for the realist (where some of the laws of the predecessor theory are genuinely limiting cases of the successor), changing ontologies or conceptual frameworks make it impossible to capture many of the central theoretical laws and mechanisms postulated by the earlier theory, then we can see how misleading is Putnam's claim that "what scientists try to do" is to preserve (Laudan, 1981, pág. 41)
} 
Los realistas han ideado diferentes estrategias para solucionar este problema. Muchas han consistido en descalificar de la lista a varias de las teorías mencionadas por Laudan, ya sea porque en realidad no tenían éxito, sólo se creía que sí; otras no estaban bien establecidas y por lo tanto no deberíamos comprometernos de manera realista con ellas; alguien más puede decir que no eran parte de la ciencia madura (estableciendo un criterio) y por último se puede mencionar que en realidad existieron muchas otras teorías que sí eran exitosas y aproximadamente verdaderas a las cuales no se hace mención. Sin embargo, es posible que muchas de esas teorías sigan prevaleciendo en el argumento de la inducción pesimista por lo cual debe de dársele una solución.

Marc Lange (2002) considera que la inducción pesimista cae en una falacia que denomina "The turnover fallacy", donde dice que, aunque nos demostraran que la mayoría de los inobservables de las teorías pasadas no existen, no es suficiente para pensar que lo mismo sucede con las actuales. Para él es obvio que las teorías falsas fracasan con más frecuencia que las verdaderas. Si realmente quiere ponerse en jaque al realismo científico, se debe partir de que todos los inobservables postulados por todas las teorías pasadas no existen.

Lewis Peter (2001) sugiere que se puede tomar al argumento de los no milagros como una estrategia confiable de para justificar la aproximación a la verdad por medio del éxito empírico de las teorías y lo hace por medio de una analogía. Supongamos que tenemos un "test" confiable para poder diagnosticar una enfermedad rara que se da de uno entre mil personas, con un índice de fallo de un $1 \%$; supongamos que lo aplicamos a esa cantidad de personas (1000), lo más seguro es que nos arroje una cantidad de 10 falsos positivos y solamente un positivo real (dada la extrañeza del padecimiento), ¿desconfiaríamos de nuestro instrumento? Diríamos que no, dado que su rango de fallo es muy bajo (falsos positivos) y el de su éxito es muy alto (detecta cuando se encuentra la enfermedad). Lo mismo sucede con el éxito en la ciencia, las teorías científicas verdaderas son muy escazas, mientras que las falsas son muchas, por lo tanto, es posible que tengamos una cantidad considerable de falsos positivos.

Otra estrategia es la tomada por Psillos (1994) (1996) (1999, págs. 96-109) y Kitcher (1993) quienes afirman que el éxito de una teoría no debe comprometernos con todas las partes de la misma, sino que se puede explicar con unas que lo provocan, otras son meramente "ociosas" y no estamos justificados para creer en su existencia, a ello se le ha denominado como divide et impera. El trabajo del realista será el de identificar cuáles son las partes centrales de cada una de las teorías que menciona Laudan en su lista, luego mostrar que esas mismas se han mantenido en el cambio inter-teórico, ya sea con la misma referencia o con otro elemento que es similar en la teoría que lo precede, Psillos hace este trabajo con el caso del calórico: 
(i) identify the theoretical constituents of past genuine successful theories that essentially contributed to their successes; and

(ii) show that these constituents, far from being characteristically false, have been retained in subsequent theories of the same domain (Psillos, 1996, pág. s310).

Por lo tanto, se defiende una postura que no es realista de toda la teoría, sino de ciertas partes. Asimismo, afirma que es una actitud común en la práctica científica, donde los científicos se comprometen con las partes de la teoría que están bien confirmadas y son escépticos de aquellas que no lo son. John Worral (1989) (2009) argumenta de manera similar, lo que para él se preserva en el cambio inter-teórico son las "estructuras" y con ellas podemos comprometernos, dando paso a la formulación del llamado realismo estructural.

Por último, está la estrategia seguida por Devitt (1997, págs. 162-165) (2014), Doppelt (2007) y Park (2011) quienes consideran que, aunque se haya demostrado que las teorías científicas pasadas son falsas, no hay razón para pensar que sucederá lo mismo a las actuales porque cada vez son mejores. Además, se puede construir una meta-inducción optimista si podemos dar una cantidad de teorías pasadas exitosas cuyos elementos referenciales se han ido manteniendo en las actuales ${ }^{20}$. Ellos afirman que podemos comprometernos con las teorías de la ciencia actuales más exitosas y mejor establecidas ${ }^{21}$ porque tienen virtudes que las anteriores no mostraban, tales como una mayor unificación, más éxito o contamos con mejores instrumentos para su corroboración, aspecto del que carecían las anteriores:

we are now much better at finding out about unobservables. Science has for two or three centuries been getting better and better at this. Indeed, scientific progress is, to a large degree, a matter of improving scientific methodologies often based on new technologies that provide new instruments for investigating the world. If this is so - and it seems fairly indubitable - then we should expect an examination of the historical details to show improvement over time in our success ratio for unobservables. If the details do show this, it will not matter to realism that the ratio for, say, two centuries ago was poor (Devitt, 2014, pág. 265).

There are two reasons to think that current theories are not going to follow the fate of the superseded theories on Laudan's list. First, the current theories are more successful than their old counterparts. It could be shown that for every successful theory on Laudan's list, there is a corresponding theory we now hold to be approximately true, and that it is more successful than its counterpart on Laudan's list (...)

Second, the theories of the twentieth century and onward have better birth qualities than the theories before the twentieth century. The better birth qualities are due to what I take to be an important revolution in science that occurred at the end of nineteenth century and the beginning of the twentieth century. During this period, various fields of science and special sciences became connected with each other (Park, 2011, pág. 80).

Our best current theories enjoy a singular degree of empirical confirmation impossible for their predecessors, given their ignorance of so many kinds of phenomena and dimensions of nature discovered by our best current theories (Doppelt, 2007, pág. 111).

20 In response, the realists could construct an optimistic induction with an equal number of past theories which are considered approximately true in the light of the current theories. The pessimistic force and the optimistic force would cancel each other out. Thus, the pessimistic inference against the current theories would be completely blocked. Notice that constructing the optimistic induction would be impossible, if most successful past theories are not even approximately true (Park, 2011, pág. 78).

${ }^{21}$ Thus, my first proposal is that realists rigorously restrict their commitment to the approximate truth of those and only those current theories that are both our most successful and well established. I will refer to current theories as 'our best' only if they are both well established and most successful (Doppelt, 2007, pág. 110). 
Park concluye que con ello podemos ver que los científicos cometieron errores en el pasado, pero que se ha aprendido de ellos y que ahora se han diseñado mejores instrumentos para corroborar las teorías científicas, entonces se cuenta con una mayor justificación sobre la aproximación a la verdad de éstas y se puede ser optimistas en cuanto a lo que nos depara el futuro al respecto del acercamiento a la verdad.

\section{Tipos de realismo científico}

Al inicio de este capítulo se mencionó que existían dificultades para poder dar una caracterización del realismo que dejara satisfechos a todos los realistas e incluso a los anti-realistas, y esto es porque suelen caracterizarlo de diferentes maneras, dicho de otro modo, existen muchas formas de ser realista. Carman (2005) hace un desglose de las diferentes tesis que pueden ir en conjunto y que pueden proporcionar un realismo diferente uno del otro, hasta sumar la totalidad de $1111^{22}$. A continuación, se hará un resumen de su trabajo sin ser tan explícitos en las formas como él los describe.

La primera división será entre los categóricos y los condicionales. Los primeros serían aquellos quienes se posicionan en el debate afirmando si son o no realistas asumiendo la realidad de lo observable como de lo inobservable, mientras que un anti-realista sólo se compromete con lo primero, pero niega lo segundo.

Los segundos, los condicionales, son casos donde se duda o niega el realismo de lo observable; y de ello dependerá después su postura sobre lo inobservable: "Si aceptara el realismo de lo observable (o si aceptara la legitimidad de la pregunta y su respuesta fuera positiva), estaríamos frente a un $\mathbf{R C}$ o a un anti-realismo, según se acepte o rechace el realismo de lo teórico respectivamente" (Carman, 2005, pág. 49) y estos, a su vez, se dividen en tres grupos.

En primera tendríamos a quienes niegan que la realidad sea independiente de nuestra mente, tales como el fenomenismo y el idealismo subjetivo. Ser un realista científico en este caso sería pensar que la naturaleza de los observables y los inobservables es la misma, aunque ninguno de los dos es extramental; el caso contrario, el anti-realista, dirían que tienen una "realidad" distinta.

En segundo lugar, estarían aquellos que dudan sobre la naturaleza de lo observable, no niegan ni afirman que sea "extramental", sino que no están seguros de su tipo de realidad. En este caso un realista científico sería quien dijera que ignora el tipo de realidad que tienen las mesas, las sillas, los planetas, etc., pero sea cual fuere, las entidades no observables son de la misma manera que las antes mencionadas: "I think that commonsense objects and theoretical objects are in the same boat, but I'm not yet sure what

${ }^{22}$ En realidad, son 1110, pero él suma uno más para "el realismo desconocido", es decir, aquel que todavía no llegamos a conocer, si es que existe (Cfr. Carman, 2005, pág. 57). 
that boat is" (Kukla, 1998, pág. 8). Por otro lado, el anti-realista pensaría que, aunque no sabemos en qué “bote” están las entidades del sentido común, sin duda es uno distinto que el de las no observables.

Por último, están quienes piensan que este tipo de cuestionamientos no es más que un pseudoproblema porque la pregunta carece de sentido como vimos con Carnap en la primera parte del capítulo.

En seguida Carman procede a dividir en dos posibilidades de ser realista, una sería la de comprometerse con la existencia de los términos teóricos (es decir, que tienen referencia exitosa) y la otra sería la correspondiente a la verdad o verdad aproximada de las proposiciones teóricas. Aquí se puede hacer una acotación y no tomar a todas las proposiciones teóricas o términos teóricos, sino únicamente aquellas que sean centrales (una característica en específico). Ahora, siendo centrales o no, el realista puede comprometerse con todas las proposiciones teóricas o términos teóricos, con algunas o con la mayoría; además puede saber con cuáles, en este caso le llamaremos "determinadas", o puede ignorarlo o no decirlo, así serán "indeterminadas”.

De la misma manera puede suceder con las teorías, alguien puede ser realista de todas, de algunas o de la mayoría, también en este caso pueden ser "determinadas" (las teorías de las ciencias maduras o las actuales, por ejemplo) $)^{23}$ o "indeterminadas"24. Hasta aquí Carman cuantifica 300 posibilidades de ser realista, a esto le llama el núcleo del realismo, puesto que de estás se irán construyendo las distintas posibilidades del realismo.

En seguida pasa a lo que denomina a los realismos literales, aquellos que simplemente afirman que los presupuestos teóricos deben leerse como si fueran verdaderas o falsas, aunque sean falsas, y los términos teóricos como si fueran referenciales, aunque fracasen en hacer referencia a una entidad de la realidad, el anti-realista se opondría a esto afirmando que deben ser tomados como adecuados empíricamente.

Después tenemos a los realismos sincrónicos los cuales se comprometen con la aproximación a la verdad o a la verdad de las teorías o presupuestos teóricos (algunos, todos o la mayoría) de cierto momento en específico, al igual puede hacerse con las entidades teóricas: “Queda claro que un realismo sincrónico determinado implica su literal correspondiente (aunque la inversa no es válida)” (pág. 53).

Después tenemos a los realismos diacrónicos, aquellos que se dedican a estudiar la historia de la ciencia e indican que hay una retención o progreso en cuanto a los elementos antes mencionados (verdad

\footnotetext{
${ }^{23}$ En el capítulo anterior vimos que Doppelt, Park y Devitt se comprometen únicamente con las mejores teorías actuales para poder rechazar la inducción pesimista.

${ }^{2424}$ Esquemáticamente el núcleo del realismo está compuesto por: la predicación de una propiedad semántica (verdad, verdad aproximada o referencia) a un determinado objeto científico (ley o término teórico) que está o no especificado (ley o término teórico central o no) y cuantificado (todos, algunos o la mayoría). En la cuantificación, a su vez, se aclara si es determinada o indeterminada. Esta propiedad, además, se predica de las teorías que deben también ser cuantificadas y especificadas (Carman, 2005, pág. 52).
} 
y referencia). Al primer tipo le podemos llamar "de conservación”, ya que no habla de un aumento o progreso, sino de una conservación de la verdad o referencia en el cambio inter-teórico, ya sea de manera completa o de algunas partes de las que causaban el éxito de la teoría anterior que se mantiene en la siguiente. Estamos hablando de familias de teorías que se avocan a explicar el mismo fenómeno desde el mismo enfoque (físico, biológico, químico, etc.). En este caso también se puede plantear si se sabe qué partes son las que se retinen (realismo diacrónico determinado) o no (realismo diacrónico indeterminado).

No obstante, hay otros que sí se comprometen con la idea de progreso, entonces se tendrá un realismo diacrónico de incremento; estos pueden ser de teorías que es cuando se posee una mayor cantidad de teorías las cuales comparten la misma propiedad referencial, aunque es posible que suceda sin retención. También se encuentra aquel que habla de un incremento "de objetos", es decir, ahora la teoría tiene un éxito referencial mayor que su antecesora, habla de entidades que de hecho existen y están justificadas en pensar que sucede.

Por último, se tiene a aquellos que afirman que el progreso consiste en un aumento de las propiedades, tal es el caso de la verdad o la verdad aproximada, entonces diríamos que cada vez acumulamos más verdades o nos aproximamos más a la verdad (aunque puede que se mantengan las mismas referencias, por ejemplo, se puede tener una mejor descripción de la estructura atómica y su comportamiento). Aquí se encuentra otra división, la primera es local, sólo se compromete con el aumento de la propiedad en una familia de teorías, mientras que la segunda es global, la adjudican el progreso en ese aspecto a todas las teorías de la ciencia. ${ }^{\text {ii }}$

Se pueden otorgar dar ejemplos de realismos en específico, pero será sólo para identificar el nombre, el autor y alguno de los puntos principales que defienden; sería muy complejo abarcar todo el espectro, ya que, como hemos mencionado, existen más realismos que realistas porque incluso los autores han cambiado sus posturas con el paso del tiempo.

Anteriormente se mencionó, por ejemplo, que Psillos (1999) y Kitcher (1993) defienden un realismo que al mismo tiempo es progresivo y conservativo puesto que aumentan en cuanto al conocimiento de objetos referenciados exitosamente y de aproximación a la verdad, así como preservar aquellos elementos centrales de la teoría anterior que provocaban su éxito.

Ian Hacking (1983) y Michael Devitt (1997) estarían dentro de un realismo de entidades puesto que no se comprometen con la aproximación a la verdad de los presupuestos teóricos, pero sí con la existencia independiente de entidades no observables a las cuales es posible corroborar por medio de instrumentos o manipularlas en los experimentos. 
Ronald Giere propone lo que él llama como "realismo constructivo" (1988), se centra en comprometerse con los modelos, los cuales son tomados por los científicos de manera realista. Mediante un análisis sociológico de la ciencia, Giere identifica a los científicos como agentes cognitivos y a los modelos como representación. Aquí se busca sustituir la noción de verdad con la de similitud, es decir, hay una relación isomórfica entre el modelo y la realidad. La parte constructiva de esta propuesta es precisamente la de los modelos, los cuales no se descubren de la realidad, sino que se fabrican socialmente; después de esto se comparan con los datos de la realidad y según sea su grado de "similitud" hay un compromiso realista hacia ellos.

El realismo científico crítico de Niiniluoto (1980) es una de las versiones que podríamos llamar más "estándar" del realismo de los últimos años. En él se defiende a la verdad como meta de la ciencia y a la verosimilitud como el tipo de progreso que se ha ido logrando, pero acepta una gran dosis de falibilismo dentro de su propuesta. Admite que el mundo no está prefabricado, sino que nosotros tenemos (y creamos) ciertas estructuras mentales para describir al mundo y por lo tanto no podemos esperar una única descripción del mundo que sea la adecuada, pero sí que unas son más adecuadas que otras según el éxito obtenido.

Por último, recordemos a Worral (1980) quien propone un realismo estructural que en un principio defendía que la estructura matemática es aquello que se conserva en el cambio inter-teórico. Ahora es posible hacer dos distinciones de dicha postura, por un lado tenemos al realismo estructural epistémico el cual afirma que sólo podemos conocer estructuras de la realidad no-observable; aquí suele surgir una controversia, entre quienes piensan si a pesar de que sólo podemos conocer aspectos relacionales también es necesario ser un realista de entidades, tal como lo cree Mauro Dorato (2000), mientras otros simplemente se pronuncian por la cautela y ser agnósticos ante el tema, por ejemplo Matteo Morganti (2004). Aunado a lo anterior, hay quienes afirman que no sólo lo que conocemos del mundo inobservable son estructuras relacionales, sino que las relaciones es lo único existente, a esto se le llama realismo estructural óntico como lo defienden French y Ladyman (2011).

\section{Conclusión}

A mediados de la década de 1980 Arthur Fine escribía lo siguiente:

Realism is dead, it's death was announced by the neopositivist who realized that they could accept all the results of science, including all the members of the scientific zoo, and still declare that the questions raised by the existence claim of realism were mere pseudo-questions. Its death was hastened by the debates over the interpretation of quantum theory, where, Bohr's nonrealist philosophy was seen to win out over Einstein's passionate realism. Its death was certified, finally, as the last two generations of physical scientist turned their backs on realism and have managed, nevertheless, to do science successfully without it. To be sure, some recent philosophical literature has appeared to pump up the ghostly shell and to give in new life. I think these efforts will eventually be seen and understood as the first stage in the process of mourning, the 
stage of denial. But I think we shall pass through this first stage and into that of acceptance, for realism is well and truly dead, and we have work to get on with, in identifying a suitable successor (1986, pág. 112). Una declaración bastante fuerte, sin embargo, pareciera que está lejos de ser verdadera. En los últimos tiempos se ha ido aumentando la literatura de los filósofos que defienden el realismo científico, lo cual indicaría que para ser una “etapa de negación” sería bastante amplia pues ya ha durado 30 años.

Lo que sí es cierto es que los anti-realistas han ganado terreno en las últimas décadas y han logrado que el realista haga cada vez defensas más modestas de su postura. El singular optimismo se ha visto mermando por la fuerza de los contra-argumentos, ahora se defiende la postura con mayor cautela.

Lo que también podemos observar es que los argumentos se han sofisticado cada vez más, el cuidado que se tiene para poder sustentar algunas tesis realistas es mayor, un ejemplo de ello es el realismo estructural.

En el presente capítulo hemos intentado dar una visión global de lo que es el realismo científico, sus argumentos a favor y en contra. Queda claro que no es debate terminado, aún no hay un vencedor en la disputa (y es posible que nunca suceda). Lo que se ha expuesto anteriormente debe tomarse más como una "puesta en contexto" que, como la última palabra en el tema, ninguno de los argumentos se ha presentado como definitivo, en todos los casos hay elementos para su discusión.

Quizá faltaron dos argumentos en contra del realismo, como lo son la inconmensurabilidad de las teorías planteado por Thomas S. Kuhn en The Structure of Scientific Revolution (1962), lo que afirma es que cuando se intenta comparar dos teorías de diferentes períodos de la ciencia normal no es posible, de tal manera que nos permita decir que una es epistémicamente superior a la otra, ya que están en diferentes paradigmas (se comprometen con diferentes representaciones simbólicas de los fenómenos metafísicos, creencias, valores y técnicas de la resolución de problemas). Esto trae como consecuencia que su "carga de teoría" no sea la misma y por lo tanto se encuentren en "dos mundos distintos". Los términos de un paradigma serán entendidos propiamente dentro de él, lo cual dificultará la comunicación entre comunidades. Así, juzgar que una teoría está más cerca de la verdad que otra se vuelve confuso, pues no hay un punto de comparación. Desde esta perspectiva, la realidad se estructura dentro de un paradigma científico en específico, lo cual va en contra de lo que afirma el realista de que es independiente de nuestra mente.

Otro problema es el que se plantea en cuanto a la referencia por parte de Putnam (1977) en su realismo interno (cabe destacar que es uno de los filósofos que ha cambiado varias veces de postura en cuanto a este tema se refiere), en esta propuesta sólo se puede hablar de objetos o propiedades que están al interior de un esquema conceptual, los cuales no son impuestos por el mundo, sino que son dependientes de nuestros intereses pragmáticos; existe una pluralidad de esquemas conceptuales (sin caer 
en el relativismo) y "verdad" se entiende como una aseverabilidad racional idealizada; mientras que comprende al realismo metafísico como a la idea de la existencia de una totalidad fija de objetos independientes de la mente, que también hay una descripción completa y verdadera del mundo; y la "verdad" se entiende como correspondencia.

Para defender su postura utiliza un experimento mental planteando que podríamos ser "cerebros en una cubeta" cuya visión del mundo es creada por un ordenador. Alguien podría tener una teoría que puede explicar todos los fenómenos del mundo, con todas las virtudes, pero no sería verdadera, puesto que a los objetos de los cuales habla no refieren verdaderamente, puesto que sólo son datos sensoriales que tienen dentro de su mente. Es decir, aunque la teoría hable de "cubetas" no hablará de cubetas reales como en la que está el cerebro, sino de "cubetas" que son producidas por el programa.

Otro argumento de Putnam es el que habla sobre la relatividad conceptual, el cual afirma que, si bien es cierto que la realidad determina el significado de los conceptos, también sucede de manera contraria. Si tenemos un mundo que tiene tres objetos X1, X2 y X3, podríamos tener una teoría que nos diga que precisamente en el mundo hay 3 objetos, pero otros podrían decir que hay 7, si tomamos como objetos a las diferentes sumas de los tres anteriores, ¿cuál de las dos es la verdadera? no podríamos discriminar de esa manera, debemos aceptar que hay varias maneras de aceptar la realidad. Esto sucede en la ciencia, podemos tener una teoría que nos diga que un elemento es un objeto o una relación, ambas podríanse tomarlas como válidas, lo cual pondría en problemas a los realistas que piensen que hay una sola descripción verdadera del mundo.

Y aunque es posible extendernos más, lo expuesto es suficiente para resaltar la importancia del debate, pero sobre todo de un aspecto que es de lo que tratarán los dos próximos capítulos: "la verosimilitud o aproximación a la verdad"; como se puede observar, son conceptos que se mencionan a menudo, pero que requieren una clarificación para que el realista pueda defender su postura. 


\section{Capítulo II. La verosimilitud: definiciones y problemas}

Placuit enim Ciceroni nostro beatum esse, qui veritatem investigat, etiamsi ad eius inventionem non valeat pervenire - Licentius.

\section{Introducción}

El objetivo de este capítulo es mostrar la importancia de la verosimilitud para el realismo científico, así como la primera definición ofrecida por Popper en la década de los sesentas y sus problemas.

En la primera sección se hará mención de los aspectos básicos de la verosimilitud y aclarará las diferentes confusiones que pudieran darse con otros términos, tomando como base las obras Truthlikeness (1987) de Ilkka Niiniluoto y Likenesss to Truth (1986) de Graham Oddie. Después pasaremos a explicar la solución popperiana a este problema, tanto en el aspecto cualitativo como en el cuantitativo; aquí se recurrieron a las fuentes originales de Popper, pero también fueron de gran utilidad otros textos, principalmente Verdades a medias (1996) de Jesús Zamora Bonilla.

\section{Nociones básicas sobre la verosimilitud \\ 1.1 Realismo científico, falibilismo y optimismo}

Recordemos que en el capítulo anterior se expuso que uno de los puntos principales del realismo científico es pensar al objetivo de la ciencia como la búsqueda y logro de la verdad, aunque uno pueda tener otros intereses para estar investigando, ese será el que nos conducirá al final de cuentas:

An inquiry is a search for the truth of some matter. A person may embark on an inquiry for all manner of reasons: to relieve boredom, to satisfy a client, to help make gadgets, to win the Nobel Prize, to get a raise, or to impress his friends. Still an inquiry qua inquiry is a search for truth, and success is determined by the extent to which the inquiry reveals that truth. Scientific inquiry may be special in various ways, but it shares with inquiry in general this constitutive goal of revealing truth (Oddie, 2014, pág. 541).

A lo anterior podemos denominarlo como la doctrina de la verdad. Recordemos otro aspecto de la historia de la ciencia, el denominado como progreso, sería difícil que alguien niegue que ha existido progreso científico, sin embargo, en qué consiste puede ser pensado de diferentes maneras (doctrina del progreso). Si conjuntamos ambas podría entenderse que la ciencia progresa por medio de la acumulación de verdades. ${ }^{25}$

La visión anterior sería bastante ingenua en cuanto al desarrollo de la ciencia, ya que podemos observar en la historia que a menudo se encuentra que las teorías son falsas, o tienen elementos falsos, por lo tanto, no se obtiene la verdad de manera mágica de una vez y para siempre, el récord muestra que es completamente lo contrario.

25 The first, which might be called the truth doctrine, is that truth is the (or an) aim of inquiry. The second, which might be called the progress doctrine, is that one theory may realise that particular aim better than another (Oddie, Likeness to Truth, 1986, pág. 1). 
Si el filósofo de la ciencia se toma en serio a la historia sin duda tendrá que aceptar que continuamente nos equivocamos y aquello que creíamos como verdadero realmente no lo era; y esto es todavía más alarmante cuando nos damos cuenta que le puede suceder a nuestras mejores teorías científicas actuales. A esta postura se le llama "falibilismo", que la revisaremos un poco en el siguiente apartado.

Ahora cabe preguntarse, ¿podríamos seguir siendo realistas con base a lo anterior? El realismo deberá reformular la doctrina de la verdad afirmando que se logran verdades aproximadas y el progreso consiste en que, aunque una teoría es estrictamente falsa, nos vamos aproximando cada vez más a la verdad: "Together these yield the conclusion that a false theory may be more truthlike, or closer to the truth, than another" (Oddie, 1986, pág. ix).

Ahora tenemos dos realismos distintos, uno que entiende el progreso como acumulación de verdades, el cual ya fue duramente criticado en el pasado y difícilmente sigue defendiéndose, y otro que afirma que se va aumentando el acercamiento hacia la verdad. ${ }^{26}$ Ahora nos podemos hacer una pregunta de si es posible que una teoría falsa pueda lograr mejor el objetivo de acercarse a la verdad que otra teoría que tampoco es verdadera; si deseamos responder a esto de manera afirmativa debemos dejar en claro qué queremos decir cuando afirmamos que una proposición o teoría está más cercana a la verdad (o tiene un mayor grado de verosimilitud) que otra.

A pesar de que la verdad es un problema recurrente en la historia de la filosofía desde sus inicios y que son muchos los autores que la abordan, la cuestión de estar más o menos aproximado a ella ha sido poco analizada, y esto se debe a las razones antes mencionadas con respecto a la mezcla entre el falibilismo, el realismo y el optimismo que sucedió en la segunda mitad del siglo anterior: "The logical problem of truthlikeness should be on the agenda of every realist who is also a fallibilist and an optimist" (Oddie, 2014, pág. 542).

\subsubsection{Falibilismo: conocimiento y error}

Aunque las doctrinas de la verdad y del progreso se encontraban desde tiempos antiquísimos en la investigación filosófica, la verosimilitud no llega a jugar un papel principal hasta que comienza la tradición epistemológica del falibilismo con Charles Sanders Peirce, quien nos muestra que las actividades humanas enfocadas a la búsqueda del conocimiento están constantemente expuesta al error (lo cual nos recuerda a la locución latina errare humanum est), el filósofo norteamericano lo define de la siguiente manera:

\footnotetext{
${ }^{26}$ The idea that this increase of exactness must be interpreted as accumulation has been severely scrutinized in the past, since no scientific theory is strictly speaking true. Scientific progress interpreted as approaching the truth differs from progress as accumulation of truths (Zwart, 2001, pág. 2).
} 
As I have already remarked, it is not my purpose to doubt that people can usually count with accuracy. Nor does fallibilism say that men cannot attain a sure knowledge of the creations of their own minds. It neither affirms nor denies that. It only says that people cannot attain absolute certainty concerning questions of fact (Peirce, 1897, 1.147-149).

Y prosigue: "For fallibilism is the doctrine that our knowledge is never absolute but always swims, as it were, in a continuum of uncertainty and of indeterminacy. Now the doctrine of continuity is that all things so swim in continua" (1.711). Dado lo anterior, podemos tomar cuando menos tres actitudes: 1) Si bien las creencias que tenemos son verosímiles, aunque posiblemente sean falsas; 2) Mostrarnos escépticos negando la posibilidad de conocimiento o 3) Ser instrumentalistas dejando de analizar a la ciencia y el conocimiento con respecto a la verdad.

Debemos distinguir cuando menos dos tipos de falibilismo, uno débil en el cual se afirma que se ha demostrado que antes estábamos en el error y es posible que eso nos suceda de nuevo. Las creencias verdaderas son posibles, quizá ya hemos conseguido algunas de ellas, pero no tenemos certeza de ello en los casos específicos. La versión fuerte dice que siempre estamos en el error, la verdad es algo imposible de conseguir para los seres humanos.

Aquí es pertinente hacer referencia a aquello que podemos tomar como un error ${ }^{27}$, el cual cuando menos viene en tres diferentes formas: (A) cuando no creemos en algo que es verdadero a ello se le llama ignorancia; (B) cuando creemos en algo que es falso se le denomina como falsedad y, por último, (C) cuando no tenemos la suficiente justificación para creer en algo, este es el caso de la incertidumbre ${ }^{\mathrm{iii}}$.

Para evitar las últimas dos se pueden tomar estrategias como no aceptar nada (escepticismo) o aceptar sólo aquello que está demostrado como verdadero (infalibilismo). De manera intermedia tenemos al falibilismo, para el caso (C) se pueden construir sistemas de inferencia no demostrativas que den medidas para la incertidumbre epistémica a las proposiciones relativas a la evidencia disponible (el bayesianismo, por ejemplo), con ello el conocimiento se hace posible o cuando menos probable para ciertas situaciones.

Es para los casos (A) y (B) cuando "The concepts of truthlikeness, partial truth, and degree of truth arise primarily in this context" (Niiniluoto, 1987, pág. 160) desde una postura falibilista.

\subsection{La intuición del sentido común y la verosimilitud}

Al igual que otros conceptos filosóficos, la verosimilitud se encuentra dentro del sentido común al igual que el de la verdad. En el habla cotidiana somos capaces de hacer varias proposiciones y luego

\footnotetext{
${ }^{27}$ Niiniluoto realiza un recorrido histórico sobre las diversas nociones de error y conocimiento (Niiniluoto, Truthlikeness, 1987, págs. 157-160) que comienza desde Platón y termina con Hintikka, pasando por autores como Aristóteles, Agustín de Hipona, Tomás de Aquino, Spinoza, David Hume, Clifford, Carnap e Isaac Levi.
} 
jerarquizarlas según su grado de verdad en diferentes situaciones ${ }^{28}$. Oddie considera que hay una unanimidad notable en esos juicios pre-teóricos, cuando menos en un nivel intuitivo, aunque eso no significa que sea una prueba de que existe una forma (y sólo una) coherente del concepto subyacente en dichos juicios, sino que corresponde al filósofo realizar esa tarea; pero que sirven como un buen parámetro para evaluar una definición de verosimilitud, pues de existir, no debería violar dichas intuiciones. Esto lo tomará como una regla metodológica básica en el momento de tener una noción sobre aproximación a la verdad:

Or rather (recognizing that even philosophers do not always traffic in pure truth and that some false philosophical theories are closer to the truth than others) an account of truthlikeness is better (other things being equal) the better it accords with low-level, uncontroversial judgements on simple cases (Oddie, 1986, pág. ix).

Oddie utiliza unos ejemplos que ilustran muy bien lo dicho anteriormente, aunque haremos una adaptación para poder mostrarlos. Supongamos que el número de planetas son 8, Pedro afirma que son 7, mientras que José dice que son 5, aunque ambas proposiciones son falsas, se puede afirmar que Pedro está más cercano a la verdad que José. Ahora, si la aseveración de Pedro fuese más débil como "los planetas son 7 u 8", mientras que la de José es “son 5, 6, 7, 8 o 9", aunque ambas son verdaderas, de nuevo intuitivamente diríamos que Pedro está más cercano a la verdad que José (Cfr. Oddie, 1986, pág. 4).

Otro ejemplo sería el siguiente: se le pregunta a Óscar por la descripción de un grupo de personas que observa a lo lejos, su primera aserción sería "son delgados y de estatura baja", al ver que se acercan cambia de parecer y dice "son altos y delgados"; pero ya cuando los tiene frente a frente se da cuenta que son altos y gordos, y realiza esa conjetura que es la verdadera: "Surely Oscar's second guess is closer to the truth than his first, and his third closer to the truth than his second" (ibídem).

Supongamos que Mario está en un lugar aislado y sellado herméticamente, se le pregunta sobre cuál será el clima fuera, el cual en realidad es caluros, con lluvia y viento; en su primer intento dice que está frío, en el segundo que es frío y seco, al final dice que está frío, seco y calmado. Podemos afirmar que él cada vez se fue alejando más de la verdad. Con ello podemos darnos cuenta que el aumento de fuerza de una afirmación no necesariamente conlleva el de verosimilitud.

El ejemplo anterior podría sugerir que entonces deberíamos considerar como más aproximada a la verdad a una teoría falsa únicamente reduciendo su contenido, pero esto tampoco es así. Supongamos que el mismo Mario inició con la conjetura de que afuera hace frío, después que hace frío y llueve, al

\footnotetext{
${ }^{28}$ It is the same with verisimilitude. An intuitive grasp of the concept comes before any theory. Not only will intuitive examples be used in the judging of the adequacy of each theory, but the very act of judging presupposes an acquaintance with the notion of a good 'fit' of theory to the known facts. To use again Neurath's well-known metaphor, the project is rather like the task of rebuilding a ship (at sea) which we have to keep afloat at the same time. (Oddie, 1986, pág. 8).
} 
último afirma que hace frío, viento y llueve. Aunque las tres conjeturas son falsas, podemos afirmar que la segunda es más aproximada a la verdad que la primera, y la tercera que las dos anteriores. Con ello nos damos cuenta que, entre teorías falsas, reducir su fuerza no es una condición necesaria ni suficiente para aumentar la verosimilitud.

Un último ejemplo sería para aquellos casos donde es preferible una afirmación falsa a una verdadera. Supongamos que la temperatura para el día de hoy es de $23^{\circ} \mathrm{c}$, encendemos el televisor y vemos en dos canales diferentes el pronóstico del tiempo, uno de ellos afirma que estamos a $20^{\circ} \mathrm{c}$, mientras que el otro dice que estamos a $23^{\circ} \mathrm{c}$ o no estamos a $23^{\circ} \mathrm{c}$, esta última información es vacía, entonces preferiremos la primera como más aproximada a la verdad por ser más informativa ${ }^{29}$. Dados los ejemplos anteriores, Oddie culmina diciendo: "What counts is what the theory says, not how much it says" (pág. 14).

Ahora el trabajo del realista científico será dar una definición clara de aproximación a la verdad que respete las intuiciones del sentido común. ${ }^{30}$

\subsection{Verosimilitud, corroboración, probabilidad y grados de justificación}

Es necesario hacer una distinción entre diferentes conceptos para evitar confusiones en cuanto al tema que suceden a menudo al pensar que hay nociones equiparables en la discusión de la verosimilitud ${ }^{31}$. El primero de ellos sería el de probabilidad, el cual deriva etimológicamente del concepto de verdad tomado como verosimilitud o apariencia:

This is not only the case with the Latin verisimilitudo and its English counterpart's 'verisimilitude', 'verisimilar', and 'likely', but also with the Russian 'veroyatnost', the German 'Wahrscheinlichkeit', the Swedish 'sannolikhet' (meaning literally 'likeness to the truth'), and the Finnish 'todennakoisyys' (meaning 'truth-looking' as in the construction 'hyvannakoinen' for 'good-looking') (Niiniluoto, 1987, pág. 160).

En las investigaciones de Popper, sobre todo en las dos adendas que le realiza a Conjectures and Refutations en 1964 y 1968, también en Truthlikeness (pág. 161-164) de Niiniluoto se realiza un análisis histórico sobre la utilización de ambos conceptos, sobre todo en algunos momentos donde hubo confusiones o distinciones entre ellos; se mencionan por ejemplo del griego antiguo Eioikota y Pithanos

\footnotetext{
${ }^{29}$ Intuitively, it seems plausible that, if two theories are roughly of the same logical strength, then a true theory is to be preferred to a false one. There are situations, however, where a false theory is by far to be preferred to a true theory. If the true theory is genuinely weak (it is almost a tautology), then a strong, relevant, and almost true theory is certainly better than the very weak true theory. In other words, intuitively, a false theory sometimes is closer to the truth a true one (Zwart, 2001, pág. 31).

${ }^{30}$ Obviously, a scientific realist should be able to give substance to the vague intuitions that among differing false theoretical accounts of the same phenomenon, some can be closer to the truth than others and that, in some sense, science progresses towards theories that are closer to the truth than earlier ones (Kieseppä, 1996, pág. 1).

${ }^{31} \mathrm{Si}$ bien las palabras y sus significados precisos nunca son importantes, el esclarecimiento de confusiones puede ser importante en la resolución de problemas; naturalmente, de aquellos problemas que tengan que ver con teorías. No podemos definir, pero a menudo podemos diferenciar, pues las confusiones, o simplemente la falta de distinciones, pueden privarnos de resolver nuestros problemas (Popper, 1983a, pág. 479).
} 
o del latín verisimilitudo y probabilitas, o cómo los utilizaron filósofo como Ciceron, Carneades, Agustín, Tomás, Kant, Peirce, Isaac Todhunter, Nozzolini, Galileo, Thomas Simpson, Lagrange, Bernoulli Laplace y Denise Poisson. No es de nuestro interés realizar un análisis sobre ello, simplemente aclarar la distinción.

Por ejemplo, tenemos dos relojes: (A) está descompuesto y siempre marca la misma hora, mientras (B) funciona, pero está 5 minutos atrasado de la hora real. Ambos son falsos, aunque (A) no siempre, porque hay dos momentos en el día en el cual es verdadero. Nuestras intuiciones nos dirán que (B) es más cercano a la verdad que (A) porque hace predicciones más precisas, excepto en esos momentos en los cuales se da la hora que marca (A). Si quisiéramos basar nuestra elección en la probabilidad, la hora de (B) es siempre falsa, entonces su probabilidad de hacer afirmaciones verdaderas es 0 , mientras que (A) es correcto cada doce horas, por lo tanto, sus probabilidades son mayores que las de (B). Podemos ver de manera clara que probabilidad y verosimilitud no son lo mismo.

Volvamos al ejemplo del clima que utilizamos anteriormente. La afirmación “hace calor” es más probable que la afirmación "hace calor y está lloviendo", lo mismo sucede con la afirmación "hace calor, está lloviendo y hay viento", si suponemos que a cada oración atómica le damos la probabilidad de 0.5 (pues su negación sería el otro 0.5), entonces la primera sería precisamente de 0.5 , mientras que la segunda de 0.25 y la última de 0.125 , vemos claramente cómo su probabilidad va decreciendo, mientras que en el caso de la aproximación a la verdad diremos, al menos intuitivamente, va en aumento. Si el objetivo de la ciencia fuera obtener teorías cada vez más probables, sería suficiente con restarles contenido, mientras que en el caso de la verosimilitud se requiere une mezcla de contenido y verdad (más delante veremos esto con Popper).

Otro concepto que no debemos confundir es el de corroboración. Se puede dar el caso en el que tengamos una teoría verdadera (la máxima verdad), pero carezcamos de los métodos para poder comprobarla o sólo unas partes de ella, por otro lado, es posible que tengamos una teoría altamente corroborada, pero no necesariamente es la verdadera o la más cercana a la verdad, sino que es la teoría que los instrumentos de la época o los experimentos realizados nos permite ratificar. Aunque, como veremos en el capítulo del problema epistémico, un alto grado de corroboración y de resistencia a la falsación puede ser un indicio de verosimilitud.

Otra confusión que se debe esclarecerse es entre la verdad en el sentido realista (absoluta y objetiva) y la que tiene un sentido subjetivo en la aceptación de lo que creemos:

La distinción tiene una importancia fundamental, en especial en lo que concierne a la teoría del conocimiento. El único problema de conocimiento importante tiene que ver con el problema de la verdad en el sentido objetivo. Mi tesis es, pura y simplemente, que la teoría de la creencia subjetiva carece totalmente de relevancia para la teoría filosófica del conocimiento. Naturalmente, si ambas concepciones 
están entremezcladas (como, de acuerdo con la tradición, sucede todavía) se acaba con esta última (Popper, 1983a, pág. 479).

Teniendo esto en mente, es menester diferenciar entre la verosimilitud y las ideas subjetivas como los grados de creencia, convicción, persuasión, verdad aparente, plausibilidad y probabilidad. Mientras que la primera, al igual que la verdad, no tiene límites temporales, aunque se diferencia de la verdad porque tiene un carácter relativo (relacional); mientras que los otros conceptos, al igual que los grados de corroboración, dependen básicamente del tiempo, varían conforme al devenir histórico o de los sujetos. En un tiempo $t_{1}$ alguien se puede sentir justificado para creer $x$ dada la evidencia disponible, pero puede ser que en $t_{2}$ es posible que haya cambiado la evidencia y ahora no creamos en $x$; a diferencia de lo que se espera con la verosimilitud que permanezca intacta con el paso del tiempo (aunque en el capítulo 4 veremos que eso cambia en las mediciones de verosimilitud estimada) $)^{32}$.

\section{4 ¿Cómo entender la verosimilitud?}

Hay cuando menos dos formas en las que podemos hablar de verosimilitud, una de ellas es como verdad parcial y la otra como verdad aproximada, entre las últimas dos se puede hacer una distinción, aunque el concepto de verosimilitud intenta conjuntarlas. Veamos el primero de los casos.

Podemos hacer una distinción entre cuando una proposición es falsa y cuando es incompleta. Diremos que una proposición es falsa si, y sólo si, es inconsistente con la verdad completa (la totalidad de todas las proposiciones). De aquí no se sigue que si una proposición es verdadera esta contiene la totalidad de la verdad, es decir, una proposición puede ser completamente verdadera, pero no ser la totalidad de la verdad. Ahora podemos hacer una serie de distinciones: 1) $H$ es en parte verdadera si no es vacía y alguna parte de $H$ es verdadera, 2) $H$ es totalmente verdadera si todo lo que se afirma en ella es verdadera, 3) $H$ es completamente falsa si ninguna parte de $H$ es verdadera (Cfr. Niiniluoto, 1987, pág. 175).

Supongamos que tenemos el conjunto de todas las proposiciones verdaderas que son a, b y c (y las tautologías), tenemos una teoría que es $\mathrm{h}_{1}$ la cual afirma $\mathrm{a}^{\wedge} \mathrm{b}$, entonces diremos que es totalmente verdadera, mientras que $\mathrm{h}_{2}$ dice $\mathrm{a}^{\wedge} \mathrm{z}$ tiene una verdad y una falsedad, por lo tanto, diremos que es parcialmente verdadera, mientras que $\mathrm{h}_{3}$ es $\mathrm{x}^{\wedge} \mathrm{y}$ sólo contiene falsedades, diremos entonces que es completamente falsa ${ }^{i v}$. Otro caso que puede darse, llamémoslo $\mathrm{h}_{4}$, podría ser $\mathrm{a}^{\wedge} \mathrm{b}^{\wedge} \mathrm{c}^{\wedge} \mathrm{x}^{\wedge} \mathrm{y}^{\wedge} \mathrm{z}$ (o una contradicción $\mathrm{a}^{\wedge} \mathrm{b}^{\wedge} \mathrm{c}^{\wedge} \neg \mathrm{a}^{\wedge} \neg \mathrm{b}^{\wedge} \neg \mathrm{c}$ ), lo cual es estrictamente falso, pero contiene el máximo grado de la verdad $^{\mathrm{v}}$.

\footnotetext{
${ }^{32}$ De la 478 a la 482 de Conjeturas y refuraciones, Popper realiza un análisis histórico de diferentes conceptos subjetivos y su diferencia con la verosimilitud.
} 
No todos los casos de verosimilitud pueden ser de esa forma. Supongamos que tenemos una teoría que para calcular sus consecuencias sería necesario un aparato matemático demasiado complejo (o existen otras limitaciones), por lo tanto, es necesario hacer simplificaciones del fenómeno para que sus fórmulas sean más tratables: "e.g., there might be a number of factors not taken into account by the theory T for the impact of which, however, limits could be deduced” (Kieseppä, 1996, pág. 12). En este caso las predicciones numéricas de la teoría podrían ser falsas, pero en cierta manera se acercarían a la verdad.

Podemos tener un ejemplo un tanto más intuitivo. En el caso de la altura de una montaña que realmente mide 1,400 metros, alguien afirma que mide 1,350 metros, diremos que su aseveración es aproximada a la verdad porque cometió "un pequeño error" o su distancia a la verdad es pequeña. Si le damos un valor numérico que exprese la distancia entre las afirmaciones, Niiniluoto les llama "grado de cercanía a la verdad", el "grado de aproximación a la verdad" o grado de verdad (Cfr. 1987, pág. 1779). Se considerará entonces que una teoría es más aproximada a la verdad o sus proposiciones lo son en los casos donde sus cálculos se acerquen más al valor numérico real del fenómeno (lo que sea que se entienda por ello).

Otro caso de verdad aproximada es cuando se ofrece un parámetro, por ejemplo, si alguien afirmara que la montaña mide entre 1,350 metros y 1,450 metros, ha dicho la verdad, por lo tanto, consideraremos que se aproxima más a la verdad si en una segunda oración afirma que la montaña mide entre 1,375 metros y 1,425 metros $^{\mathrm{vi}}$.

Dado lo anterior, se pueden enlistar las diferencias entre verdad parcial y cercanía a la verdad pueden en los siguientes principios:

(1) Tautologies have a minimal degree of partial truth but a maximal degree of nearness to the truth.

(2) Contradictions have a maximal degree of partial truth but a low degree of nearness to the truth.

(3) All true statements have the same degree of nearness to the truth, but their degrees of partial truth vary depending on their information content.

(4) If $h$ has a positive degree of partial truth, its negation $-h$ cannot be the whole truth. If $h$ has a nonmaximal degree of nearness to the truth, its negation - $h$ has the maximal degree of nearness to the truth. (Niiniluoto, Truthlikeness, 1987, págs. 177-178)

Tomando lo anterior en cuenta, una noción de verosimilitud debería poder incluir ambos casos o, en caso de no hacerlo, justificar por qué da dos nociones diferentes para cada caso o por qué deberíamos atender sólo uno de ellos.

\subsubsection{Los dos problemas de la verosimilitud: epistémico y el semántico}

La idea principal detrás de este concepto es que nuestras teorías más útiles son estrictamente falsas, pero dentro de un margen de error son aceptables o aproximadamente verdaderas. Por ejemplo, la ley Boile-Gay Lussac para los gases ideales es estrictamente hablando falsa, puesto que no existen los gases ideales, pero nos provee de resultados aceptables dentro de cierto margen de error. Lo mismo 
aplicaría para la mecánica newtoniana. Los científicos suelen distinguir entre dos tipos de falsedades. Por ejemplo, la teoría mecánica cartesiana no está a la par de la newtoniana, cuando observamos algunas cuestiones elementales de mecánica, las leyes de Newton producen respuestas correctas en las cuales la teoría proporcionada por Descartes falla completamente. Los realistas dirán que la mecánica del filósofo francés es falsa, mientras que la del inglés es aproximadamente verdadera (Cfr. Zwart, 2001, pág. 6).

Recordemos que en el capítulo anterior vimos que los realistas argumentaban que nuestras mejores teorías (al menos las actuales) deben se ser consideradas como parecidas a la verdad: "Yet, a common challenge levelled against realists is that there is no coherent formal notion of truth-likeness, or verisimilitude. The implication is that the realist claim cannot be properly defended" (Psillos, 1999, pág. 252).

Sin embargo, para evitar confusiones debemos diferenciar entre los problemas que se abordan en la verosimilitud, uno de ellos es el semántico y el otro es el epistémico. El primero de ellos es el intento por clarificar qué entendemos cuando afirmamos que una proposición o teoría es más cercana a la verdad que otra, el segundo es acerca de cómo lo sabemos o cómo estamos justificados para afirmarlo.

Para el aspecto semántico debemos tomar en cuenta que no sabemos cuál sea la verdad completa, entonces las comparaciones en verosimilitud deben hacerse de la siguiente manera: la teoría A es más cercana a la verdad que la B si es el caso que la verdad es de tal forma; en el epistémico sería la teoría A es más cercana a la verdad que B tomando en cuenta la evidencia x, y, z.

Según lo dicho por Psillos, el objetivo principal de la teoría de la verosimilitud en el aspecto semántico puede ser entendido como el proyecto de crear una explicación de la siguiente forma: “(1) The expression 'The sentence $\mathrm{T}_{1}$ is closer to the truth than the sentence $T_{2}$ ' means ' $B$ ', when $T_{1}$ and $T_{2}$ are sentences belonging to the class of sentences X” (Kieseppä, 1996, pág. 20).

Existe una vaguedad contra la que se enfrenta la teoría de la verosimilitud, pero ésta es externa porque no sabemos cómo se aplica y a qué, pero la noción de "grado de verosimilitud" debe ser entendido muy concretamente como una cantidad, que nos proporciona una vaguedad interna. Cuando se opta por una explicación de que una afirmación tiene un mayor grado de verosimilitud que otra, los valores cuantitativos con los que se representan estos grados son convencionales.

Recordemos que para Oddie una definición de verosimilitud debe ser capaz de reproducir todos los juicios comparativos de aproximación a la verdad que son intuitivamente obvios cuando se conoce la verdad, como en los ejemplos dados anteriormente, y aunque la "designación de grados" sea convencional, debe respetar ese principio para que sea realmente útil. Claro que hay casos en los cuales esto caerá dentro de un área "gris" donde las intuiciones no podrán ser del todo útiles, pero otras serán 
absolutamente claras: "and any adequate theory of truthlikeness would have to deliver the appropriate judgement in such cases" (Oddie, 1981, pág. 254). Si estamos de acuerdo con Oddie, entonces el procedimiento a seguir es el de verificar si la noción de verosimilitud ofrecida por un autor es coherente con los ejemplos del sentido común, en dado caso de no serlo, entonces deberá ser desechada:

If such concrete examples are abandoned, then it is no longer clear how proposals are to be evaluated. In the absence of clear-cut examples for regulating speculation, anything goes. Hence if we are to take the problem of truthlike- ness seriously the above explications have to be rejected as inadequate (pág. 249).

Por otro lado, Niiniluoto considera que la situación es analógica con la metodología de las ciencias especiales donde no es necesario aceptar las afirmaciones observacionales como infalibles a pesar de la importancia que tienen en cualquier ciencia empírica:

Tichý thinks that intuitive examples are used to test general principles, not vice versa. However, I do not think that there is something like a pre-existing intuition about truthlikeness which is sufficiently rich to be employed as a basis for testing all interesting principles. Therefore, intuitive examples are not only used for testing principles, but it is also the case that general principles are needed to test and develop our intuition (Niiniluoto, 1979a, pág. 372).

Kiseppä considera que la posición de Niiniluoto combina a la perfección con la idea carnapiana de que un explicatum es un nuevo concepto que no tiene por qué ser idéntico al explicandum. Aunque se aceptara la postura de Oddie de la existencia de un conjunto mínimo de juicios evidentes sobre la verosimilitud y que una noción de ella debe ser capaz de reproducirlos, parece claro que, cuando se explica la cercanía a la verdad, una posición liberal debería ser elegida en el continuo de actitudes hacia la variación de significados en la explicación. Es complicado suponer que existe una esencia del significado de la verosimilitud o de la relación "es más cercano a la verdad que" y que una teoría correcta de la verosimilitud tendría que revelárnoslo: “A theory of verisimilitude, when put to the form (1), does not express a previously existing meaning of the relation of being closer to the truth but, rather, it proposes a clear meaning for this vague notion” (Kieseppä, 1996, pág. 23).

\subsubsection{Clasificaciones de los proyectos de verosimilitud}

Los enfoques de la verosimilitud pueden clasificarse de diferentes formas, el más utilizado es aquel que los divide entre las propuestas de contenido y las de semejanza, con esta nos guiaremos en el presente capítulo y el siguiente. Sin embargo, también podemos distinguirlas entre comparativas y cuantitativas. Las comparativas afirman que una teoría es más similar a la verdad que otra tomando en cuenta los elementos que las componen. Por otro lado, las definiciones cuantitativas asignan números a las teorías de manera convencional que miden en qué grado o medida se asemeja la teoría a la verdad.

Zwart (2001) admite que esto podría levantar sospechas por parecer artificial (otorgar grados de verosimilitud de forma cuantitativa), pero se justifica afirmando que las ciencias naturales en su mayoría realizan afirmaciones cuantitativas, entonces la comparación de conjuntos de afirmaciones cuantitativas fácilmente se convierte en una evaluación cuantitativa. Las definiciones cuantitativas a menudo son 
reflexivas, por lo tanto, son preordenadas; mientras que las comparativas pueden ser irreflexiva, por lo tanto, desembocan en ordenamientos parcialmente estrictos.

La gran mayoría de las ciencias maduras utilizan hipótesis y teorías cuantitativas. Una definición cuantitativa simplifica enormemente la comparación de estas afirmaciones cuantitativas. Otra ventaja de utilizar una definición cuantitativa es el aumento de la fuerza de la comparación. En general, las teorías cualitativas de comparación establecen ordenamientos parciales entre las declaraciones formales; esto significa que no podemos comparar todas las afirmaciones. Una explicación cuantitativa da un orden total y por lo tanto todas las teorías se pueden comparar mutuamente.

Una desventaja de las propuestas cuantitativas es que la elección de la medida es arbitraria; si no contamos con un argumento lo suficientemente fuerte para decidir cuál es la métrica que debemos utilizar, entonces la noción de verosimilitud se vuelve demasiado subjetiva: "This is an important reason for first establishing a compelling, qualitative truthlikeness definition and subsequently extending the proposal towards a stronger one, which might ultimately result in an objective quantitative notion" (Zwart, 2001, pág. 30).

En los siguientes apartados (y en el siguiente capítulo) se mostrará algunas de las diferentes propuestas para dar una noción de verosimilitud, las que se toman como las principales en el debate, algunas de ellas son comparativas y otras cuantitativas. También es necesario aclarar que principalmente se revisan aquellas que están dentro de la lógica clásica bivalente, pero eso no significa que no existan otras que utilicen un tipo de lógica diferente, de hecho, hay autores que en cuyo proyecto usan lógica plurivalente, no-monotónicas y probabilísticas.

\section{Karl Popper y el inicio del proyecto de la verosimilitud 2.1 Antecedentes}

Si bien anteriormente se afirmó que el tema de la verosimilitud fue poco debatido en la historia de la filosofía, también hablamos de sus raíces y la relación que tiene con la probabilidad. Fueron varios los autores que lo abordaron, pero no se dedicaron mucho al tema, sin embargo, la idea de aproximación a la verdad tomó especial importancia en los últimos años del siglo XIX; los cuales fueron inspirados principalmente por la teoría de la evolución y la metafísica dinámica de Hegel. Entre los que menciona Niiniluoto en Truthlikeness (1987, pág. 166) se encuentran Engels, Lenin y Bradley; no obstante, nos interesa más hablar de Peirce cuyas ideas tienen similitud, no sólo en este tema, con las de Karl Popper.

En el año de 1910 el padre del pragmatismo norteamericano escribió:

I will now give an idea of what I mean by likely or verisimilar. [-] I call that theory likely which is not yet proved but is supported by such evidence, that if the rest of the conceivably possible evidence should turn out upon examination to be of a similar character, the theory would be conclusively proved. Strictly 
speaking, matters of fact never can be demonstrably proved, since it will always remain conceivable that there should be some mistake about it. (Peirce, 2.663). ${ }^{33}$

Observamos que la verosimilitud es un tipo específico de probabilidad, aquella que no está probada en este momento, pero que cuenta con cierta evidencia que la soporta, además si contáramos con toda la evidencia posible y esta siguiera apoyando a la teoría, entonces la tomaríamos como probada. Aunque después nos dice que los hechos no pueden ser completamente demostrados, recordemos el carácter falibilista de su filosofía, siempre es posible que cometamos algún error.

Peirce, como otros realistas, piensa que la verdad y la realidad pueden ser tomadas como el último objetivo de la investigación científica, el cual conduce a la comunidad sin definir los límites, pero somos capaces de aumentar nuestro conocimiento conforme a ellas. Para él, una de las características principales del método científico es que las cosas reales influyen por medio de interacción causal en las opiniones de la comunidad científica: "That different minds may set out with most antagonist views, but the process of investigation carries them by force outside of themselves to one and the same conclusion" (5.407).

Su filosofía estaba basada en el principio de continuo (synechism): "[Synechism is] that tendency of philosophical thought which insists upon the idea of continuity as of prime importance in philosophy and, in particular, upon the necessity of hypotheses involving true continuity" (CP 6.169). Cuando aplicamos dicho principio a la idea de verdad absoluta o final, tenemos como resultado una concepción dinámica del conocimiento que consiste en irnos aproximando cada vez más a la verdad.

El término de verdad aproximada, además de la idea de irnos acercando cada vez más a la verdad, se encuentra en diferentes notas de sus manuscritos, tomemos la siguiente como un ejemplo:

At each stage of his long investigation, Kepler has a theory which is approximately true, since it approximately satisfies the observations (that is, within 8', which is less than any but Tycho's observations could decisively pronounce an error), and he proceeds to modify this theory, after the most careful and judicious reflection, in such a way as to render it more rational or closer to the observed fact. Thus, having found that the centre of the orbit bisects the eccentricity, he finds in this an indication of the falsity of the theory of the equant and substitutes, for this artificial device, the principle of the equable description of areas. Subsequently, finding that the planet moves faster at ninety degrees from its apsides than it ought to do, the question is whether this is owing to an error in the law of areas or to a compression of the orbit. He ingeniously proves that the latter is the case (CP. 1.73).

Esta idea de aplicar la noción de cercano a la verdad o aproximado a la verdad no sería aceptada por filósofos como Quine quien en Word and Object expresó:

\footnotetext{
${ }^{33}$ En una carta para Paul Carus en 1910 escribe: By verisimilitude I mean that kind of recommendation of a proposition which consists in evidence which is insufficient because there is not enough of it, but which will amount to proof if that evidence which is not yet examined continues to be of the same virtue as that already examined, or if the evidence not at hand and that never will be complete, should be like that which is at hand. All determinations of probability ultimately rest on such verisimilitudes. I mean that if we throw a die 216 times in order to ascertain whether the probability of its turning up a six at any one throw differs decidedly from 1/6 or not, our conclusion is an affair not of probability as Laplace would have it, by assuming that the antecedent probabilities of the different values of the probability are equal, but is a verisimilitude or as we say a "likelihood" (222-224).
} 
But there is a lot wrong with Peirce's notion, besides its assumption of a final organon of scientific method and its appeal to an infinite process. There is a faulty use of numerical analogy in speaking of a limit of theories, since the notion of limit depends on that of "nearer than", which is defined for numbers and not for theories (Quine, 1960, pág. 21).

Con ello en mente, entonces tendremos que centrarnos únicamente en las afirmaciones numéricas de las que hablábamos anteriormente que son aproximadamente verdaderas, pero para las teorías el término no podría aplicarse, Quine piensa que una afirmación como esa carece de sentido. Como veremos en el siguiente apartado, Popper tendrá el gran logro de darle sentido a esa noción.

\subsection{Teoría de la verdad por correspondencia y la verosimilitud}

En 1962 Popper presenta una reformulación de su filosofía acerca de temas como la verdad, la racionalidad y el desarrollo del conocimiento científico, esto es en el capítulo 10 de Conjectures and Refutations, el cual es la versión extendida de una ponencia que presentó en el Congreso Internacional de Filosofía de la Ciencia en Stanford en el año de 1960, esto significaría el resurgimiento del tema de la verosimilitud y su definición dentro del debate entre el realismo y el anti-realismo (dato interesante porque es el mismo año en el que Quine critica la noción de aproximación a la verdad de Peirce).

En dicho capítulo, Popper comienza recordándonos lo que él veía como el punto central en el progreso de la ciencia, el cual consistía en la elección racional de las teorías, la mejor de ellas era la que pudiera salir airosa al ponerse a prueba ante examinaciones exhaustivas. Lo deseable era entonces que las teorías fueran audaces al plantear aspectos del mundo, pero que también lograran superar los intentos de falsación que se les plantearan. La tarea del científico sería la de realizar conjeturas y luego intentar derrocarlas; si lo segundo no se lograba, entonces se podía mantener cuando menos de forma momentánea. La actividad científica se da por medio del ensayo y el error, como sucede también con el conocimiento precientífico.

Esto llevará a Popper a afirmar que deseable en ciencia son las teorías audaces, interesantes y con un alto grado de información en lugar de las teorías triviales, porque las primeras son más susceptibles de ser testadas; por lo tanto, lo que se debe buscar es que una teoría tenga un alto grado de contenido, es decir, que diga más cosas sobre el mundo.

Consideremos lo siguiente: el contenido de la conjunción $\mathrm{a}^{\wedge} \mathrm{b}$ de dos enunciados a y b, siempre será mayor o igual que el de cualquiera de sus componentes por sí mismos. Lo que también es obvio es que la probabilidad de la conjunción será menor que la de sus componentes. Supongamos que tenemos dos enunciados como "mañana lloverá" y "mañana hará viento”, ambos por sí mismos tienen una probabilidad de 0.5 , mientras que en conjunto sería de 0.25 , vemos cómo su probabilidad disminuye, sin embargo, su contenido aumenta. Con ello obtenemos lo siguiente: $\mathrm{Ct}$ (a) es el contenido del enunciado a 
y $\mathrm{Ct}(\mathrm{ab})$ es el de la conjunción de a y b, por lo tanto (1) $\mathrm{Ct}(\mathrm{a}) \leq \mathrm{Ct}(\mathrm{ab}) \geq \mathrm{Ct}(\mathrm{b})$; lo cual es opuesto a lo que daría como resultado en la ley de cálculo de probabilidades: (2) $p(a) \geq p(a b) \leq p(b)$

Podemos observar que si aumenta el contenido disminuye la probabilidad y viceversa, o el contenido aumenta con la improbabilidad ${ }^{34}$. Como resultado de lo anterior, la desiderata en la ciencia es que progrese mediante la obtención de teorías con mayor contenido empírico; lo cual tiene como consecuencia que tengan una baja probabilidad ${ }^{35}$. Dado que no podemos atenernos al cálculo de probabilidades para evaluar a una teoría debemos idear otra manera para poder hacerlo, es aquí cuando va surgiendo el problema de la verosimilitud o de la aproximación a la verdad.

Karl Popper reconoce que en el principio consideraba que una idea como la verdad no era necesaria para el análisis del objetivo de la ciencia y su progreso, sino que lo veía como la solución de problemas y se avanzaba conforme se resolvieran (y se plantearan) los que tuvieran mayor profundidad. Sin embargo, su postura cambió cuando conoció la teoría de la verdad por correspondencia de Alfred Tarski, le parecía que con ella se lograba un buen criterio para hablar de la verdad objetiva como correspondencia con los hechos del mundo. Esto nos permitía evitar confusiones entre lo verdadero o lo conocido como verdadero, con ella podemos afirmar que una teoría es verdadera sin importar que nadie crea en ella o tenemos razones para aceptarla, así como una teoría es falsa, aunque muchos crean en ella o tengamos buenas razones para aceptarla; lo cual no sería posible dentro de una teoría subjetiva de la verdad.

Considera que gracias a la teoría objetiva ambas afirmaciones no sólo son compatibles, sino que son evidentemente ciertas: "A similar assertion which the objective correspondence theory would make quite natural is this: even if we hit upon a true theory, we shall as a rule be merely guessing, and it may well be impossible for us to know that it is true” (Popper, 1962, pág. 225). Y nos recuerda que Jenófanes de Colofón ya había dicho algo similar hace bastantes siglos atrás, pero que esto sólo con el trabajo de Tarski se removieron las sospechas, dado que las anteriores teorías objetivas de la verdad como correspondencia podían caer en contradicciones (como la paradoja del mentiroso), ser vacías (como lo sugirió Ramsey), o estériles (o redudantes), como lo creyó Popper al inicio de su carrera.

\footnotetext{
${ }^{34}$ Se toma como contenido lógico de un enunciado como es la clase de todos los enunciados lógicamente implicados por él. Un enunciado a es lógicamente más fuerte que uno b si tiene una mayor cantidad de implicaciones.

${ }^{35}$ Thus, if we aim, in science, at a high informative content--if the growth of knowledge means that we know more, that we know a and $b$, rather than an alone, and that the content of our theories thus increases--then we have to admit that we also aim at a low probability, in the sense of the calculus of probability. And since a low probability means a high probability of being falsified, it follows that a high degree of falsifiability, or refutability, or testability, is one of the aims of science--in fact, precisely the same aim as a high informative content. The criterion of potential satisfactoriness is thus testability, or improbability: only a highly testable or improbable theory is worth testing, and is actually (and not merely potentially) satisfactory if it withstands severe tests -especially those tests to which we could point as crucial for the theory before they were ever undertaken. (Popper, 1962, págs. 219-220).
} 
Popper considera que desde Tarski ya no ven problemas en utilizar a la verdad como objetivo de la ciencia, incluso piensa que si es nuestro deseo es aclarar la diferencia entre ciencia pura y aplicada, entre la búsqueda del conocimiento y la búsqueda de poder manipular a la naturaleza o de crear instrumentos que lo hagan, entonces no se puede prescindir de esta noción. En las ciencias puras lo que se busca es encontrar las teorías verdaderas, o cuando menos las que estén más cerca de la verdad que otras (que se corresponden mejor con los hechos); mientras que en las aplicadas se puede trabajar perfectamente con teorías que sabemos que son falsas.

Al igual que Jenófanes, podemos afirmar, ahora que buscamos la verdad, aunque no sepamos si la hemos encontrado, si carecemos de criterio para establecerla, pero nos deja guiarnos por la idea de la verdad como un principio regulador; aunque carecemos de un criterio general con el cual podamos reconocer a la verdad, no obstante, hay algo parecido a los criterios de progreso hacia la verdad (se enlistarán más adelante). Y pone como ejemplo a los alpinistas cuando escalan una montaña cuya cima no es visible, pero pueden tener idea de que han ido subiéndola con éxito, aunque no sepan cuánto han avanzado o cuánto falta para terminar su camino:

The status of truth in the objective sense, as correspondence to the facts, and its role as a regulative principle, may be compared to that of a mountain peak which is permanently, or almost permanently, wrapped in clouds. The climber may not merely have difficulties in getting there--he may not know when he gets there, because he may be unable to distinguish, in the clouds, between the main summit and some subsidiary peak. Yet this does not affect the objective existence of the summit, and if the climber tells us 'I have some doubts whether I reached the actual summit', then he does, by implication, recognize the objective existence of the summit. The very idea of error, or of doubt (in its normal straightforward sense) implies the idea of an objective truth which we may fail to reach.

Though it may be impossible for the climber ever to make sure that he has reached the summit, it will often be easy for him to realize that he has not reached it (or not yet reached it); for example, when he is turned back by an overhanging wall. Similarly, there will be cases when we are quite sure that we have not reached the truth. Thus, while coherence, or consistency, is no criterion of truth, simply because even demonstrably consistent systems may be false in fact, incoherence or inconsistency do establish falsity; so, if we are lucky, we may discover inconsistencies and use them to establish the falsity of some of our theories. (Popper, 1962, pág. 226)

Como podemos ver, el realismo poppereano se toma en serio la noción de error, se adscribe dentro de los filósofos falsacionistas o falibistas, afirma que, en principio, aquello que no puede ser derrocado por la crítica actual es indigno de ser considerado seriamente, mientras que lo que sí y además resiste a nuestros esfuerzos de mostrarlo como equivocado podemos considerarlo como digno de ser creído como verdadero cuando menos provisionalmente porque en un futuro puede ser encontrado como falso. El hecho de ser falibilistas es un indicativo de que estamos dispuestos o esperamos aprender de nuestros errores. Además, únicamente la idea de la verdad nos permite hablar con sensatez de los errores, mientras seamos críticos podemos mantener una posición racional que nos permita buscar y eliminar los errores, y así acercarnos a la verdad: "Thus the very idea of error--and of fallibility--involves the idea of an 
objective truth as the standard of which we may fall short. (It is in this sense that the idea of truth is a regulative idea)" (pág. 229).

Esto le da como resultado que el objetivo de la ciencia es la búsqueda de la verdad o de teorías verdaderas (aunque no sepamos si las conseguimos), pero acepta que la verdad sin más no es el objetivo de la ciencia, sino verdades interesantes y estas son bastante complicadas de conseguir: "And in the natural sciences (as distinct from mathematics) what we look for is truth which has a high degree of explanatory power, which implies that it is logically improbable" (ídem). ${ }^{36}$

Pone como ejemplo el caso de un juicio legal, donde a la corte le interesa únicamente la verdad que sea pertinente y relevante para ese momento, verdades cualesquiera las puede decir (como las tautologías y las obviedades), sin embargo, hay unas que son importantes para cada tema en específico.

Con ello Popper asevera que es preferible intentar resolver un problema interesante con una conjetura audaz, aunque, como muchas veces sucede, esta llegue a ser falsa, en lugar de buscar un cúmulo de lugares comunes e irrelevantes, porque así es como podemos aprender de nuestros errores y darnos cuenta de que la conjetura era falsa, de esta manera habremos aprendido mucho acerca de la verdad y nos hemos acercado a ella.

A pesar de que ignoramos si estamos lejos o cerca de la verdad (y cuánto), podemos acercarnos cada vez más a ella. Reconoce que anteriormente esta afirmación lo hacía sentirse incómodo, pues no tenía claro qué significaba cuando decía que una teoría estaba más cercana a la verdad que otra, tampoco pretende que lo dicho sea más claro de lo que es, con la condición de que no intentemos derivar consecuencias exactas de premisas dudosas o vagas: "There is no harm whatever in occasional vagueness, or in voicing every now and then our feelings and general intuitive impressions about things" (pág. 231).

Aunque no podemos saber con certeza nuestro acercamiento a la verdad, Popper considera que existe una teoría verdadera conforme a la cual se aproximarían (o no) cada vez más hacia ella nuestras teorías científicas. Enlista seis criterios epistémicos que ayudarán a justificarnos en dicha afirmación, los cuales pueden ser tomados como un intento de solucionar el problema epistémico del cual se hablará en el cuarto capítulo:

1. $t_{2}$ makes more precise assertions than $t_{1}$, and these more precise assertions stand up to more precise tests. 2. $t_{2}$ takes account of, and explains, more facts than $t_{1}$ (which will include for example the above case that, other things being equal, $t_{2}$ 's assertions are more precise).

\footnotetext{
36 Accordingly, the statement that scientists are interested in truth and nothing but the truth must not be taken too literally. Investigators are not equally interested in all kinds of truths, for instance, $\mathrm{H}$ is preferred to $\mathrm{Hv} \neg \mathrm{H}$. The intuitive basis for this preference is obvious: $\mathrm{H}$ is a factual truth, and factual truths are more interesting than tautologies; scientists are interested in informative truths. It thus seems that in addition to truth there is another epistemic utility, information (Hilpinen, 1968, pág. 88).
} 
3. $\mathrm{t}_{2}$ describes, or explains, the facts in more detail than $t_{1}$.

4. $t_{2}$ has passed tests which $t_{1}$ has failed to pass.

5. $t_{2}$ has suggested new experimental tests, not considered before $t_{2}$ was designed (and not suggested by $t_{1}$, and perhaps not even applicable to $t_{1}$ ); and $t_{2}$ has passed these tests.

6. $t_{2}$ has unified or connected various hitherto unrelated problems (pág. 232).

Para Popper esta lista mostraba claramente que el contenido de $t_{2}$ es mayor que el de $t_{1}$. Con ello piensa que hay una posibilidad de combinar a la verdad con el contenido, así crear una sola: el grado de mejor correspondencia con la verdad, de mayor semejanza o similitud con la verdad "or to use a term already mentioned above (in contradistinction to probability) the idea of (degrees of) verisimilitude" (pág. 233). ${ }^{37}$

Con ello intenta dar una respuesta a la cuestión epistémica, en los siguientes dos apartados veremos sus propuestas para la parte semántica, para poder hacer una distinción entre ambos es que responden a dos preguntas diferentes:

Accordingly, we have here again to distinguish between the question 'What do you intend to say if you say that the theory $t_{2}$ has a higher degree of verisimilitude than the theory $t_{1}$ ?', and the question 'How do you know that the theory $t_{2}$ has a higher degree of verisimilitude than the theory $t_{1}$ ?' (pág. 234).

La respuesta al segundo cuestionamiento es análoga acerca de la verdad (en lugar de hacer comparaciones de teorías): "I do not know-I only guess. But I can examine my guess critically, and if it withstands severe criticism, then this fact may be taken as a good critical reason in favour of it" (ídem). Popper aclara que no está sugiriendo que la verosimilitud hará cambios en la teoría del método, sino que el falsacionismo es la contraparte metodológica a esta nueva idea. Lo único que mejora es la aclaración sobre qué se quiere decir con "verosimilitud". Anteriormente ha dicho que es preferible una teoría t 2 que ha pasado ciertas pruebas severas y que $\mathrm{t}_{1}$ no lo logró, entonces una teoría falsa es peor que una que posiblemente sea cierta. ${ }^{38}$

\subsection{Definición de verosimilitud cualitativa}

Ahora consideremos que el contenido de un enunciado $a$ (todas las consecuencias lógicas de $a$ ), si $a$ es verdadero, entonces todas sus consecuencias serán enunciados verdaderos, ya que la verdad se transmite siempre de una premisa a sus conclusiones, pero si $a$ es falsa, entonces tendrá conclusiones verdades y falsas (pone como ejemplo que si $a$ es el enunciado "siempre llueve en domingo", la cual es falsa, pero la conclusión "llovió el domingo pasado", puede ser verdadera). Una afirmación verdadera o

\footnotetext{
${ }^{37}$ Cabe destacar que, aunque Popper ya conocía la existencia de lógica multivaluadas, él ceñirá su análisis a la lógica clásica bivalente.

${ }^{38}$ Aún y cuando $t_{2}$ haya sido refutada podemos seguir prefiriéndola a $t_{1}$, pues es mejor porque ha resistido más test, así que decimos que es posible que esté más cercana a la verdad. También se puede decir que si una teoría es más precisa que otra (siempre y cuando su contenido de falsedad no sea mayor) tiene un grado de verosimilitud mayor, lo mismo sucede para las consecuencias numéricas, pueden ser falsas, pero se acercan a los valores numéricos verdaderos.
} 
falsa puede tener más o menos consecuencias verdaderas si su contenido consiste en un mayor o menor número de enunciados verdaderos. Abreviaremos como $\mathrm{Ctv}$ (a) a las consecuencias verdaderas de $a$ y Ctf(a) a sus consecuencias falsas, a la suma de las dos será Ct(a).

En la lógica clásica bivalente donde contamos con los principios del tercio exclusor y el de no contradicción estamos obligados a aceptar que cada par de enunciados opuestos contradictoriamente, sólo uno de ellos es verdadero y el otro falso. La verdad será definida como el conjunto de todos los enunciados verdaderos, el cual será un conjunto completo (en él se encuentra una afirmación o su negación), y deductivamente cerrado, entonces esta será la teoría máxima verdadera, la cual denominaremos como Tv (Cfr. Zamora, 1996, pág. 34).

Entonces podemos hacer las siguientes definiciones:

(i) $\operatorname{Ctv}(\mathrm{a})=\mathrm{Ct}(\mathrm{a}) \cap \mathrm{Tv}$, el contenido de verdad de $a$ es igual a la intersección del contenido de $a$ y de la teoría verdadera.

(ii) $\mathrm{Ctf}(\mathrm{a})=\mathrm{Ct}(\mathrm{a}) \cap \mathrm{k}(\mathrm{Tv})$, el contenido de falsedad de $a$ es igual a la intersección del contenido de $a$ y del complemento de la teoría verdadera.

(iii) $\mathrm{Ct}(\mathrm{a})=\operatorname{Ctv}(\mathrm{a}) \cup \mathrm{Ctf}(\mathrm{a})$ el contenido de $a$ es igual a la unión de su contenido de falsedad y de verdad.

Así podemos afirmar que, si el contenido de dos teorías puede compararse, $a$ es más verosímil que $b$ si, y sólo si,: iv) el contenido de verdad, pero no el contenido de falsedad de $a$ supera al de $b$, v) el contenido de falsedad de $b$ supera al de $a$, pero no su contenido de verdad.

(iv) $\operatorname{Ctv}(\mathrm{b}) \subseteq \operatorname{Ctv}(\mathrm{a})$ el contenido de verdad de $b$ está incluido en el contenido de verdad de $a$.

(v) $\mathrm{Ctf}(\mathrm{a}) \subseteq \mathrm{Ctf}(\mathrm{b})$ el contenido de falsedad de $a$ está incluido en el contenido de falsedad de $b$. Cuando menos una de las dos inclusiones debe ser estricta.

En caso de que ambas fuesen verdaderas, sería suficiente con que $b$ tuviese mayor contenido que $a^{v i i}$. Mientras que, si ambas son falsas, como en los casos de las teorías científicas, para que $a$ sea más verosímil que $b$ puede ser en los dos siguientes casos: (1) $a$ debe tener igual o menor contenido de falsedad que $b$ y más contenido de verdad que $b$; o (2) $b$ debe tener más contenido de falsedad que $a$ y menos o igual contenido de verdad que $a^{\text {viii }}$.

Aunque pareciera una noción intuitiva clara, se puede notar que es imposible que se pueda realizar así la comparación. Supongamos que $r$ es una verdad de $a$, pero no de $b$ para cumplir el primer caso, mientras que $f$ es una falsedad que ambas comparten; tenemos como consecuencia que $\mathrm{r}^{\wedge} \mathrm{f}$ es una falsedad en $a$, pero no en $b$, por lo tanto, no es posible que $a$ tenga más contenido de verdad que $b$, sin generar un mayor contenido de falsedad, entonces (1) no es posible. Ahora, si $b$ tiene la falsedad $s$ que no está en $a$, $b$ tendría en su contenido de verdad $\mathrm{s} \rightarrow \mathrm{f}$, pero no estaría en $a$, por lo tanto (2) tampoco es posible: 
This result deals a death blow to Popper's definition. What we call truthlikeness cannot be captured by comparing truth contents and falsity contents in this way. The intuitive idea behind the theorem is obvious. Adding truths to a false theory generates falsehoods-adding falsehoods generates more truths (Oddie, 1986, pág. 26).

Supongamos que Popper quisiera evitar estos problemas limitándose a comparar el contenido de falsedad de ambas teorías, sin tomar en cuenta el contenido de verdad, es decir, sería más verosímil una teoría mientras menos falsedades tenga. Esto iría ir en contra de los objetivos de la ciencia, puesto que nosotros podríamos crear teorías con menos falsedades simplemente restándole contenido, lo cual no sería deseable, puesto que lo que queremos son teorías altamente informativas.

Ahora, si quisiéramos cambiar de estrategia considerando únicamente el contenido de verdad, tampoco nos estaríamos librando de problemas. Esto nos diría que para que una teoría fuese más cercana a la verdad que una rival basta con que tenga más consecuencias verdaderas. El problema aquí es que para que una teoría tenga más consecuencias verdaderas es suficiente con agregarle más contenido sin importar si este es falso o verdadero, puesto que necesariamente esto aumentará el contenido de verdad:

But, it can obviously be objected, and rightly, mere aggregation of consequences is of no use in itself; we want these new consequences to be true. After all, any old fairy tale, however preposterous, if grafted on to Galileo's theory, will beget new consequences. But we would be disinclined to accept such an augmented theory, in contrast to Newton's, as a step in the direction of the truth. Or to put the matter in another way: increase in truthlikeness surely depends to at least some extent on what is true. But the suggestion would make it quite independent of the truth (Miller, 1974a, pág. 167).

O en otro ejemplo:

Imagine the witness to a murder selecting features from the detective's identikit [...]. He is asked to start with the ears. He replies, 'I am not sure whether he had a wart on his ears or not-but pair 13 look pretty close.' The detective seems delighted. 'Well that's just great,' he says, 'So long as you get the ears wrong then anything you choose after that will make it a better and better fit.' According to the revised definition the detective's elation would be entirely justified, for each successive description amounts to a stronger theory than its predecessor. If each member of the sequence is false, then each theory comes closer to the truth than its predecessor, regardless of its claims. The witness selects some further features arbitrarily, and someone who fits the description exactly is charged with the crime. 'I was nowhere near the scene of the crime' he protests in court. 'Ah well,' says the prosecutor, seizing this bit of information with delight, 'If you admit that it is false to say that you were at the scene of the crime, then it would be a significant step towards the truth to claim both that you were at the scene of the crime and that you committed the crime. Moreover, progress can only be made if we add to this that you planned the crime in advance, committed it in cold blood, and proceeded to rape the victim's wife as soon as you had disposed of the body.' The judge takes a quick glance at Popper's revised definition, and nods gravely: 'I find the argument of the prosecutor impeccable.' (Oddie, 1986, págs. 27-28). ${ }^{39}$

Pavel Tichý y David Miller en sus artículos de 1974, se dieron cuenta de esto, de que ninguna proposición falsa puede estar más cercana a la verdad que otra proposición falsa sin generar los problemas

\footnotetext{
${ }^{39}$ A esta objeción la bautizó Pavel Tichý como “child's play", Todo antecedente falso de una proposición p es más cercano a la verdad que p por sí misma. Es suficiente con adherir una proposición falsa q (un cuento de hadas, como lo dice miller) a una proposición falsa $\mathrm{p}$, donde $\mathrm{p} \vdash \mathrm{q}$ y $\mathrm{q} \vdash \mathrm{p}$, y la conjunción $\mathrm{p}^{\wedge} \mathrm{q}$ es más cercana a la verdad. Esta objeción tiene un trasfondo epistemológico, en comparación con la dinámica real de la ciencia, aproximarse a la verdad de acuerdo con una definición de contenido es demasiado fácil, es suficiente con adherir falsedades.
} 
anteriormente mencionados. También notaron que no es posible que una proposición falsa esté más cercana a la verdad que una verdadera que no tiene ningún contenido como las tautologías ${ }^{40}$.

Además, otro problema que Popper ya había avizorado, son muy pocas o ninguna las teorías que se pueden comparar de esa manera porque podemos tener tres teorías: A, B y C; para los cuales no es posible comparar sus grados de verosimilitud porque no se entrelazan sus contenidos de verdad o de falsedad ${ }^{\text {ix }}$.

\subsection{Noción cuantitativa de la verosimilitud}

Como mencionamos anteriormente, una de las problemáticas de la noción cualitativa de Popper es que deja sin comparar a muchas teorías que no se contienen de la manera en la que hablábamos en los ejemplos anteriores, sino que hablan de aspectos distintos de la verdad. Entonces se debe buscar una nueva estrategia para poder comparar a dos teorías y poder afirmar que una es más verosímil que la otra y esto lo hizo mediante una definición cuantitativa de la verosimilitud, es decir, que pudiéramos obtener un número mediante ciertas asignaciones y operaciones. La idea consiste en contar las consecuencias verdaderas y falsas de cada teoría. Se trata de medir la cantidad de información proporcionada por la teoría o el enunciado, a esto le llama "grado de contenido". Entre mayor sea la probabilidad de un enunciado será menor su información (como en las tautologías) y también sucede a la inversa (con las contradicciones).

Popper decide formalizarlo de la siguiente manera: (i) $\mathrm{Ct}(\mathrm{a})=1-\mathrm{p}$ (a) así la verosimilitud se obtiene mediante una resta entre el contenido de verdad menos el de falsedad. Luego nos pide que supongamos que podemos medir el contenido de una teoría, entonces ahora es posible conocer su grado de verosimilitud: (ii) Vs(a)= Ctv (a) - Ctf(a). Aquí la fortaleza es si el contenido de verdad aumenta (y no el de falsedad), aumenta el de Vs(a), lo mismo sucede si disminuye el de falsedad, pero el de verdad no. Cuando decimos que una teoría es más verosímil que otra bastará con afirmar que su grado de verosimilitud es mayor (iii) $\mathrm{Vs}(\mathrm{a})>\mathrm{Vs}(\mathrm{b})$.

Lo primero que debemos hacer es distinguir la información falsa de la verdadera. El contenido de verdad de un enunciado $a$ será el grado de contenido de la teoría formado por todos aquellos enunciados verdaderos que se derivan de $a$; si la verdad (Tv) es axiomatizable mediante el enunciado $t$, entonces la definición será ésta:

(iv) $\operatorname{Ctv}(\mathrm{a})=\mathrm{Ct}(\mathrm{avt})=1-\mathrm{p}(\mathrm{avt})=1-[\mathrm{p}(\mathrm{a})+\mathrm{p}(\mathrm{t})]$ si $a$ es falsa.

(v) $\mathrm{Ctv}(\mathrm{a})=\mathrm{Ct}$ (a) si $a$ es verdadera.

${ }^{40}$ Otro problema que menciona Niiniluoto es que únicamente corresponde a la idea de verdad parcial y no dice nada sobre verdad aproximada, lo cual es una carencia de esta definición de verosimilitud (Cfr. Niiniluoto, 1987, pág. 192). 
Podemos notar que las consecuencias de avt son las mismas que las consecuencias verdaderas de $a$ : "Si las funciones $\mathrm{p}$ y $\mathrm{Ct}$ están definidas para clases de consecuencias, y no sólo para enunciados, entonces no es necesario que Tv sea axiomatizable, y podemos sustituir en la definición anterior la expresión 'avt' por 'Cont(a) $\cap$ Tv'” (Zamora, 1996, pág. 39).

Recordemos que, aunque un enunciado sea falso, también puede tener un contenido de verdad:

For assume that today is Monday. Then the statement 'Today is Tuesday' will be false. But this false statement will entail a number of true statements, such as 'Today is not Wednesday' or 'Today is either Monday or Tuesday'; and the class of all those true statements which it entails will be its (logical) truthcontent. In other words, the fact that every false statement entails a class of true statements is the basis for ascribing a truth-content to every false statement (Popper, 1962, pág. 392).

Las letras $a$ y $b$, aunque las estamos utilizando como si fuesen enunciados, también se pueden tomar como si fueran un conjunto de ellos (o una teoría). Asimismo, el símbolo $p$ se utiliza como uno de los valores constantes que pueden adoptar las variables "a", "b" u otra.

Ahora bien, ya definimos cómo se obtiene el contenido de verdad, pero para medir la verosimilitud de $a$ también es necesario saber el contenido de falsedad, pero aquí la clase $\mathrm{F}$ de todos los enunciados falsos de una afirmación no es una clase de consecuencia. Mientras que T tiene todas sus consecuencias lógicas (de un enunciado verdadero sus consecuencias serán siempre verdaderas) en el caso de F no contiene todas sus consecuencias lógicas, de un enunciado falso se deducen tanto enunciados falsos como verdaderos.

Entonces tenemos que buscar una manera distinta de definir el contenido de falsedad- Ctf (a)para ello deben tomarse en cuenta los siguientes requisitos:

a) Si un enunciado es verdadero, su contenido de falsedad será de 0 . $a \in T \rightarrow \operatorname{Ctf}(a)=0$.

b) Si un enunciado es falso, su contenido de falsedad será menor o igual a su contenido total a $\notin \mathrm{T} \longrightarrow$ $\operatorname{Ctf}(a) \leq \operatorname{Ct}(a)$

c) El contenido de falsedad de un enunciado debe ser mayor o igual a cero, a su vez que menor o igual que su contenido de verdad, mientras que el contenido de verdad debe ser menor o igual a 1. $0 \leq \operatorname{Ctf}(\mathrm{a}) \leq \mathrm{Ct}(\mathrm{a}) \geq \operatorname{Ctv}(\mathrm{a}) \geq 1$

d) El contenido de falsedad de una contradicción es igual a su contenido que es igual a 1; mientras que el contenido de verdad de una tautología es igual a su contenido que es $0 . \mathrm{Ctf}($ contrad $)=\mathrm{Ct}($ contrad $)=1$ $\mathrm{y} \operatorname{Ctv}($ tautol $)=\mathrm{Ct}($ tautol $)=0$

e) Si el contenido de verdad de $a$ es 0 , entonces su contenido de falsedad es igual a su contenido. Ctv(a) $=0 \rightarrow \operatorname{Ctf}(\mathrm{a})=\mathrm{Ct}(\mathrm{a})$.

f) $\mathrm{Si}$ su contenido de falsedad es igual a 0 , entones su contenido de verdad es igual a su contenido. Ctf(a) $=0 \rightarrow \operatorname{Ctv}(\mathrm{a})=\mathrm{Ct}(\mathrm{a})$. 
g) La suma de su contenido de falsedad y de verdad debe ser mayor o igual a su contenido. Ctv(a) + $\operatorname{Ctf}(\mathrm{a}) \geq \operatorname{Ct}(\mathrm{a}) .^{41}$

h) $\mathrm{Ctf}$ y $\mathrm{Ctv}$ son simétricos con respecto a $\mathrm{Ct}$.

La primera posibilidad para definir la falsedad es poner como contenido de falsedad todo lo que sobre del contenido de verdad: (vi) $\operatorname{Ctf}(a)=\operatorname{Ct}(a)-\operatorname{Ctv}(a)$, pero esto es problemático porque daría a las contradicciones un mayor contenido de verdad que de falsedad. Entonces Popper define el grado de falsedad como aquellos casos donde las consecuencias de $a$ no son las mismas que las consecuencias de $a v t$ :

(vii) $\mathrm{CtF}(\mathrm{a})=\mathrm{Ct}(\mathrm{a}, \mathrm{avt})=1-\mathrm{p}(\mathrm{a}, \mathrm{avt})=1-(\mathrm{p}(\mathrm{a}) / \mathrm{p}(\mathrm{avt}))=1-[(\mathrm{p}(\mathrm{a}) /(\mathrm{p}(\mathrm{a})+\mathrm{p}(\mathrm{t}))]$

Recordemos que esto es sólo para los casos en los que $a$ es falsa. Como mencionamos, la verosimilitud $a$ sería el resultante de restar el contenido de verdad menos el de falsedad como en (ii), sin embargo, Popper le añade un factor de normalización, esto con la finalidad de garantizar que la magnitud de Vs esté siempre entre 1 y -1 , con ello se logra que las contradicciones tengan un valor mínimo constante. Entonces Vs(a) se definirá de la siguiente manera: (viii) Vs (a) = $[\mathrm{CtV}(\mathrm{a})-\mathrm{CtF}(\mathrm{a})] /[\mathrm{p}(\mathrm{avt})+\mathrm{p}(\mathrm{a}, \operatorname{avt})]$. Según Popper con esta definición lograba cumplir los siguientes requisitos:

(1) $\mathrm{Si} a$ es verdadera, entonces $\mathrm{Vs}(\mathrm{a})=\mathrm{Ct}(\mathrm{a})$.

(2) Si $a$ es falsa, entonces $\mathrm{Vs}(\mathrm{a})<\mathrm{Vs}(\mathrm{vt})=\mathrm{Ct}(\mathrm{avt})$.

(c) Para cualquier $a$, $-1<\mathrm{Vs}(\mathrm{a})<\mathrm{Vs}(\mathrm{t})<1$.

(d) Vs (taut) $=0$

(e) Vs $($ contrad) $=-1$ (donde "contrad representa cualquier enunciado contradictorio") (Zamora, 1996, pág. 40).

Podemos notar que el contenido de un enunciado más fuerte lógicamente que otro es también mayor, es decir si $\mathrm{a} \vdash \mathrm{b}$ tenemos como consecuencia que $\mathrm{Ct}(\mathrm{a}) \geq \mathrm{Ct}(\mathrm{b})$, de aquí se sigue otro requisito fundamental: entre enunciados verdaderos, la verosimilitud aumenta con el contenido lógico, lo cual nos ayuda a distinguirla diferencia entre verosimilitud y probabilidad, pues en el segundo sucede lo contrario $\mathrm{p}(\mathrm{a}) \leq \mathrm{p}(\mathrm{b})$. Zamora menciona que otro resultado interesante el cual no mencionó Popper, es que algunos enunciados falsos pueden tener un grado mayor de verosimilitud que algunos otros enunciados verdaderos (Cfr,.1996, pág. 41). Esto y otras de los requisitos cumplidos por parte de la definición poppereana pueden observarse en las aplicaciones numéricas que realiza en una de las adendas (Cfr. Popper, 1963, pág. 397).

Con lo anterior, Popper cree haber logrado un concepto de verosimilitud con el cual se pudiera decir que hay teorías que se aproximan más o menos a la verdad, sin temer a decir sin sentidos; pero que

\footnotetext{
${ }^{41}$ the reason for putting here ' $\geq$ ' rather than ' $=$ ' will be seen if we take 'a' to be, for example, 'contrad'; for in this case, we obtain $\mathrm{Ctf}(\mathrm{a})=\mathrm{Ct}(\mathrm{a})=1$, by (iv) and $\mathrm{Ct} \mathrm{T}(\mathrm{a})=\mathrm{Ct}(\mathrm{t})$; but $\mathrm{Ct}(\mathrm{t})$ is the maximum truth-content, which will in general be different from zero. In an infinite universe, $\mathrm{Ct}(\mathrm{t})=1-\mathrm{p}(\mathrm{t})$ will as a rule be equal to 1 (Popper, 1962, pág. 394)
} 
no sugiere la existencia de un criterio de aplicabilidad de esta idea, de la misma forma como sucede con la verdad:

But some of us (for example Einstein himself) sometimes wish to say things as that we have reason to conjecture that Einstein's theory of gravity is not true, but that it is a better approximation to truth than Newton's. To be able to say such things with a good conscience seem to me a major desideratum of methodology of the natural sciences (Popper, 1972, pág. 335).

Además, Popper considera que la aproximación a la verdad tendría el mismo carácter e ideal regulador que la verdad absoluta u objetiva. Aunque después dice que es preferible incluso tener mejor a la verosimilitud como ideal regulador, puesto que a veces preferiremos teorías falsas en lugar de las verdaderas, si su contenido de verdad supera al de falsedad. Esto también aplica para los casos donde las teorías hacen abstracciones, idealizaciones y simplificaciones, por lo tanto, no se puede obtener una teoría verdadera, sino solamente aproximadas y la desiderata sería irnos acercando cada vez a la verdad (significativa).

\subsubsection{Problemas de la definición cuantitativa de verosimilitud popperana}

En el volumen 25 número dos de The British Journal of Philosophy of Science de 1974 aparecieron sendos artículos que criticaban tanto la versión cuantitativa y cualitativa de Popper, los cuales fueron resultado de investigaciones por separado, pero finalmente llegan a las mismas conclusiones, aunque lo explican de diferente manera, los autores son, como ya lo habíamos mencionado: David Miller y Pavel Tichý.

El principal problema es que la noción cuantitativa de Popper produce un enorme volumen de doble contabilidad y el recuento de consecuencias es arbitrario e indiscriminado, a esto se le ha denominado como el resultado de la trivialización Tichý-Miller.

Consideremos que la verdad es h, $\mathrm{r}$ y w. Las combinaciones posibles al hacer conjunciones con los tres enunciados y sus negaciones son nada más 8. Si la afirmación verdadera es $\mathrm{p}^{\wedge} \mathrm{q}^{\wedge} \mathrm{r}$, la más alejada a la verdad sería $\neg \mathrm{p}^{\wedge} \neg \mathrm{q}^{\wedge} \neg \mathrm{r}$, mientras que $\neg \mathrm{p}^{\wedge} \neg \mathrm{q}^{\wedge} \mathrm{r}$ estaría menos alejada de la verdad y $\neg \mathrm{p}^{\wedge} \mathrm{q}^{\wedge} \mathrm{r}$ estaría más cercana. Aunque estos ejemplos nos pueden parecer sencillo e intuitivamente correctos, la noción cuantitativa de la verosimilitud de Popper no puede acomodarlas ${ }^{\mathrm{x}}$.

En dado caso que pudiésemos acomodarlas, no podemos evaluar a todas las consecuencias verdaderas y falsas por igual porque las tres últimas afirmaciones tienen el mismo número de consecuencias falsas y verdaderas. Por ejemplo, tenemos dos teorías, una que dice $\mathrm{p}^{\wedge} \mathrm{q}^{\wedge} \neg \mathrm{r}$ y la segunda $\neg \mathrm{p}^{\wedge} \mathrm{q}^{\wedge} \neg \mathrm{r} ; \mathrm{p}$ y q deberían contar para aumentar su contenido de verdad en la primera teoría; y a la segunda deberían restársele las falsedades $\neg$ p y $\neg$ r. Pero ahora tenemos sus consecuencias, $\mathrm{p} \longrightarrow \neg \mathrm{r}$ es una falsedad en el primer caso y $\neg \mathrm{p} \longrightarrow \neg \mathrm{r}$ es una consecuencia verdadera para el segundo. Como contamos a $\mathrm{p}$ en favor de la verosimilitud y $\neg$ r en contra de ella, ¿deberíamos contar a la consecuencia $\neg p \longrightarrow \neg$ r en favor de ella 
y a la falsedad $\mathrm{p} \longrightarrow \neg \mathrm{r}$ en contra? Seguramente ambos casos son innecesarios y erróneos. Y esto es lo que precisamente a la noción de Popper lo hace vulnerable al argumento de Tichý y Miller.

Dos año más tarde, Popper contestaría que "As a first step beyond this, I suggest that this set $\mathrm{T}$ is too big. We may admit into our universe of statements only such statements as we conjecture to be relevant; relevant, that is, to the problem situation in hand" (Popper, 1976, pág. 155), y esta es la estrategia que se ha seguido entre quienes siguen tomando en cuenta el enfoque de la verosimilitud por consecuencias o por contenido, es decir, decir que unas consecuencias son más importantes que otras y limitarse a únicamente ellas. Sin embargo, muchas de ellas fallan en definir cuáles y por qué son esas las relevantes, o tienen otros problemas al momento de dar su noción de verosimilitud (Cfr. Zwart, 2001, págs. 35-73) (Cfr. Zamora, 1996, págs. 71-98) ${ }^{42}$.

La nueva modificación de Popper a su definición sería la de medir la distancia de la verdad de una hipótesis $a$ por la probabilidad a la diferencia simétrica de $a$ y la verdad $t: \mathrm{P}(\mathrm{a} \Delta \neg \mathrm{t})+\mathrm{P}(\neg \mathrm{a} \Delta \mathrm{t})$. Sin embargo está expuesta a críticas muy similares a las anteriores, una teoría falsa aumenta su verosimilitud con agregarles más enunciados, sin importar su calidad, por ejemplo si tenemos $a$ que es la teoría de Newton y $q$ que dice "la luna es de queso", entonces a^q es más verosímil en esta definición: “This absurd result provides us with sufficient reasons for discarding also the third definition put forward by Popper together with its modifications" (Kieseppä, 1996, pág. 27).

\subsection{El fracaso de Popper}

Ante las críticas de Pavel Tichý y David Miller, además de los siguientes fallidos intentos por definir la verosimilitud, Karl Popper expresó que afortunadamente era suficiente con la noción intuitiva, que esto demostraba que no se podían resolver los problemas filosóficos por medios formales y que éste era el castigo por hablar libremente de la verdad (Cfr. Kuipers, 2000, pág. 139).

¿Representaba esto un fracaso para todo el sistema poppereano? Karl Popper no lo consideraba así, sólo que una de las formas en las que intentó fortalecer su filosofía no fue posible, pero que el “edificio" se mantenía intacto, esto lo declara en 1983 en Realism and the Aim of Science:

La esperanza de fortalecer aún más (mi) teoría de los objetivos de la ciencia por medio de una definición de similaridad con la verdad fue, desgraciadamente, vana. Pero la concepción, muy extendida, de que el abandono de esta definición debilita mi teoría, carece por completo de fundamento (...) Nadie ha mostrado nunca que mi teoría del conocimiento, que desarrollé en 1933 y que lleva creciendo vigorosamente desde entonces y que es muy utilizada por los científicos en activo, haya resultado debilitada (...) o que la idea de similaridad con la verdad (que no es una parte esencial de mi teoría) no pueda seguir usándose dentro de mi teoría como concepción sin definir (Citado por Zamora, 1996, pág. 65).

\footnotetext{
${ }^{42}$ Otro intento ha consistido en utilizar otras lógicas que no sean la lógica clásica, por ejemplo, Chris Mortensen en 1983 propuso usar la lógica relevante para evitar estos problemas, sin embargo, todos los intentos los han llevado a resultados desastrosos.
} 
A pesar de este paso de costado, Niiniluoto considera que el gran logro de Popper fue mostrar que quienes criticaban la idea de "cercanía a la verdad" era con base a un prejuicio más que a un argumento y que anteriormente nadie había intentado seriamente definir este concepto, a pesar de que se oponía al programa de utilizar explicaciones formales dentro de la filosofía de la ciencia: "And he also cherished the hope that the proposal to build a fallibilist theory of science upon the concept of verisimilitude would finally help us to get rid of formal systems of inductive logic, as developed by Rudolf Carnap" (Niiniluoto, 1987, pág. xi).

Este acto de valentía y de esfuerzo intelectual por parte de Popper, iniciaría un programa de investigación que tenía como eje central responder qué queremos decir cuando expresamos que una afirmación o teoría es (más) aproximada a la verdad (que sus rivales o antecesoras). En palabras de Gunnar Anderson: "Semejanza a la verdad era uno de los problemas irresueltos más fascinantes de la moderna Filosofía de la Ciencia” (Citado por Zamora, 1996, pág. 66), aunque reconocía que era exagerado considerar que una definición precisa de la verosimilitud fuera necesaria para el racionalismo crítico, dado que hay muchas razones para preferir una hipótesis falsa por sobre otras, además de que una sea más cercana a la verdad que sus adversarias. 


\section{Capítulo III. El enfoque de la similitud}

Ella estaba en el horizonte. Me acerco dos pasos, ella se aleja dos pasos. Camino dos pasos y el horizonte se corre diez pasos más allá. Por mucho que yo camine, nunca la alcanzaré. ¿Para qué sirve Introducción la Utopía? Para eso sirve: para caminar - Eduardo Galeano.

En este capítulo se verán otras propuestas para resolver el problema semántico de la verosimilitud. El primero de ellos será el enfoque de la similitud tanto en lógica modal como en lógica proposicional, así como los argumentos más fuertes. También se expondrán unas propuestas que no están formalizadas y se piensan que con ello es suficiente para darnos a entender sobre el tema.

Cabe destacar que las reconstrucciones intentarán darse de la manera más simple posible, a pesar de que muchas de ellas en su forma original constan de un aparato lógico y matemático más complejo, para ello se utilizaron las fórmulas reconstruidas, sobre todo las que maneja Zamora Bonilla en Verdades a medias (1996).

\section{El enfoque de la similitud}

A pesar del abandono del tema por parte de su iniciador, seguía siendo necesario dar una noción de verosimilitud que fuese clara, tal como lo menciona Mario Bunge en The Myth of Simplicity: "philosophers still owe scientists a clarification of the concept of relative and partial truth as employed in factual science" (Bunge, 1963, pág. 116), fue entonces cuando empezaron a surgir diversas propuestas para dar una respuesta al problema.

En el presente apartado veremos el enfoque más conocido en cuanto al tema de la verosimilitud, sobre todo el que se ha hecho por medio de las herramientas lógicas más sofisticadas; es una mezcla entre “similitud" y "verdad", por eso en inglés se encuentra como Truthlikeness ${ }^{43}$.

El enfoque de la similitud fue desarrollado en 1974 de dos maneras distintas y de forma independiente, el primero de ellos es el del finlandés Hilpinen que se desarrolla dentro de la semántica de mundos posibles, contrafactuales y las esferas anidadas de Lewis; el otro es el resultado de las críticas de Pavel Tichý (quien se basa en los constituyentes de Hintikka) a la definición poppereana de la verosimilitud, él utiliza lógica proposicional y muestra cómo una proposición falsa puede estar más cercana a la verdad que otra que también sea falsa. Alrededor de este programa se han utilizado diversos tipos de extensiones lógicas como la lógica completa de primer orden, lógica de orden superior y lógica intencional. Hay desacuerdos técnicos y filosóficos en cuanto a este enfoque de acuerdo a los detalles que están dentro de este programa y en cuanto a los retos generales de la propuesta completa.

\footnotetext{
${ }^{43}$ Hay diferencias entre verisimilitude y truthlikeness, la primera defina la distancia a la verdad utilizando valores de verdad y fuerza lógica, mientras que la segunda establece la distancia a la verdad utilizando la similitud entre mundos posibles.
} 
Uno de los aspectos que se debe remarcar es que ya no se toma en cuenta a "la verdad completa", sino que se restringe a un determinado problema cognitivo y las respuestas que se le pueden dar. La idea básica es que, si $g$ es una respuesta potencial parcial a un problema B, su grado de verosimilitud depende de la similitud entre el estado de cosas dentro de $g$ y el verdadero estado de cosas expresado por la verdad del elemento h* de B. Para esta definición se deben especificar dos funciones: la función similitud que expresa la distancia entre los elementos de B y una función reducción que extiende la función similitud de la respuesta completa en $\mathrm{B}$ a las respuestas parciales en $\mathrm{D}(\mathrm{B})^{44}$. Entonces, el problema general en este enfoque es encontrar una métrica razonable de similitud entre la respuesta parcial del problema que nos diga qué tan cerca o lejos estamos de la verdad. ${ }^{45}$

Recordemos que, para un realista científico, el objetivo de una investigación es descubrir la verdad sobre un tema, el cual cuando menos tiene dos elementos: una colección de objetos (dominio de la investigación) y una de rasgos (propiedades y relaciones de los objetos, o lo que Tichý nombra como la base intencional de la investigación), a la base y al dominio en conjunto se les llama marco conceptual. El investigador querrá descubrir hasta qué punto los rasgos en la base se distribuyen a través del dominio. En un inicio se enfrentará a una gama de diferentes posibilidades, hay una cantidad limitada o ilimitada de maneras en las que los rasgos pueden distribuirse entre los objetos; a cada una de las distribuciones completas es denominado como "mundo posible", al conjunto de todos los mundos posibles generados por un marco teórico se le nombra "espacio lógico del marco". Uno de estos mundos dentro del espacio lógico del marco es el mundo real, pero no es parte del marco especificar cuál es, esto se define por los hechos. Cabe destacar que el mundo real no es ontológicamente diferente de los otros mundos posibles (no es no más ni menos concreto), solamente es una distribución de los rasgos que coincide con los hechos ${ }^{46}$.

\footnotetext{
${ }^{44}$ In defining the degree of truthlikeness of a proposition h, our 'goal' or 'target' is not THE WORLD - the actual world in its infinite variety - but only that part of it which exhibits the relevant features of the cognitive problem situation. If the relevant language in which $\mathrm{h}$ is expressed is $\mathrm{L}$, then - as a first approximation at least - we may choose as our target the L-structure $\Omega *_{L}$ (Niiniluoto, 1987, pág. 203).

${ }^{45}$ What we want to find is a measure expressing how close a subset of $\mathrm{Rn}$ is to a point of $\mathrm{Rn}$. Now, a natural way to proceed in defining such a measure seems to be this. First, one defines a metric on $\mathbf{R}^{\mathbf{n}}$. Such a metric express, among other things, the distance between each point estimate for the $n$ parameters and their true values. In a second step, one generalizes this metric somehow to a function expressing the degree of "closeness" of a subset of Rn with each point of $\mathbf{R}^{\mathbf{n}}$ (Kieseppä, 1996, pág. $31)$.

${ }^{46}$ Of course, actual research programs are inevitably vague entities and any precise reconstruction of them is bound to be idealized, simplified and open to dispute. But such simplification and idealization is necessary if the theories and concepts to be dealt with are to be open to precise logical manipulation and analysis. Thus, each inquiry is taken to involve some definite conceptual framework (Oddie, 1986, pág. 34).
} 
El ejemplo más utilizado es el que ya mencionamos en el apartado anterior acerca del clima, el cual se compone de tres rasgos: calor (h), lluvia (r) y viento (w), si obtenemos distintas descripciones con la conjunción de los tres estados y sus negaciones, logramos obtener 8 mundos posibles (W) ${ }^{\mathrm{xi}}$.

Dado un marco conceptual y el espacio lógico generado por él, hay varias nociones clave que deben ser explicadas. Una proposición es algo que puede o no puede ser verdadero. Cierto en algunas circunstancias posibles y falso en otros. Así, una proposición no se limita a escoger un valor de verdad, sino que se escoge un valor de verdad en cada mundo posible. Una proposición que induce una función de los mundos de los valores de verdad. Cada proposición P induce una función que toma mundos en los que $\mathrm{p}$ es verdadera a T, y los mundos en los que es falsa a F. Por otra parte, no parece haber nada más que una proposición de la dicotomía de manera inducida. Para saber cuál es la proposición de la cual se está hablando en una ocasión dada, simplemente se necesita saber lo qué haría falta para que fuese verdadera. Es decir, tener conocimiento de una proposición es saber en qué circunstancias sería verdadera y aquellas en las que sería falsa. Pero la posesión de la función inducida da precisamente estas condiciones. Así, una proposición puede ser identificada con una función que va de los mundos posibles a valores de verdad.

Tomando como base nuestro ejemplo, la proposición $h$ está en el conjunto de mundos w1, w2, w3, w4, $r$ en w1, w2, w5, w6, y w en w1, w3, w5, w7. La negación de A es verdadera en un mundo W si es el caso que A es falsa en W. La negación toma a los complementos de una proposición, por ejemplo: $\neg$ h está en los mundos w5, w6, w7, w8, es decir, aquellos donde h no está. La conjunción toma un par de proposiciones y con ello a la intersección de conjuntos entre dos afirmaciones ( $\mathrm{h}^{\wedge} \mathrm{r}$ están en w1 y w2). La disyunción es la unión, y junta a aquellos conjuntos donde al menos una de las proposiciones es verdadera (hvr está de w1 a w6).

Si suponemos que w1 es la descripción real del mundo, podemos acomodar a los demás mundos de acuerdo a su similitud de una manera intuitiva, por ejemplo, los más cercanos a él (y en el mismo nivel) serán aquellos que tengan sólo una afirmación equivocada por lo tanto w2, w3 y w5; en el siguiente nivel quedarían las que tuvieran dos errores, es decir w4, w6 y w7, por último, aquel mundo que es completamente lo opuesto al verdadero: $w 8^{\text {xii }}$. Uno esperaría que una medida de verosimilitud pudiese rescatar esto, pero hay otros casos más problemáticos, tales como el grado de verosimilitud de descripción incompletas $\left(\mathrm{h}^{\wedge} \mathrm{W}\right)$, una negación de un sólo estado ( $\left.\neg \mathrm{W}\right)$ o de disyunciones (hvrvw), esto es a lo que han intentado resolver los ya mencionados Hilpinen y Tichý, pero también a otros filósofos reconocidos como Kuipers, Oddie, Kisseppä, Heidema, Brink, Burger y Niiniluoto. 


\subsection{Similitud entre esferas}

Risto Hilpinen desarrolla su teoría de la verosimilitud tomando como base los contrafácticos de David Lewis para realizar la ordenación de mundos con respecto al mundo real, en este enfoque se toma como primitiva la noción de similitud entre los diferentes mundos posibles. En esta propuesta las condiciones de verdad de un enunciado dependerán de su existencia en el mundo, será verdadera si se encuentra en él y falsa en caso contrario. En este sentido, se hace uso de un operador condicional contrafactual que no es un valor de verdad, sino una función utilizada en proposiciones, por ejemplo, los valores de verdad de una proposición como la siguiente "si A entonces B” dependerán no solamente de sus valores en el mundo actual, sino también de lo que suceda en los otros mundos posibles.

Un contrafactual es verdadero en un mundo $\mathrm{W}$ cuando los mundos en los que el antecedente es verdadero son cercanos a $\mathrm{W}$, también sea el caso en los que el consecuente es verdadero. Para hacer clara esta idea, es necesario que supongamos que los mundos están ordenados de acuerdo a su similitud mediante diferentes esferas, es decir, tenemos un mundo en el centro $(w)$, que sería la primera esfera, luego tenemos otra esfera donde se encuentran mundos diferentes a $w$, pero no mucho, luego otra esfera donde se van pareciendo cada vez menos y así hasta llegar al mundo más disímil ${ }^{47}$.

Las esferas están "anidadas" y al sistema completo de esferas lo representaremos como $N_{w}$. La similitud, entonces, consistirá en localizar en qué mundo(s) es verdadera una afirmación (o estado de cosas) y ver qué tan cercano se encuentra de W ( $\mathrm{Si}$ es el caso que $U$ se encuentra en una esfera muy pequeña - es decir, cercana a $\mathrm{W}$ - entonces su grado de similitud es muy alto, mientras que si se encuentra en una esfera muy grande - muy alejada a W- entonces diremos que es muy diferente o su grado de similitud es muy bajo) $)^{\text {xiii. }}$

If a sentence $P$ is not strictly, but only approximately true at $u$, then $P$ is true in some world which is in some respect(s) slightly different, but nevertheless close to $u$. In other words, if $P$ is approximately true at $u, P$ is true in some world $v \in U$ which is in no respect essentially dissimilar to $u$ (Hilpinen, 1976, pág. 24).

Hilpinen afirma que "The truthlikeness of a proposition depends on two factors: on its closeness to truth, and on the degree to which it conveys information about the truth" (pág. 29), y se dispone a dar un criterio para poder determinar a ambos. Recordemos que una proposición puede ser verdadera en ninguno, uno o varios mundos (es decir, se observa el modelo de la proposición). El factor verdad se mide tomando como parámetro cuál es el mundo en el que una proposición $A$ es más cercano al mundo actual $\mathrm{W}$, esto se logra definiendo min (A) como la última esfera más cercana a W que no contiene ningún

\footnotetext{
47 As was mentioned above, possible worlds differ from each other in various respects; the degree of similarity between possible worlds (or possible situations) depends on the basis of comparison. Comparisons between possible worlds can be made with respect to different characteristics $\mathrm{Ci}$. Thus, we can assign to every $u \in U$ family of nonempty sets $\mathrm{N} \sim$, one for each characteristic $C i$. (Hilpinen, 1976, pág. 27)
} 
mundo en el que $A$ sea verdadera: $\min (\mathrm{A})=\mathrm{U}\left\{\mathrm{K} \in \mathrm{N}_{\mathrm{w}}: \mathrm{K} \subseteq \neg \mathrm{A}\right\}$ (K es una esfera que pertenece al sistema de esfera $\mathrm{N}_{\mathrm{w}}$ en donde $A$ es falsa).

Si min(A) está muy alejada de $\mathrm{W}$, entonces $A$ no contiene a ningún mundo similar al mundo actual. Si $A$ es verdadera (contiene a W) entonces min (a) es el conjunto vacío \{\}. Si tenemos dos proposiciones $A$ y $B$, entonces min (A) y min (B) siempre serán comparables (una esfera es un subconjunto de la otra): "Min(A) can plausibly be regarded as a measure of closeness to being true, but not closeness to the whole truth" (Oddie, 1986, pág. 53).

Recordemos que para la verosimilitud no es suficiente con la verdad, pues esto nos daría que las tautologías siempre serán tan verosímiles como cualquier enunciado verdadero, por lo tanto, es necesario hablar del "factor información", el cual se definirá por medio de la función max $(a)=\cap\left\{K \in N_{w}: K \subseteq A\right\}$ (K es una esfera que pertenece al sistema de esfera $N_{w}$ en donde $A$ es verdadera), aquí se tomará en cuenta la última esfera que lo contiene (o la cantidad de esferas donde la afirmación es modelo). Al igual que $\min (\mathrm{A}), \max (\mathrm{A})$ también es una esfera y por lo tanto hace posible la comparación con otras proposiciones. Podemos notar que si los mundos de $A$ están muy cercanos a W entonces max (A) será muy pequeños (o cercano) y si A contiene mundos muy alejados, entonces max (A) será muy grande (o alejado).

Hilpinen piensa que al combinar ambos factores podremos capturar la noción de verosimilitud: “A hypothesis $P$ has a higher degree of truthlikeness than $Q$ if and only if $P$ is closer to the truth than $Q$ and more informative about the truth than $Q$ ” (Hilpinen, 1976, pág. 32), es decir, $A$ es más verosímil que $B$ si $A$ es tan cercano a la verdad como $B$, pero contiene más información; $A$ contiene la misma información que $B$, pero $A$ está más cercano a la verdad (W): (a) $\min (\mathrm{A}) \subseteq \min (\mathrm{B})$ y $\max (\mathrm{A}) \subset \max (\mathrm{B}), \mathrm{o}$, (b) $\min (\mathrm{A}) \subset \min (\mathrm{B}) \mathrm{y} \max (\mathrm{A}) \subseteq \max (\mathrm{B})$.

Podemos observar que es una propuesta muy similar a la de Popper, pero más refinada porque permite comparar dos proposiciones (o teorías) aún y cuando su contenido sea diferente (acerca de lo que hablan de la realidad) y saber cuál está más aproximada a la verdad en el caso de que ambas sean falsas, en este sentido no sólo importan el contenido de verdad y el de información (como en la propuesta poppereana), aquí se agrega el aspecto de la similitud.

La siguiente figura nos puede ayudar a poner un ejemplo, las oraciones $\mathrm{h} \mathrm{y} \mathrm{g}$ son falsas, incluso ambas comparten la medida max, tanto $\max (\mathrm{h}) \mathrm{y} \max (\mathrm{g})$ incluyen tres esferas, sin embargo, vemos que h es más aproximada a la verdad porque min(h) se encuentra en la esfera $S_{1}$, puesto que en $S_{2} h$ ya es verdadera, mientras que min (g) está más alejada al situarse en $\mathrm{S}_{2}$, dado que g es modelo hasta $\mathrm{S}_{3}$. Asimismo, podemos notar que k es una oración verdadera y su grado de información se extiende por 
todas las esferas ${ }^{\mathrm{xiv}}$. Sin embargo, aquí podemos notar una de las problemáticas más serias que tiene esta propuesta, en ella es imposible que una falsedad por más informativa que sea esté más cercana a la verdad que una oración verdadera (dada la medida min), lo cual va en contra de las desideratas dado que nos gustaría afirmar que la teoría de Newton es más verosímil, a pesar de ser falsa, que una tautología, por ejemplo $^{\mathrm{xv}}$.

Otra de las problemáticas que se presenta es que hay muchas teorías o afirmaciones que se vuelven incomparables y esto fue algo que el mismo Hilpinen se dio cuenta de ello, tales casos son los siguientes: 1) Imaginemos que $P$ es más cercana a la verdad que $Q$, pero $Q$ es más informativa que $P$; y 2) $Q$ es más cercana a la verdad, pero menos informativa acerca de la verdad que $P$, ¿cómo podemos saber en estos casos cuál de las dos afirmaciones es más verosímil? Hilpinen responde:

Since situations of this type of are possible, any numerical measure of truthlikeness (e.g., based on a numerical distance function defined on $U$ ) must involve some mechanism by which the two main components of truthlikeness can be balanced against each other, for instance, a weighting parameter similar to those employed in some recent theories of acceptance (Hilpinen, 1976, pág. 32).

Sin embargo, no ofreció dicha métrica, por eso es que algunos afirman que no se trata de una propuesta acabada, sino de un esbozo o proyecto de investigación. Por último, Niiniluoto critica lo siguiente:

The fundamental problem about the approach outlined above - we may call it the similarity approach concerns the nature of the similarity relations or the similarity metrics. Does it make sense to speak of overall similarity between possible worlds? Do we understand such a relation better than notions like 'counterfactual' and 'truthlikeness'? What entitles us to assume the existence of the similarity relations and metrics? Is there any objective basis of making them accessible to us? (Niiniluoto, 1979b, pág. 440).

Esta objeción ya la había pensado Lewis en Conterfactuals y tras un análisis decide tomar la noción de similitud de los mundos como un concepto primitivo porque es vago y no claro, pero que sigue siendo entendible (Cfr. Lewis, 1973, págs. 91-95) ${ }^{48}$.

Oddie piensa que en el enfoque de Hilpinen la verosimilitud es un caso especial del problema de la similitud, por lo tanto, se vuelve necesario que también se explique ese concepto, si no hay una definición por parte de Lewis o Hilpinen sobre dicho concepto (si lo toman como primitivo), entonces es casi imposible poner a prueba este enfoque (Cfr. Oddie, 1986, pág. 56).

\subsection{Verosimilitud en marcos proposicionales}

\subsubsection{La propuesta de Miller}

El segundo proyecto que nació desde este enfoque, pero con lógica proposicional, intenta medir la distancia entre dos proposiciones o un conjunto de las mismas, las cuales representan "mundos"

\footnotetext{
48 It may be said that even if possible worlds are tolerable, still the notion of comparative overall similarity of worlds is hopelessly unclear, and so no fit foundation for the clarification of counterfactuals or anything else. I think the objection is wrong. 'Unclear' is unclear: does it mean 'ill-understood' or does it mean 'vague'? Ill-understood notions are bad primitives because an analysis by means of them will be an illunderstood analysis. (It may yet be better than no analysis at all.) But comparative similarity is not ill-understood. It is vague--very vague--in a well-understood way. Therefore, it is just the sort of primitive that we must use to give a correct analysis of something that is itself undeniably vague (Lewis, 1973, pág. 91).
} 
diferentes, como lo vimos al principio del capítulo. Así podremos dar una solución que parece ser más clara e inmediata, una proposición será más verosímil que otra en el caso en que su distancia a toda la verdad sea menor que la de su competidora.

Uno de los primeros autores que desarrolló una definición con estas ideas fue David Miller (aunque aquí no abordaremos a detalle su propuesta) quien utilizó la operación de diferencia simétrica $(\Delta)$ para medir la distancia entre subconjunto de un espacio lógico. Las propiedades que debía satisfacer a función $\Delta$ para llevar a cabo la métrica eran muy débiles, la primera era que la distancia entre $A$ y $B$ es 0 en el caso de $A$ sea idéntico a $B(\Delta(\mathrm{A}, \mathrm{B})=0$ si, y sólo si, $\mathrm{A}=\mathrm{B})$; la segunda, la distancia de $A B$ es la misma que la distancia de $B$ a $(\Delta(\mathrm{A}, \mathrm{B})=\Delta(\mathrm{B}, \mathrm{A})$; y la tercera, ambos lados de un triángulo son al menos tan grandes como un tercero $(\Delta(\mathrm{A}, \mathrm{B})+\Delta(\mathrm{B}, \mathrm{C}) \geq(\Delta(\mathrm{A}, \mathrm{C}))$.

Las condiciones anteriores facilitan construir una medición que las satisfaga, pero difícilmente podrán ser una noción de verosimilitud, por ejemplo M(A,B): 0 si $A$ y $B$ tienen el mismo valor de verdad y 1 si difieren; no es adecuada para definir la verosimilitud porque todas las teorías verdaderas tendrían una distancia 0 , mientras que el de todas las falsas sería 1. Podríamos intentar con una nueva medida, $\mathrm{N}(\mathrm{A}, \mathrm{B})=0$ si $\mathrm{A}=\mathrm{B}, 0.5$ si tienen el mismo valor de verdad, pero $\mathrm{A} \neq \mathrm{B}$; y 1 si tienen diferente valor de verdad. Sin embargo, el resultado no es mejor, ya que sólo la verdad completa tiene una distancia de 0 , mientras que todas las teorías verdaderas serían de $0.5 \mathrm{y}$ las falsas de 1 . Miller realiza varios intentos para evitar este problema, sin embargo, no logra evitar tener resultados desastrosos como aquel en el que es suficiente agregar una proposición a una teoría falsa (sin importar su calidad) para que esté más cercana a la verdad (lo que veíamos como el argumento Child Play) (Cfr. Oddie, Likeness to Truth, 1986, págs. 38-42).

\subsubsection{Verosimilitud y marcos proposicionales}

Oddie considera que una de las maneras más claras por las cuales se debe desechar el enfoque de la probabilidad como verosimilitud es considerando el aspecto de los mundos posibles. Si definiéramos la distancia al mundo actual por medio de la probabilidad lógica, todos los otros mundos no actuales tendrían la misma distancia al mundo actual, ninguno estaría más cercano o alejado, lo cual parece absurdo. Así vemos como la distancia entre mundos, qué tan parecido es un mundo con otro, no puede obtenerse por medio de la probabilidad lógica. Más bien, tiene algo que ver con la forma en que los rasgos se distribuyen a través de los objetos. De igual manera, qué tan cercana está una proposición a la verdad tampoco tiene nada que ver con la probabilidad lógica, sino con los tipos de mundos en los que la proposición es verdadera, y qué tan cercanos estos mundos se encuentran al mundo real.

Si nos remontamos al ejemplo del clima mencionado antes, podemos ver claramente que w2 es más cercano a la verdad que w8, pero esto no tiene nada qué ver con el número total de proposiciones en 
las que ambos mundos estén de acuerdo o no. La cantidad de proposiciones en las que w1 y w2 comparten el mismo valor de verdad es el número de subconjuntos en los que ambos son miembros (2), y el número de falsedades es en el que ambos discrepan (2): "Thus the closeness of W5 to W 1 cannot be captured if the distinction between basic and non-basic propositions is obliterated. The distance between worlds is clearly something to do with the number of basic states they share” (Oddie, 1986, pág. 45).

La manera de obtener una métrica adecuada para la distancia entre mundos es aplicando la diferencia simétrica de Miller no al conjunto de mundos posibles, sino a un conjunto de estados básicos. La diferencia simétrica entre dos mundos es el conjunto de estados básicos sobre los que no están de acuerdo. $U$ es más cercano a $W$ que $V$ si es el caso en el que la diferencia simétrica entre $U$ y $W$ es un conjunto propio de la diferencia simétrica entre $V$ y $W$, es decir, $V$ discrepa en un estado más que entre los que no están de acuerdo $U$ y $W$. En nuestro ejemplo del clima, la diferencia simétrica entre w1 y w8 es de los tres estados, mientras que con w3 es de sólo 1, entonces w3 es más cercano a la verdad que w8.

Pero lo importante no es el ordenamiento de esos casos que se pueden ver como obvios, aunque sí es importante que se respeten, sino los casos complicados que requieren una función para obtener un ordenamiento completo: "The kernel of the likeness approach can be characterized thus: truthlikeness is a function of the closeness of the worlds in the range to the actual world, together with some logical weighting function" (Oddie, Truthlikeness, 2014, pág. 544), para ello, se le asigna a cada estado B un valor, $\mathrm{M}(\mathrm{B})$, y el resultado de la suma de cada uno de esos valores de todos los estados básicos sea 1, el valor de $\mathrm{M}(\mathrm{W})$ de un conjunto de todos los estados $W$ es el resultado de una función que toma en cuenta el valor de cada uno de sus miembros. Por lo tanto, la distancia numérica entre $U$ y $W$ es el valor de su diferencia simétrica $\mathrm{M}(\mathrm{U} \Delta \mathrm{W})$.

Alguien que se adhiera a este enfoque de la noción de la verosimilitud, lo primero que debería de hacer es definir la función que nos dé un ordenamiento plausible de los mundos en un marco simple. Entre más grande sea la diferencia simétrica de un mundo con el mundo actual, será menor su grado de verosimilitud.

Tomemos como base la primera propuesta de Tichý (1974) para ilustrar cómo funciona. Si asignamos el mismo valor a todos los estados básicos, entonces tenemos que la distancia de w1 es 0 , mientras que la de w2, w3 y w5 es 0.33; la de w4, w6 y w7 es 0.67, y w8 es 1. Tichý toma en cuenta lo que se llama como "la distancia media" que se toma desde el mundo real a los mundos que lo contienen. Una vez que tenemos la distancia, la verosimilitud se obtiene restando 1 menos la distancia, por lo tanto, w1 sería de 1 , el segundo grupo de 0.67 , el tercero de 0.33 y el último de 0 . 
Con algunos ejemplos podemos mostrar que este tipo de definición es más adecuada que las que hemos visto anteriormente: $\neg$ h, $\neg \mathrm{r}$ y $\neg \mathrm{w}$ cada una tiene una distancia de 0.67 (el resultado es simple, si sumamos $0.33+0.67+1$ y lo dividimos entre 3), por lo tanto, una verosimilitud de 0.33 . Podemos hacer más fuerte alguna de estar proposiciones adhiriendo otro estado básico más o su negación, si le adherimos una proposición básica verdadera el resultado será de 0.5 , como es el caso de $\neg h^{\wedge} \mathrm{r}$ (es el resultado de $0.33+0.67$ divididos entre 2), pero si se le hubiera adherido una proposición falsa la distancia hubiese sido $0.83(\mathrm{Vs}=0.17)$, por ejemplo $\neg \mathrm{h}^{\wedge} \neg \mathrm{r}(0.67+1$ entre 2$)$. Así también tenemos que $\neg \mathrm{h}^{\wedge} \mathrm{r}^{\wedge} \mathrm{W}$ tienen una distancia de 0.33 (Vs=0.67), la de $\neg \mathrm{h}^{\wedge} \neg \mathrm{r}^{\wedge} \mathrm{W}$ es de 0.67 (Vs=0.33), y la de $\neg \mathrm{h}^{\wedge} \neg \mathrm{r}^{\wedge} \neg \mathrm{W}$ es la máxima distancia de 1 ( Vs=0). Podemos ver que en estos casos la verosimilitud de una proposición es relativamente independiente de su fuerza lógica, aumentar la fuerza de una proposición falsa no necesariamente nos llevará a que sea más verosímil, sino que depende de la calidad de la proposición.

Veamos el caso de la tautología cuya distancia es de 0.5 , hv $\neg$ h $(0+0.33+0.33+0.33+0.67+0.67+0.67+1$ entre 8 o puede ser simplemente $0.33+0.67$ entre 2$)$, mientras que las conjunciones más informativas $\mathrm{h} \& \mathrm{r}$ es de $0.17(0+0.33$ entre 2$)(\mathrm{Vs}=0.83)$, mientras que $\mathrm{h}^{\wedge} \mathrm{r}^{\wedge} \mathrm{W}$ es de $0(\mathrm{Vs}=1){ }^{49}$

Con los casos anteriores podemos ver que fortalecer a una teoría verdadera nos da como resultado una mayor verosimilitud, y ninguna teoría es mejor que toda la verdad completa. Sin embargo, dado la verdad hvr cuya distancia es de $0.39(\mathrm{Vs}=0.61)$, podemos obtener la implicación $\mathrm{hv}\left(\mathrm{r}^{\wedge} \neg \mathrm{W}\right)$ su distancia es de $0.40(\mathrm{Vs}=0.60)$, aquí nos damos cuenta que fortalecer a una teoría verdadera también puede dar como resultado el decrecimiento de la verosimilitud.

Asimismo, se da el caso en el que una proposición falsa puede estar más cerca que una verdadera, tal es el caso de $\neg \mathrm{h}^{\wedge} \mathrm{r}^{\wedge} \mathrm{W}$ que está más cercana a la verdad que la tautología y hvrvw. Una proposición falsa puede estar más cercana a la verdad que su negación $\neg \mathrm{h}^{\wedge} \mathrm{r}^{\wedge} \mathrm{W}$ tiene una distancia de $0.33(\mathrm{Vs}=0.67)$ mientras que su negación es de 0.48 (Vs=0.52). En los casos anteriores podemos observar que en el caso de la verosimilitud no es tan importante cuánto diga una proposición, sino qué dice: "The truthlikeness of a proposition depends on the quality of the guesses it offers, not on the quantity" (Oddie, 1986, pág. 47).

Existen diferentes mediciones dentro de este enfoque para lograr medir la verosimilitud, todas ellas con resultados distintos e interesantes, sin embargo, hay una lista de desideratas consideradas por Niiniluoto (1987, 232-33) que debería cumplir cada una de las mediciones:

\footnotetext{
${ }^{49}$ Podemos observar que en la disyunción se suman los mundos en las que cada una es verdadera por separado y luego se dividen (o por sus valores independientes de inicio), mientras que en la conjunción se toman en cuenta para la suma los mundos en los que ambas son verdaderas.
} 
(I) Rango: la verosimilitud de una proposición será mayor o igual a 0 y menor o igual a 1. (II) Target: Vs(a)= 1 si y sólo si a $=\mathrm{cv}^{50}$, es decir, que solamente puede ser completamente verosímil aquello que describa la verdad completa. (III) No trivialidad: Nos dice que, aunque varias teorías sean verdaderas, no tienen por qué tener el mismo valor de verosimilitud, tampoco las teorías falsas. (IV) Verdad y fuerza lógica: Si $a$ y $b$ son teorías verdaderas, y si $a$ implica a $b$ entonces la verosimilitud de $a$ debe ser mayor o igual que la de $b$. (V) Falsedad y fuerza lógica: Se puede dar el caso en el que $a$ y $b$ sean proposiciones falsas y $a$ implique a $b$, sin embargo, la verosimilitud de $a$ sea menor que la de $b$. (IV) Similitud: si la distancia de un enunciado es mayor, menor o igual que otro, su verosimilitud también será mayor, menor o igual. (VII) Contenido de verdad: Si $a$ es falsa, entonces la verosimilitud del contenido de verdad de $a$ debe ser mayor o igual que la de a por completo. (VIII) Cercanía a la verdad: si tenemos una teoría alejada de la verdad, su verosimilitud aumentara si le añadimos un enunciado que esté más próximo a la verdad que su constituyente más cercano a la verdad. (IX) Distancia a la verdad: Sea la distancia de $L$ menor que la de $I$, entonces la verosimilitud de $L v I$ decrece cuando la distancia aumenta. (X) La falsedad puede ser mejor que la verdad: Algunas afirmaciones falsas pueden ser más verosímiles que algunas afirmaciones verdaderas. (XI) "Delgado es mejor que gordo": Si la distancia de $i$ es igual la de $j$ y ambas son mayores que 0 , además $i$ no es igual a $j$, entonces la verosimilitud de la conjunción de $i \mathrm{v} j$ es menor que la de $i$ por si sola. (XII) "Ovate better than obovate": Si la distancia de $L$ es menor que la de $I$ y a esta a su vez que la de $Z$, entonces la verosimilitud de su conjunción aumenta cuando la distancia de $I$ disminuye. (XIII) Distancia complemento: La verosimilitud de $g$ es mínima, si $g$ consiste en la distancia complemento de la verdad.

Las primeras dos candidatas ya las conocemos, la primera es min(a) que corresponde a la distancia de $A$ que está más cercana al mundo actual. $A$ es verdadera simpliciter si min(a) es igual a cero, y es cercana a ser verdadera si $\min (\mathrm{A})^{51}$ es un número pequeño. Por otro lado, $\max (\mathrm{A})^{52}$ nos indica la distancia más lejana al mundo actual en la que A es verdadera ${ }^{x v i}$. Los problemas saltan rápidamente a la vista, $\min (\mathrm{A})$ no cumple con (II) y (III) ya que muchas todas las proposiciones verdaderas tienen la misma distancia a la verdad, tampoco cumple con $(\mathrm{X})$ ya que ningún enunciado falso será más cercano a la verdad que cualquier verdad, incluso con la tautología. A pesar de que max(A) logra hacer que haya falsedades más cercanas a la verdad (como las tautologías), tiene la problemática de que el mundo completamente opuesto al actual tiene la misma distancia que una tautología.

\footnotetext{
${ }^{50} \mathrm{Cv}$ es el "mundo actual" o "la verdad completa" y $a$ es la proposición de la que estamos midiendo su verosimilitud o la teoría.

${ }^{51} \mathrm{D}_{\min }\left(\mathrm{C}_{\mathrm{k}}, \mathrm{a}\right)=\operatorname{mín}(\mathrm{i} \in \mathrm{I}(\mathrm{A}))\left[\mathrm{d}\left(\mathrm{c}_{\mathrm{k}}, \mathrm{c}_{\mathrm{i}}\right)\right]$

${ }^{52} \mathrm{D}_{\max }\left(\mathrm{C}_{\mathrm{k}}, \mathrm{a}\right)=\operatorname{máx}(\mathrm{i} \in \mathrm{I}(\mathrm{A}))\left[\mathrm{d}\left(\mathrm{c}_{\mathrm{k}}, \mathrm{c}_{\mathrm{i}}\right)\right]$
} 
Una posible salida es combinar $\max (\mathrm{A})$ con $\min (\mathrm{B})^{53}$ mediante la suma de ambas y dividirlas entre $\operatorname{dos}^{\mathrm{x} v i i}$ donde se soluciona el problema de que todas las oraciones verdaderas tengan la misma distancia y al menos algunas falsedades son más cercanas a la verdad que otras verdades, el problema aquí es que pone en el mismo nivel a $h$ y $h v r$ con lo cual se viola el principio de contenido de verdades.

La siguiente opción es la función promedio (average) ${ }^{54}$ que consiste en sumar la distancia de todos los mundos en los cuales la proposición es verdadera y luego dividirlos por la cantidad de mundos en las que aparece, es decir, lo que vimos anteriormente con Tichý y sus resultados interesantes. Sin embargo, no respeta (IV) porque hay casos donde entre dos proposiciones verdaderas la más fuerte está más alejada de la verdad; incluso hay afirmaciones verdaderas que están a la misma distancia que la tautología, por lo tanto, la medida promedio viola el principio del valor del contenido de las verdades ${ }^{\mathrm{xviii}}$.

Quizá alguien en lugar de sacar el promedio le gustaría defender una distancia que sume ${ }^{55}$ todos los mundos en los que una proposición sea verdadera (aunque en realidad no ha sido defendido por nadie $)^{\mathrm{xix}}$. Aunque visiblemente no cumple con (I) siempre sería posible dar un criterio de normalización para evitar que esto suceda, sin embargo, tiene errores más graves. Sumar logra que los enunciados verdaderos débiles estén más alejados de la verdad que otros verdaderos más fuertes, lo mismo sucede si las comparamos con algunas falsedades que sean más audaces y que tenga contenido de verdad. En la tabla podemos observar que no se logra (VII) dado que el contenido de verdad de un enunciado falso no necesariamente está más cercano a la verdad que el enunciado en sí. Pero el error más desastroso es con (V) porque en los enunciados falsos la verosimilitud co-varía con la fuerza lógica, un enunciado es más cercano a la verdad entre más fuerte sea, sin importar si todos sus enunciados sean falsos (véase $\neg$ h y $\left.\neg \mathrm{h}^{\wedge} \neg \mathrm{r}^{\wedge} \neg \mathrm{w}\right)$.

Por último, tenemos la propuesta de medición de Niiniluoto que es una combinación entre mínimo, suma y promedio, se le denomina como la función min-sum-prom (min-sum-average) ${ }^{56}$, la cual obviamente cumple con todos los requisitos que él mismo propuso ${ }^{\mathrm{xx}}$ (pareciera que no cumple (I) por la tabla, sin embargo, incluye un valor $\gamma$ que permite que todo esté entre los rangos entre 0 y 1 , pero para nosotros es suficiente con lo mostrado). Con ello se ha logrado que $\mathrm{h}^{\wedge} \mathrm{r}^{\wedge} \mathrm{W}$ sea más verosímiles que $\mathrm{h}^{\wedge} \mathrm{r}$, lo mismo sucede con el segundo y h, así se respeta el valor del contenido de verdad. Recordemos que para cualquier verdad min es siempre 0 , y el factor suma aumenta a medida que disminuye el contenido.

\footnotetext{
${ }^{53} \mathrm{D}_{\mathrm{mm}}\left(\mathrm{C}_{\mathrm{k}}, \mathrm{a}\right)=1 / 2\left[\mathrm{D}_{\min }\left(\mathrm{c}_{\mathrm{k}}, \mathrm{a}\right)\right]+\left[\mathrm{D}_{\max }\left(\mathrm{c}_{\mathrm{k}}, \mathrm{a}\right)\right]$

${ }^{54} \mathrm{D}_{\mathrm{av}}\left(\mathrm{C}_{\mathrm{k}}, \mathrm{a}\right)=\left[\Sigma(\mathrm{i} \in \mathrm{I}(\mathrm{A}))\left[\mathrm{d}\left(\mathrm{c}_{\mathrm{k}}, \mathrm{c}_{\mathrm{i}}\right)\right] /|(\mathrm{A})|\right.$

${ }^{55} \mathrm{D}_{\text {sum }}\left(\mathrm{C}_{\mathrm{k}}, \mathrm{a}\right)=\sum(\mathrm{i} \in \mathrm{I}(\mathrm{A}))\left[\mathrm{d}\left(\mathrm{c}_{\mathrm{k}}, \mathrm{c}_{\mathrm{i}}\right)\right.$

${ }^{56} D_{\text {nms }}\left(C_{k}, a\right)=\gamma D_{\min }\left(c_{k}, a\right)+\gamma$ ' $D_{\text {nsum }}\left(C_{k}, a\right)$, donde $D_{\text {nsum }}\left(C_{k}, a\right)=\left[\Sigma(i \in I(A))\left[d\left(c_{k}, c_{i}\right)\right] /\left[\left[\Sigma(i \in I)\left[d\left(c_{k}, c_{i}\right)\right] D_{n s u m}\left(C_{k}, a\right)=[\Sigma\right.\right.\right.$ $(\mathrm{i} \in \mathrm{I}(\mathrm{A}))\left[\mathrm{d}\left(\mathrm{c}_{\mathrm{k}}, \mathrm{c}_{\mathrm{i}}\right)\right] /\left[\left[\Sigma(\mathrm{i} \in \mathrm{I})\left[\mathrm{d}\left(\mathrm{c}_{\mathrm{k}}, \mathrm{c}_{\mathrm{i}}\right)\right]\right.\right.$ y $\gamma \gamma^{\prime}$ son valores elegidos de tal manera de que la función total varíe entre 0 y 1 (Cfr. Zamora Bonilla, 1996, págs. 19-22).
} 
Esta medida tampoco tiene problemas en obtener que $\neg \mathrm{h}^{\wedge} \neg \mathrm{r}^{\wedge} \neg \mathrm{W}$ esté más alejado de la verdad que $\neg \mathrm{h}$, pero su error es que $\neg \mathrm{h}^{\wedge} \neg \mathrm{r}$ sí es más cercana a la verdad, esto se debe a que $\neg \mathrm{h}^{\wedge} \neg \mathrm{r}^{\wedge} \neg \mathrm{w}$ pierde su cercanía con el mundo actual mediante el factor min, pero se aumenta con su fuerza con el factor sum.

Elegir entre una métrica u otra se vuelve una cuestión metodológica en diferentes intentos de argumentar cuál de ellas es la adecuada; algunos podrían decir que promedio lo es, puesto que se acerca más a nuestras intuiciones, mientras que otros se decantarían por la de Niiniluoto porque cumple de mejor manera con los requisitos que él mismo ha estipulado; aunque contra él juega la idea que al parecer ya está "creando" un nuevo concepto en lugar de intentar explicar uno ya existente.

\subsection{Problemáticas del enfoque}

Anteriormente vimos que existen diferentes medidas dentro de este enfoque, cada una de ellas presenta dificultades ante los requisitos planteados por Niiniluoto, aunque esos errores atacan sólo a una propuesta en particular, alguien podría decir que después se daría con una métrica que pudiera cumplirlos todos. Sin embargo, hay dos argumentos que van contra el enfoque de los marcos de mundos posibles de manera proposicional.

El primero de ellos es el que plantea Aronson en 1990 y retoma Psillos en 1999, quienes notan que al adherir nuevos estados básicos o descripciones al mundo la distancia (y la verosimilitud) se vuelve estática y problemática (en otras palabras, inútil). Por ejemplo, tomando en cuenta la función promedio, en nuestro marco de tres estados la verosimilitud de h es de 0.67 (distancia de 0.33), si agregamos un nuevo estado, por ejemplo, nublado (c), su verosimilitud decrece a 0.625 ; y con otro más llega a 0.6. Con el enunciado falso $\neg$ h podemos observar que la verosimilitud aumenta al incluir nuevos estados, recordemos que de manera inicial tiene una verosimilitud de 0.33 , con un cuarto estado sería de $0.375 \mathrm{y}$ con el quinto será de 0.4. Estos resultados no tendrían por qué ser tan preocupantes, podemos decir que es un resultado que se esperaba si se le adhieren estados al marco, dado que $h$ cada vez es menos informativa y el error de $\neg$ se va haciendo menor.

Lo realmente problemático en este caso es que se llegará a un momento en el que dada la cantidad de estados en el marco $h$ y $\neg h$ tendrán el mismo grado de verosimilitud: 0.5 , y ya no importará si se le agregan hasta el infinito, esa cantidad se quedará congelada, ahora tendremos que una proposición verdadera tendrá la misma verosimilitud que su negación, y dado que su valor se mantendrá estático sin importar lo que $h$ diga o $\neg h$ niega, incluso ambas tendrán la misma verosimilitud que una tautología ${ }^{57}$.

\footnotetext{
${ }^{57}$ Aronson (1990) and Psillos (1999) argue that the combination of symmetric difference and overall-average violates this desideratum, because the degree of truthlikeness of a proposition depends on the number of other basic states generating the space in which it is framed. Where $n$ is the number of basic states, the truthlikeness of a true atomic proposition is $(n 11) / 2 n$ and the truthlikeness of a false atomic proposition is $(n 21) / 2 n$. So, in our little weather frame, $h$ has truthlikeness $2 / 3$ and $\sim h$ has truthlikeness 1/3. Embedded in a frame of ten basic states, however, $h$ drops to $11 / 20$ and $\sim h$ rises to $9 / 20$. Both approach
} 
Psillos considera que la dependencia de la verosimilitud en función con el número de estados es desagradable, ya que sólo sería aceptable si tiene una relación con los ya existentes (que sea relevante), porque en caso de que el estado adherido sea irrelevante ("una mariposa volaba bajo la lluvia), esto no debería afectar a la verosimilitud de las afirmaciones que describen hechos causalmente independientes. Las afirmaciones con dos conyuntos, uno negado y el otro afirmado (como $\neg \mathrm{h}^{\wedge} \mathrm{r} \mathrm{o} \mathrm{h}^{\wedge} \neg \mathrm{r}$ ), mantienen siempre la misma verosimilitud (0.5) sin importar el número de estados del marco; el único caso en el que agregar nuevos estados aumenta a la verosimilitud es cuando las proposiciones tienen dos estados negados.

Psillos menciona una posible respuesta que ha dado Niiniluoto a este problema mediante una comunicación privada (p. 260). Considera que la crítica falla el objetivo porque las medidas de verosimilitud son "contextuales"; las mediciones se dan en relación con un objetivo específico en conexión con alguna información, y es de esperar que si la información cambia (varíe el número de estados), lo misma suceda con el grado de verosimilitud de una proposición:

Suppose, for instance, that you are asked to tell the colour of Professor Niiniluoto's eyes, and that you have a theory h which says (correctly) that they are blue. But now suppose you give the same answer in the context of a question that concerns the colour of his eyes, hair and skin. In this context, the answer $h$ is less verisimilar than it was in the context of the previous question, because it gives much less information about the relevant truth (Psillos, 1999, págs. 159-260).

Psillos considera que es una buena respuesta, pero que los grados de verosimilitud dependan o sean relativos al contexto puede incomodar al realista. Además, considera como inadecuada a dicha respuesta porque cuando la información tiende a ser máxima (cuando la aproximación a la verdad se juzga con respecto a un problema cognitivo que implique un gran número de estados básicos) el grado de verosimilitud tanto de $h$ como de $\neg h$ se congelará en 0.5 sin importar qué es lo que cada una de ellas esté diciendo.

Esto nos da como resultado que entre más compleja sea la información, entonces será más difícil discriminar entre una afirmación o su negación en cuanto a su distancia a la verdad. En una investigación real (como las que llevan a cabo los científicos) es muy común que el número de estados básicos sea muy grande; por lo tanto, si uno se basa en el enfoque de los mundos posibles, se volvería imposible elegir

the truthlikeness of a tautology (1/2) as $n$ increases. Niiniluoto notes that truthlikeness should be dependent on the context of the cognitive problem at issue, since the target proposition (the truth) may change. As the truth is enlarged, the proportion of the truth that $h$ captures shrinks. While that response is certainly cogent, another is also possible. The invariance at issue is an artifact of normalization, and can be simply eliminated. Take the closeness of two worlds to be given by the number of agreements on basic states minus the number disagreements. Then, taking truthlikeness to be given by the average closeness of worlds, this yields the same ordering as the normalized measure, while absolute closeness of a proposition to the truth is independent of the number of atomic states. For example, the truthlikeness of any conjunction of $t$ true and $f$ false atomic propositions is simply $\left(t^{\wedge} f\right)$, whatever $n$ is (Oddie, 2014, págs. 547-548). 
cualquiera de las dos opciones $(h$ o $\neg h)$ tomando en cuenta a su verosimilitud: "So, I conclude that the possible worlds approach fails to offer a cogent formal account of truth-likeness" (pág. 160) ${ }^{58}$.

Pasando al segundo argumento, debemos explicar uno de las desideratas para las teorías de la verosimilitud, este es que debe ser invariante bajo la equivalencia del lenguaje, es decir, que su grado de aproximación a la verdad no dependa (ni varíe) del lenguaje con el que se exprese la oración: “This is akin to the condition which could be called invariance under logical equivalence: a definition oftruthlikeness should give the same results for any two logically equivalent theories within one and the same language”. La verosimilitud de un enunciado depende de qué se dice y no en cómo se dice, por lo tanto, dos enunciados lógicamente equivalentes son solamente dos maneras distintas de expresar la misma proposición y, por lo tanto, deberían tener la misma distancia hacia la verdad.

Miller desarrolló un argumento en 1974 que, de estar en lo correcto, sería devastador para la noción de verosimilitud, cuando menos dentro de este enfoque, en él demuestra que una teoría (A) completamente falsa como $\neg \mathrm{h}^{\wedge} \neg \mathrm{r}^{\wedge} \neg \mathrm{W}$ que era considerada como la más alejada de la verdad en nuestro ejemplo, puede tener una distancia menor que una teoría rival si utilizamos otro lenguaje lógicamente equivalente, en este caso que la teoría (B) $\neg \mathrm{h}^{\wedge} \mathrm{r}^{\wedge} \mathrm{W}$ :

Consider another rudimentary weather language, trivially intertranslatable with L. This language also has three atomic sentences. One is $h$ ('It is hot'). Another is $m$ ('It is Minnesotan'); the third is $a$ ('It is Arizonan'). The weather in Minnesota, we may suppose, is either hot and wet or cold and dry. Thus, $m$ is equivalent to $h \leftrightarrow r$. Arizonan weather, on the other hand, is either hot and windy or cold and still. Thus, $a$ is equivalent to $h \leftrightarrow w$. The three sentences $h, m, a$ are logically independent of one another; and the eight constituents that can be formed from the three generators $h, m, a$ are just the eight constituents that can be formed from $h, r, w$. Moreover, $r$ is equivalent to $h \leftrightarrow m$, and $w$ is equivalent to $h \leftrightarrow a$. There is perfect symmetry. And there seems no good reason-beyond sheer prejudice for treating the $h-r$ - $w$ language as more fundamental than the $h-m-a$ one ${ }^{\mathrm{xxi}}$ (Miller, 1974a, pág. 176).

Si tenemos el caso de dos personas, el primero sostiene la teoría $\neg \mathrm{h}^{\wedge} \mathrm{r}^{\wedge} \mathrm{W}$ (B), mientras que el segundo dice que el mundo es $\neg \mathrm{h}^{\wedge} \neg \mathrm{r}^{\wedge} \neg \mathrm{W}$ (A), si retomamos las tablas anteriormente vistas, podríamos afirmar que la primera (B) está más aproximado a la verdad que la segunda (A). Sin embargo, al hacer el cambio de lenguaje mediante la equivalencia, B estaría sosteniendo que el mundo es $\neg \mathrm{h}^{\wedge} \neg \mathrm{m}^{\wedge} \neg \mathrm{a}, \mathrm{y}$ A $\neg \mathrm{h}^{\wedge} \mathrm{m}^{\wedge} \mathrm{a}$; ahora el (A) estaría más aproximado a la verdad que (B). Podemos darnos cuenta que es difícil saber entonces cuál teoría está más cercana a la verdad puesto que cambia su distancia según sea el lenguaje en el cual esté articulada.

Pero de lo que podemos estar seguros es que ambas "teorías verdaderas" $\left(\mathrm{h}^{\wedge} \mathrm{r}^{\wedge} \mathrm{w}\right.$ y $\left.\mathrm{h}^{\wedge} \mathrm{m}^{\wedge} \mathrm{a}\right)$ son equivalentes porque tienen una extensión definicional en común:

\footnotetext{
${ }^{58}$ Una posible réplica a dicho argumento que podríamos hacer es que los científicos no eligen entre un estado por sí sólo como menciona el ejemplo, sino un conjunto bastante amplio de los mismos.
} 
Verisimilitude, like truth, will always, if defined, be defined relative to a language. But just as truth is language-independent (this is one of the things that Tarski's T-schema insists on), so must judgments of verisimilitude be, if they are to have any objective significance at all (ídem).

Con este resultado, Miller piensa que la definición de verosimilitud de Tichý (que era la única existente en el marco de mundos posibles en ese momento, pero esta objeción termina afectando a todas las medidas de distancia dentro de ese enfoque) no podía ser aceptada y si se deseaba dar una teoría apropiada de la verosimilitud era necesario que estuviera libre de este defecto. El resultado era, entonces, devastador.

En resumidas cuentas, la dependencia del lenguaje muestra que, dada la descripción de la verdad en dos lenguajes lógicamente equivalentes, las teorías pueden variar su grado de verosimilitud porque ahora parecen decir "diferentes cosas sobre el mundo", y para Miller, no existe manera con la cual podamos preferir una descripción del mundo actual por sobre la otra.

Ante este problema, uno puede tomar tres posibles salidas: (i) Rendirse en cuanto a la posibilidad de dar una noción de verosimilitud y abandonarla como una opción de progreso objetivo; (ii) Aceptar que la verosimilitud depende del lenguaje y dar paso con ello al subjetivismo; o (iii) "Any rebuttal of the Miller argument, whatever its semantic presuppositions, must grant certain properties, magnitudes, or constants, a privileged status" (Oddie, pág. 159), con ello, mostrar que el cambio de lenguaje que realiza Miller es demasiado artificial y parasitario del original como para tomarlo en cuenta (o no captura la esencia del mundo).

El defensor del marco proposicional intentará decir que la representación con Minnesota y Arizona está manipulada engañosamente (gerrymandared) ya que se obtienen mediante la referencia a dos estados diferentes, pero al igual que con el problema del verdul de Goodman, esta situación es simétrica, dado que, si tomamos a Minnesota y a Arizona como básicos, podemos definir a $r$ y $w$ como lo vimos anteriormente.

A pesar de lo anterior, alguien podría seguir defendiendo que $r$ es una condición más natural que Minnesota, por lo que no es totalmente simétrico, pues $r$ (lluvioso) "está más atrincherada en la realidad". También puede decir que una propiedad verdadera es apropiadamente primitiva cuando: es una condición necesaria que se puede determinar de manera a priori que es más genuina o a posteriori por medio de las ciencias maduras (y no solamente de forma lógica): "Either way, some conditions are more fundamental, more basic, than others, and it is the basic properties and relations, not gerrymandered conditions, which determine relations of similarity between worlds" (Hilpinen, 1976, pág. 548)

Esta forma de responder nos lleva a lo que Miller denomina como una falacia del esencialismo:

I think that there is not, and that any attempt to show some parameters to be more important, more significant, more fundamental, or whatever, than others are a symptom of an outmoded - and fallacious - 
way of thought: is sentialism. It is a way of thinking that takes words, rather than theories, far too seriously. Moreover, it takes things, rather than states of affairs, far too seriously too, especially things which it regards as, for some reason or another, unchanging, or anyway reasonably stable. Thus, essentialists will typically hold that some versions of a scientific theory are more fundamental - and even more like the truth - than other equivalent versions. This makes no sense at all from the critical or falsificationist standpoint, according to which a theory is the set of its consequences, however expressed (Miller, 1975, pág. 184).

Lo que podría hacer aquí el defensor de este enfoque es afirmar que es cierto que existirán algunas características "esenciales", pero no constituye una falacia, dado que para que tenga sentido una afirmación de semejanza debió tomarse en cuenta que unas propiedades están tomando un papel de mayor importancia que las demás: "Since truthlikeness is a species of likeness, it is not at all surprising that an account of truthlikeness should require a set of privileged properties” (Oddie, 1986, pág. 164).

Oddie ofrece un interesante ejemplo acerca de unos gemelos (1986, 162-165), no se escribirá en esta tesis; pero haremos uso de uno similar (aunque el de Oddie es mucho mejor y detallado): tomemos que X y Y son gemelos, la mayoría de las personas afirman que no pueden distinguirlos entre ellos porque son idénticos, mientras su madre lo hace con facilidad y arguye que son muy diferentes, ¿cómo sucede esto? Es gracias a que ambos toman un conjunto de características para la similitud en estos casos (la madre toma en cuenta aquellos aspectos que los diferencian, mientras que las demás personas aquellos que comparten).

Ahora, decir que la madre o las otras personas realizan una afirmación más verosímil que los otros, dependerá de los aspectos de similitud que se tomen en cuenta, pero atreverse a expresar que una de las dos formas es más esencial que la otra caerá en lo que Forster (2004) denomina como el argumento del chauvinismo cultural, además:

The incontestable fact that objects similar with respect to one property may be dissimilar with respect to logically independent properties - people of like age may be unlike in hair colour, height, wealth, and so on - cannot provide any encouragement for the fiction that similarity with respect to some properties is compatible with dissimilarity with respect to properties with which they are interdefinable (Miller, 2006, pág. 231).

Regresando al ejemplo del clima. Supongamos que en otro planeta existe un grupo de aliens que viven en un lugar donde crecen dos tipos de maíz: maíz Minnesota y maíz Arizona, el primero crece en las partes bajas y el segundo en las más altas. Sus decisiones diarias no giran alrededor de vestir ropas cálidas, utilizar un paraguas o un rompe-vientos, sino que necesitan cuidar su maíz Minnesota o Arizona, sin perder el tiempo bajando o subiendo del lugar de manera innecesaria. Tienen que atender al maíz Minnesota si, y sólo si, el clima es Minnesota, mientras que lo harán con el maíz Arizona si, y si sólo, si es Arizona el clima:

Should we say that their science is not progressive? Why should we deny that their achievement is genuine and objective simply because the questions that concerned them happen not to be about the "true objective essences" of the world? Wouldn't that be an unsavory kind of cultural chauvinism? Why should scientific 
progress depend on the "true essences" of the world (assuming that essentialism is not an outmoded doctrine) if essences make no difference to the success of the theory (Forster, 2004, pág. 9).

El argumento no asume que los hechos acerca de las esencias no puedan hacer una diferencia en la verdad y la verosimilitud o entre las teorías. Si una teoría científica hizo una afirmación explícita sobre qué propiedades son fundamentales, y estaba equivocada, entonces debería recibir una puntuación negativa para esa consecuencia falsa. Eso no se discute. La pregunta es si las puntuaciones de la verosimilitud deberían depender de los hechos sobre el mundo de los cuales las teorías rivales no dicen nada. Tal es el caso del clima en las teorías A y B. Ellas no hacen afirmaciones acerca de cuál conjunto de predicados es el primitivo. Es por ello que las teorías pueden ser traducidas de un idioma a otro, y viceversa.

Forster afirma que, aunque pareciera que este argumento apoya al subjetivismo como en la estrategia (ii), ese no es el objetivo, sino lo contrario. Para evitar el argumento del chauvinismo cultural, cada cultura debería reconocer los logros científicos de la otra: "The conclusion recommended in response (2) is that relative to the standard language, the other scientific community in our story have not progressed. They, in turn, say the same about our weather science” (2004, pág. 10). Esto dará como resultado un fracaso en la comunicación porque la manera de ordenar la verosimilitud no se conservará cuando las teorías se traduzcan en el otro idioma, por ello es posible que se objete la existencia del subjetivismo.

Forster también analiza una posible cuarta solución (iv) a la objeción de Miller (que fue planteada por primera vez por Zwart en 1998) en la cual se afirma que no deberíamos esperar que las relaciones de la verosimilitud entre una teoría y la verdad pueda ser medida con una sola escala numérica ya que los aspectos de la verosimilitud son relativos a un conjuntos de preguntas particulares y existe alguna fórmula para medir la importancia relativa de esas preguntas: "There is a truthlikeness relation, but it is not one dimensional as solution (3) assumes" (ídem) $)^{59}$.

Pero aquí se debe tener cuidado con no dar un paso hacia el relativismo, sino que una teoría con un alto grado de verosimilitud en un conjunto de preguntas, también debería tener una puntación alta en otro conjunto que fuera similar: "What counts as 'relevantly similar' depends on the theory under consideration, and what is true. When there is a correlation, it needs explaining, but only to the extent that it is true" (pág. 11).

Las teorías A y B tienen cuando menos dos puntuaciones, una con el conjunto 1: ¿¿está caluroso?, ¿llueve? o ¿hace viento?" y otro con el conjunto 2: "¿hace calor?, ¿hace Arizona? o ¿hace Minnesota?"

${ }^{59}$ Tal como sucedió con la inteligencia que en un principio se creía que con sólo un instrumento de medición era suficiente en el caso del IQ, pero después fue necesario desarrollar otros mecanismos por los distintos tipos de inteligencia. 
ambos cuentan, aunque en este ejemplo sucede algo inusual: sus ordenamientos son opuestos en cada conjunto. Sin embargo, ambos ordenamientos de verosimilitud son medidas equivalentes objetivas de progreso, aunque midan diferentes tipos o aspectos del progreso. Así, si existe una cultura cuyo objetivo de la ciencia fuese predecir el clima como lo necesitan los alienígenas, pasar de la teoría B a A es progresivo a través de una dimensión de verosimilitud y degenerativo en otra.

Según esta solución, no existe una contradicción entre las dos afirmaciones de verosimilitud, y no hay un problema de variancia de lenguaje: "Nor is there any appeal to any privileged ontological status of one language over another" (ídem).

Consideremos una teoría $\varphi$ arbitraria y una pregunta acerca de si $x$ es verdadera y queremos demostrar que al traducir de un idioma a otro a la pregunta y a la teoría la puntuación de verosimilitud de $\varphi$ en $x$ no cambia, $\varphi$ implica a $x$ o no. Cuando traducimos ambos $\varphi$ y $x$ a $\varphi^{\prime}$ y $x^{\prime}$, entonces debería mantener el mismo grado de verosimilitud. El valor de verdad de $x$ y $x^{\prime}$ debería ser el mismo porque son lógicamente equivalentes, por lo tanto, las puntuaciones de $\varphi$ y $\varphi^{\prime}$ deberían ser los mismo dado que los puntajes se determinan en función de si $\varphi$ implica $x$, y $\varphi^{\prime}$ implica $x^{\prime}$. Si las puntuaciones de todas las preguntas en un conjunto de idiomas son invariantes, por lo tanto, las puntuaciones totales son invariantes, dado que se ponderan de la misma manera. Así vemos que esta solución (iv) no cae en el subjetivismo (ii).

Así pues, la existencia de diferentes lenguajes sería irrelevante para la verosimilitud. Podría darse el caso en el que una comunidad científica diferente a la nuestra utilizara el mismo lenguaje sobre el clima para responder diferentes preguntas, como predecir si es $\mathrm{h}^{\wedge} \mathrm{r} \mathrm{o} \neg \mathrm{h}^{\wedge} \neg \mathrm{r}$. Vemos que aquí no se introducen nuevos predicados de tiempo climático, el progreso se tomaría de la misma manera: aceptar a la teoría B en lugar de la A sería progresar hacia la verdad con respecto a la pregunta que se está investigando. Y esto es un hecho objetivo.

La propuesta de Zwart no se reduce a la propuesta de Oddie (iii) porque no se está afirmando que exista una serie de preguntas como privilegiadas de acuerdo con "la forma en la que el mundo es".

Se puede objetar a esta solución que con ello es imposible dar una noción objetiva del progreso científico, porque para cada conjunto de preguntas en las que A está más cerca de la verdad que B, puede haber otra serie de preguntas donde suceda lo contrario. Zwart podría decir que esa posibilidad de la segunda serie de preguntas no socava la afirmación de que hay un progreso objetivo con respecto a la primera serie de preguntas. Las comunidades científicas sólo pueden estar preocupadas de ciertos aspectos de la verosimilitud. Su enfoque puede ser motivado de manera pragmática, pero el grado de 
verosimilitud que produce los esfuerzos científicos no están determinada por ellos porque dependen de lo que es verdadero. ${ }^{60}$

Miller le responde a Forster y a Zwart en el año 2006 en un capítulo denominado "Thirty Years of Language Dependence" de su libro Out of Errors, donde realiza una revisión de los diferentes contraargumentos que se han hecho contra la dependencia del lenguaje y presenta sus formas de refutarlos.

A Forster y Zwart podría acusárseles de lo mismo que a Oddie en cuanto a decir que es un hecho que la similitud de los objetos se toma respecto a ciertas propiedades, mientras que su diferencia se hace respecto a otras, y que esto es lógicamente independiente; pero no pueden con ello responder al caso planteado de que la similitud de una teoría es diferente en los casos cuando las propiedades son interdefinibles:

In the present discussion the matter is made a little more complicated, but not essentially changed, by the fact that in all the examples a pair of logically independent properties are considered together, and set at odds with a pair of other properties, also mutually independent, with which as a pair (but not individually) they are interdefinable (Miller, 2006, pág. 231).

Los ejemplos de las diferencias genéticas y fenotípicas de Zwart (2001) y de los diferentes tipos de inteligencia de Forster (2004) pueden ser claramente distintos objetivos cognitivos que requieren teorías que se aproximan de manera diferente a la verdad si se aplican en ambos casos, aunque puedan ser extensionalmente equivalentes, su vocabulario no es explícitamente interdefinible de un vocabulario original, por lo tanto, no están respondiendo al planteamiento de Miller.

Dado lo anterior, Miller afirma:

The poverty of what Oddie likes to call the 'likeness program for truthlikeness' cannot any longer be disguised. The project to distil comparisons and even measures of truthlikeness from syntactic structure must be abandoned, despite there not being a great deal to put in its place (2006, págs. 231-232).

Sin embargo, esto no quiere decir que el proyecto de dar una noción clara de la verosimilitud deba ser abandonado o sea imposible, simplemente que se debe de hacer de diferente manera, considera que hay propuestas que no son afectadas por ningún tipo de dependencia del lenguaje (como la de él mismo).

Miller dice que se debe tener cuidado de no caer en el subjetivismo o el relativismo. Es necesario que quede en claro que la similitud no debería depender de los intereses, dado que dos elementos pueden ser similares en un aspecto y diferentes en otro que es lógicamente independiente. Continúa subyaciendo el problema de cómo los diferentes aspectos deben ser evaluados o agregados, y cómo la similitud global se mide de manera objetiva. Los casos particulares de la similitud quedan bastante claros y podrían verse

${ }^{60}$ Forster considera que (iv) es la mejor solución al problema de Miller. La alternativa es tener en cuenta las hipótesis probabilísitcas. Es comprensible que los popperianos no han sido rápidos en explorar esta posibilidad porque hipótesis probabilísticas no son falsables en ningún sentido estrictamente lógico, a pesar de que alguna noción generalizada de la falsación podría aplicarse. 
como objetivos, la problemática es cuando se pasa a buscar una manera en que la similitud de manera global pueda ser evaluada:

I suggest that, despite what may seem obvious, overall similarity or superiority cannot coherently be understood as an objective aggregate of more specialized similarities and agreements. It is a holistic property, like beauty perhaps. What makes an object or a person beautiful is as much concerned with proportion and balance as it is concerned with beautiful features (pág. 233).

Comparte la opinión de Lewis de que los juicios de verosimilitud o de aproximación a la verdad son vagos, pero eso no quiere decir que no sean objetivos, aunque en otros casos la vaguedad sirve para apoyar a la subjetividad. La vaguedad es una consecuencia de la ignorancia sobre lo que es el caso objetivamente, entonces es necesario esforzarnos para aprender más y eliminarla. El problema en el caso de la verosimilitud es que el grado de vaguedad es lo suficientemente alto como para que nuestros juicios sean incomprobables; y dado que la capacidad de probar es una de nuestras desideratas originales, debemos reconocer que hasta el momento sólo es posible obtener una teoría fragmentaria de la verosimilitud o de la aproximación a la verdad.

\section{Enfoques no formalizados de la verosimilitud}

Después de mostrar los fracasos de diversos intentos por formalizar la noción de verosimilitud, ya sea porque no cumplen los requisitos planteados como el de poder comparar dos teorías falsas o verdaderas con diferentes grados de aproximación a la verdad de manera satisfactoria o porque sucumben ante argumentos como el de la dependencia del lenguaje (incluido el argumento del chauvinismo cultural), entonces debemos buscar cuáles son las mejores alternativas para solucionar este problema.

A continuación, se expondrán tres propuestas acerca de la verdad aproximada, las cuales no se encuentran formalizadas, de alguna manera podemos llamarlas "intuitivas", pero que pueden presentar una respuesta clara a nuestro problema y ser útiles para el realista científico defensor de la aproximación a la verdad como objetivo y logro de la ciencia, no obstante, también se mostrarán los contraargumentos con los que se enfrentan.

\subsection{Verosimilitud en el realismo constructivista de Ronald Giere}

Ronald N. Giere es uno de los filósofos que ha presentado un cambio de visión en cuanto a lo que debería revisarse en el aspecto de la verosimilitud. Para él este concepto de "verdad aproximada" no es un tipo de verdad, al contrario, lo considera como una especie de falsedad, es decir, cuando mencionamos “aproximadamente verdadero", lo que en realidad se expresa es que: "no es exactamente así", por lo tanto, es (estrictamente) falso. A pesar del fracaso de los filósofos para construir una noción de aproximación a la verdad de manera formalizada no quiere decir que debamos renunciar a la idea de “aproximación” como un aspecto fundamental en la práctica científica. El problema, para Giere, es que estamos enfocando mal en lo que debemos medir como aproximado, para él no es precisamente la verdad. 
Giere considera que, curiosamente, quien ha estado más cerca de la correcta medición ha sido un anti-realista: Bas van Fraassen $(1980,12)^{61}$; quien sostiene que para que una hipótesis sea aproximadamente correcta debe ser en función de una familia de modelos, y uno de los cuales debe ser exactamente correcto, es decir, que sea isomorfo con el sistema real previsto. Sin embargo, Giere encuentra esta definición demasiado restrictiva:

Whatever approximation means in science, it must be true that the dynamical models of classical mechanics are approximately correct for many real systems. Yet if it is agreed that the world is really Einsteinian rather than Newtonian, no dynamical Newtonian model is exactly correct for any real system $(1988$, p. 106).

La sugerencia de Giere, es que se debe comprender la aproximación como una noción de similitud entre los modelos y los sistemas reales. Con ello se elimina "the bastard semantic relationship of approximate truth" (ídem), además muestra (lo que era ocultado por la verdad aproximada) que la aproximación se da cuando menos en dos dimensiones: aproximación en aspectos y aproximación en grados. Esto debe ser entendido como parte de su proyecto de liberar a la Filosofía de la Ciencia de las preguntas de Filosofía del Lenguaje ${ }^{62}$, considera que debemos abandonar el enfoque de ver a las teorías de una manera proposicional (legado del empirismo lógico) y es mejor enfocarnos en la visión semántica de las teorías que construye a las teorías como un conjunto de modelos. De acuerdo con Giere, los modelos son dispositivos de representaciones no lingüísticos que sirven para satisfacer ciertas definiciones teóricas, generalmente son un conjunto de ecuaciones matemáticas.

Para él existe una relación entre los modelos teóricos y el mundo físico, es decir, los primeros intentan ser una réplica fiel de los sistemas reales en ciertos aspectos relevantes (no son una copia exacta). De ahí que el filósofo norteamericano sugiera se puede hacer en aspectos específicos y en determinados grados:

I propose we take theoretical hypotheses to have the following general form:

The designated real system is similar to the proposed model in specified respects and to specified degrees. We might claim, for example, that all quantities in our spring and weight system remained within ten percent of the ideal values for the first minute of operation. The restriction to specified respects and degrees insures that our claims of similarity are not vacuous (1999, pág. 179).

En pocas palabras, lo que quiere resaltar es que el sistema real es similar al modelo en un grado específico y en ciertos aspectos.

El significado ordinario de la palabra "modelo" sugiere que los modelos teóricos son entendidos como modelos de algo, no meramente como ejemplos para ser usados en la construcción de otros modelos

${ }^{61}$ This must of course be distinguished from belief that the theory is approximately true, which seems to mean belief that some member of a class centring on the mentioned theory is (exactly) true (van Fraassen, 1980, pág. 9).

62 The desire to free philosophy of science from general questions about language is laudable. Philosophy of science should no more be just a branch of the philosophy of language than of epistemology or the foundations of mathematics. One cannot, however, eliminate all questions about language or interpretation. Any consistent formal structure has purely mathematical models, say in number theory. Some additional semantic categories, such as meaning or reference, are needed to distinguish masses from numbers-and thus mechanics from pure mathematics (Giere, 1999, pág. 176). 
teóricos. Giere piensa que deben tener la función de ser representaciones del mundo. Los modelos teóricos son la forma en que los científicos representan los diversos sistemas que encontramos en el mundo ${ }^{63}$.

Las hipótesis teóricas son entidades lingüísticas que tendrían la siguiente forma: el sistema físico X es, o está muy cerca de ser, como M (la entidad abstracta que se intenta describir en el modelo), así se da la forma en cómo la hipótesis teórica se enlaza con el modelo y el mundo. Una hipótesis teórica son las que pueden ser falsas o verdaderas (si aciertan o no en lo que sostienen), sin embargo, las relaciones entre los modelos y el mundo no pueden ser verdaderas o falsas, dado que no son entidades lingüísticas. La forma general de una hipótesis teórica sería: "Such-and-such identifiable real system is similar to a designated model in indicated respects and degrees" (Giere, 1988, p. 81) y un ejemplo:

The position and velocities of the earth and the moon in the earth-moon system (i.e. the physical system $X$ ) are very close to those of a two particle Newtonian system with an inverse-square central force (the abstract entity $M$ described in the model). Or, equivalently, the earth and the moon form, to some degree of approximation, a two-particle Newtonian system (Psillos, 1999, pág. 264).

Gracias a esas hipótesis es la manera en la que los modelos consiguen representar sistemas físicos concretos, y así es como las teorías adquieren contenido empírico. Mientras que las hipótesis afirman cosas sobre el mundo, como el comportamiento de un sistema físico X que se encuentra en una particular relación con el comportamiento de la entidad abstracta $\mathrm{M}$ descrita en el modelo; los modelos describen el comportamiento de la entidad abstracta $\mathrm{M}$ que se encuentra relacionada con el sistema físico X, así podemos llegar a hacer predicciones, conocer, probar, etc. el comportamiento de $\mathrm{M}$, y obtener información relevante sobre el sistema físico X.

La relación que deben guardar el modelo y el sistema físico es de similitud, es decir, el comportamiento de la entidad abstracta en la hipótesis teórica debe ser similar a la que se encuentra en el modelo. La "similitud" es tomada como un concepto primitivo (no definido), además esta se da, como mencionamos anteriormente, en aspectos y en grados, pero no nos muestra una métrica para poder medir dichos grados (estaríamos hablando de una noción cualitativa como el primer intento de Popper y el de Hilpinen) ${ }^{64}$.

\footnotetext{
${ }^{63}$ Como lo sostiene Nancy Cartwrigt: "Here I want to argue for a different kind of separation: theories in physics do not generally represent what happens in the world; only models represent in this way, and the models that do so are not already part of any theory" (Cartwright, 1999, pág. 180).

${ }^{64}$ I wish to emphasize that representing aspects of real systems in this way does not require the existence of an objective measure of similarity between the model and the real system. Nor does the lack of such an objective measure introduce an undesirable amount of relativity in claims of similarity between the model and the real system. Claims about features of the world remain as objective as they ever were (Giere, 2004, pág. 748).
} 
Giere no le da importancia a que las hipótesis teóricas sean verdaderas o falsas. Decir que una hipótesis es verdadera es decir más o menos que existe un tipo indicado y un grado de similitud entre un modelo y un sistema real. Recomienda que nos olvidemos de la verdad y nos centremos en la similitud ${ }^{65}$ : "A 'theory of truth' is not a prerequisite for an adequate theory of science" (Giere, 1988, p. 81).

En cuanto a la acusación de que la idea de similitud es vaga, dice que podemos buscar evidencias en las ciencias cognitivas, específicamente en la neurociencia (haciendo referencia al libro Neurophilosophy de 1986 de Churchland), donde se sugiere que la cognición humana y la percepción opera con base a un tipo de similitud, así vuelve a la similitud una relación prometedora dentro de la teoría naturalista de la ciencia.

Giere se niega a utilizar una teoría de la verdad por correspondencia, en su propuesta existe una relación indirecta a través de los modelos teóricos ${ }^{x x i i}$. Dicha propuesta se constituye de tres elementos: (i) un conjunto de enunciados teóricos, (ii) $\operatorname{los}_{\text {modelos }}{ }^{66}$ y (iii) el sistema real. Las afirmaciones sobre la existencia de relaciones de similitud entre los modelos y los sistemas reales requieren hipótesis teóricas (las cuales son entidades lingüísticas), pero a él le parece suficiente con una teoría redundante de la $\operatorname{verdad}^{67}$.

Existe una verdadera relación de correspondencia entre las afirmaciones que caracterizan un modelo abstracto (i) y el modelo en sí mismo (ii) (a la cual le denomina como definición), pero esta no es problemática. En donde realmente debemos de poner atención es en la similitud entre dos objetos: uno abstracto (ii) y otro real (iii), no entre las entidades lingüísticas (i) y el objeto real (iii). Lo problemático es cuando intentamos plantear una correspondencia entre los estados que caracterizan el modelo (i) y el mundo (iii), eliminando el papel de los modelos como intermediarios.

\subsubsection{Los modelos, la similitud y la inducción pesimista}

Con lo anterior, Giere piensa que podemos hacer frente a uno de los argumentos que generalmente se plantea en contra del realismo: la inducción pesimista. Si abandonamos la visión de verdad aproximada para hacer el giro a la similitud entre el modelo y el mundo, entonces los argumentos de Laudan colapsarán, ahora la aproximación nos permitirá incluir aspectos y grados de similitud. Si existen o no

\footnotetext{
${ }^{65}$ Recordemos que esta estrategia de utilizar como primitiva la idea de "similitud" ya había sido cuestionada por Oddie en contra de la propuesta de Hilpinen y Lewis.

66 "models in advanced sciences such as physics and biology should be abstract objects constructed in conformity with appropriate general principles and specific conditions" (Giere, 2004, pág. 747).

${ }^{67}$ The exception, as most philosophers will note, is the "redundancy theory of truth" according to which the content of any statement, S, is exactly the same as that of the metalinguistic statement"S is true." In this view the main function of the predicate "is true" is to facilitate "semantic ascent," that is, to talk about statements themselves rather than more directly about nonlinguistic objects (Giere, 1988, p. 286).
} 
algunos de los inobservables planteados por las teorías, sigue habiendo aspectos en los que parece como si existiesen. Por lo tanto, esas teorías son en cierto sentido aproximaciones.

El hecho de no que existan esos inobservables es un aspecto importante en el que fallan los modelos basados en ese inobservable y el mundo. Podemos negar esos modelos tomando como base a los fracasos que hayan tenido, pero no por ello quiere decir que debamos negar todo lo que el realista entiende acerca de las afirmaciones de la similitud entre los modelos del éter y el mundo.

Para Giere, una forma en que la ciencia progresa es cuando se descubren nuevos aspectos del mundo, aquellos en los que nuestros modelos pueden parecerse al mundo, también hay avance cuando se descubren otros aspectos en los que la similitud entre el modelo y el mundo no son como se pensaba. Ambos son consistentes con el realismo constructivo (Cfr. Giere, 1988, pp. 106-107).

\subsubsection{El realismo constructivo}

El realismo constructivo es la postura de Giere en cuanto al debate realismo/anti-realismo en el cual usa las herramientas utilizadas por Bas van Fraassen en la creación de su empirismo constructivo. En un principio las palabras "realismo" y "constructivo" podrían parecer incompatibles, sin embargo, Giere piensa que no es así. Una de las cualidades de esta propuesta es que utiliza los descubrimientos de las ciencias cognitivas para explicar el proceso creativo y de investigación de los científico, donde nos muestra que el científico no es simplemente un agente pasivo, sino que participa en el proceso de la obtención del conocimiento científico, además, dentro de este proceso, que es colectivo, intervienen aspectos como la cultura y las características especiales de la disciplina como sus estrategias de investigación, evaluación y sus normas.

El aspecto en el cual debemos centrarnos es en la relación de los conjuntos o familias de modelos (mapas cognitivos o representacionales) con el mundo, porque afirma que los seres humanos tenemos una tendencia y capacidad natural por estar generando mapas para representarnos el mundo y aplicarlos en la solución de problemas. En este sentido, las leyes científicas no son verdades universales, sino que son consensuadas por la comunidad científica. Un modelo tiene un grado de similitud con el mundo y su elección depende de razones pragmáticas y ontológico-epistémicas

La ciencia debe producir modelos similares, en ciertos aspectos, a la realidad, pero no es necesario que ofrezcan una copia fiel de ella. Hay diferentes razones por las cuales se puede decantar la comunidad para elegir un modelo u otro, aunque generalmente se elegirá aquel que dé la mejor representación posible, no obstante, en esta elección intervienen tanto motivos epistémicos como no-epistémicos, esto no significa que vaya a permitirse un relativismo en los aspectos ontológicos, solamente que los científicos escogerán y descartarán los aspectos que consideren relevantes en un fenómeno y dejarán de lado los que no. 
La parte constructivista de la propuesta no significa que estén inventando la realidad, simplemente que el mundo es tan complejo que es posible obtener (construir) diferentes modelos para representar el mismo fenómeno. Algunos modelos serán mejores dentro de ciertos intereses o propósitos, pero al cambiar los objetivos, también es posible que cambie el modelo elegido.

Giere dice defender una postura realista porque:

I agree completely with the suggestion that different arrays of interests may lead to different decisions about which models better represent the world. I disagree only that this is incompatible with a reasonable realism. My form of realism requires two things. First, that it makes sense to suppose that some models fit the world better than others in recognized respects and to measurable degrees. Second, that it is possible to design experiments which make it more likely, although maybe still far from certain, that one will choose the better fitting model. Both of these requirements are compatible with different arrays of interests leading science in different directions (1992, pág. 103).

El autor remarca que no debemos abandonar la idea de que existen mejores modelos que otros en el sentido de que representan mejor al mundo y que el progreso se encamina en encontrar modelos que cada vez lo hagan mejor; pero a ello debe agregársele que existen intereses personales, profesionales o sociales dentro de la comunidad científica, no obstante los experimentos sirven como una herramienta para que se puedan sobrepasar dichas interacciones e intereses particulares, acotando la libertad de la comunidad para elegir entre un modelo u otro.

Giere defiende un realismo sin verdad en el sentido de que no sostiene una defensa de la verdad por correspondencia, pero acepta que la existencia del mundo no depende del observador, también afirma que cada vez obtenemos mejores descripciones de la realidad; aunque acepta que la ciencia es una construcción social de gran complejidad, por lo tanto, la objetividad depende en gran parte de la cooperación y competición entre los científicos, además la elección de los modelos se basa en criterios más complejos que simplemente los criterios lógicos como en la adecuación al propósito de nuestro conocimiento.

\subsection{3 ¿Está la propuesta de Giere dentro del proyecto de la verosimilitud?}

Ilkka Niiniluoto considera que el "realismo constructivo" de Giere es parte del programa de la verosimilitud porque su combinación de verdad y similitud (vero-similitud) nos da precisamente la noción de verdad aproximada, cuando nuestro mejor modelo que nos provee una teoría es cercano al sistema real; y es verosímil cuando la clase completa de los modelos de una teoría es suficientemente cercano al sistema real, si la teoría es máximamente informativa y tiene únicamente un modelo, la distinción colapsa (Cfr. Niiniluoto, 1998, p. 18). Incluso en la reinterpretación realizada por Harré, Aronson y Cornell Way, donde la verdad se convierte en un caso límite de la verosimilitud: el modelo es idéntico con el estado actual de cosas, lo cual corresponde al principio 7 acerca de la verosimilitud 
máxima: “ $\left(\operatorname{Tr}\left(\mathrm{g}, \mathrm{h}^{*}\right)=1\right.$ if and only if $\mathrm{g}$ is equivalent to the whole truth $\mathrm{h}^{*}$ " (7) (Niiniluoto, 1998, pág. 6)).

Psillos estima de manera similar que Giere también está en el programa de responder al problema de la verosimilitud: "What I try to argue for in this section is that whatever the merits of Giere's approach, it hardly avoids use of some notion of truth-likeness" (1999, pág. 264).

Psillos critica la propuesta de Giere porque las hipótesis teóricas son las que hacen todo el trabajo para realizar representaciones si las teorías se utilizan para adquirir contenido empírico. Recordemos que tienen la cualidad de ser verdaderas o falsas, de acuerdo a si el sistema físico X es relevantemente similar al modelo M. Eso es únicamente una manera indirecta de decir que las descripciones del sistema real que ofrece el modelo son verosímiles. Aunque recordemos que Giere indica que las hipótesis teóricas no especifican las relaciones entre las entidades lingüísticas y los objetos reales, sino que especifican conexiones entre dos objetos, uno abstracto y uno verdadero. Psillos toma esto como cierto, pero cree que la diferencia no es realmente importante porque los modelos permiten las descripciones lingüísticas.

Las hipótesis teóricas asocian estas descripciones de los sistemas abstractos con descripciones idealizadas de sistemas reales. De ahí continúa afirmando que las dos descripciones son similares en ciertos aspectos y grados ${ }^{68}$. Entonces Giere no logra evitar las implicaciones semánticas que intentaba evadir, pues necesariamente las hipótesis teóricas tendrán un rol importante en la creación de representaciones. Dado estos razonamientos, Psillos reestructura la figura (xx) que nos proporcionó Giere quedando como la figura $(\mathrm{xxiii})^{\mathrm{xxiii}}$ :

Con ello, Psillos nos muestra que hay una interacción entre los tres elementos y cada uno nos muestra una diferente relación, las descripciones teóricas (i) (o hipótesis teóricas) son verdaderas dentro de un modelo (ii), mientras que con el sistema real (iii) son verosímiles; del sistema real (iii) al modelo (i) hay una idealización, mientras que de la manera contraria existe una des-idealización.

Por último, Psillos no comparte las dudas que tiene Giere acerca de la verosimilitud, al contrario, cree que el filósofo norteamericano legitima en su enfoque a este programa ya que capta su noción intuitiva que se revisará más adelante.

\footnotetext{
68 Take for instance, the study of the behaviour of the earth-moon system. A theoretical hypothesis says that its behaviour is similar to the behaviour of a two-body system, where the latter is an abstract mathematical entity described by Newton's law of gravitation. The similarity judgement is grounded in several idealisations. Strictly speaking, the moon is not a point-mass, the bodies involved are not perfect spheres, the gravitational force between the earth and the moon is not the only force acting on them, etc. Yet, thanks to suitable idealisations, the influence of the earth on the moon can be adequately studied by being subsumed under the mathematical description of a Newtonian two-body system. It is trivial to conclude that the description of a Newtonian two-body system is approximately true of the earthmoon system and, hence, that it is a truth-like description, where the degree of truth-likeness is a function of the idealisations and approximations involved in the description of the earth-moon system, (i.e. of the real system) (Psillos, 1999, pág. 265).
} 


\subsection{El enfoque "type-hierarchy" de Aronson, Harré y Way}

En diferentes trabajos de Aronson (1990) y (1997), además en su libro Realism Rescued que publicó en conjunto con Harré y Way (1994), se interpreta a las teorías científicas como si fueran jerarquías de tipo cuya intención es capturar las relaciones estructurales entre clases naturales. Se utiliza un diagrama de tipo árbol cuyos nodos van recorriendo de una mayor especificidad a una menor, las cuales comparten ciertas características entre sí. Es una buena forma para facilitar el aprendizaje de las representaciones y las inferencias que se pueden hacer con ellas.

Con ello los autores pretenden dar una noción de verosimilitud utilizando las relaciones que se dan dentro de su estructura, esto se hace en términos de similitud. A diferencia de otros autores como Niiniluoto o Tichý, AHW no definen a la verosimilitud en cuanto a la distancia a la verdad completa, al contrario, delimitan a la verdad en cuanto a la verosimilitud, recordemos que para ellos la verdad es un caso límite de la verosimilitud ${ }^{69}$.

Para AHW la verosimilitud se refiere a los casos en que el tipo elegido es similar al tipo real, por otro lado, la verdad se refiere a los casos de coincidencia real entre los dos tipos (el elegido y el real). Es decir, dos tipos son similares cuando se representan como subtipos del mismo súper-tipo. La similitud se da en diferentes grados y esto se determinará en una comparación entre los dos tipos en función de sus posiciones.

Tomemos como ejemplo la figura (xxiv) ${ }^{\mathrm{xxiv}}$, la medición se hace tomando en cuenta dos aspectos: 1) lo que los objetos tienen en común y 2) aquello que los hace diferentes. En este caso, la afirmación " $x$ es una ballena jorobada" es más verosímil que decir "x es un atún” en el caso de que x sea realmente una ballena azul. La verdad se da en los casos en que lo afirmado sea igual al tipo que le corresponde al objeto, afirmar, por ejemplo, "x es una ballena azul"xxv.

El principal problema es que podemos tener diferentes maneras de representar mediante jerarquías de tipo, lo cual hace que las relaciones de similitud sean dependientes del contexto, esto nos dará como resultado diferentes formas de evaluar la verosimilitud de una afirmación. Por ejemplo, si hiciera una jerarquía de tipo donde se dividieran a los animales entre terrestres y acuáticos, entonces " $\mathrm{x}$ es una ballena azul" y "x es un atún" comparten el mismo grado de verosimilitud respecto a si x es realmente una ballena jorobada. ¿Cómo sabríamos cuál es la verosimilitud de una afirmación en estos casos? ¿Cómo sabríamos cuál es la jerarquía de tipo correcta? “On AHW's theory, claims to

\footnotetext{
${ }^{69} \mathrm{We}$ have reserved primitive or basic epistemic concepts here. Traditional theories of verisimilitude or approximate truth use the truth of a proposition and sets of proposition as a basic unit in trying to construct some sort of measure of the distance any given theory lies from the truth. According to our scheme the concepts of truth and verisimilitud must be ranked in just the reverse order. If truth is a limiting case of verisimilitude, we must first understand what verisimilitude is in order to understand what truth is (Aronson J. H., 1994, pág. 10).
} 
verisimilitude can arise only in particular contexts, expressed in terms of certain type- hierarchies, and they can be questioned in other contexts, where different type-hierarchies are chosen" (Psillos, 1999, pág. 262).

Psillos considera que este contextualismo creará serios problemas: el primero de ellos es acerca de qué o quién determinara el contexto relevante donde se juzgará la verdad o la verosimilitud, es decir, cuál representación de jerarquía de tipo debemos elegir, si no tenemos un criterio objetivo, entonces será convencional y ambiguo; y el segundo es, si llegasen a responder que eso se resuelve apelando a consideraciones pragmáticas, como lo que nuestros intereses requieran en ese momento, lo cual fijará el contexto en donde será evaluada la verosimilitud; Psillos considera que esto no elimina la ambigüedad porque es posible que exista más de una jerarquía de tipo relevante para la determinación de la verdad aproximada de una afirmación. Además, las jerarquías de tipo se construyen tomando en cuenta las similitudes o diferencias que consideremos relevantes para hacer una representación, no precisamente porque así venga dictado por la naturaleza.

Para Stathis Psillos la comprensión realista de la verosimilitud no puede capturarse por medio del contextualismo, dado que se busca que una afirmación sea más verosímil que otra sin depender de la jerarquía de tipo que se esté usando, esto nos deja sin saber cuál es el grado de verosimilitud correcta de una afirmación si es diferente en cada contexto. Por lo tanto, no se puede ver cómo este enfoque pueda ser de utilidad para las pretensiones de un realismo científico en cuanto al tema de la verosimilitud y la verdad.

\subsection{El enfoque intuitivo de Stathis Psillos}

Psillos considera que la propuesta de Giere va por buen camino, aunque no le parece suficiente, así que propone esbozar un enfoque de la verosimilitud que sí lo convenza y sea de utilidad para su propio realismo científico. Si bien después de su libro de 1999 Scientific realism: How the Science Track the Truth no ha vuelto a hacer una apología del mismo.

Considera que la verosimilitud es la noción de verdad con la que se puede trabajar en la ciencia porque no podemos obtener la verdad exacta en nuestra interacción con el mundo, sobre todo en los aspectos de lo inobservable o lo que está espacio-temporalmente muy alejado. Por lo tanto, una perfecta relación (entendida como una copia fiel y completa) entre nuestras teorías y el mundo es imposible por diferentes razones: 1) Para que nuestras teorías científicas sean eficaces y podamos estudiar la naturaleza debemos hacer idealizaciones y simplificaciones para que sea posible tener representaciones del mundo a pesar de que los fenómenos de la naturaleza sean complejos y estén interconectados, 2) Algunas leyes se deducen de otras bajo condiciones específicas de aproximación y ciertos supuestos ceteris paribus, 3) 
Las predicciones teóricas se prueban contra resultados experimentales, pero casi todos los resultados experimentales son susceptibles a tener errores, además, son muy pocas las predicciones que coinciden exactamente con los resultados experimentales (todas presentan una estimación de error que es aceptable hasta ciertos grados). Dado lo anterior concluye:

Demanding the exact truth in science would amount to demanding the exclusion of all approximations, simplifications, idealisations, approximate derivations, sources of error in measurements and calculations. Even were this sort of science possible, it would not be the science with which we are familiar (Psillos, 1999, pág. 266).

Aunque los resultados científicos, la mayoría de las veces, son autocorregibles con la intención de explicar mejor el fenómeno con el que se enfrentan.

Cuando se postulan leyes o mecanismos teóricos se especifica que estos están dentro de una idealización o aproximación, igualmente también se mencionan los aspectos y en los grados en que los fenómenos naturales se desvían de las representaciones teóricas, es decir, se mencionan cuáles fueron los elementos que se tomaron en cuenta y cuáles no, o en qué grado se hizo con cada uno de ellos. Es aquí donde entra la idea de verosimilitud, dado que lo postulado por una teoría no es exactamente como sucede en la naturaleza, pero tiene un alto grado de similitud o de aproximación con referencia a su comportamiento.

Psillos propone que entendamos a la verdad como "adecuación", por lo tanto, una teoría sería verdadera si, y sólo si, se adecua al mundo; entonces verosimilitud será entendida como una "adecuación aproximada": una descripción, afirmación, ley o teoría es verosímil si, y sólo si, hay aspectos y grados que se ajustan a los hechos. Psillos afirma que se puede resumir en palabras de Thomas Weston: "A statement will count as approximately true to the degree that it is accurate in whatever it asserts" (Citado por Psillos, 1999, pág. 267).

La razón por la que Psillos llama a este enfoque "intuitivo" es porque busca que esté lo más cercano posible a nuestras intuiciones acerca de lo que consideramos como verosímil. Por lo tanto, una teoría sería aproximadamente verdadera si existen las entidades de tipo general postuladas a desempeñar un papel causal central en la teoría, y si los mecanismos básicos y leyes postuladas por la teoría se aproximan a las propiedades en el mundo, bajo condiciones específicas de aproximación.

Podemos observar que Psillos se centra específicamente en los aspectos que son centrales en la teoría y causales, con ello sigue la estrategia que utilizó para argumentar en contra de la inducción pesimista, la cual denominó como divide et impera, donde menciona que hay aspectos de la teoría que sí tienen consecuencias en cuanto a su éxito logrado y hay otros que no lo tienen, y que estos pueden ser 
identificados por los científicos en su momento, tal y como lo argumenta con su análisis de caso con respecto al calórico y el cambio de teoría ${ }^{70} 71$.

Psillos continúa diciendo que el argumento positivo para que una descripción o ley falsa, o entidad, puede ser verosímil, es la siguiente: estrictamente hablando, una descripción falsa puede ser cognitivamente significativa; puede adecuarse mejor o peor con los hechos que pretende describir. Una descripción puede representar el dominio para la que fue hecha con un grado alto o bajo de exactitud.

Lo que aquí está intentando el filósofo griego es encaminar la ruta de la conceptualización acerca de la verdad aproximada, en lugar de abandonarla pese a los fracasos que se han tenido para poder estructurar una definición formalizada, lo que se debe buscar es capturar lo mejor posible cuáles son las condiciones en las que una representación se adecua con la mayor precisión posible a los hechos relevantes (aunque no da una caracterización para saber cuáles son precisamente esos hechos relevantes).

Psillos elabora un "esqueleto", como él lo llama, de una teoría de la verosimilitud, donde captura las intuiciones del enfoque de los mundos posibles (de Hilpinen, Tichý, Oddie y Niiniluoto) y el de Giere. Los juicios acerca de la verdad aproximada se harán mediante una comparación entre el mundo real y el mundo descrito por la teoría. Y queda planteado de la siguiente manera:

A description $D$ approximately fits a state $S$ (i.e. $D$ is approximately true of $S)$ if there is another state $S^{\prime}$ such that $S$ and $S^{\prime}$ are linked by specific conditions of approximation, and $D$ fits $S^{\prime}\left(D\right.$ is true of $\left.S^{\prime}\right)(1999$, p. 268).

Así pone el ejemplo de que una ley teórica sería aproximadamente verdadera en el mundo real si es estrictamente verdadera en un mundo que se aproxima al nuestro bajo ciertas condiciones.

Una de los cuestionamientos es, si al brindar una noción no formalizada de la verdad, entonces no se podrá utilizar como un objetivo de la ciencia; como el mismo Laudan lo ha planteado en diversas ocasiones. Para Psillos este no es precisamente un defecto, lo cual se piensa cuando se confunde claridad con formalización, además agrega que es escéptico del proyecto para formalizar la verosimilitud. La necesidad de formalizar la verdad, por ejemplo, surgió porque las nociones intuitivas provocaban paradojas como la del mentiroso, por ello fueron necesarios los trabajos de Tarsky. Sin embargo, no se

${ }^{70}$ Cfr. Psillos: "Scientific Realism and the 'Pessimistic Induction' (1996) y "Philosophical Study of the Transition from the Caloric Theory of Heat to Thermodynamics: Resisting the Pessimistic Meta-Induction" (1994).

${ }^{71}$ Hasok Chang argumenta en "Preservative Realism and Its Discontents: Revisiting Caloric" (2003) que en el caso del calórico, los científicos sí estaban comprometidos de que era uno de los elementos activos en el éxito de la teoría y no lo consideraban como ocioso. La acusación más fuerte de Chang es que Psillos sufre de "precursoritis", es decir, que tomó sólo los elementos que le eran útiles para reconstruir la historia de su ejemplo y que podían tomarse como precursores de los elementos actuales. Además en este texto se muestra escéptico sobre el soporte que daría la preservación al realismo: "Even extraordinary cases of preservation, in themselves, do not necessarily show anything beyond human limitations, or conservatism assisted by enough obstinacy and ingenuity. Preservation is far from a sufficient condition for realist acceptance" (pág. 912). 
conoce que se pueda tener ese tipo de problemas en la aproximación a la verdad. Por lo tanto, no es relevante una formalización en este aspecto.

Anticipándose a las objeciones que un autor como Fine podría hacer al respecto de que esta noción es vaga, Psillos dice que hasta cierto punto dicha objeción es acertada, dado que es cualitativa. Sin embargo, no es un problema insoluble. La solución se encuentra en centrarnos en la noción de aproximación, la cual puede ser más precisa y exacta, quizá no es posible que se haga de una manera abstracta y se pueda aplicar a todas las teorías, pero sí podemos hacerlo de manera discreta que se aplique a ciertas teorías particulares. Así cuando se intente examinar una descripción teórica en particular, los aspectos y grados de similitud, una noción que es crucial en la explicación de verosimilitud, entonces puede ser más precisa y concreta. Si esto es posible, entonces se gana la claridad necesaria.

La tercera objeción refiere a que esta propuesta podría no ser lo suficientemente robusta para las ambiciones de los realistas, dado que se centra básicamente en la noción de aproximación y con ello no podemos defender el optimismo epistémico del realismo científico acerca de que nuestras teorías actuales son aproximadamente verdaderas. Psillos dice que estas objeciones son erróneas porque una cosa es explicar la afirmación de que una teoría es aproximadamente verdadera, es decir es un aspecto semántico, y la otra es fundamentar el juicio de que sea aproximadamente verdadera, en este caso estamos ante un problema epistemológico. Lo que ha intentado Psillos mediante su esqueleto es darle una respuesta a la primera parte de una manera legítima para aclarar cuando hablamos de que una teoría es aproximadamente verdadera. Los argumentos para justificar el optimismo epistémico son otros (no milagros, inferencia a la mejor explicación, etc.).

\subsubsection{Poniéndole el músculo al esqueleto de Stathis Psillos}

El único lugar donde Psillos ha defendido la postura de su noción intuitiva de verosimilitud ha sido en su libro de 1999, a pesar de que se le han hecho críticas no ha respondido a ellas, y son muy pocos los autores que se han dado a la tarea de aplicarlo o retomarlo para su defensa del realismo.

Sin embargo, en el año 2014, Tony Lloyd escribe un artículo denominado "Putting flesh on Stathis Psillos' skeleton" donde se da a la tarea de tomarse más enserio esta propuesta y ve cuáles serían los alcances a los que se puede llegar.

De entrada, nos pide que consideremos las siguientes tres afirmaciones: 1) La tierra es plana (FE), 2) La tierra es una esfera (SE) y 3) La tierra es un esferoide achatado (OE); como sabemos, las tres son falsas, pero también la última es la más cercana a la forma de nuestro planeta. Las tres tienen relación en cuanto a se refieren a la forma de la tierra y esa relación se puede describir en términos de las diferencias que tienen con respecto a la afirmación verdadera. Sin embargo, carecemos de una cuantificación de esta diferencia, únicamente contamos con términos vagos como "pequeña", "muy pequeña", "insignificante", 
y otras, pero el hecho de que no haya forma de cuantificarlas no importa para poder hacer una relación entre los estados.

Aunque no tengamos un valor para saber la diferencia entre OE y le afirmación verdadera sabemos que es menor que la diferencia de SE con la verdad y a su vez a SE le sucede con FE. Lo cual

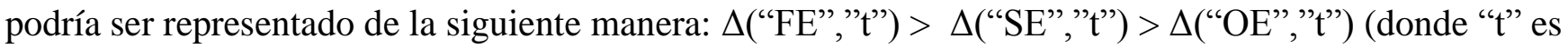
el enunciado verdadero y $\Delta$ es la diferencia) (Lloyd, 2014).

El objetivo de Lloyd es establecer esta relación de una manera más segura que solamente apelar a la intuición o llevarlo a lo obvio. El "esqueleto" propuesto por Psillos es parecido a la comprensión matemática de las similitudes de las relaciones que hace Russell ${ }^{\text {xxvi. }}$

Let $x$ and $y$ be two terms having the relation $P$. Then there are to be two terms $z, w$, such that $\mathrm{x}$ has the relation $S$ to w, $y$ has the relation $S$ to $w$, and $z$ has the relation $Q$ to $w$ (Russell, 1920, pág. 54).

En la figura xxiv la relación xPy es similar a zQw. Así mismo sucede con xSz y ySw. En el esqueleto de Psillos, la relación S se reemplaza por una de correspondencia, lo cual puede convertirse en el esquema de la figura xxvii ${ }^{x x v i i}$.

En la imagen xxvii se está diciendo que la afirmación, teoría, entidad o fenómeno “D”, es verdadero dentro de un mundo $S^{\prime}$ que es aproximadamente a como es el mundo real S, a su vez, D es aproximadamente adecuado a t que es verdadero en el mundo real.

El estado que sería el caso si fuera D para ser verdadero puede ser denotado por la eliminación de las comillas de la afirmación: Si "FE" sería verdadera si fuera el caso de una tierra plana, lo mismo sucede con "SE" y "OE", mientras que la descripción "t" es la forma verdadera de la tierra ${ }^{\mathrm{xxviii}}$.

Por hipótesis, la relación entre "FE", "SE" y "OE" es una diferencia que va en disminución en relación a "t". Eso sucede de manera similar entre FE, SE y OE.

A diferencia de Psillos, quien ve esta relación como de aproximación e idealización, Lloyd la ve como una relación "like...er...'like'" y utiliza un divertido ejemplo de cuando se observan a gemelos idénticos:

Tweedledum (TM), Tweedledee (TE) and Alice (AL) provide us with three pairings: (TM,TE), (TM,AL) and (TE,AL). As Tweedledum and Tweedledee are "identical" twins we can expect the differences (TM,TE) are smaller than the differences in either of the other two parings. Now Tweedledum and Tweedledee are not, actually, identical. Close family and friends (CFF) can distinguish the two, as is usual with "identical" twins. It is other people (OP) who have the difficulty. OP have no difficulty distinguishing either Tweedledum or Tweedledee from Alice. Of course, CFF have no difficulty here, either Consider the set $\{\mathrm{CFF}, \mathrm{OP}\}$ to be a set of distinguishers. It is the differences in appearance that enable, were they do so enable, the members of that set to make the distinction. The distinguishers "fire" depending on the differences within the pairings. And they "fire" differentially. Not only differentially but the distinguishers that "fire" when presented by Tweedledum and Tweedledee, $\{\mathrm{CFF}\}$, is a proper subset of those that "fire" when presented with either of the other two pairings. From the set of distinguishers \{CFF, $\mathrm{OP}\}$ the differences (TM, TE) receive a smaller response than either of the other two pairings. The differences (TM,TE) are, therefore, smaller (Lloyd, 2014). 
¿Cuáles medios tenemos para diferenciar entre FE y T? En el esquema anterior vimos que la relación entre FE y $\mathrm{T}$ es similar a la que existe entre las afirmaciones "FE" y "t" y no tiene que preocuparse demasiado de la diferenciación FE y T o "FE" y "t". Asimismo, tenemos un medio fácil de diferenciar entre "FE" y "t": las cosas que nos permiten decir que "FE" es falsa: a) La forma de la sombra proyectada por la Tierra sobre la Luna es siempre la misma. Si la tierra fuera un disco plano, entonces, a veces los rayos del sol golpearían de lado a la tierra y resultaría una línea de sombra elíptica; b) El mástil es lo primero en desaparecer cuando un barco viaja sobre el horizonte y lo primero en aparecer cuando viene de regreso; c) Las estrellas desaparecen y aparecen en el horizonte a diferentes latitudes.

Para distinguir entre "SE” y "t" tenemos los siguientes elementos: d) La observación de otros objetos astronómicos, e) Las predicciones teóricas de la física newtoniana y f) La tecnología topográfica del siglo XVIII.

En el caso de “OE” y “t”: g) Las mediciones detalladas de los satélites. En resumidas cuentas, contamos con criterios confiables para afirmar la falsedad de "FE", "SE" y "OE". Cabe destacar que los elementos que hacen falsa a "OE", también lo hacen a "SE" y "FE"; lo mismo sucede con los de "SE" con respecto a "FE". Las evidencias que falsifican la forma de las teorías de la tierra son:

FE: Set of distinguishers of ("FE", " $t "):\{a, b, c, d, e, f, g\}$

SE: Set of distinguishers of ("SE", " $t$ "): $\{d, e, f, g\}$

OE: Set of distinguishers of ("OE", " $t$ "): $\{\mathrm{g}\}$ (Lloyd, 2014)

Podemos ver que los falsificadores de OE son un subconjunto propio de los de SE, que a su vez lo es de FE. OE es más pequeño que SE, a su vez es menor que $\mathrm{FE}^{\mathrm{xxix}}$. Con esto, Lloyd considera que tenemos razones sólidas para justificar por qué acomodábamos las distancias hacia la verdad de esa manera en los puntos anteriores, ahora se le han dado "razones" a los distinguidores para diferenciar exitosamente las distancias de cada teoría hacia la verdad.

Quizá Psillos estaría de acuerdo en los diagramas que se expusieron en un inicio con relación al utilizado por Russell, pero puede que no lo esté del todo con el método de "medición" utilizado por Lloyd. Surgen dudas, por ejemplo, si con esta estrategia que está midiendo lo que sabemos como falso de una teoría, pueda realmente satisfacer los diversos criterios que establece Popper, por ejemplo, ¿qué sucedería con una teoría verdadera que nos diga que la tierra no es plana? Carecemos de un método que explique que una teoría puede ser falsa, pero más aproximada a la verdad que una verdadera en este tipo de casos (dado que es posible obtener una teoría que solamente tuviera proposiciones negadas, sería muy poco informativa, preferiríamos una falsa cuyas afirmaciones fuesen aproximadas). Este tipo de objeciones o situaciones no fueron tomadas en cuenta por Lloyd. 


\subsubsection{Objeciones a la propuesta de Psillos}

El libro de 1999 de Psillos ha sido uno de los más importantes de las últimas décadas en cuanto a la defensa del realismo científico se refiere. Por ello se han publicado diferentes artículos revisando lo que en él se dice, por un lado, hay quienes resaltan sus aciertos y por otro están los que critican su proyecto. Sin embargo, no es raro darnos cuenta que muy pocos se centran en el aspecto de la verosimilitud y el enfoque intuitivo, ya que como él mismo autor ha mencionado es un "esqueleto", quizá han estado esperando a que el autor desarrolle más su propuesta, sin embargo, han pasado 17 años y al parecer no ha retomado la defensa de lo que escribió en 1999.

Bird comienza por preguntarse si la verosimilitud es realmente muy importante para los realistas y antepone su propia visión sobre el progreso científico. Piensa que es más útil para la visión epistémica acumulativa pensar que la ciencia nos da cada vez más conocimiento. Ve como una manera más natural de concebir el desarrollo científico como, en primera, una adquisición de conocimiento acerca de tipo general y después el conocimiento de aspectos más detallados. Ya que el principal objetivo de las teorías sucesivas puede cambiar (de átomos a sus componentes), por ejemplo, no necesitamos suponer que este desarrollo consiste en una serie de proposiciones falsas y mutuamente inconsistentes que se van acercando cada vez a la verdad, por lo cual no sería un análisis genuino del todo. Con ello no sólo critica la noción de verosimilitud de Psillos, sino el proyecto que ha iniciado desde Popper por lograr solucionar este problema (en el capítulo siguiente detallaremos el problema). Sin embargo, piensa que la mayoría de los argumentos ofrecidos por Psillos contra el antirealismo están acertado y que "Future research in that direction will start from here" (Bird, 2002, pág. 107).

A diferencia de Bird, que se centra en todo el proyecto "verosimilitudiriano", Otávio Bueno se enfoca en criticar específicamente la propuesta de Psillos, y comienza con la siguiente pregunta: "But wait, why exactly don't realists need to provide a formal account of truth-likeness?” (Bueno, 2001, pág. 360), recordemos que la respuesta sería que, a diferencia de la noción de verdad, la verosimilitud no cae en paradojas como la del mentiroso. El problema, para Bueno, es que la caracterización de la noción intuitiva de la verosimilitud se encuentra en términos de la verdad, y si la verdad es susceptible a las paradojas, entonces también lo estará la verosimilitud ${ }^{72}$. Un realista podría responder que siempre se puede adoptar una descripción formal adecuada de la verdad para evitar paradojas, el problema es que si Psillos define la verosimilitud en término de una descripción formal de la verdad (la teoría de la verdad

\footnotetext{
72 Anteriormente hemos trabajado, por ejemplo, en que si el enunciado "el número de planetas es 8 " es verdadero, el enunciado “el número de planetas es 7” es aproximadamente verdadero y la noción se define a partir de lo que se considera como verdad. En la cuestión de las paradojas es posible que Bueno se esté haciendo referencia a "este enunciado es falso" que causaría problemas al intentar otorgarle un valor de verdad sin provocar una contradicción; tampoco podríamos decir que es aproximadamente verdadera sin caer en los mismos problemas, ¿cómo estimaríamos la aproximación es en ese caso?
} 
correspondentista de Tarsky), entonces ya no se puede pretender una noción intuitiva. Si la verosimilitud se define en términos de una verdad formal, entonces la verosimilitud también se vuelve formal (y debe darse una propuesta formal).

Bueno dice que todavía es más importante para el realista establecer una conexión entre verdad y verosimilitud, piensa que esto debería ser más allá de una definición. Por ello algunos realistas afirman que la verdad es un caso límite de la verosimilitud. No queda claro cómo una noción intuitiva de la verosimilitud puede utilizarse para mantener esa conexión con la verdad si está formalizada: "How can truth be a limiting case of truth-likeness if in order to define truth-likeness the notion of truth is presupposed?" (p. 361).

Quizá un realista podría decir que la verdad no es un caso límite de la verosimilitud, pero esto parece que dejaría a la verosimilitud sin mucha utilidad para el realismo. Los realistas están en última instancia preocupados por la verdad y la verosimilitud, como vimos con Psillos, es la noción de verdad con la que se trabaja en la ciencia. Es decir, puede ser vista como un recurso pragmático dado el "desorden" de la práctica científica: "But I take it that the idea is to eventually get to truth - via truthlikeness. But how can this be done?" (Ídem).

Para el profesor de la Universidad de Miami no está claro que esto se pueda hacer dado que la dificultad es que la propuesta de Psillo es totalmente dependiente del contexto porque las condiciones específicas de aproximación que son utilizadas en esta definición la verosimilitud cambia de un contexto a otro (porque en cada caso se toman en cuenta diferentes condiciones de aproximación para aplicarla), sin embargo, la verdad no depende del contexto, sobre todo en un marco realista. Aceptar una verdad que sea dependiente del contexto sería abrirse al relativismo que es lo opuesto al realismo científico (cuando menos en la forma estándar). Y esto nos muestra una brecha entre la verosimilitud y la verdad, y no ve cómo puede cerrarse por medio de una noción intuitiva porque depende crucialmente profundamente del contexto de las condiciones específicas de aproximación. Incluso lo que es peor, la propuesta de Psillos parece aumentar dicha brecha. Por todo lo anterior, Bueno concluye:

This seems to leave the scientific realist in an unstable situation: there is the need for truth-likeness in the realist view, given the difficulties to assert the truth of a theory (due to the presence of idealisations, simplifications and so on). However, neither the formal account of truth-likeness nor the intuitive view seem to work (pp. 361-362).

En este escenario, sugiere Bueno, quizá moverse a algo más débil que la verdad, como la adecuación empírica, no parecería tan malo, después de todo; aunque esto obviamente significaría el abandono del realismo científico.

En esta misma revista, donde hay una serie de ensayos dedicados al libro de Psillos, se le dio la oportunidad al autor de realizar una contra-réplica, sin embargo, en cuanto al aspecto de la verosimilitud, 
no hubo ninguna respuesta para defender su postura, esto es comprensible dado que tenía que responder a muchos autores que hacían críticas a diversos aspectos de lo que escribió, pero queda la duda de por qué no lo hizo después, pueden plantearse dos preguntas: ¿ha dejado de creer en esta propuesta? ¿O prefiere que sean otros los que se dediquen a desarrollar el tema de la verosimilitud?

Por otro lado, Hasanoglu considera que la teoría de Psillos es muy nebulosa (2006, pág. 56) porque la noción intuitiva de verosimilitud simplemente asume lo que necesita ser comprobado y que su propuesta no logra reivindicar de forma convincente al realismo, incluso sería una invitación a que los realistas buscaran otras formas de caracterizar el progreso científico que sean menos atractivas (similar a lo que afirmaba Otávio Bueno): "Indeed, any force such a notion carries seems to rest solely in its vagueness" (2006, p. 85).

Psillos no ofrece ninguna respuesta clara acerca de cuáles serían las "condiciones de aproximación" en el esqueleto de su noción intuitiva, únicamente menciona un ejemplo, pero no ofrece un criterio que se pueda utilizar de manera general. Recordemos que dice que no es necesario ni posible que se dé una noción formalizada de verdad aproximada, en caso de que tuviese razón estaría distanciando a su visión aún más de la plausibilidad. Es decir, si es correcto, uno podría preguntarse si la noción puede dar algún contenido significativo en absoluto, y deja al realista sin un contenido en el cual puede confiar, por ello es que menciona al argumento de los no milagros como la estrategia que tiene el realista para poder mantener el optimismo epistémico. Recordemos que lo que la noción intuitiva está queriendo resolver es el problema semántico, pero no el epistémico.

Psillos ya se había anticipado a la acusación de que su propuesta era vaga, nos sugería para ello que nos centráramos en la idea de aproximación y que quizá si su propuesta no podría ser abstracta y aplicarse de manera general, sí podría adecuarse para casos particulares. Si podemos aplicar esta versión de verosimilitud a ciertos casos particulares (y cada vez a una mayor cantidad de ellos), entonces podemos irla tomando como base para una propuesta más general que pueda ser útil para el realista.

Hasanoglu se mantiene escéptico en cuanto a la utilidad que pueda resultar de esta propuesta: "it seems unlikely that anything substantive can result from it" (2006, p. 113), porque piensa que aunque tenga aplicación a casos particulares de manera convincente, el realista requiere que esto se haga de manera general, sobre todo cuando se afirma que si una teoría es empíricamente exitosa por lo tanto es aproximadamente verdadera y que esto no se logrará mostrando los casos particulares en que la verosimilitud de una teoría puede entenderse y no ayudará a este objetivo a menos que se abstraiga algo de manera general a partir de ellos. Para él este intento de abstracción será siempre en vano; a menos que 
se pueda articular un concepto convincente de verosimilitud que también pueda aplicarse a situaciones epistémicas cruciales que reivindiquen al realismo.

Además, esta propuesta sería ineficaz para ponerse por encima de otras propuestas de progreso científico, no habría manera de tener que preferir al realismo por encima de las otras propuestas antirealistas que ahora parecerían más plausibles: "If I merely have a different intuition, I can have a different philosophy of science" (p. 114).

Consideramos que las objeciones de Hasanoglu estarían en lo correcto si el programa de Psillos intentase ofrecer la noción intuitiva de verosimilitud como una noción de progreso científico, sin embargo, el autor realiza varios comentarios de que ése no es precisamente su intento, sino que busca dejar en claro qué se quiere decir cuando un autor utiliza la palabra "verosimilitud" o "verdad aproximada", por eso mismo no ofrece una versión cuantitativa, porque piensa que podemos observar la aproximación a la verdad mediante otro tipo de estrategias y no con la definición de un concepto.

\section{Cierre}

El presente capítulo tuvo como objetivo exponer el enfoque que ha tenido mayor presencia en el debate de la definición de la verdad aproximada, es decir, el de la similitud, el cual tuvo un auge en la década de 1970, pero 20 años después parecía poco viable que se pudiera rescatar el proyecto dado los problemas insalvables que mostraba; sin embargo, como afirma Gunnar Andersson: "en la segunda mitad de los años setenta que la tarea de dar definición precisa del concepto de semejanza a la verdad era uno de los problemas irresueltos más fascinantes de la moderna filosofía de la ciencia” (1982, pág. 275).

Las siguientes alternativas fueron los intentos por defender una noción que estuviera definida de manera no formalizada. Como vimos, podría ser muy clara para casos particulares o de sentido común, pero parece que están muy alejadas para resultar de utilidad dentro del debate del realismo científico.

A estas alturas, alguien podría pensar que el proyecto ha fracasado y poco se puede hacer para rescatarlo, tendríamos que optar por dos alternativas: renunciar al realismo o renunciar a defenderlo mediante la aproximación a la verdad. Esa sería una postura pesimista, aunque hay autores que buscan sacar de la derrota un aprendizaje y sostener que no todo está perdido:

And even if we have not yet lighted upon the demonstrably correct account, at least we now know of several proposals that they are inadequate, and of others that they have weaknesses as well as strengths - evidence that we have made some progress (Oddie, 2014, pág. 550). 


\section{Capítulo IV. El problema epistémico}

The most that can be maintained is, that we seek for a belief that we shall think to be true -Charles

Sanders Peirce.

\section{Introducción}

En los dos capítulos anteriores se revisaron las diferentes propuestas que se han dado para disipar el problema semántico de la verosimilitud, es decir, a responder la pregunta ¿qué se quiere decir o significa que una afirmación o teoría esté (más) aproximada a la verdad? (en otras palabras, ¿qué sentido tiene?). Cuestión que es fundamental dentro de nuestra Idónea Comunicación de Resultados, mientras que ahora se hablará de manera breve acerca del problema epistémico, esto es, ¿cómo podemos creer justificadamente (o sabemos) que una teoría o afirmación $\varphi$ está más aproximada a la verdad que $\psi$ ?

La diferencia central entre el problema semántico y el epistémico es acerca del conocimiento que tenemos de una teoría verdadera. En el primero se realiza la suposición de que ya conocemos cuál es la verdad completa y se busca saber las condiciones bajo las cuales una teoría se acerca más a la verdad que otra. En el segundo no se puede asumir ello, dado que los científicos no conocen la verdad cuando están realizando una investigación empírica, con lo que ellos cuentan es con una cantidad restringida de información acerca del mundo, la evidencia, por lo tanto, con base a esa evidencia, que podemos afirmar si una teoría está más cercana a la verdad que sus rivales. Si el objetivo de la ciencia es tener teorías que cada vez se aproximan más a la verdad, entonces, los científicos deberán elegir las teorías que tengan un mayor grado de verosimilitud con base a la evidencia; en consecuencia, el problema de la verosimilitud se convierte también en un criterio de elección de teorías.

Aunque Popper no hizo este tipo de compromisos, recordemos que para él los criterios de falsación eran los que se deberían de utilizar para poder justificar nuestra elección de una teoría y no su definición de verosimilitud, después de su fracaso se volvió una condición para dar una noción semántica de verosimilitud la posibilidad de ofrecer un criterio de elección de teorías, lo cual fue tomado en cuenta por Kuipers, Oddie y Niiniluoto quienes dedicaron bastante tiempo a este objetivo.

Popper y Miller utilizaron la noción de que la evidencia es representada por las consecuencias lógicas, y simbolizaba a una teoría como un conjunto cerrado de consecuencias de un axioma $r, \mathrm{Cn}(\mathrm{r}) \mathrm{y}$ además asumen la verdad completa. Para Niiniluoto una teoría es la disyunción de sus constituyentes que son respuestas parciales a un problema cognitivo donde la verdad es una respuesta completa al mismo y basa su regla de evidencia en las consecuencias lógicas verdaderas de todas las respuestas completas confirmadas por $h_{i}$. Por otro lado, Kuipers utiliza el método de Suppes-Sneed en el cual se afirma que, en un universo de posibilidades lógicas, la teoría verdadera será aquella que recoja todas las posibilidades lógicas que, también, son físicamente posibles y nada más. Esto tiene como consecuencia que, en caso 
de que la evidencia empírica aumente, lo mismo sucederá con el conjunto de estructuras establecidas realizables físicamente.

Los defensores de la verosimilitud deben proveer una regla que permita llevar a cabo un ordenamiento de las teorías conforme al apoyo que tengan con la evidencia disponible, las cuales deberían ser las mismas pautas aplicables para cuando tengamos la verdad completa. A esta norma se le pide que cumpla con dos requisitos: el primero de ellos es que sea revisable, es decir, cuando tengamos nueva evidencia, deberá permitir que se retráctese de un ordenamiento que se haya preferido; la segunda es más fuerte, se hace la petición de que sea reversible, por ejemplo, si en t afirmábamos que $x$ es más aproximada a la verdad que $y$, pero ahora contamos con nueva evidencia, es posible que en t' $y$ esté más aproximada a la verdad que $x$ (de manera conjunta al requisito de reversibilidad, también debe cuestionarse si la regla es funcional como un criterio para acercarse a la verdad):

An epistemic rule $\rho$ is (weakly) functional for approaching the truth if for all evidence $e$, $\rho$ 's preference of $\psi$ on basis of $e, \psi<\mathrm{p}_{\mathrm{e}} \varphi$, implies $\varphi \nless_{\mathrm{t}} \psi$ and leaves open the possibility that $\psi<_{\mathrm{t}} \varphi$ (Zwart, 2001, pág. 123).

Niiniluoto, por ejemplo, toma en cuenta que en la práctica científica no existen reglas epistémicas funcionales e irreversibles, sino que los científicos realizan conjeturas y refutaciones, y ninguno de sus métodos evade la reversibilidad, por ello, las evaluaciones de verosimilitud estimadas serán falibles y revisables; lo cual nos permite tener una regla que sea revisable y reversible; con ello invertir el orden de la preferencia de teorías cuando se obtenga nueva evidencia. La desventaja que tendría asumir esta postura es que no sería adecuada para la toma de decisiones. El problema reside en que, sin importar la cantidad y calidad de la evidencia, permite que nuevas pruebas inviertan el orden de preferencia, por lo tanto, no se puede explicar el éxito de la ciencia por medio de la aproximación a la verdad. Sean $\varphi$ y $\psi$ dos teorías en competencia, con la evidencia disponible en el tiempo t $\varphi$ es más cercano a la verdad que $\psi$; pero en t' a la luz de nueva evidencia $\psi$ es más cercana a la verdad que $\varphi$; si esto sucede, la primera afirmación debería explicar a la última situación, lo cual es una contradicción. Este sería el argumento de Laudan contra la aproximación a la verdad.

Kuipers realiza su propuesta mediante una regla que es irreversible para evitar ese problema, sin embargo, tiene un gran inconveniente, si observamos la práctica científica nos daremos cuenta de que los ordenamientos se revierten a la luz de nueva evidencia.

Otro de los aspectos del problema epistémico es que casi todas las teorías de la verosimilitud trabajan con la idea de la completitud de la verdad. La regla para la elección de teoría debe, por lo tanto, ser útil cuando se tiene en competencia cualquier par de teorías, incluso si éstas están formuladas en un marco conceptual indefinido. Debido a los términos teóricos que se utilizan en éstas, puede haber contextos en los cuales la verdad de la combinación de dos lenguajes puede estar incompleta (por 
ejemplo, combinar el éter con el flogisto). Esto abre la puerta a que algunas afirmaciones carezcan de un valor de verdad definido.

Si la verdad es indefinida, ¿por qué una regla epistemológica debe decidir entre teorías? se pregunta Zwart (pág. 124), para lo cual pone el ejemplo que supongamos que estamos en la época del flogisto, y que la mayoría de las observaciones que tenemos confirman a la teoría del mismo, mientras que sólo se han producido pocas anomalías que permiten mantener a dicha teoría como superior a la de sus predecesoras; entonces podemos llegar a la conclusión de que "está más cercana a la verdad" que sus rivales; y además estamos convencidos de que las nuevas pruebas que se conseguirán no van a revertir la actual jerarquía de teorías (incluso se cree que la corroboración es mayor, es decir, se tendrá como más verosímil). Aquí puede surgir una duda, ¿cuál es el contenido de la teoría verdadera en el marco del flogisto? Es muy escaso; principalmente porque el flogisto no existe, esto da como resultado que afirmaciones como "el flogisto tiene peso negativo" carezcan de referente y de valor de verdad definido. La regla $\rho$ debe ordenar dos teorías en un marco combinado entre flogisto y oxígeno donde algunas frases carecerán de valor de verdad:

In contrast to the context of the definition, in the epistemic context an adequate rule of theory-choice must inevitably deal with indeterminate languages. If a rule of theory-choice accompanies a truthlikeness definition, it must cope with the situation in which the truth is incomplete (ídem).

Zwart aclara que la regla $\rho$ no tiene que resolver el problema de variación linguiística. Si llega a suceder que la nueva evidencia dé lugar a un nuevo marco conceptual en lugar de la formulación de una nueva teoría en el marco anterior, esto irá más allá del alcance de la norma. La función de la regla es la de comparar dos o más teorías existentes dentro de un espacio conceptual y de ahí poder elegir una de ellas, porque está situada dentro del marco de justificación y no en el de descubrimiento.

Para la realización de este apartado se tomaron varias obras en cuenta, pero principalmente fueron Refined Verisimilitude (2001) de Zwart en la parte sobre las diferentes mediciones para el problema epistémico y las reglas que ofrecen, Verdades a medias (1996) de Zamora Bonilla para las críticas al programa de la verosimilitud y Likeness to truth (1986) de Graham Oddie en los aspectos de la crítica por medio del dilema y la relación entre verosimilitud y exactitud.

\section{Críticas al proyecto de la verosimilitud}

Una de las críticas más comunes al programa de la verosimilitud es que carece de utilidad para la práctica científica (Cohen, 1980) (Newton-Smith, 1981). El primer argumento es mediante un dilema; un cuerno dice que, si ya conocemos la verdad completa, entonces la noción es redundante, ¿para qué buscaríamos definir la verosimilitud o buscaríamos teorías aproximadas si ya tenemos la verdad?; el otro es si desconocemos la verdad, entonces tampoco sabríamos cuáles son los grados de verosimilitud de 
una proposición, entonces aquí veríamos que carece de aplicación el concepto. Por lo tanto, necesitamos que el problema lógico se relacione con el epistemológico y el metodológico.

Otra objeción es que en realidad la ciencia no está interesada en la verdad completa, sino que tienen metas más modestas, aunque estas pueden estar relacionados con ciertos aspectos de la verdad como las leyes causales del universo y no meramente describir todos los aspectos de la estructura del mundo. Entonces, si la ciencia no tiene como objetivo la verdad completa, intentar clarificar conceptos como aproximado a la verdad no tiene mucho sentido, porque lo que realmente se busca es la verdad acerca de las leyes de la naturaleza. Cohen piensa que entonces lo que debería explicarse es un concepto diferente al cual llama "legisimitud""73:

It looks as though the truth or likeness to truth that much of science pursues is of a rather special kind-we might call it 'physically necessary truth'-which is, as it were, truth about other physically possible worlds as well as about the actual one (Cohen, 1980, pág. 500).

Tomando eso en cuenta, los defensores de la verosimilitud parecen no mostrar mucho problema, por ejemplo, Niiniluoto (1998) opina que es suficiente con incluir un operador modal o de necesidad nómica para tomar en cuenta únicamente a las leyes.

Cohen considera que el enfoque verosimilituridiano falla como objetivo de la ciencia porque no logra explicar los siguientes requisitos: (1) lo que se busca no es sólo la verdad, sino el "conocimiento", es decir, no se trata únicamente de acumular verdades, sino de contar con buenas razones para aceptarlas; (2) la ciencia debe proporcionar un buen fundamento para la acción racional y así conseguir otros objetivos extracientíficos; (3) la ciencia no tiene como meta encontrar las peculiaridades accidentales del mundo, sino leyes causales verdaderas (Cfr. Zamora, 1996, 165-166). Del tercero ya se sabe la manera de resolverse, ahora veamos cómo justifica que la verdad aproximada no logra los primeros dos puntos.

En el caso del segundo requisito, el enfoque de la verosimilitud nos diría: si $\mathrm{h}_{1}$ tiene un valor de verosimilitud mayor que el de $\mathrm{h}_{2}$, entonces sería racional actuar con base a $\mathrm{h}_{1}$, sin embargo, Cohen piensa que esto es problemático. Da como ejemplo el caso de dos medicamentos diferentes que son altamente efectivos para curar alguna enfermedad, digamos que tienen un grado de verosimilitud de 90\%, alguien podría pensar al estilo de Popper que conjuntar ambas medicinas tendría un grado mayor de efectividad (y de verosimilitud) para curar dicha enfermedad, pero resulta que ingerirlas de manera conjunta es letal, por lo cual su mérito práctico es de 0 (Cfr. Cohen, 1980, pág. 494).

Zamora señala correctamente que Cohen está cometiendo una falacia en este ejemplo, puesto que afirmar que dos medicamentos por separado curan una enfermedad no equivale a que los dos

73 If we cannot convey such information in any other form than (1), it looks as though we are stuck with a problem about legisimilitude, not verisimilitude (Cohen, 1980, pág. 502). 
medicamentos en conjunto vayan a ser más efectivos: "El error de Cohen se debe a que interpreta la proposición que dice 'ambas medicinas curan la enfermedad' como si su significado fuese 'ambas medicinas administradas a la vez curan la enfermedad"” (1996, pág. 168).

Niiniluoto (Cfr. 1987, pág. 423) consideró esta objeción y utiliza un ejemplo donde una persona medita si puede caminar sobre una capa de hielo y tiene dos teorías, una que sobreestima el grosor real y otra que la subestima, aunque ambas tienen la misma distancia a la verdad, para la situación práctica utilizar la segunda teoría sería mejor porque en caso de elegir la primera podría caer; pero no considera que este sea un problema para la verosimilitud porque esto dependerá del problema cognitivo en cuestión.

El primero de los criterios es uno de los más utilizados para criticar el enfoque de la verosimilitud desde una perspectiva realista y hay varios autores que lo han esgrimido en contra de ella. Cohen lo ilustra de la siguiente manera:

Suppose, for example, a man who invents his own hypotheses prays to his deity that he will accept a proposition if and only if it is true or highly truthlike. He has the right aim, it seems, so far as defenders of the truth doctrine are concerned. But suppose that, having made his prayer and offered up his sacrifice, he then uses a lottery device, rather than a strategy of experimental tests, to guide his selection of hypotheses to accept or retain. Such an enquirer is hardly to be described as being engaged on serious scientific research, even if his hypotheses are all quite original and no-one else has yet solved any of the problems that he is tackling. Indeed, even if such a shaman, by some lucky chance or divine intervention, actually had a considerable run of success in picking the right propositions, subsequent historians would scarcely record his achievement as part of the history of science (1980, pág. 491).

Otro que ha empleado un argumento similar más recientemente es Alexander Bird:

Imagine a scientific community that has formed its beliefs using some very weak or even irrational method M, such as astrology. But by fluke this sequence of beliefs is a sequence of true beliefs. These true beliefs are believed solely because they are generated by $\mathrm{M}$ and they do not have independent confirmation. Now imagine that at time $t$ an Archimedes-like scientist in this society realises and comes to know that $\mathrm{M}$ is weak. This scientist persuades (using different, reliable methods) her colleagues that $\mathrm{M}$ is unreliable. This may be that society's first piece of scientific knowledge. The scientific community now rejectsits earlier beliefs as unsound, realising that they were formed solely on the basis of a poor method (2007, pág. 66).

Aquí ambos autores toman como idea de progreso a la acumulación de conocimiento y no meramente de verdades, podemos considerar que la ciencia progresa cuando tenemos más conocimiento que en la etapa anterior, lo cual no puede ser explicado por medio del enfoque de la verosimilitud porque en él sería suficiente la acumulación de verdades sin la debida justificación (pueden ser meramente accidentales), lo cual haría irracional a la empresa científica. Para Bird el progreso y la racionalidad no pueden ser divergentes.

Si observamos el ejemplo, para el defensor de la verosimilitud la comunidad pensada por Bird había conseguido progresar hasta antes del momento de que llegará el método adecuado, después tendría un retroceso y luego comenzaría a progresar de nuevo, lo cual parece un veredicto contradictorio de 
nuestras intuiciones ${ }^{74}$ : "The acquisition of beliefs by an unreliable method cannot be genuine scientific progress, even if the beliefs so acquired are, by accident, true" (ídem). Mientras que, para el defensor de la acumulación de conocimiento, el progreso comienza a suceder a partir de que tienen el método confiable.

Aquí lo que podría objetar el defensor del enfoque de la verosimilitud es que deben ser utilizados los conceptos de verosimilitud estimada o de distancia respecto a la evidencia que utilizan Kuipers y Niniiluoto; donde se afirma que el progreso no es en cuanto a la verosimilitud objetiva, sino a la estimada, y por lo tanto debemos elegir aquella teoría que tenga el mayor grado de verosimilitud estimada o su distancia a la evidencia sea menor. Sin embargo, se tiene el posible problema de si entonces los científicos ya no buscarían más evidencia, sino que plantearían sus nuevas teorías intentando que sean más cercanas a la evidencia disponible sin generar nueva evidencia. Otro asunto aquí es que los científicos tendrían aversión a la falsedad, puesto que no se ocuparían de ella, simplemente se dedicarían a buscar más y más verdades que apoyen a sus teorías.

\section{Mediciones de verosimilitud epistémica}

Para atacar el segundo cuerno del dilema, los defensores de la verosimilitud han planteado diferentes estrategias para poder afirmar que una teoría es aproximadamente verdadera o tiene mayor grado de verosimilitud que sus rivales, aunque no se conozca la verdad completa y así reivindicar la utilidad de la noción. A continuación, se explicarán algunas de las estrategias de la manera más breve posible.

\subsection{Popper: falsacionismo y corroboración}

Recordemos cuando se abordó la noción de verosimilitud de Popper que él mismo afirmaba que no pretendía que ella tuviera alguna utilidad epistémica, sino solamente semántica. Así sus criterios de justificación no derivan de la definición de verdad aproximada, pero sí de conceptos anteriores que él ya había planteado en su obra Logik der Forschung (1935) en donde se encuentra la denominada como falsación.

A la pregunta, ¿cómo podemos saber que una teoría $\mathrm{t}_{2}$ tiene mayor grado de verdad que $\mathrm{t}_{1}$ ? La respuesta sería que no sabe, simplemente hace conjeturas, las cuales se examinan mediante la crítica

\footnotetext{
${ }^{74}$ Eric Barnes comparte estas críticas al proyecto de la verosimiltud y comparte este enfoque de progreso como grados de conocimiento o knowledgelikeness, además expresa: $\mathrm{d}$. The problem with the verisimilitude project, in short, is that it can only evaluate a scien tist's performance at the level of the truth and falsity of his beliefs. But this level of analysis is too shallow to illuminate the notions of scientific 'success', 'failure', or 'progress'. The notion of 'truthlikeness' lacks the conceptual resources to understand science, its objective or its means of attaining it, in this very fundamental sense (1991, pág. 334).
} 
severa, si llega a resistir, entonces es una buena razón a favor para optar por ella, aunque esto puede ser falsable y después cambiemos de opinión ${ }^{75}$.

Una de las problemáticas de tomar la noción semántica de la verosimilitud de Popper para hacer este tipo de aseveraciones, haciéndola coincidir con el método de falsación, es que todas las teorías falsadas tienen el mismo valor: -1, lo cual no nos permitiría afirmar que una teoría falsa es más aproximada a la verdad que otra que, también, es falsa, lo cual iba en contra de los deseos de Popper porque una teoría falsada podría mantenerse como más cercana a la verdad que otra.

En el caso de que tuviésemos evidencia $e$ que describa de manera adecuada los experimentos pertinentes, entonces Popper sugiere dos reglas: 1) Proponer una teoría fuerte $\varphi$ que explique $e$ y después se intente falsar, si tenemos éxito en falsarla, entonces debemos proponer otra teoría $\psi$ que explique también los nuevos resultados experimentales $e^{\prime}$. Si la teoría $\varphi$ logra soportar la falsación, entonces $e$ y $e^{\prime}$ corroboran $\left.\varphi ; 2\right)$ Aceptaremos momentáneamente $\varphi$ como una explicación razonable de $e^{, 76}$.

Mediante este ejercicio es posible explicar por qué este proceso metodológico puede acercarnos más a la verdad. Esto es porque la falsación de las teorías aumenta el número de experimentos cruciales: "An experiment $e$ is a crucial test for $\varphi$ and $\psi$ iff, the truth of $e$ implies the falsification of $\varphi$ and corroboration of $\psi "$ (Zwart, 2001, pág. 126).

De lo anterior podemos derivar las siguientes reglas metodológicas que nos permitirán acercarnos más a la verdad según Popper. La primera es la de encontrar nuevas evidencias que falsen a una teoría $\varphi$ y que explique todas las evidencias previas se está haciendo un paso pequeño hacia la verdad. Si tomamos a $e$ como la evidencia explicada por $\varphi$, es decir $\varphi \vDash e$, y $e$ ' que es el resultado de nuevos experimentos falsee $\varphi$, por lo tanto, $e^{\prime} \vDash e \vDash \varphi$, podemos afirmar que $\varphi$ nos ha traído los nuevos conocimientos $e^{\prime}$. Si después alguien propone la nueva teoría $\mu$ que tampoco logra pasar los test $e$ ' entonces tenemos ahora un nuevo conocimiento $e$ ". Si hemos obtenido datos experimentales correctos, entonces mediante estos pasos conseguimos acumular evidencia y esto nos lleva cada vez más cercas a la verdad.

Ahora, el segundo paso, es que imaginemos que al intentar falsar la teoría $\psi$ no tenemos éxito, entonces tenemos $\psi \vDash e$ ’. Si después de muchos intentos por falsar $\psi$ no lo logramos, podemos tenerla como aproximada a la verdad (o verdadera) cuando menos de forma provisional. Si finalmente $\psi$ resulta

\footnotetext{
75 To put it a little differently, I assert that we know what a good scientific theory should be like, and-even before it has been tested-what kind of theory would be better still, provided it passes certain crucial tests. And it is this (metascientific) knowledge which makes it possible to speak of progress in science, and of a rational choice between theories (Popper, 1962, pág. 217).

76 Thus, it is my first thesis that we can know of a theory, even before it has been tested, that if it passes certain tests it will be better than some other theory. My first thesis implies that we have a criterion of relative potential satisfactoriness, or of potential progressiveness, which can be applied to a theory even before we know whether or not it will turn out, by the passing of some crucial tests, to be satisfactory in fact (Popper, 1962, pág. 217).
} 
falsada, volveremos al paso anterior. Así podemos ir aumentando nuestro conocimiento con nuevos datos empíricos.

In short: given error free evidence, crucial experiments bring us small steps closer to the truth. Moreover, failing attempts to falsify a strong theory $\phi$ corroborate a larger step towards the truth; if $\phi$ is true we have made a substantial step towards the truth (Zwart, 2001, pág. 126)

La siguiente recomendación que podemos tomar de Popper es que, si $\psi$ y $\varphi$ tienen el mismo grado de corroboración frente a $e$, entonces debemos optar por aquella teoría que sea menos probable, es decir, que su fuerza lógica sea mayor ${ }^{77}$.

La aceptación de una teoría es un aspecto falible. La afirmación " $\varphi$ es más cercana a la verdad que $\psi^{\prime \prime}$ es falible. Las recomendaciones metodológicas de Popper únicamente proveen una indicación falible de la verosimilitud de las teorías. Como todas las teorías falsadas reciben el mismo grado de corroboración -1, Zwart concluye que Popper se podría oponer a la regla reversible de la teoría de la elección. Una vez que $\varphi$ ha sido falsada por los experimentos cruciales que corroboran $\psi$, ya no se podría preferir $\varphi$ sobre $\psi$.

Además, como Popper y Miller suponen la completitud de la verdad, su noción no puede ser útil para cuando la verdad es incompleta porque asumen el lenguaje como si fuera semánticamente determinado.

\subsection{Kuipers y la regla del éxito}

Aunque no hablamos de la definición semántica de Kuipers, podemos hacer algunas referencias a su propuesta epistémica. Cabe aclarar que es complicado hacerlo de manera breve y difícilmente se le puede hacer justicia en poco espacio.

Básicamente la propuesta de Kuipers, que no es cuantitativa, se basa en lo que denomina como la regla del éxito (Cfr. 2000, pág. 114): mayor similitud con la verdad implica mayor éxito empírico. Esto quiere decir que, si una teoría $\varphi$ se prueba que tiene una mayor cantidad de éxito que la teoría $\psi$, entonces eliminaremos $\psi$ en favor de $\varphi$, cuando menos por un tiempo.

Aunque una teoría haya sido falsada todavía puede ser la mejor que tengamos a disposición, por lo tanto, puede ser la que esté más cercana a la verdad entre las diferentes teorías disponibles. Así, si una teoría $\varphi$ ha demostrado ser la más exitosa, entonces realizamos la inferencia a la mejor teoría (Cfr. 2000,

\footnotetext{
77 This criterion of relative potential satisfactoriness (which I formulated some time ago, 2 and which, incidentally, allows us to grade theories according to their degree of relative potential satisfactoriness) is extremely simple and intuitive. It characterizes as preferable the theory which tells us more; that is to say, the theory which contains the greater amount of empirical information or content; which is logically stronger; which has the greater explanatory and predictive power; and which can therefore be more severely tested by comparing predicted facts with observations. In short, we prefer an interesting, daring, and highly informative theory to a trivial one.

All these properties which, it thus appears, we desire in a theory can be shown to amount to one and the same thing: to a higher degree of empirical content or of testability. (Popper, 1962, pág. 217).
} 
pág. 171). Kuipers piensa que con ello estamos justificados para concluir cuando menos provisionalmente que $\varphi$ está más cerca de la verdad que sus rivales. Además, considera que es necesario añadir que una vez que hayamos tomado a $\varphi$ como más aproximada a la verdad, esto no es suficiente, sino que debemos aplicarle varias pruebas para ver si las pasa y poder evaluar su confiabilidad.

El problema con este tipo de estrategias es que el realismo científico intenta establecer que el éxito empírico se explica por medio del alto grado de aproximación a la verdad, y si estamos explicando el grado de verosimilitud con base a su éxito empírico, entonces estamos cayendo en una circularidad. La complicación aumenta cuando sabemos que muchas teorías han sido altamente exitosas a pesar de estar muy alejadas de la verdadera estructura del mundo.

\subsection{La verosimilitud estimada}

Los defensores del enfoque de similitud Truthlikeness han propuesto una medición específica para solucionar el problema epistémico. Zwart (2001) lo explica mediante un ejemplo: imaginemos un juego donde un participante reciba una suma de dinero en un inicio, a continuación, debe pronosticar el resultado del lanzamiento de un dado, la diferencia entre su conjetura, el resultado real será la cantidad de dinero que se le reste. El jugador deberá preguntarse cuál será la conjetura más razonable y la respuesta es aquella que minimice las posibles pérdidas ante el resultado, es decir: 3 o 4.

Un caso similar aplicaría para los científicos en el momento que tienen que elegir una teoría cuando tienen varias opciones deberán optar por la que consideren más cercana a la verdad (cuál tendría menos pérdidas ante la evidencia). Así, la teoría con una mayor verosimilitud estimada es preferible.

¿Cómo se hace la medición estimada de la verosimilitud? Niiniluoto propone que se utilice la lógica de inductiva de Hintikka (aunque Tichý y Oddie preferirían que se utilizase otra lógica inductiva que no causara tanta controversia), puesto que únicamente contamos con una muestra empírica (el resultado de experimentos y observaciones) denominado como evidencia $e$ con la cual se asigna grados de probabilidad distintos a cero a por lo menos alguno de los constituyentes de un espacio lógico.

Tomaremos a p(a,e) como la función de probabilidad inductiva, su valor será 0 si $e$ implica $\neg$ a y 1 si $e$ implica a, el valor puede variar entre esos dos límites si no es ninguno de los dos casos, p(a,e) puede entenderse como "el grado de confirmación de a en función de $e$ ", la función de verosimilitud estimada de una hipótesis dada la evidencia $e$ será la siguiente:

$\mathrm{Ve}(\mathrm{a}, \mathrm{e})=1-\Sigma(\mathrm{i} \in \mathrm{I}) \mathrm{P}\left(\mathrm{c}_{\mathrm{i}}, \mathrm{e}\right) \bullet \mathrm{D}\left(\mathrm{c}_{\mathrm{i}}, \mathrm{a}\right)=\Sigma(\mathrm{i} \in \mathrm{I}) \mathrm{P}\left(\mathrm{c}_{\mathrm{i}}, \mathrm{e}\right) \bullet \mathrm{Vs}\left(\mathrm{c}_{\mathrm{i}}, \mathrm{a}\right)$ (Zamora, 1996, pág. 124)

Así tenemos como resultado que el grado de Ve de una hipótesis a es el valor esperado de la función Vs dada la probabilidad que asigna la evidencia $e$ a cada uno de los constituyentes del espacio lógico. Se 
puede observar que cuando $\mathrm{Ve}=1$ o muy cercano, entonces $\mathrm{Ve}(\mathrm{a}, \mathrm{e})=\mathrm{Vs}(\mathrm{a})$ que es una de las condiciones que se pide para que una noción de Ve sea aceptada.

Otro de las desideratas es que sea útil para saber si una hipótesis es más aproximada a la verdad que otra sin la necesidad de realizar cálculos muy complicados. Sin embargo, los casos en los que esto sucede son muy poco interesantes, además suponen que $\mathrm{P}\left(\mathrm{c}_{\mathrm{i}}, \mathrm{e}\right)$ es 1 o muy cercana, por ejemplo: la verosimilitud estimada de $a$ es mayor que la de $b$ dada la evidencia $e$ cuando $a$ es idéntica a $e$ y $b$ no lo es, cuando $b$ es una tautología y $a$ es un enunciado contingente, o si $a$ implica lógicamente a $b$, pero no sucede a la inversa, también cuando $c_{i}$ está en la forma normal disyuntiva de $a$. El problema con esto es que hace una suposición muy fuerte que equivale a saber cuál es el constituyente verdadero, dado que exige que la evidencia otorgue a uno sólo la máxima probabilidad, o muy alta, y (casi) nulo a los demás.

La verosimilitud estimada de Niiniluoto es revisable y reversible, si dado $e$ a tiene un grado de verosimilitud estimada mayor que $b$, al pasar del tiempo con $e$ ' es posible que $b$ tenga una mayor verosimilitud estimada que $a$. Sin embargo, esto carece de utilidad si en la mayoría de los casos de Ve es imposible saber el grado estimado de verosimilitud tanto de $e$ como de $e^{\wedge} e^{\prime}$ otorgan $a$ y $b$, debido a la alta dificultad de los cálculos que se necesitan.

La principal problemática para la noción de $V e$ es que la probabilidad inductiva sólo es útil en lenguajes muy simples, puesto que tenemos un gran número de constituyentes $\mathrm{c}_{\mathrm{i}}$ se complicaría demasiado saber los valores de $P$ en cada caso, al igual que los de $\mathrm{D}_{\mathrm{i}}$, a esto se le suma la imposibilidad de encontrar un método para determinar el conjunto de constituyentes que equivalen a cada enunciado. Dado que no cumple con ser una función manejable es difícil saber cuándo una teoría tiene un valor estimado de verosimilitud mayor que otra. Su aplicación es muy restringida y por lo tanto tiene resultados pobres: "Vemos, por lo tanto, que las 'soluciones' que se han dado hasta ahora para el problema metodológico no son ni mucho menos satisfactorias" (Zamora, 1996, pág. 156).

El defensor de este enfoque podría tentarlo el afirmar que sólo debería tomarse en cuenta la “evidencia relevante” respecto a un problema y con ello poder hacer los cálculos de una manera más tratable. Sin embargo, esto no haría más que provocar problemáticas, puesto que no está claro cómo se podría elegir cuál sería la evidencia relevante, además de que es posible que dada la de elección de una parte de la evidencia, $\varphi$ tenga un grado de verosimilitud estimado mayor que el de $\psi$, mientras que, si se hubiera elegido otra parte de la evidencia, puede suceder que se revierta el ordenamiento.

Niiniluoto desea que su noción de verosimilitud estimada sea utilizada para analizar la historia de la ciencia más que como un criterio de elección de teorías. Mediante ello su propuesta es reconstruir los cambios de teoría a través del tiempo y mostrar que ellas van aumentando su verosimilitud estimada. Sin 
embargo muestra algunas problemáticas, dado que parece obvio que nuestras teorías actuales serán más aproximadas a la verdad ya que se tomará como más importante la evidencia con la que ahora contamos (con la cual es juzgado su éxito), las teorías inmediatas anteriores (si son lo suficientemente parecidas a la actual) tendrán una mayor verosimilitud que sus predecesoras, y así sucesivamente (sólo se verán cambios drásticos en los momentos de revolución): "Because of this circularity, also this way of using the notion of verisimilitude in a reconstruction of scientific methodology seems rather uninteresting" (Kieseppä, 1996, pág. 49).

A pesar de las complicaciones, Oddie destaca algunos resultados interesantes de esta noción en marcos muy restringidos como el que hemos utilizado acerca del clima. Por ejemplo, supongamos que $e$ nos arroja que es $h^{\wedge}(\neg \mathrm{rv} \neg \mathrm{w})$, este tendría un grado estimado de 0.70 , mientras que $h$ de 0.66 , $\neg$ rv $\neg$ w de 0.54 y la tautología es de 0.50. También se tiene que algunas hipótesis tienen un grado de verosimilitud esperada mayor que el que apoya la totalidad de $e$, la hipótesis con mayor Ve es la que tiene mayor fuerza: $\mathrm{h}^{\wedge} \neg \mathrm{r}$ y $\mathrm{h}^{\wedge} \neg \mathrm{w}$ es de 0.72 , mientras que $\mathrm{h}^{\wedge} \neg \mathrm{r}^{\wedge} \neg \mathrm{w}=0.77$.

Tomar a la verosimilitud estimada como una medida de utilidad epistémica tiene virtudes que no presentan otras como la de Hempel, Pietarinen y Hintikka, tal es el caso de que una hipótesis falsada puede tener un mejor valor de aproximación a la verdad que una verdadera, por ejemplo, la afirmación $\mathrm{h}^{\wedge} \mathrm{r}^{\wedge} \mathrm{W}$ que no está apoyada por la evidencia (es falsa), tiene un valor de 0.55 que está por encima de la tautología.

Otra virtud es que si la evidencia completa nos dice que la verdad es $\mathrm{h}^{\wedge} \mathrm{r}^{\wedge} \mathrm{W}$, entonces $\mathrm{h}^{\wedge} \mathrm{r}^{\wedge} \neg \mathrm{W}$ tendrá un valor de 0.66 , lo cual es la misma medida para la verosimilitud semántica; entonces verosimilitud estimada y real coinciden.

\section{Respuestas a las críticas}

Oddie considera que el dilema que comentamos en un inicio comete en varias falacias. Afirma que el hecho de que no se puede asignar el grado de verosimilitud de manera infalible cuando sólo se cuenta con el conocimiento parcial, eso no quiere decir que carezca de utilidad. Es útil para conocer si una proposición posee cierto grado verosimilitud (si sabemos o no el grado que tenga) como en el caso de si una proposición posee un valor de verdad (aunque no sepamos si es verdadero o falso). Considera que si la noción de verosimilitud es coherente no debemos desesperarnos, al contrario, es un motivo para el optimismo.

La segunda falacia se refiere a que sí es posible conocer el grado de verosimilitud en condiciones de conocimiento parcial de algunas proposiciones. Las tautologías, por ejemplo, siempre tendrán el valor de 0.5 , las contradicciones de 0 , incluso si sabemos que la verdad es w y desconocemos los demás estados, entonces la afirmación w tiene la verosimilitud de 0.66 . 
La tercera falacia es acerca de la noción de verosimilitud estimada. En ciencia, incluso cuando no sabemos una magnitud de manera exacta y precisa, se pueden hacer buenas estimaciones conforme a la evidencia hacia el valor real. El valor esperado de una magnitud es la mejor estimación de su valor que se obtiene con la evidencia disponible. Por lo tanto, aunque el grado de verosimilitud de una proposición no se puede comprobar empíricamente en todos los casos, podemos ver que es similar a otras nociones.

De hecho, Oddie muestra que hay una especie de tendencia con la cual se pueden correlacionar exactitud, precisión y verosimilitud estimada, mostrando con ello que, si los científicos optan por las teorías que ofrecen una mejor exactitud o precisión global, entonces también lo están haciendo por una de mayor verosimilitud (Cfr. Oddie, 1986, págs. 183-187) xxx78. $^{\text {. }}$

Respecto a quienes consideran que el progreso es una acumulación de conocimiento más allá que acumulación de verdades, parece que los defensores de este enfoque conceden que tienen la razón, sin embargo, con la noción de verosimilitud estimada cumplen con ese requisito. Aclaran que analizar el progreso científico como un aumento de verosimilitud no implica que todos los cambios hayan sido siempre progresivos, sino que en algunas ocasiones han sucedido regresiones y la posibilidad de que suceda de nuevo está abierta; pero dada la cualidad de que la ciencia es autocorrectiva puede tomarse como una garantía de que el cambio de teorías típicamente es progresivo.

Niiniluoto (2014), Tambolo (2011) y Cevolani (2013) hacen hincapié en la distinción entre progreso real y progreso estimado, el primero se da si sabemos la verdad completa, lo cual es muy complicado, el segundo es más accesible porque se mide conforme a la evidencia disponible; además que al ser falibilista dicha estimación puede ser errónea cuando se hagan reconsideraciones con las nuevas evidencias teóricas y observacionales. Así, un progreso real sucede cuando se da un cambio de $\varphi$ a $\psi$ y $\operatorname{Vs}(\varphi)<\operatorname{Vs}(\psi)$, mientras que el progreso estimado sería cuando se hace un paso de $\varphi$ a $\psi$ con base a la evidencia $e \operatorname{Ve}(\varphi, \mathrm{e})<\operatorname{Ve}(\psi, \mathrm{e})^{79}$.

\footnotetext{
${ }^{78}$ Muy similar a lo propuesto por Zwart: It is argued that truthlikeness is the best candidate for the role of epistemic (or cognitive) utility (or value). I define the overall accuracy of a proposition with respect to particular questions, and develop a plausible conjecture concerning the close relationship between degrees of truthlikeness and degrees of overall question answering accuracy. If correct, this conjecture is of considerable importance for both theory and practice. Confidence in the truthlikeness of apparently accurate theories would be justified. And the more truthlike a theory, the more likely it would be to give accurate answers to pressing practical problems. (Zwart, 2001, pág. xii).

79 As a consequence of the above mentioned distinction between the logical and the epistemic problem of verisimilitude, progress can be characterized within VS both as real progress (or progress in the logical sense), construed as increasing verisimilitude, and as estimated progress (or progress in the epistemic sense), construed as increasing estimated verisimilitude (Niiniluoto 1999a, 2011a). Within VS, then, the step from T to T' is said to be progressive (in the sense that it constitutes real progress) if and only if T0 is more verisimilar than T, while the step from $\mathrm{T}$ to $\mathrm{T}$ ' is said to seem progressive (in the sense that it constitutes estimated progress), given the available evidence, if and only if the verisimilitude of T0 is estimated higher than the verisimilitude of $\mathrm{T}$ on the basis of that evidence.

To sum up: within VS, the (whole) truth is seen as the ideal goal of inquiry. Nevertheless, it seems extremely unlikely that we shall ever be able to reach such a goal, since as far as we know even our best theories may well be false. As a consequence,
} 
Como sabemos, medir la verosimilitud con la verdad total es un asunto prácticamente imposible, lo único que podemos hacer es respecto a la evidencia disponible. Dado que las teorías que estén mejor soportadas por la evidencia serán las de mayor grado de verosimilitud estimada, entonces no hay razón por la cual tengan cabida creencias irracionales o creencias sin algún tipo de justificación ${ }^{80}$. Por lo tanto, si tomamos en cuenta Ve, el progreso de la comunidad de Bird comenzará después de obtener un buen método para justificar sus hipótesis.

Además, Niiniluoto (2014, pág. 76) considera que Ve puede explicar bien casos históricos cuando los científicos preferían una teoría $\varphi$ a otra $\psi$ y ahora nosotros tenemos la preferencia contraria, y esto es porque la evidencia disponible en ese momento mostraba la estimación de la verosimilitud de $\varphi$ con grado mayor que la de $\psi$, es decir, estaban más justificados en creer $\varphi$ que $\psi$; pero con la llegada de nueva evidencia se invirtió la jerarquía. Esto sucedió con Aristarco contra Ptolomeo con el heliocentrismo y el geocentrismo, o con Wegener y la deriva continental.

Respecto a la objeción de que si tomamos a la verosimilitud estimada como nuestro parámetro para el progreso, entonces los científicos únicamente se dedicarían a formular teorías que fueran cada vez más verosímiles con la evidencia disponible y no saldrían a buscar nuevas evidencias; tenemos que recordar que desde una perspectiva falibilista se propone poner a prueba a nuestras mejores hipótesis y esto generará nueva evidencia constantemente con la cual serán evaluadas las teorías científicas.

La otra acusación de Bird es que los defensores de la verosimilitud plantearían al científico como una especie de buscador de verdades que no se interesa por evitar la falsedad mientras pueda seguir aumentando la cantidad de verdades. Con ello es suficiente aclarar que lo que busca el defensor de la verosimilitud es la verdad informativa, la combinación entre verdad y contenido con respecto a una pregunta relevante o un problema cognitivo. Recordemos que una teoría es altamente verosímil cuando dice muchas cosas sobre el mundo, muchas de ellas son verdaderas y pocas son falsas. El defensor de la verosimilitud plantea el juego de excluir falsedades y preservar (y aumentar) las verdades. En las mediciones anteriores vimos de manera clara que las afirmaciones $\neg \mathrm{h}^{\wedge} \neg \mathrm{r}^{\wedge} \mathrm{W}$ y $\neg \mathrm{h}^{\wedge} \neg \mathrm{r}$ tiene un valor de

the main cognitive goal of scientific research is assumed to be the search for highly verisimilar theories, i.e., theories which, though presumably false, are close to the truth (Cevolani \& Tambolo, 2013, pág. 927).

${ }^{80}$ Consider again the distinction between real and estimated progress. Such a distinction is motivated by the fact that there is no way to ascertain whether a given belief exhibits a genuine correspondence to "the real world": progress, construed as real progress, is something to which we have no epistemic access. On the other hand, progress, construed as estimated progress, is something to which we do have epistemic access. However, since the estimates of the verisimilitude of theories are subject to revision in the light of new evidence, the champions of VS recommend caution in the acceptance of theories. In other words, we may say that, contrary to what Bird seems to believe, VS has a well-developed "epistemic side", aimed at exerting control over the beliefs that the scientific community embraces; and that the epistemic side of VS works as a kind of filter, which minimizes cases of acceptance of beliefs lacking appropriate grounding in the evidence. In order to appreciate this, one only needs to elaborate a bit on what has been said above concerning Kuipers' Inference to the Best Theory (Tambolo, 2011, pág. 565). 
verosimilitud mayor que el de $\neg \mathrm{h}^{\wedge} \neg \mathrm{r}^{\wedge} \neg \mathrm{w}$, lo cual nos parece suficiente para ver que se buscará eliminar la falsedad y preservar las verdades. Por lo tanto, el enfoque verosimilituridiano sí da cuenta de los experimentos mentales planteados por Bird y Cohen, además puede sortear las objeciones que se le atribuyen.

Aunque su principal problemática reside en las dificultades para medir los grados de verosimilitud estimada en los casos realmente interesantes de la historia de la ciencia, lo cual terminaría resultando en una herramienta inútil para lo que fue ideada por su alta complejidad para poder ser aplicada. 


\section{Capítulo V. Verdad aproximada, deflacionismo y modelos}

Truth ... is much too complicated to allow anything but approximations.

John von Neumann

\section{Introducción}

Aunque Psillos no ha defendido su noción de verosimilitud, sí ha indicado cuál es una posible respuesta para resolver este problema, lo menciona en las notas al final de su libro de 1999 (p. 304) y de la misma manera en "The Present State of the Scientific Realism Debate” (2000, pág. 722), y lo que nos dice es que el camino a seguir es la propuesta de Peter Smith que se encuentra en su libro El caos (2001, págs. 77-95) $)^{81}$ y en otros dos ensayos: "Approximate Truth and Dynamical Theories” (1998a) y “Approximate Truth for Minimalists" (1998b). En este capítulo se analizará lo que se afirma en esta propuesta, sus posibles problemas y aplicaciones.

\section{Un enfoque minimalista para la aproximación a la verdad}

Al igual que Psillos, Smith afirma que las teorías científicas "no pueden ser estrictamente verdaderas" (Smith, 2001, pág. 77), dado que para poder crearlas y manejarlas se realizan una gran cantidad de idealizaciones y de abstracciones, por lo tanto, no están haciendo referencia de manera exacta al mundo al real, ¿esto provocaría un escepticismo global conforme a las teorías? Smith considera que lo natural es reconocer que, aunque las teorías suelen idealizar y hacer abstracciones no serán ciertas si les aplicamos estándares muy estrictos, pero que pueden ser más o menos aproximadamente verdaderas.

La propuesta de Smith al respecto de qué queremos decir cuando expresamos "aproximadamente verdadero" se enmarcará dentro de una perspectiva minimalista o deflacionista de la verdad, donde afirmar que "la nieve es blanca" es verdadera, es únicamente decir que la nieve es blanca, en lugar de comprometerse con una teoría correspondentista, e intentará ver si es posible utilizar dicha propuesta dentro del realismo científico optimista, a esta propuesta le llama exposición ingenua de la verdad aproximada (Cfr. 2001, pág. 79).

$\mathrm{Su}$ deflacionismo es aquel en donde se afirma que los predicados de verdad son simplemente un dispositivo formal descitacional (decir que algo es verdadero es simplemente decir que algo es). La problemática surge porque no se puede "descitar" en grados, no hay un más o menos en el aspecto de la discitación, entonces Smith se pregunta: "how can there be more or less in matters of truth?" (1998b, pág. 119).

Nos pide primero que supongamos que la teoría minimalista es correcta y que casi toda la verdad acerca de la verdad se encuentra dada por el esquema desentrecomillador: “[D] ' $\mathrm{P}$ ' is true if and only if

${ }^{81}$ The Chaos 1994. 
P" (1998b, pág. 120). Si los predicados de verdad son únicamente un predicado formal de descitación, entonces sólo se pueden utilizar para respaldar afirmaciones con o sin repetirlas explícitamente; por lo tanto, nos encontramos ante una propiedad que no puede estar en diferentes modos o grados. Así pues, las modificaciones aparentes de los predicados de verdad deberán ser mejor entendidas como modificaciones de las proposiciones que se está diciendo que son verdaderas ${ }^{82}$.

Los casos paradigmáticos donde una construcción de la forma 'P' es M-mente verdadera es legítima será en los casos en que M-mente es en realidad un adverbio modificador de la frase y en tales casos la descitación predice que tendremos el esquema: "[M] 'P' is M-ly true if and only if M-ly P" (1998b, pág. 120) (1998a, pág. 256) ${ }^{83}$ donde el lado derecho del bicondicional explica el contenido del izquierdo [Exp]. Y entonces tenemos la siguiente aplicación: “'P' is allegedly / unfortunately / unexpectedly / probably true if and only if allegedly / unfortunately / unexpectedly / probably P" (1998b, pág. 121). Aquí se pueden tolerar pequeñas excepciones a la afirmación general de que los adverbios que no sean modificadores no se aplican a la verdad. Por ejemplo: " $\mathrm{P}$ ' is partly/nearly all/wholly true" (ídem). Pero son apropiadas sólo cuando 'P' es suficientemente complejo, por lo tanto son equivalentes a "Part of/nearly all of/the whole of 'P' is true" (ídem). Los adverbios como "parte" no modifican descriptivamente el predicado de verdad, simplemente restringen su alcance de aplicación ${ }^{84}$. Esta definición podría ser útil para los casos en los que verosimilitud se utiliza cuando las partes o la totalidad de una teoría o un conjunto de afirmaciones son verdaderas (o falsas), es decir, como el primer ejemplo mostrado en el capítulo 2 .

De nuevo, el descitacionista puede tolerar excepciones menores al principio $[\mathrm{M}]$ aplicado a adverbios modificadores de frases, por ejemplo: “[P] 'P' is possibly true if and only possibly P" (1988b, pág. 121): "Suppose that, pointing to the headline in the tabloid - 'Junior Minister Took Bribes' - you claim that this allegation may be unlikely but remains possibly true: what you say is correct just if the relevant junior minister possibly took bribes" (ídem), pero hay otros casos donde lo que se debe considerar como una posibilidad no se encuentra relacionado con una cuestión política o psicológica, sino a la lógica o a las consideraciones conceptuales, por ejemplo: “'Todos los solteros son casados' es posiblemente verdadera si todos los solteros son casados”, esto sólo sería posible si se nos permitiera

82 "Lo que significa que el predicado de verdad no expresa una propiedad que pueda presentarse en diversas modalidades o grados. Por tanto, más vale que las modificaciones aparentes del predicado de verdad se entiendan como modificaciones de la proposición cuya veracidad se afirma" (Smith, 2001, pág. 80)

83 [M] M es $M$-mente verdadero si, y sólo si, es M-mente P.

${ }^{84}$ Una de las objeciones que considera Smith es el problema de los malapropismos, cuando se da un ligero cambio a las palabras, pero la confusión en estos casos es evidente, una cosa es decir que una frase casi está en lo cierto respecto a cómo son las cosas en el mundo y otra cosa es que una frase sea muy similar a otra. Esta es la diferencia entre estar cerca de la verdad y estar cerca de una verdad, nuestro esquema se aplica al primero y no al segundo (Cfr. 2001, pág. 82). 
hacer un cambio en los significados, pero dado [Exp] el significado de la parte derecha del bicondicional nos dirá cómo tomaremos el de la izquierda, ahora si estamos dentro de nuestro uso común del significado de "soltero" y "casado" dicha afirmación falla (puesto que es falsa). Sin embargo, este tipo de salida de la aplicabilidad general de $[\mathrm{M}]$ no es ninguna amenaza para el descitacionalismo (ídem).

Estas son algunas excepciones explicables, por lo tanto, un descitacionismo mínimo predice que [M] se mantiene para los adverbios oracionales, y que los adverbios no oracionales serán inaplicables a los predicados de verdad. Por el contrario, las excepciones a $[\mathrm{M}]$ hundirían al descitacionalismo al revelar la verdad como una propiedad más que formal que puede "come in its own proprietary flavours" (1998b, pág. 122).

Este descitacionismo predice: "[A] 'P' is approximately true if and only if approximately $\mathrm{P}$ ” (1998b, pág. 122) (1998a, pág. 256) ${ }^{85}$, se mantiene bien, donde el orden de la explicación va, de nuevo, de derecha a izquierda a través del bicondicional [Exp] (1998a, pág. 256) ${ }^{86}$, también aclara que "aproximadamente" debe ser tomado como "al menos aproximadamente" para no descartar lo estrictamente verdadero. Hablar de verdad aproximada obtendrá apoyo en los dominios donde el modificador "aproximadamente" pueda sensatamente ser aplicado a las proposiciones: "And the task of construing the notion of approximate truth then decomposes into the many tasks of explaining how the modifier works in its application to propositions of various types" (1998b, pág. 123).

En los tres textos maneja los mismos dos ejemplos para esta parte: 1) "Pedro mide 2 metros" es aproximadamente verdadero porque Pedro mide aproximadamente 2 metros. El segundo "aproximadamente" sirve para hacer difusa (fuzzify) la afirmación y el grado de indeterminación será indicado por una dependencia contextual. Smith reconoce que aquí habrá problemas en la semántica de los conceptos vagos, por lo tanto, también los habrá en la semántica de un operador difuminador; sin embargo, considera que no hay ningún problema adicional para comprender la noción de verdad aproximada de alguna proposición cuando se entiende el significado de que una proposición sea aproximadamente verdadera cuando esto es equivalente a afirmar la veracidad correspondiente a la proposición difusa (Cfr. 1998, pág. 257).

El segundo ejemplo nos dice que "Snoopie es un spaniel" es aproximadamente verdadero porque Snoopy es aproximadamente un spaniel, lo cual es bastante aproximado en algunos contextos. Aquí no hay problema con predicados difusos, sino que ser aproximadamente de un tipo se interpreta de forma natural como ejemplo de algún tipo de árbol jerárquico. Así, la afirmación es aproximadamente a la

85 «» es aproximadamente verdadera si, y sólo si, es aproximadamente P (Smith, 2001, pág. 79).

86 [Exp] El orden de explicación va de derecha a izquierda a través del bicondicional [A] (Smith, 2001, pág. 79). 
verdad porque ser un spaniel es muy cercano a ser un beagle en el árbol de la familia zoológica, no tanto si afirmáramos que es un oso, los cuales están más retirados (Cfr. 1998, pág. 257).

Este caso nos puede recordar a los que proporcionaron Aronson, Arre y Way vistos en el capítulo 3, pero su error es suponer que el orden de las clases naturales en subtipo y supertipo podrían proporcionar la base de una teoría general de la verdad aproximada. Smith no se compromete con la existencia de esos supertipos y subtipos como clases naturales, los dominios pueden tomarse de manera distinta.

Para otros afirmar que "Snoopy es un cocker spaniel" es aproximadamente verdadero les parece un poco extraño, pero también piensan lo mismo de "Snoopy es aproximadamente un cocker spaniel", al ser iguales sus reacciones, entonces Smith considera que podemos decir que confirman que su esquema funciona bien al lado de [Exp] dado que los grados de aceptabilidad deben ir unidos (Cfr. 1998, pág. 257).

Con ello Smith sugiere que el modificador "aproximadamente" debe ser sensible para ser aplicado a una proposición dada, algún término focal (o varios) en la proposición debe ser localizable en un dominio que está sujeto a cierta ordenación natural (clase de las alturas o de los mamíferos) (si hay varios dominios donde puede estar la proposición, el contexto o la persona puede aclarar cuál es); dicha estructura del dominio relevante para la comparación puede variar ampliamente entre los diferentes tipos de proposición. Recordemos que la lectura descitacional de [A] va de derecha a izquierda, sus aplicaciones de la verdad aproximada se explican a través de la aplicación del operador de aproximación a cualquier proposición en donde se trate. Por lo tanto, los dos ejemplos ya nos indicaron diferentes nociones de la verdad aproximada que requerirán distintos tipos de dilucidación detallada. Por ello tenemos una razón principal de por qué no debemos esperar que lo que sirvió en un dominio necesariamente vaya a ser útil en otro ${ }^{87}$.

Smith piensa que su propuesta puede ser atractiva dentro de otros minimalismos: "We need not consider here which of the candidate 'thin' theories run best: for I conjecture that, if you are any sort of minimalist, you should be happy to proceed on the basis of the same framework stance on approximate truth which is compulsory for the pure disquotationalist” (1998b, pág. 126). Menciona como ejemplo a la postura de Wright y otra que denomina como "minimalismo filtrado", en estos casos se eliminan ciertas oraciones como "candidatas" a aplicárseles el predicado de verdad; sin embargo, en ese conjunto

\footnotetext{
${ }^{87}$ Similar a lo expuesto por Brink: But we are also convinced that it is incorrect to speak of "the notion of necessity', since in different modal logics (co-existing more or less peacefully) the necessity operato behaves differently. The point is that we could not have known at the outsel whethter computability or necessity would have a single or various reasonmable explications, and there is no reason to think that verisimilitude is any diferrent (Brink, 1989, pág. 199)
} 
resultante de oraciones donde es válido aplicarse el predicado de verdad también podrá utilizarse nuestro esquema de aproximación a la verdad:

To be sure, pure disquotationalism, Wright's brand of minimalism, and the 'filtered minimalism' just sketched don't exhaust the class of relatively minimal or 'thin' theories of truth; but similar considerations seem to apply across a range of cases. We need not consider here which of the candidate 'thin' theories runs best: for I conjecture that, if you are any sort of minimalist, you should be happy to proceed on the basis of the same framework stance on approximate truth which is compulsory for the pure disquotationalist (pág. 125).

Además, considera que este enfoque también debe servir para quienes creen que la verdad es una cuestión de existencia de algo correspondiente a una situación o hecho; pero la existencia no admite grados, en este caso tampoco podría admitirlos la verdad. Si tomamos esta perspectiva, cualquier enfoque que tenga como objetivo dar contenido a alguna noción de verdad aproximada debe respetar la noción de que la verdad (como la existencia) es un asunto de todo o nada. Si esto es así: "what else is there to do but explain apparent modifications of the truth-predicate by appeal once more to [M], read right-toleft?" (ídem).

Smith declara que no necesariamente se refiere a una noción de verdad deflacionista (únicamente) $)^{88}$, lo que nos ofrece es lo que hay que entender para poder controlar la noción de verdad aproximada, cómo el modificador "aproximadamente" funciona aplicándose a diferentes frases que carecen de predicados de verdad, explicando que, en detalle, requiere una historia sustancial, la cual será bastante diferente en los distintos casos.

Una última aclaración de Smith es con respecto a los grados de verdad, dado que no podemos descitar en grados, no podemos tolerar una invocación a los grados de verdad como si tuviéramos una base firme para hacerlo - es decir, no podemos asignar un número para decir cuán cerca o lejos está una afirmación de la verdad. Sin embargo, no por ello debemos rechazar que hablemos de los grados de verdad, por ejemplo, puesto que podemos dar sentido a las afirmaciones sobre la estatura de Jack como “se aproxima a seis pies" es extremadamente cercano / muy cercano / algo cercano / muy alejado a la verdad. Así, en lugar de decir que un enunciado se aproxima más o menos a la verdad, es posible afirmar que es verdadero en varios grados:

However, the crucial point for the minimalist (of any persuasion) is that our grasp of any such constructed notion of degrees of truth must be elucidated by independently explaining how the adverbs like 'approximately', 'very roughly' work and then reading [A] (or its close kin) from right to left rather than vice versa (pág. 126).

88 “aunque la aproximación marco a la verdad aproximada, encapsulada en [A] y [Exp], debiera resultar especialmente atractiva a quienes ya se sienten atraídos por una exposición reduccionista de la verdad llana, la aproximación no es en sí, y no pretender ser, deflacionaria en sentido alguno. (Smith, El caos: una explicación a la teoría, 2001, pág. 83) 


\subsection{Aplicación a las teorías}

¿Cómo podríamos aplicar [A] y [Exp] a las teorías científicas? Si tenemos una teoría con una conjunción de proposiciones $\mathrm{P}^{\wedge} \mathrm{Q}^{\wedge} \mathrm{R}$ le aplicaríamos el esquema $[\mathrm{A}]$ y quedaría “ $« \mathrm{P}^{\wedge} \mathrm{Q}^{\wedge} \mathrm{R}$ ” es aproximadamente verdadero si, sólo si, es aproximadamente $\mathrm{P}^{\wedge} \mathrm{Q}^{\wedge} \mathrm{R}$ ”, aquí el problema es cómo se debe desplazar el operador aproximadamente porque "aproximadamente $\left\langle\mathrm{P}^{\wedge} \mathrm{Q}^{\wedge} \mathrm{R} »\right.$ ” no es equivalente a “aproximadamente $\mathrm{P}^{\wedge}$ aproximadamente $\mathrm{Q}^{\wedge}$ aproximadamente $\mathrm{R}$ », puesto que lo último no implica lo primero. Por ejemplo, si afirmamos que Amanda es “alta, blanca y está embarazada” es aproximadamente verdadero porque Amanda es aproximadamente alta, blanca y está embarazada, quizá en estos casos la verdad es que únicamente es alta y blanca, pero no está embarazada, por lo tanto, la afirmación no es equivalente a "aproximadamente alta, aproximadamente blanca y aproximadamente está embarazada", dada que la característica de "estar embarazada" no es algo que se pueda estar aproximadamente ${ }^{89}$, con otras palabras, a veces queremos hablar de que un conjunto de afirmaciones es aproximado a la verdad, pero no cada una de sus partes lo es por separado. Entonces necesitamos tener en claro el modo de distribuir dicho operador cuando se presente una conjunción.

Utiliza el caso de una teoría de modelado geométrico que tiene dos componentes principales: $M$ que es puramente matemático, especificando cierta estructura geométrica y $A$ que da una aplicación empírica a la estructura matemáticamente caracterizada afirmando que es una réplica de una estructura geométrica identificable en algún fenómeno del mundo real. Entonces nos quedaría que "La teoría MG que comprende $\mathrm{M}$ y A es aproximadamente verdadera es lo mismo que decir que, aproximadamente, $\mathrm{M}$ y A" (Smith, 2001, pág. 84), si tomamos a $M$ como perfectamente correcto de alguna estructura geométrica abstracta, entonces saltaremos al operador directamente a $A$. Y para ilustrarlo utiliza el ejemplo de la explicación del comportamiento del péndulo en el libro de texto ${ }^{90}$, cuyo seguimiento es cercano en un lapso limitado.

La aplicación principal que ha hecho Smith es acerca de las teorías dinámicas, a continuación un ejemplo de cómo aplica su propuesta: "Suppose T is a classical dynamical theory which claims, in effect, Here's a mathematical model of the time-evolutions of certain quantities, and the time-evolutions in the

\footnotetext{
${ }^{89}$ Este ejemplo está tomado de un comentario gracioso hecho por Swan (2015).

${ }^{90}$ Peter Smith (1998) as well provides two valuable insights into approximate truth, the first being that if approximate truth is going to work then it makes sense that due to the differing nature of things being approximated in different theories that there must be different ways of defining approximate truth for each different type of theory. The second valuable insight is his way of defining approximate truth for dynamical theories; that is to break theories into two parts, their idealized geometrical/mathematical frameworks and the claim that they are isomorphic to the world. The idealized part is just assumed to be true while the claim about isomorphism is said to "closely follow reality." Thus, a theory is approximately true if and only if its models are close to the way that the world is. This is to be contrasted with Lewisian-possible world theories of approximate truth and Niinliuoto's theory that "most bullseyes" win (Swan, 2015, págs. 19-20).
} 
model match the real world evolutions of those quantities" (1998b, pág. 127), y luego se puede hacer la afirmación que aproximadamente $\mathrm{T}$ equivale simplemente a la afirmación de que los tiempos de evolución en el modelo coinciden aproximadamente con las evoluciones en el mundo real ${ }^{91}$. Estamos hablando que un grupo de cantidades, las del modelo y las de la realidad, son aproximadamente iguales ${ }^{92}$, aquí no hay ninguna problemática conceptual:

Generalizando, podemos decir que una teoría dinámica es aproximadamente verdadera si la estructura geométrica que la modela se aproxima (en aspectos relevantes) a la estructura que se ha de modelar. Un caso básico es aquel en el que las trayectorias del modelo siguen de cerca a las que codifican comportamiento físicamente reales (o, al menos, las siguen durante un tiempo suficiente) (Smith, 2001, pág. 79).

En este caso podemos preguntar qué significa que una estructura geométrica se aproxime a otra, a lo cual Smith responde que cada caso requerirá un tratamiento especial que dependerá del foco de interés en un contexto dado. En este caso, una estructura se aproxima a la otra si la primera curva puede distorsionarse y luego igualar a la segunda mediante una transformación que a) mueve los puntos no más de algún valor $e$ y b) preserva la homogeneidad, si esto sucede, una curva seguirá de cerca a la otra ${ }^{93}$.

De otras afirmaciones como "la teoría del átomo de Bohr fue aproximadamente verdadera" y similares, es afirmar aproximadamente B, donde B es una larga historia que encapsula a la teoría de Bohr, esto se interpreta como que la afirmación B es simplemente opaca. Es decir, en este caso, afirmar "La teoría del átomo de Bohr fue aproximadamente verdadera" equivale a hacer un desglose de los diferentes enunciados que forman parte de la teoría de Bohr, luego analizar cuáles y en qué sentido son aproximadamente verdaderos:

Undoubtedly it would appear that one would speak of approximate truth differently based on situation, for example some theories will deal primarily with quantities while others will speak of probabilities, some about living organisms and some about inert gases or explosive chemicals. The vastness of the world and the different approaches needed to properly experience and understand it gives credence to the idea that science is not a catch-all term and that each individual field ought to be taken on its own and treated for what it is rather than as a part of some grand scheme (Swan, 2015, págs. 20-21).

\section{2 ¿Qué se considera una estructura?}

Smith seguirá el camino de Suppes (1960) en cuanto a plantear que los objetos abordados por la mecánica clásica, es decir, las masas puntuales sometidas sólo a la gravitación, muelles sin masa,

\footnotetext{
${ }^{91}$ Aquí podemos encontrar algunas similitudes entre Putnam y Smith en cuanto a lo que consideran como aproximadamente verdadero, dado que ambos piensan que no se trata de una cualidad de grados y respeten en ese sentido a Frege: "In addition, rational acceptability is a matter of degree; truth is sometimes spoken of as a matter of degree (e.g., we sometimes say, "the earth is a sphere' is approximately true); but the degree' here is the accuracy of the statement" (Putnam, 1981, pág. 55).

${ }^{92}$ Así, la afirmación de que una teoría MG es aproximadamente verdadera habremos de entenderla, naturalmente como la afirmación de que la estructura geométrica en cuestión reproduce aproximadamente la estructura relevante presente en el fenómeno objetivo del mundo real (Smith, 2001, pág. 84)

${ }^{93}$ Dilucidar la afirmación sólo requerirá exponer con detalle qué significa que exista una proximidad geométrica entre estructuras de los tipos relevantes. La aplicación de este punto abstracto a las teorías dinámicas, caóticas y de otro tipo es inmediata, porque tales teorías como hemos visto son candidatas aptas para su regimentación bajo la forma MG. (Smith, 2001, pág. 85)
} 
articulaciones sin fricciones, etc. son en realidad ficciones y debemos entenderlos como objetos abstractos cuyo comportamiento pretende "representar" alguna clase de fenómenos naturales. Por lo tanto, varias teorías articuladas matemáticamente deberían verse como poseedoras de un núcleo que especifica una estructura abstracta o un conjunto de ellas, y un conjunto de reglas de aplicación que asocia dicha estructura (o conjunto) con algunos fenómenos del mundo real (por ejemplo, el comportamiento del péndulo real asociado a las evoluciones marcadas por una ecuación). Esta estrategia es ontológicamente económica, y nos permite poder dar una explicación de la verdad aproximada para las teorías dinámicas.

Esta postura fue muy atractiva para los empiristas lógicos, puesto que las teorías comprendían un cálculo formal y reglas de correspondencia que relacionaban a ciertos términos formales con los observables. Van Fraassen, por ejemplo, considera al cálculo formal no como inicialmente nointerpretado, sino como la especificación de alguna estructura formal en la cual sus reglas de correspondencia no enlazan términos con observables, sino estructuras formales con observables. Así, una teoría es una "familia de estructuras (modelos)" y se especifica que ciertas partes de estos modelos "representan" de manera directa fenómenos no observables (Cfr. 1980, 64). Aquí Smith hace una acotación, puesto que podría entonces pensarse que su noción de verdad aproximada no es más que de adecuación, pero aclara que una cosa es defender que tomemos a las teorías como contenedoras de dos partes: estructuras formales y reglas de aplicación con el mundo, pero es muy distinto a decir que la correlación entre las abstracciones del libro de texto y el mundo real ha de ser solamente entre fenómenos observables.

Se puede mantener de manera consistente nuestra noción de aproximación general con las correlaciones teoría-mundo donde se vinculen estructuras geométricas abstractas a la evolución en tiempo de un rango de cantidades físicas que incluyan no observables, y no necesariamente tenemos que ser empiristas en esta perspectiva:

I certainly don't want to endorse this empiricism, which is no essential part of the Suppes program. It is entirely consistent with the basic idea to hold that theory-to-world correlations can link abstract geometric structures with (say) structures encoding the time-evolution of a range of physical quantities including unobservables (Smith, 1998a, pág. 262).

Por ejemplo, entre las preocupaciones de Smith está la de explicar cómo los modelos poco realistas como el de Lorenz pueden expresar algo acerca del mundo, su propuesta es que quizá la duda pueda disiparse afirmando que un modelo dinámico semejante puede darnos una explicación aproximadamente verdadera de ciertos fenómenos (Cfr. Smith, 2001, pág. 25). Otra de sus dudas es saber hasta qué punto se corresponde con el mundo una estructura dinámica semejante creada para modelar algún sistema físico, así debemos tomar al conjunto de comportamientos físicamente posibles del sistema 
dinámico modelado y representarlo mediante una estructura geométrica. Igualmente, para cada comportamiento físicamente posible tendremos una correspondiente evolución en el tiempo de las cantidades físicas relevantes. Si suponemos que dichas cantidades físicas están perfectamente determinadas, podemos codificarlas tomando en cuenta un tiempo determinado y con un punto en un espacio de fase apropiado. Tendremos ahora dos estructuras geométricas: una que está encargada de modelar y otra que codifica lo modelado. Si una es réplica de la otra, entonces diremos que el modelo es verdadero, si son suficientemente similares, afirmaremos que es aproximadamente verdadero.

Alguien, entonces, podría decir que estamos dejando de lado las partes causales del modelo y nos estamos refiriendo únicamente a estructuras observables, dado que los modelos dinámicos nos muestran cómo evolucionan las variables en cierto tiempo, pero dejan de lado el porqué (nos dejan sin historia causalmente explicativa). Bien, es posible construir una teoría dinámica teniendo conocimiento causal de lo que ocurre, introduciríamos términos en la parte derecha de nuestras ecuaciones para representar a los factores causales que perturban en el tiempo a las cantidades relevantes. A pesar de que nuestras ecuaciones estén motivadas por las hipótesis causales, estas últimas no forman parte del contenido del modelo dinámico resultante, únicamente informan qué sucedería a lo largo del tiempo a partir de varios estados iniciales posibles y será aproximadamente verdadero en la medida en que eso ocurra.

Ya se mencionó el caso del péndulo y el modelado que se hace de él, podemos incluso agregar variables a nuestro modelo como la longitud y la fuerza aplicada; recordando que los péndulos ideales oscilan eternamente, los reales no (dada la fricción), pero tomaremos como un modelo aproximadamente verdadero si hay una coincidencia de trayectorias en una cantidad "aceptable" de tiempo.

Imaginemos que hemos logrado una teoría aceptable, para ello se ignoraron algunos pequeños efectos de la fricción y la resistencia del aire, si quisiéramos ser más precisos, se podrá manipular las ecuaciones añadiéndoles los términos necesarios de corrección. Pero esto puede acarrear problemas, dado que quizá resulte en una teoría matemáticamente menos tratable (o intratable), por eso se opta por elegir una teoría imprecisa que idealiza e ignora algunas pequeñas perturbaciones.

Alguien podría decir que una teoría es aproximadamente verdadera si se puede obtener una teoría verdadera añadiéndoles los términos de corrección, o que una teoría es aproximadamente verdadera si se obtiene de una teoría verdadera mediante la simplificación. Sin embargo, esto resultaría en problemas, dado que existen teorías que por más que se les agreguen modificaciones nunca se conseguirá una teoría verdadera, a esas Smith les llama teorías tozudamente no revisables, y en este caso se encuentra la mecánica clásica de fluidos, por ello concluye:

Aseverar que una teoría es aproximadamente verdadera es decir que el mundo es a grandes rasgos como la teoría dice que es, no que otra teoría, relacionada con ella a través de pequeños ajustes, sea exactamente 
verdadera (...) una teoría puede ser verdadera respecto a un mundo apropiadamente cercano, aunque no lo sea ninguna otra teoría cercana (2001, pág. 87).

\subsection{Comparación con otros enfoques}

Smith compara la utilidad de su esquema con los otros enfoques anteriormente analizados sobre la verdad aproximada. Por ejemplo, tómese el caso de los de Popper, Oddie y Niiniluoto, los cuales considera que no son útiles para hablar de la verdad aproximada porque nos llevan a una dirección totalmente equivocada cuando menos en el caso de las teorías dinámicas. Esta manera de ver a la verosimilitud como un enfoque donde una teoría que da con la verdad más a menudo que otra, será más cercana a la verdad, así da entender, que lo importante es la cantidad de dianas alcanzadas:

Su construcción de un sistema métrico aplicable a la distancia respecto a la verdad parte de ideas como la siguiente: una conjunción básica de proposiciones atómicas o sus negaciones se acerca más a la verdad que otras si un mayor número de sus conjuntos dan con la verdad (Smith, 2001, pág. 88).

Desde esta concepción la verdad aproximada es como una especie de test donde se responde sí o no, y se estará acercando cada vez cuando se inserten o eliminen algunos signos de negación. Pero esto no es útil porque algunas teorías científicas no se pueden explicar de esa manera, dado que no dicen nada estrictamente verdadero sobre la realidad, pero sus aseveraciones sí se aproximan (como en el caso de cantidades, idealizaciones y abstracciones).

Otro enfoque es el de Lewis donde una teoría como aproximadamente verdadera si es estrictamente verdadera en un mundo que es muy cercano al mundo real. Es decir, nos preguntamos cómo las cosas habrían sido de ser nuestra teoría estrictamente verdadera. Su verdad aproximada dependerá de qué tan alejado sea ese mundo resultante, y los ordenaríamos del menos al más lejano.

Smith expone dos versiones, la primera (ya mencionada) sería Modelo I la cual no sirve porque el mundo donde, por ejemplo, la teoría clásica de fluidos es verdadera está bastante alejado de las características que tiene el mundo real, por lo tanto, dicha teoría no sería aproximadamente verdadera: "Esto es una reductio, dado que lo que perseguimos es precisamente una explicación del sentido preteórico en el que tales teorías son aproximadamente verdaderas" (2001, pág. 89).

Sin embargo, alguien podría decir que este tipo de refutación no es más que un hombre de paja, pues la idea de que diferentes aplicaciones del marco de mundos posibles pueden requerir distintos estándares de similitud. Así, sólo se requeriría una exposición adecuadamente cualificada de lo que constituye una similitud razonable entre mundos, que permita que los mundos cuenten como relevantemente similares para los fines propuestos, aunque difieran enormemente en otros aspectos nomológicos, esto sería el Modelo II.

En el Modelo II, afirmar que la Teoría T es aproximadamente verdadera es decir que el mundo real y algún mundo en el que $\mathrm{T}$ es estrictamente verdadera se asemejan suficientemente entre sí en los 
aspectos relevantes que T pretende describir. Aquí se puede preguntar a cuáles aspectos debemos darles más peso y cuándo se consideran suficientes, esto dependerá de los intereses que se tengan:

Así pues, la mecánica clásica de los fluidos es aproximadamente verdadera porque el mundo real y algún mundo en el que la teoría es verdadera se asemejan entre sí en lo que se refiere al comportamiento a escala media y grande del flujo de fluidos (las divergencias nomológicas en microaspectos no tienen importancia) (pág. 89).

Smith considera que, aunque esta propuesta puede dar respuesta a las objeciones, es demasiado el precio que se debe pagar para que funcione, ya que los mundos posibles a gran escala tienen una estructura muy rica: "Hablar de algún mundo en el que la teoría dada es verdadera es, en el caso general, referirse a algo muchísimo más detallado de lo necesario para satisfacer simplemente la teoría” (pág. 90). Esto es problemático porque primero planteamos un mundo con una gran cantidad de características para que la teoría fuese estrictamente verdadera, luego lo comparamos con el mundo real ignorando gran parte de esos aspectos para tomar en cuenta sólo aquellos que son el objetivo de la teoría, así nos damos cuenta que habremos hecho un camino bastante tortuoso.

En el caso de las teorías MG, la propuesta de Lewis sería que la teoría es aproximadamente verdadera cuando el mundo real se asemeja íntimamente a alguno de otros mundos posibles en los que los fenómenos objetivos ejemplifican con exactitud la estructura geométrica requerida por la teoría donde la semejanza se produce en los aspectos relevantes que la teoría aborda: "De modo que la teoría lewisiana Modelo II implica que una teoría es aproximadamente verdadera si el mundo real exhibe alguna estructura geométrica suficientemente próxima a la estructura que lo describe en aspectos relevantes para la teoría" (ídem), Smith señala que es la misma idea que él ya ha ofrecido, por consiguiente, esta propuesta no nos ha hecho avanzar:

(...) por lo tanto, aplicada al modelado dinámico, la tosca ejemplificación lewisiana Modelo I de la verdad aproximada es simple y llanamente errónea; mientras que la versión Modelo II, aplicada al modelado dinámico, implica nuestra disquisición anterior (ídem).

Por último, se compara con la propuesta de Giere, la cual piensa que es bastante similar a la suya, aunque difieren en dos puntos importantes: para Giere, las afirmaciones sobre la verdad teórica ya son las afirmaciones sobre la verdad aproximada, mientras que las de similitud son entre el modelo y la realidad. Smith prefiere no dejar de lado a la verdad, y ésta la toma cuando se trata del modelo que concuerda exactamente con el mundo, y la similitud será la verdad aproximada, aunque piensa que esta diferencia podría ser mera retórica.

Una diferencia más significativa es que Giere tiene propósitos más altos, aunque únicamente utiliza ejemplos de teorías dinámicas clásicas, parece que su objetivo es abordar la totalidad de las hipótesis teóricas. Dado que todas las hipótesis teóricas son aproximativas, en efecto esto significa decir algo general sobre la verdad aproximada. Smith duda que podamos decir algo sobre ambos: lo general y 
lo sustantivo. El precio que Giere debe pagar por su generalidad es que depende ampliamente de la noción "resbaladiza" de similitud, sobre la cual se le han hecho varias críticas, pero él no ha dado respuesta.

Smith cree que quienes mencionan una idea de verdad aproximada para respaldar su realismo científico es poco probable que se convenzan con la postura de la similitud de Giere. Además, Giere pasó por alto el análisis que se podía hacer dentro de la conceptualización geométrica de los modelos dinámicos clásicos y las ganancias que podía obtener:

To repeat, it allows us to use the metric structure of the space in which a model lives to talking conceptually unproblematic ways of its geometric structure approximating a structure representing possible real-world time-evolutions. In the domain of classical dynamical models, then, we can avoid relying on any inchoate notion of similarity, and we can ground an attractively clear proposal about what would constitute at least the simplest cases of approximate truth- namely, close tracking of phase - space trajectories (Smith, 1998a, pág. 273).

\subsection{El problema de Miller}

Smith pone a prueba su propuesta frente al problema de la dependencia del lenguaje planteado por Miller, el cual revisamos en el capítulo 3. Tomemos dos teoría rivales $\mathrm{H}$ y $\mathrm{K}$ las cuales describen a dos variables $(\mathrm{x}, \mathrm{y})$ y en un tiempo $T$; en este marco, $\mathrm{K}$ es más aproximada a la verdad que $\mathrm{H}$, pero si transformamos las coordenadas a $\mathrm{x}^{*}, \mathrm{y}^{*}$ el ordenamiento se cambiará: "No obstante, toda elucidación plausible de la distancia a la verdad debería hacer invariante la coordenada de aproximación comparativa a la verdad" (2001, pág. 91), y si esto sucede de nuevo caemos en las problemáticas mostradas hace dos capítulos.

A continuación, Smith expone el ejemplo que utiliza Miller: $H: x(t)=t, y(t)=5 t, K: x(t)=t+a y(t): 2 t$, mientras que los valores verdaderos son $\mathrm{x}(\mathrm{t})=\mathrm{t}+2 \mathrm{a}, \mathrm{y}(\mathrm{t})=\mathrm{t}$. Vemos que $\mathrm{K}$ sigue mejor las coordenadas verdaderas que $H$. La transformada es la siguiente: $x^{*}=x+\left(5^{a} / 12 t\right) y, y^{*}=\left(5 t / 2^{a}\right) x+y$. Ahora $H$ : $\mathrm{x} *(\mathrm{t})=\mathrm{t}+25 \mathrm{a} / 12, \mathrm{y} *(\mathrm{t})=5 \mathrm{t} 2 / 2 \mathrm{a}+5 \mathrm{t} ; \mathrm{K}: \mathrm{x} *(\mathrm{t})=\mathrm{t}+22 \mathrm{a} / 12, \mathrm{y} *(\mathrm{t})=5 \mathrm{t} 2 / 2 \mathrm{a}+9 \mathrm{t} / 2 ;$ los valores verdaderos serán: $x^{*}(t)=t+29 a / 12, y^{*}(t)=5 t 2 / 2 a+6 t$. Así H sigue más de cerca a los valores verdaderos que $K$, lo cual sería un problema porque $\mathrm{H}$ es más cercana y a la vez más lejana que $\mathrm{K}$ si simplemente hacemos una transformada (Cfr. pág. 91).

Pero Smith considera que no deberíamos tomarnos en serio tales ejemplos porque dichas transformadas dependen del tiempo de una manera muy extraña y antinatural. Aunque su refutación tiene fuerza intuitiva, no es inmediatamente obvia y es difícil que se mantenga en pie. Una opción sería prohibir las transformaciones que dependen extrañamente del tiempo, pero no resuelve la cuestión. Propone el siguiente ejemplo con dos hipótesis: $\mathrm{H}^{\prime}: \mathrm{x}(\mathrm{t})=5 \mathrm{t}, \mathrm{y}(\mathrm{t})=3 \mathrm{t} ; \mathrm{K}^{\prime}: \mathrm{x}(\mathrm{t})=4 \mathrm{t}, \mathrm{y}(\mathrm{t})=2 \mathrm{t}$; los valores verdaderos son $\mathrm{x}(\mathrm{t})=\mathrm{t} ; \mathrm{y}(\mathrm{t})=\mathrm{t}$. Aunque ninguna de ellas se acerca demasiado a los valores verdaderos, $\mathrm{K}$ ' lo hace mejor. Ahora si hacemos una transformación: $x^{*}=x-3 y / 2 ; y^{*}=y-3 x / 4$, las hipótesis serán ahora $H^{\prime}: x^{*}(t)=t / 2$; 
$y^{*}(t)=-3 t / 4 ; K^{\prime}: x(t)=t, y^{*}(t)=-t ;$ mientras que los valores verdaderos son: $x^{*}(t)=-t / 2, y^{*}(t)=t / 4$. Podemos observar que H' realiza mejor las predicciones que K'.

Esta transformación de coordenadas no depende del tiempo, pero sigue invirtiendo la aproximación de las dos hipótesis. Smith se pregunta si esto sucede porque únicamente se consideran situaciones donde hay hipótesis alternativas para trayectorias únicas en el espacio de fases, no hipótesis sobre familias enteras de trayectorias que parten de diferentes estados iniciales. Pero esto también podría suceder en esos casos. Si generalizamos el segundo ejemplo, suponiendo que las hipótesis rivales dicen que para cualesquiera los valores iniciales son $\mathrm{x}(0)=\mathrm{a}, \mathrm{y}(0)=\mathrm{b}$, las trayectorias resultantes serán: H': $x(t)=5 t+a, y(t)=3 t+b ; K^{\prime \prime}: x(t)=4 t+a, y(t)=2 t+b$, mientras que los valores verdaderos son: $\left.x(t)=t+a, y\right) t=$ t+b. En ese caso K" hace mejor el trabajo que $H^{\prime \prime}$ partiendo de cualquier estado inicial, pero si se hacen las transformaciones esto se invierte.

Smith nos recuerda que la verdad es relativa respecto a nuestros intereses y que una teoría será aproximadamente verdadera si sigue la pista de cerca al mundo en algunos aspectos que son nuestro interés:

Por ejemplo, supongamos por un momento que nuestro último ejemplo x e y representan, respectivamente, temperatura y velocidad de circulación en un líquido en convección calentado continuo, con lo que H' y $\mathrm{K}$ " son hipótesis sobre cómo estas cantidades aumentan en el tiempo. Entonces $\mathrm{x}$ * representa la temperatura menos un $150 \%$ de la velocidad de circulación. Y bien podríamos preguntar: ¿qué significado real tiene esto? (pág. 93).

Una objeción, dice Smith, es que la pregunta es una trampa porque no es una cantidad dimensionalmente coherente, pero da como respuesta que podemos suponer que se manipulan los pares $\mathrm{H} / \mathrm{K}$ con constantes multiplicadoras del valor unidad adecuadamente dimensionadas, de modo que se recupere la coherencia dimensional. Entonces vuelve a afirmar que no hay razón alguna para suponer que, si x e y son cantidades físicamente significativas, $x^{*}$ e $y^{*}$ también lo serán. Si las transformadas carecen de interés, no parece que deba importar si las teorías siguen de cerca la pista de ellas, dado que el objetivo de las teorías MG es seguir la evolución en el tiempo de cantidades físicamente significativas, y una teoría se considera aproximadamente verdadera si obtiene valores de esas cantidades que estén muy próximas a los reales durante un tiempo suficiente. Se tomarán en cuenta para hacer las comparaciones en aquellos casos donde las cantidades sean físicamente significativas.

Para poder hacer que el argumento de Miller funcione, es necesario hacer transformaciones de coordenadas de una manera muy anómala, cuando eso sucede las variables dejan de ser significativas. Smith considera que el único caso que podría preocuparnos es cuando las transformaciones que son independientes del tiempo de un modo anómalo nos llevan de un espacio a otro, invirtiendo el ordenamiento de las hipótesis, en este caso las variables de estado de ambos espacios tienen igual derecho 
de reclamar para sí un interés físico; pero afirma no conocer ningún caso así, y si llegase a suceder, sólo queda aceptarlo y decir que H y K están en una especie de empate, y no se puede preferir una a la otra. Una noción de la verdad aproximada no tiene por qué descartar esos casos.

No obstante, un caso que se puede presentar en cuanto a esta situación dependiente de los intereses es que un modelo de Ptolomeo puede seguir mejor los datos relevantes que uno de Newton, por ejemplo, en la navegación, sin embargo, nos gustaría que este último fuese más aproximado a la verdad. La estrategia a sugerida es que la teoría newtoniana da en el blanco cuando se le considera como algo producido de acuerdo con una fórmula más general que unifica otras muchas teorías dinámicas, donde un número suficiente de esas otras teorías son aproximadamente verdaderas en un sentido básico de seguimiento (criterio de unificación). Aunque no siga las cantidades relevantes tomando en cuenta cierto interés.

\section{5 Últimas consideraciones de Smith}

Smith considera que esto puede ser útil para el realista optimista puesto que podemos observar que el minimalismo acerca de la verdad no tiene por qué resistirse a expresar que una teoría $\mathrm{T}$ es aproximadamente verdadera - aunque dicha afirmación deba ser coherente en ese sentido. Es decir, tendremos que explicar cómo funciona el esquema de verdad aproximada en cada uno de los casos, por ejemplo:

Suppose $\mathrm{T}$ is a classical dynamical theory which claims, in effect, 'Here's a mathematical model of the timeevolutions of certain quantities, and the time-evolutions in the model match the real world evolutions of those quantities'. Then the more modest claim that approximately $\mathrm{T}$ just amounts to the claim that timeevolutions in the model approximately match the real world evolutions (1998b, págs. 126-127).

Aquí estamos hablando de un conjunto de cantidades (las arrojadas por el modelo) que son aproximadamente iguales que otro conjunto (las del fenómeno modelado), aquí no hay ninguna dificultad conceptual para entender la afirmación sobre la aproximación, cuya configuración reside precisamente en la configuración de la métrica. Por lo tanto, afirmar que algunas teorías dinámicas clásicas (como la del péndulo) son aproximadamente verdaderas, tampoco son conceptualmente problemáticas para quienes defienden el minimalismo. Aunque Smith hace hincapié en que no se trata de afirmar sin más que una teoría es aproximadamente verdadera sólo por su precisión. Dicha afirmación es sólo una proposición limitada, conectada a las teorías $M G$, las cuales pretenden decirnos cómo evolucionan en el tiempo ciertas cantidades: "Sólo en este caso basta el seguimiento próximo como criterio de verdad aproximada" (2001, pág. 94).

Para finalizar, como hemos visto, los realistas a veces suponen una noción de verdad aproximada o verosimilitud para poder lidiar con objeciones desagradables como la inducción pesimista, pero para Smith, en la versión minimalista, sólo nos explica qué queremos decir cuándo afirmamos que una teoría 
es aproximadamente verdadera: "All the hard work for the optimistic realist remains, then, as she is faced with explaining on a case by case basis, what work the 'approximately' is doing as applied to her various favoured cases" (1998b, pág. 127).

\section{Objeciones y algunos detalles sobre la propuesta de Smith \\ 2.1 Con este esquema cualquier afirmación sería aproximadamente verdadera}

Al ser una noción que únicamente habla de aproximación de una manera cualitativa, es decir, no brinda "grados de aproximación a la verdad" como sucede en el caso de Niiniluoto u Oddie, uno podría pensar que entonces cualquier afirmación sería aproximadamente verdadera; pero eso no es el correcto, de entrada hay enunciados que nunca serán aproximadamente verdaderos, tal es el caso de las contradicciones, no parece que haya un caso en que esta situación pueda producirse de una manera válida en nuestro esquema a pesar de que se lea de derecha a izquierda del bicondicional.

Otras aseveraciones que podemos descartar son aquellas que carezcan de sentido, por ejemplo, si alguien expresa "La estatura de Jorge es verde" es aproximadamente verdadera si, y sólo si, la estatura de Jorge es aproximadamente verde, esto difícilmente podrá sostenerse cuando las palabras se entienden con su significado "común". Aunque esto puede darnos motivaciones para apuntar la sensibilidad al contexto anteriormente mencionado, puede ser que en este ejemplo la persona haya dividido las estaturas de las personas en ciertos rangos y le haya otorgado a cada una el nombre de un color - por ejemplo, el rango de 1.60 a 1.75 es verde, mientras que de 1.76 a 1.90 es azul, y así sucesivamente.

Ahora, en el caso de afirmaciones que sí tienen sentido, habrá que hacer las observaciones pertinentes para cada caso específico y cuáles serán los márgenes que se utilizarán para evaluar la cercanía a la verdad de una proposición, para ello podemos utilizar adverbios como los que propone Smith: “es extremadamente cercano, muy cercano, algo cercano o muy alejado a la verdad". Por ejemplo, volviendo al caso de las estaturas, una afirmación puede estar "extremadamente cercana" si falla por un centímetro, "muy cercana" si está en un rango de 5 centímetros, "algo cercano" si es menor a 10 centímetro y "muy alejado" si es mayor de 10 (según sea el caso, alguien podría dar criterios distintos para un caso en específico, según sean sus intereses, esto es sólo para ilustrar el ejemplo) (esto al tratarse de estatura humanas, quizá si estamos hablando de ballenas o elefantes los criterios puedan cambiar, dado que equivocarse por 10 centímetros parece "no haber fallado mucho el objetivo"). Algo similar podría hacerse en el caso del ejemplo de Snoopy.

Cuando se estén comparando dos proposiciones, teorías o modelos, se debe explicar cuál es la parte central que se está tomando en cuenta, es decir, que es lo que buscamos "que haga mejor" una que la otra, y así proceder a decir que una es más aproximada a la verdad que la otra. 


\subsection{Similitud y relatividad contextual (la carencia de verosimilitud objetiva)}

Uno de los problemas que analiza Teller (2001, pág. 401) en cuanto a la similitud de los modelos con el mundo (y en este caso también a la verdad aproximada) es que esta siempre será limitada en aspectos y en grados. Algunos pedirían que se les diga qué es la similitud, dado que dos objetos serán similares en una cantidad de maneras muy diversas, entonces cabe preguntarse ¿cuáles son los aspectos relevantes y en qué grado deberían serlo? Si intentamos dar una respuesta general a esta pregunta pareciese que nos encontramos ante una tarea imposible.

Tanto Urbach (1983) como Teller (2001) coinciden que el problema se disuelve cuando nos damos cuenta que dicha petición no se puede cumplir porque lo que cuenta como "similar" de manera relevante depende de los detalles que nos ocupan en cada caso; y no es necesario un enfoque general porque se tratan a los detalles de manera diferente en cualquier caso que estemos manejando, en el cual se proporcionará la base para poder decidir qué cuenta como similitud relevante: "In other words, the very facts which make this demand impossible to meet also show that the demand was misguided to begin with" (Teller, 2001, pág. 401).

Esto lo ilustra con dos ejemplos para demostrar que, al momento de construir un modelo, nuestros intereses harán que elijamos cuáles son las partes relevantes que se tomarán en cuenta y la forma de evaluarlas, en este caso el primero es sobre la explicación del flujo del agua y la propagación de ondas, y el otro es sobre la difusión de una gota de tinta en un vaso de agua. Para construir cada modelo se utilizaron aspectos radicalmente diferentes del agua, aunque sea "la misma agua". Si estamos únicamente interesados en la explicación cualitativa del flujo o de la difusión, entonces las similitudes inexactas también lo estarán, pero si la meta es la predicción o la explicación de detalles cualitativos, entonces deberemos especificar cuáles son los intereses de quienes están utilizando esos modelos: si se tomará en cuenta la distancia (y cuánta), la tensión superficial, la temperatura, la presión, la precisión de los números, las funciones de costo que indiquen los errores que estamos dispuestos a tolerar o que harán "daño" al modelo:

In short, once the relevant context has been specified, for example by saying what is to be explained or predicted and how much damage will result from what kinds of error, the needs of the case will provide the required basis for determining what kind of similarity is correctly demanded for the case at hand (Teller, 2001, pág. 403).

La similitud entre el modelo y la realidad implica el acuerdo y la diferencia de ciertas propiedades, las necesidades de cada caso nos permitirán dirimir si el acuerdo es suficiente o si las diferencias son tolerables dadas nuestros objetivos. Esto nos indica que no hay una explicación general de similitud, pero tampoco hay necesidad de dicho enfoque general, dado que los detalles de cualquier situación nos 
proporcionarán la información que establecerá lo que debe contar como "similitud relevante": "There is no general problem of similiraty, just many specific problems, and no general reason why any of the specific problems need be intractable" (pág. 402).

Alguien podría estar tentado a hablar de verosimilitud (o similitud) objetiva o que cuando menos en ciertos ejemplos "intuitivos" debería funcionar siempre de la misma forma, pero esto es un aspecto que Urbach no aceptaría, puesto que las intuiciones pueden cambiar de un individuo a otro ya sea por sus intereses o por su cultura:

This story can, I think, illustrate the serious point that there is no unique, absolute, objective sense in which two different structures are more or less like some third structure. There may be a greater or a lesser similarity depending on which aspects of the structures are being considered; a shoe is more like a ship than sealing wax in some respects but in other ways there is greater similarity with the wax. It is absurd to elevate some of these properties to the standard by which "real" likeness between structures is to be gauged. Our so-called 'intuitions' seem merely to reflect a preoccupation with certain aspects of a situation which happen to be of interest to us (Urbach, 1983, pág. 271).

Para hacer diferencias de similitud estamos influencias por factores biológicos y culturales, tal es el caso de cuando se intentan diferenciar personas por ejemplo entre los chinos y los occidentales. Sería un error decirle a un visitante chino que un par de gemelos idénticos Pérez son mucho más parecidos de lo que son el señor y la señora Hernández; para él es posible que un lunar pequeño en uno de los gemelos Pérez sea la mejor manera para poder diferenciar a uno del otro, mientras que un occidental quizá no podría notarlo. ${ }^{94}$

A Urbach le parece imposible que se logre tal cosa como la idea de "verosimilitud objetiva", para ello sería necesario establecer que ciertas propiedades de las estructuras físicas están privilegiadas por sobre las otras, incluso esta preminencia tendría que ser de un tipo especial que no dependiese de las peculiaridades de los humanos: la percepción, su inteligencia o preocupaciones, sino de la naturaleza misma:

The argument would have to sanction the inference from 'A is more like $\mathrm{B}$ than $\mathrm{C}$ in regard to properties $\mathrm{p}_{1}$, $\mathrm{p}_{2}, \ldots, \mathrm{p}_{\mathrm{n}}{ }^{\prime}$ to 'A is objectively more like $\mathrm{B}$ than $\mathrm{C}$ '. But it is natural to ask what 'objectively more like' signifies. Presumably it means 'more like with respect to $\mathrm{p}_{1}, \mathrm{p}_{2}, \ldots, \mathrm{p}_{\mathrm{n}}$ ', where the qualification 'objectively' is applied because $\mathrm{p}_{1}, \mathrm{p}_{2}, \ldots, \mathrm{p}_{\mathrm{n}}$ ', are 'privileged', and indeed privileged in the sense that they form the basis for judgements of 'objective similarity' (pág. 274).

Salir de este círculo parece complicado, lo mejor sería considerar que las cuestiones de verosimilitud (y similitud) son sensibles al contexto y dependientes de diversos factores (nuestra cultura o capacidades cognitivas):

As I have argued, which properties we regard as particularly important is strongly influenced by our constitution and our language and culture. Any theory of 'verisimilitude' which is raised on foundations such

\footnotetext{
${ }^{94}$ Son recurrentes los comentarios al respecto de que los orientales son "todos iguales" y que no logramos distinguirlos de una persona a otra o de un país a otro, situación que a ellos les molesta porque para ellos "es bastante claro" que ni siquiera se parecen en lo más mínimo.
} 
as these will, therefore, fail to capture a crucial feature of any significant or interesting notion of truthlikeness, namely its objectivity (pág. 275).

Para Northcott (2004) estos problemas de la ambigüedad de la objetividad sólo es posible resolverlos si aceptamos la existencia de elementos subjetivos inevitables, es decir, hacer explícito en qué estamos interesados (condiciones iniciales, resultados finales, etc.). En el momento que hemos caracterizado a nuestro interés subjetivo, ahora podemos formular una medida objetiva al respecto: "So here the ambiguity can only be resolved subjectively, and after that - but only after that - we can bring in an objective apparatus" (pág. 64). Y de manera más detallada con un ejemplo:

... in order to calculate a model's accuracy, we also need always to specify exactly which causal strengths we are concerned with in the first place. For example, in the Hiroshima case, the Los Alamos project, the course of the American advance on Japan, and the weather that day could all be seen as being part of the same Bayes net leading to the explosion. But different explananda will demand focusing on different areas within this net. Again, it is true that we could just focus on that subsection of the network that contained our causes of interest, and then call only this subsection our 'Bayes net'. But given that the choice of net in the first place is so critical yet is left unmodelled by Bayes net theory itself, and given that Bayes nets offer no definition of causal strength superior to ours anyway, it seems to me that the real philosophical work is being done here by our theory. For our specific purpose of defining approximate truth, that is, Bayes nets do not offer us anything substantively new (pág. 216).

\subsection{La visión semántica de las teorías y el realismo}

El ejemplo favorito de Smith (2001) es el de teorías dinámicas del caos vistas específicamente como una comparación de modelos que hacen el seguimiento de ciertas estructuras. Se adhiere a lo que llamaríamos la visión semántica como la ejemplifica Suppe:

Many critiques of the syntactic view have coalesced around an alternative account of theories: the so-called semantic view. The term 'semantic' here is used in the sense of formal semantics or model theory in mathematical logic. That is, the semantic view 'construes theories as what their formulations refer to when the formulations are given a (formal) semantic interpretation' (Suppe, 1989, 4).

En este sentido, una teoría será entendida como una familia de modelos ${ }^{95}$, es decir, sistemas que satisfacen las leyes teóricas que comúnmente son asociadas con las teorías científicas, con ello se pretende desembarazarse de ciertos problemas lingüísticos que han causado grandes debates en la Filosofía de la Ciencia. Aquí, la relación entre una formulación lingüística y sus modelos es meramente la de definición. Los modelos son sólo aquellos que satisfacen las ecuaciones matemáticas de una teoría cuantitativa, si las teorías son modelos en el sentido de la estructura pura, las entidades abstractas y las relaciones entre ellas son una excepción de las formulaciones lingüísticas con las que se pueden enlazar.

El realista ahora debe determinar cuáles aspectos de los modelos pueden ser considerados como representadores del mundo natural y cómo lo hacen, Chakravartty piensa que esto no es posible, que la visión semántica no puede hacer posible ningún tipo de realismo científico:

\footnotetext{
95 On the semantic view, theories are families of models. The very notion of a model invites comparisons with that which is modelled. Models are generally caricatures of the natural world (Chakravartty A., 2001, pág. 327).
} 
In some cases, an emphasis on models seems tailor-made to promote varieties of instrumentalism. Realism on the semantic view is by no means impossible, but faced with precisely those familiar, perennial difficulties of reference and correspondence that some semanticists think their approach does without (2001, pág. 327).

La visión de modelos ha sido pensada principalmente para desembarazarse de algunas problemáticas tales como la forma en que se vinculan las entidades lingüísticas con el mundo. Y esto se disuelve cuando la cuestión es vincular únicamente entidades no lingüísticas (modelo-mundo). Parece más claro que los modelos se adapten mejor a la representación de los fenómenos que un conjunto de enunciados. El realista tendría que estar comprometido en que ciertas afirmaciones al respecto de la naturaleza de las relaciones entre descripciones detalladas de los modelos y la realidad "corresponden". Cuando se utilizan esos dispositivos lingüísticos para crear dichas relaciones se está yendo en contra de la aspiración de Suppes de independizarse de la semántica lingüística.

Los modelos incluyen dentro de sí una gran cantidad de idealizaciones, lo cual, según Chakravartty, no puede ser adoptado por un análisis realista; puesto que dichas idealizaciones contradicen lo que parecer ser verdadero de la realidad. Si algún elemento de un modelo constituye una idealización, podemos cuando menos creer en la existencia de esos aspectos de la realidad que ha sido idealizada:

When idealizations concern abstracted but nonetheless genuine parameters, as in the example of masses in classical mechanics, the realist can admit the existence of such parameters. Is much more in the way of a realist commitment possible here, or are such theories better thought of as promising precursors to more realistically construed theories? (pág. 329)

El realista no solamente está comprometido con la predicción exitosa del modelo, sino que además piensa que debe dar una explicación a ese éxito mediante una apelación a la ontología. Esto significa que hay una afirmación lingüística de correspondencia entre un elemento del modelo y un elemento de la realidad. Desde esta perspectiva, las teorías no podrán decir nada sustancial sobre el mundo si no se hace uso del lenguaje. Los modelos pueden no ser verdaderos o falsos per se, pero sin duda las descripciones de ellos tienen la capacidad de aplicarse o no al mundo, y esto proporciona la posibilidad del realismo. Para el punto de vista del realista la utilización de criterios de verdad por correspondencia de los enunciados no ha sido ayudada por la visión semántica de los modelos. Es decir, si quisimos deshacernos de los problemas lingüísticos que aquejaban al realista por medio de la visión semántica no se ha logrado, por lo que se requiere aclarar nociones como la correspondencia y la referencia, y en este sentido los elementos "lingüísticos" hacen todo el trabajo (en la comparación entre el modelo y el sistema real).

Teller acepta que las entidades lingüísticas son utilizadas para comparar las propiedades que son parte de los modelos y propiedades que el objeto en concreto tiene, pero esto no quiere decir que lo que 
se estén comparando sean las afirmaciones en sí. Por ejemplo ${ }^{96}$, en algunos modelos ${ }^{97}$, la función del lenguaje es la de seleccionar las funciones relevantes y fijar la interpretación de las variables, pero sigue siendo la función (el curso de los valores en el modelo) la que se compara con el curso real del sistema físico:

In particular, the fact that language is used to indicate which function (construed, say, as a set of ordered pairs of values) constitutes (part of) the model does not show that linguistic entities are the objects of comparisons. Such a suggestion would make the mistake of confusing language with what language is used to describe (Teller, 2001, pág. 400).

Aquí hace la distinción entre el trabajo hecho (work doing) como proceso en contra del trabajo logrado (work accomplished) como producto. Tal como en el caso de un martillo en la construcción de una casa, el martillo "hace todo el trabajo", pero no es la casa; en este sentido las "entidades lingüísticas" son "el martillo" cuando se está haciendo la comparación entre el modelo y el sistema real. El hecho de que utilicemos términos lingüísticos no elimina a cualquiera de los otros dos componentes: "That we use language to compare the paper cutout with something does not show that what we compare it with is the definition of a triangle" (pág. 401).

\subsection{La visión semántica de las teorías y la aproximación a la verdad de Smith}

Algunas de las objeciones que se le hacen al enfoque basado en modelos también recaen en la propuesta de Smith porque él se adhiere a dicha propuesta, aquí se presentarán dos objeciones que se hacen al respecto de verdad aproximada.

Como bien señala Northcott, Smith sigue a Giere al proponer que entenderemos a un modelo como la verdad exacta de alguna descripción abstracta, después esta descripción tiene un grado de similitud con algún sistema real en específico. La verdad aproximada viene siendo el grado de similitud entre el sistema del mundo real y el sistema postulado por el modelo. Es decir, postulan una estructura geométrica determinada, y cuando se aplican al mundo real están atribuyendo cierta estructura geométrica a los fenómenos reales. La definición de verdad aproximada es un cierto grado de similitud

\footnotetext{
${ }^{96}$ Otro utilizado por Teller (2001) en referencia a Savage es en la comparación entre una hoja de papel triangular y el modelo de triángulo, para hacer dicha comparación se hace uso del lenguaje mediante la especificación de, por ejemplo, los vértices que tiene un triángulo (tres por definición). Así, contamos el número de vértices del modelo y el número de nuestras piezas de papel, se formulan mediante enunciados y luego se comparan entre sí, pareciera que en este caso se están comparando únicamente entidades lingüísticas, es decir, que esas entidades "hacen todo el trabajo" entre la descripción del papel y la definición del triángulo.

${ }^{97}$ To see what has gone wrong in this line of thinking, consider a slightly more robust example. Consider a physical system, such as the pendulum in Giere's grandfather clock, and the varying values of some physical quantity of interest, such as the pendulum's angle of deflection. Call this sequence of values over time the 'actual course of values'. One models the system using an abstract object specified, to be sure, linguistically, using a formula to specify a function, say $x(t)=A \sin (\omega t)$. On interpreting (values of) $t$ as (corresponding to values of) time and (values of) $x$ as (corresponding to values of) the physical quantity in question, one can make comparisons of similarity between the function, so interpreted, which is part of the model, and the actual course of values (Teller, 2001, pág. 400).
} 
geométrica (seguimiento de cerca) entre estas dos estructuras geométricas ${ }^{98}$. Y esto enmarca varias ventajas:

Since defining such a measure presents no particular technical difficulty, so neither should defining approximate truth. By thinking of similarity explicitly in these geometrical terms it also becomes easy to define it precisely, since there are many readily available measures of geometrical similarity. His approach carries other advantages too, to whit the usual welcome benefits of an ontological approach - thus it is inherently context-specific, and it is able easily to accommodate the approximate truth of stubbornly false theories. (Northcott, 2004, págs. 61-62).

La primera objeción puede ser que, si bien la similitud geométrica puede aplicarse para evaluar a los modelos de sistemas dinámicos, no parece que sea exitosa con las otras teorías científicas en general, dado que la mayoría de ellas no se especifican o pueden re-expresarse fácilmente en términos geométricos. Esto fue algo que el propio Smith admite, puesto que él estaba únicamente interesado en las teorías de sistemas dinámicos y no presenta a su definición como candidata a ser una medida general de verosimilitud. Para esos casos habría que buscar cuál sería la noción idónea para expresar "la cercanía" entre una teoría y el mundo, tal como lo muestra en los diversos ejemplos en los que utiliza su esquema de descitación.

Chakravartty ha criticado la propuesta de Smith desde dos perspectivas. La primera es que, si el enfoque de Smith se centra únicamente en los elementos observables, entonces solamente puede ser una propuesta para apoyar al instrumentalismo. Si decir que una teoría-MG es aproximadamente verdadera se limita a los fenómenos observables (aquí sólo estaríamos hablando de una aproximación empírica adecuada), entonces puede hacer predicciones exactas: "this by itself makes no commitment with respect to ontology, and in particular, with respect to the "unobservable"” (Chakravartty A. , 2001, pág. 340). Sin embargo, y como vimos anteriormente, Smith rechaza explícitamente el punto de vista empirista de que las correspondencias entre el modelo y el mundo se limiten exclusivamente a las características observables, para que la verdad sea aproximada también se deberán de reflejar características modales de "espectro de posible comportamiento" de un sistema. Belanger considera que esta es la manera correcta para esquivar dicha objeción (2015, pág. 45).

La segunda objeción de Chakravartty es en el caso de que las teorías-MG si incorporen elementos no observables:

But in the case of models that incorporate elements whose putative counterparts in the world are "unobservable", geometrical closeness of model parameters and worldly measurements does not entail that such counterparts exist. If they do not, such theories will not count as approximately true for the realist. (pág. 341).

98 "This provides an attractive reduction of the somewhat mysterious notion of approximate truth to the more familiar notion of geometrical similarity" (Belanger, 2015, pág. 44). 
Se puede decir que está en lo correcto, pero este problema es epistemológico, no ontológico. Lo que hacemos es evaluar la verdad aproximada por medio de la cercanía de dos estructuras geométricas, pero si no sabemos lo que es una de las estructuras, no podemos evaluar su cercanía. Esto no quiere decir que geométricamente no podrían existir en el mundo real homólogos similares a la estructura de un modelo, o que no se podría cumplir con los demás criterios propuestos por Smith para la verdad aproximada: "We can agree that this is a problem for Smith's notion of approximate truth in practice, but not in principle" (Belanger, 2015, pág. 45).

De manera simultánea, Teller (2001) consideró que esta podía ser una de las objeciones más fuertes que se le pueden hacer a quien quiera ser realista y adherirse a la visión de los modelos. Dado que muchos parecen inclinarse a creer que los modelos únicamente se evaluarán con respecto a la precisión en el modelado de los fenómenos y esto tendría como consecuencia dejar de lado todo aquello que vaya más allá de lo observable, es decir, no tienen ningún interés en mecanismos o entidades no observables. Además, parece que solamente están comprometidos con dar soluciones con respecto a estructuras que representan los fenómenos en lugar de buscar los mecanismos subyacentes y los enfoques unificadores. En pocas palabras, la visión de los modelos apoyará únicamente posturas anti-realistas.

Teller responde que no cree que exista una distinción fija e independiente del contexto entre los fenómenos observables y los hechos (o entidades) teóricos no observables. Nuestro acceso a ambos es indirecto, en algunos casos es más indirecto uno que otro, pero es de la misma naturaleza el de los átomos que el de las manzanas. Dado que no considera una distinción tajante entre fenómenos observables y teóricos, los modelos pueden evaluarse por su exactitud. Por lo tanto, quienes se adhieran a esta postura puede que tenga mucho sentido que busquen los mecanismos ocultos dado que se caracterizarán dentro de los modelos; después de ello evaluarlos con respecto a su exactitud cuando se caracterizan diversos aspectos, además:

There is nothing in the modeling program which prohibits or discourages efforts to find and model 'hidden mechanisms' or other ways in which disparate phenomena that are relatively close to immediate observation fit together or are manifestations of something more basic or general (Teller, 2001, pág. 408).

Belanger por su cuenta considera que el mayor fallo de Smith es que utiliza una noción de "proximidad geométrica" sin analizarla, y esto nos lleva a problemas conceptuales cuando intentamos que sea precisa. Cualquier noción única de aproximación geométrica es poco probable que pueda cubrir todos los casos, y si se da un enfoque más complicado se pierde toda la sencillez que hizo atractivo al enfoque de Smith, pero sin una definición de este término, su propuesta es incompleta:

If the relevant quantities in nature have discrete rather than continuous properties, the structures in the models and nature will have qualitatively very different natures. Accordingly, a simple comparison of the distance between the values of the quantities in the model and the corresponding quantities in nature is 
misguided. There is no obvious standard of geometrical similarity that will cover all of these situations (Belanger, 2015, págs. 46-47).

Tanto Smith como Teller no verían realmente un problema en este caso, simplemente se remiten de nuevo a hablar de que la noción de "proximidad geométrica" requerida dependerá de cada caso en el cual sea necesaria para llevar a cabo las comparaciones.

\subsection{El problema Ptolomeo}

Esta última objeción, que el mismo Smith vio como posible, se considera como una de las más fuertes para su proyecto. Es necesario recordar que si dos modelos están evaluados por la proximidad geométrica en un interés en específico es el que se considera como aproximadamente verdadero. Sin embargo, si el interés es, por ejemplo, la navegación y se tienen dos modelos T1 y T2, el primero es de Ptolomeo y el segundo de Newton, se daría el caso de que T1 sigue mejor los resultados de los intereses que T2, por lo tanto, se tomará como más aproximada a la verdad. Esto provocaría un problema porque obviamente se quiere afirmar que el modelo newtoniano se encuentra más cercano a la verdad.

Una posible salida sería decir que la familia de modelos newtonianos ha tenido un mayor éxito en una mayor cantidad de casos que la ptolemaica. Sin embargo, este tipo de holismo va en contra de una de las ventajas del enfoque ontológico, es decir, su capacidad para dar sentido a los juicios singulares de verdad aproximada: "It implicitly is saying, for apparently arbitrary reasons of convenience, that the geometric definition should in this case be applied only to general theories, not to particular models" (Northcott, 2004, págs. 64-65).

La respuesta de Smith fue utilizar el criterio de unificación, es decir, cuando juntamos un modelo de Newton con los que ahora consideramos como los más aproximados a la verdad causa menos problemáticas, o da mejores resultados, que si lo hacemos con uno de Ptolomeo. Si T2 puede ser más aproximadamente verdadera que T1 a pesar de que le va menos bien en el criterio de proximidad geométrica de Smith cuando nuestro interés es la navegación, entonces podría decirse que la cercanía geométrica por sí misma no se puede utilizar para determinar qué otras teorías - con las que se unifican T1 y T2 - son más o menos aproximadas a la verdad: "In order to determine the relative approximate truth of these other theories, one would have to take into account the approximate truth of theories with which they can be unified, and this courts worries of circularity and regress" (Chakravartty A. , 2007, pág. 211).

Robert Northcott (2004, pág. 63) sugiere que el problema podría ser más manejable si en lugar de la geometría se hablase en términos de causalidad ${ }^{99}$. Entonces podríamos imaginar que el modelo

99 The key underlying suggestion here is this: that interest-relativity boils down to the choice of causal strengths on which our definition of approximate truth should operate. In particular, in this example the short-term explanandum implied the 
newtoniano capta con mayor precisión los procesos causales reales que provocan los fenómenos observados en el firmamento, esto tendrá como consecuencia que en alguna definición de casualidad se le asignará mayor aproximación a la verdad. Aunque se debe reconocer que incluso cuando se hace referencia a la causalidad, el análisis del problema Ptolomeo resulta tener complicaciones debido a las diferentes ontologías planteadas por los modelos que están en competencia, y un elemento integral puede entrar en la interpretación de la referencia de cada modelo. Aunque remarca que para poder decir que un modelo newtoniano es preferible a uno ptolemaico es deseable que podamos hacerlo sin hacer referencia obligada a otros contextos o a la forma como se desempeñan otros modelos en problemas diferentes: "At root a causal ontology, on a realistic interpretation, enables us straightaway to target as it were what is actually going on in the world, whereas the geometric ontology is revealed by this example to carry only a more instrumental flavour" (ídem).

Sugiere que podemos hablar en dos sentidos distintos de aproximación a la verdad en estos casos, uno sería aproximación a la verdad empírica y el otro a la aproximación a la verdad ontológica, el modelo de Ptolomeo tendría una mejor evaluación en la primera y el de Newton en la segunda: "We have just argued that EAT is indeed distinct from OAT. If desired, this distinctness could also have been seen the other way around, so to speak - it turns out that OAT cannot be reduced to EAT either" (pág. 82).

Ante la posible paradoja de que una teoría sea aproximadamente verdadera y no aproximadamente verdadera al mismo tiempo (dependiendo de las divisiones), responde que no existe tal, sino que se encuentra aproximadamente verdadera con respecto algunos focos de interés, pero no con respecto a otros. Aunque él mismo reconoce que su propuesta en general colapsa en aproximación a la verdad empírica, esto lo llevaría a dejar sin solución a este problema pues debe preferir el modelo de Ptolomeo, en el caso planteado, sobre el de Newton.

Chakravartty (2007, pág. 209) sugiere que para solucionar estos casos es necesario darnos cuenta de que la aproximación geométrica no es una condición suficiente para hablar de aproximación a la verdad en sentido realista, sino que debe ser entendido como un criterio que puede ser utilizado en combinación con otros, él propone que sean la cantidad de abstracciones e idealizaciones que hace un modelo. Un modelo estará más cercano de la verdad si son muy pocos los elementos que excluye de la realidad, es decir sus abstracciones son pocas ${ }^{100}$, mientras que la idealización estará más cercana si el

calculation of one particular set of causal strengths, while the long-term explanandum implied the calculation of a different set (Northcott, 2004, pág. 119).

100 This suggests a straightforward articulation of the notion of approximate truth qua abstraction. Consider all of the parameters potentially relevant to the behavior of a particular target system. Degrees of approximate truth are correlated here with the extent to which representations incorporate these parameters. The greater the number of factors built into the representation, the greater its approximate truth. This suggestion for assessing relative degrees of approximate truth does 
número de valores idealizados es reducido ${ }^{101}$ : "The greater the discrepancy between the output of an abstract representation and the behavior of its target system, the less approximately true it may seem" (Chakravartty A. , 2010, pág. 38).

Las abstracciones puras dan descripciones de las propiedades y relaciones que son verdaderas simpliciter de ciertas clases de sistemas destino, y pueden ser más o menos aproximadamente verdaderas cuando se aplican a otras. La abstracción como verdad aproximada es simplemente el concepto de integralidad, evaluado en relación con un sistema de destino específico, y la condición correspondiente de aproximación en este ámbito es el grado en que el número de factores incorporados en una representación coinciden con los del sistema destino al que se aplican.

En el caso de las idealizaciones el concepto es muy diferente, puesto que el problema no es la amplitud de las representaciones, en su primer caso sería el éxito de la referencia, y después de ello, la exactitud con la que caracteriza a la naturaleza de los parámetros específicos que representan. Las idealizaciones no ofrecen caracterizaciones verdaderas de las propiedades y relaciones concernientes, al reducir el número suposiciones idealizadas (desidealizar), uno describe los sistemas destino de manera que admiten mayores grados de verdad aproximada:

Approximate truth qua idealization concerns the degree to which a representation that has successfully latched on to an aspect or aspects of some target system resembles a non-idealized representation of that system, where degrees of resemblance are defined in specific cases. The relevant condition of approximation here is not comprehensiveness, but successful reference, and degrees of distortion or simplification of the specific properties and relations targeted (Chakravartty A., Truth and Representation in Science: Two Inspirations from Art, 2010, pág. 44).

Chakravartty concluye que la verdad aproximada se entenderá mejor como una virtud que se realiza por múltiples medios de diferentes tipos de relaciones de representación entre los productos científicos (teorías y modelos) y los sistemas reales por otro: "These different conventions of representation reflect the degrees to which theories and models abstract and idealize, and as a consequence, anyone hoping to understand the ways in which they approximate truth must first subject these conventions to serious consideration" (pág. 50).

justice, I think, to the intuition that higher degrees of abstraction may correspond to lesser degrees of truth, but without failing to appreciate that abstractions may yet characterize some things perfectly accurately (Chakravartty A., 2010, pág. 38).

${ }^{101}$ Some idealizations approximate true descriptions of properties and relations better than others, and this is an important consideration in assessing their relative approximate truth. The relevant notion of approximation here is usually specified mathematically. One can define mathematically how Newtonian descriptions of certain properties approximate those of special relativity, for example, by showing how the equations of Newtonian mechanics are limiting cases of relativistic equations. The ideal gas law assumes that molecules of gas are point particles and that there are no forces of attraction between them, but it is possible to take into account both the space occupied by molecules of gas and small forces of mutual attraction. Thus, while the van der Waals equation generates values for various properties that approach those given by the ideal gas law at lower pressures (larger volumes), it yields different, more accurate values at higher pressures (smaller volumes). 4 The Van der Waals equation, over certain ranges of pressure, volume, and temperature, describes the natures of these properties and their relations more accurately than the ideal gas law (Chakravartty A., 2010, pág. 43). 
Tomando la propuesta de Northcott y Chakravartty podemos notar que no debe tomarse en cuenta únicamente la cercanía geométrica, pues si ese fuera el caso, el problema persistiría, sino que deben analizarse otros factores como los elementos causales y su fuerza, las abstracciones e idealizaciones.

Ahora, utilizando nuestro "esquema" de verdad aproximada, podemos agregarle los siguientes pasos como lo recomienda Northcott (2005, pág. 164) y tomando en cuenta los puntos analizados por Chakravartty: primero se debe especificar el contexto de interés, es decir, determinar la ontología, el vocabulario, cuáles son las fuerzas causales relevantes, las idealizaciones y las abstracciones (la distancia geométrica si es el caso). Después se tomarán a los modelos para competir en ese contexto en concreto, las especificaciones del primer paso tendrán ciertos valores particulares de verdad y los modelos en competencia intentarán atrapar dichos valores. Ahora, el grado de similitud o de verdad aproximada será el resultado que obtenga el modelo al compararse con esos parámetros al sistema real.

\subsection{La crítica de Miller}

Un último golpe a la propuesta de Smith en cuanto a tomar a la verosimilitud como cercanía geométrica es la crítica que realiza Miller en 2006 en su libro Out Of Error: Further Essays on Critical Rationalism, es en el capítulo 11 denominado “Thirty Years of Language Dependence” (pág. 197-233) donde muestra cómo se pueden obtener equivalencias en el lenguaje y revertir la verdad aproximada en cada uno de los casos en los cuales Smith pensaba que no era posible o relevante. A continuación, se expondrán cuáles son los contra-argumentos de Miller para mostrar que la propuesta de Smith no se encuentra libre del problema de dependencia del lenguaje.

Al respecto de concentrarse únicamente en las cantidades físicamente significativas, le parece que sería una estrategia espléndida, solamente si se estuviera seguro de cuáles son éstas. Smith había mencionado a la presión, el volumen y la viscosidad, pero dado que las cantidades $\eta$ y $\xi$ se definen en términos de $\varphi$ у $\psi$, entonces contarán con el mismo número de relaciones funcionales al igual que $\varphi$ y $\psi$. Puesto que las cantidades son interdefinibles, ninguna distinción puede ser trazada entre cuáles de ellas realmente participan en las leyes universales. Suponer que esas cantidades son las que se producen en las leyes que tenemos actualmente como las preferibles es una especie de esencialismo.

Miller pone como ejemplo a la Ley de Stefan-Botlzmann sobre la radiación del cuerpo negro que postula que "la emisión total de poder J", o la energía total de todas las longitudes de onda emitidas por unidad de tiempo y por unidad de área, es directamente proporcional a $\mathrm{T}^{4}$, la cuarta potencia de la temperatura absoluta de la superficie. Esto lleva a pensar que algunas magnitudes son causalmente significativas pueden contar $\mathrm{T}^{4}$ como una magnitud causal significante, pero esto era difícil de creer antes 
de que se derivara la ley de la teoría de Maxwell, aunado al éxito de sus pruebas. Sin embargo, Miller piensa que es posible que $\mathrm{T}^{3}$ y $\mathrm{T}^{5} \mathrm{u}$ otras funciones de $\mathrm{T}$ podrían convertirse en leyes en el futuro:

Forster (2004), p. 9, observes that causal significance seems not to be an empirical characteristic of a magnitude; certainly no one has suggested how we may submit a claim of causal significance to independent test. It is therefore worrying that, according to some authors, the truthlikeness of empirical theories is crucially dependent on it (Miller, 2006, pág. 213).

Miller menciona que Weston sostiene que podemos saber cuáles son las cantidades empíricamente significativas por medio de la inducción y que la evidencia de la verdad de una teoría también constituye una evidencia de que las cantidades significativas son aquellas que la teoría considera como relevantes; pero Miller piensa que incluso si se pudiera dar sentido a la idea de "significado causal", no le agrada que una teoría falsa pueda ser juzgada como aproximadamente verdadera simplemente porque se desempeña bien en aquellas cantidades que falsamente identifica como causalmente significativa:

It should be remembered that most quantities measured in physics laboratories are contrived quantities by any intuitive standard, yet predicting accurate values for them is normally thought to be an aim of experimental science. I do not know whether any such quantities (such as the distances between specks on photographs) count as physically or causally significant (ídem).

Lo que interesa especialmente a Smith son las trayectorias en el espacio físico, lo cual se presenta en las primeras cuatro columnas de la tabla (xxxi) ${ }^{\mathrm{xxxi}}$, es el ejemplo que el mismo Smith daba en el apartado donde mencionamos el problema de Miller, recordemos que propone a $x$ y $y$ como las coordenadas iniciales y después se transforman en $x^{*}$ e $y^{*}$ utilizando las ecuaciones $\mathrm{x}^{*}=\mathrm{x}-3 \mathrm{y} / 2 \mathrm{y} \mathrm{y}^{*}=\mathrm{y}-2 \mathrm{x} / 4$.

Las dos últimas columnas de la tabla son una sugerencia de Deryck Horton a Miller, donde se muestran cómo las cantidades $y$ e $y^{*}$ varían en función de $x$ y $x^{*}$. Dado que $x$ e $y$ son las coordenadas espaciales expresadas como funciones del tiempo t, la función f es la trayectoria a través de los puntos con esas coordenadas, y lo mismo para $x^{*}, y^{*}, f^{*}$. Podemos observar que, aunque $\mathrm{X}$ es más precisa que $\mathrm{Z}$ en $x$ y $y$, es menos precisa cuando se toma $f$; y aunque $\mathrm{Z}$ es más precisa que $\mathrm{X}$ está en $y^{*}$ y $x^{*}$, lo es menos en $f^{*}$ :

In other words, the transformations concocted by Smith are hardly needed in order to demonstrate that what is more accurate from one perspective may be less accurate from another perspective. Indeed, if we are interested in the movements of particles in physical space, then the separation of their trajectories seems as valid a quantity to be interested in as the separation of their individual $\mathrm{x}$ and $\mathrm{y}$ coordinates (pág. 214).

Respecto a los casos cuyas transformadas dependían del tiempo de una manera muy extraña, y por eso Smith las desechaba, Miller plantea que las transformaciones unidimensionales de Galileo y Lorentz son dependientes del tiempo de la manera en la que Smith las encuentra desagradables ${ }^{\mathrm{xx} x i i}$.

Nadie pensaría que en este enfoque las longitudes en la mecánica clásica y la relativista varían sin causa y efecto, ni tampoco que las leyes clásicas y relativistas dejan de ser invariantes en el tiempo. Miller muestra que no son invariables en el tiempo, si eso significa que una ley $f(x, t)=$ constante en un marco se transforma en la misma ley $\mathrm{f}\left(\mathrm{x}^{*}, \mathrm{t}^{*}\right)=$ constante en un marco con movimiento relativo uniforme. 
Una valija en reposo sobre una plataforma de la estación no está en reposo respecto a un tren que pasa a través de la estación, pero el marco en movimiento hace obedecer a una ley $\mathrm{f}^{*}\left(\mathrm{x}^{*}, \mathrm{t}^{*}\right)=$ constante, donde la forma de la función $\mathrm{f}^{*}$ se obtiene aplicando las transformaciones de coordenadas:

Smith's objection is accordingly without much force even in the case of greatest interest to him, in which the quantities transformed are spatial coordinates. It is even flimsier in the more general case, where what are transformed are physical magnitudes such as temperature and circulation velocity (pág. 219).

Miller concluye que cada vez que una teoría X es más exacta en los valores de una cantidad $p$ e $y$ que una teoría Z, donde cada una de las teorías $\mathrm{X}, \mathrm{Z}, \mathrm{T}$ afirman que $p$ e $y$ son múltiplos constantes de $\mathrm{t}$, entonces existe algún número de transformaciones dependientes del tiempo que revierten el ordenamiento por su exactitud ${ }^{\mathrm{xxxiii}}$.

Al respecto de la última aseveración de Smith sobre que no sería problemático si llegarán a ocurrir reversiones en el ordenamiento de manera ocasional, Miller apunta que el problema no es su argumento, sino la total falta de uno que apoyara esta postura:

It was because I too thought that the occasional instance of incomparability amongst numerical theories would not be devastating to an account of approximate truth that I attempted to establish that the order in which two sufficiently different theories are ordered by accuracy can always be reversed. For if incomparable theories are the norm, an account that says nothing about them is at best incomplete, and perhaps (like Popper's original theory) of only limited value. (págs. 225-226).

Miller acusa a Smith de no atacar a sus tesis planteadas anteriormente de manera directa y hace caso omiso a las pruebas que ofrece, en lugar de intentar demostrar que no existe un sólo caso en el que no haya transformación admisible que pueda afectar el ordenamiento en el que dos teorías se clasifican por su exactitud, se centra en objetar aspectos particulares de un ejemplo que había presentado como una ilustración de su tesis. Si Smith estuviese en lo correcto con respecto a que la dependencia del tiempo es un defecto y que algunas cantidades bien definidas pueden ser descalificadas como físicamente insignificativas, con ello apenas habría comenzado a restaurar la respetabilidad de su propuesta. Se admite que la tabla xxxiii carece de elegancia, aunque demuestra que puede no haya transformaciones independientes del tiempo que "permitan el engaño", y que puede pasar en todos los casos similares.

El fracaso del ejemplo de la tabla xxxiii, si es que falla, para la construcción de buena fe de cantidad físicas también nos dice poco acerca de lo que sucede en el caso general. Smith se centra demasiado en casos específicos y no toma lo suficientemente en cuenta la gran cantidad de posibilidades alternativas. Miller propone un ejemplo (xxxiv) ${ }^{\mathrm{xxxiv}}$ que puede ser considerado como posible candidato a una generalización, donde una transición de un plano cartesiano de coordenadas polares se invierte el orden de la exactitud de las teorías X y Z. En este caso los ángulos deben ser medidos en sentido antihorario, desde el eje x positivo, por lo tanto, el ángulo polar $\delta=\tan ^{-1}(\mathrm{x} / \mathrm{y})$ mientras que el radio vector $\mathrm{r}=$ $\sqrt{ }(\mathrm{x} 2+\mathrm{y} 2)$. Así, los valores de las coordenadas $x$ e $y$, y sus equivalentes $r$ y $d$ son los que están en la tabla 
$(v)^{\mathrm{xxx}}$. Podemos observar que aquí la transformación no depende del tiempo, y difícilmente la tomaríamos como descabellada.

Dado lo anterior, Miller termina reclamando: "My complaint is not that Smith does not acknowledge the possibility of genuine reversal of accuracy, for he does acknowledge it (op. cit., p. 89). What is discouraging is that he makes no effort to assess its scope" (pág. 227), además de que eligió confrontarse únicamente contra casos en los cuales su propuesta podría salir victoriosa, mientras ignoraba la gran cantidad de "frentes" con las cuales se le podía atacar de manera legítima.

\section{Realismo científico y deflacionismo}

En el primer capítulo se habló al respecto de las diferentes formas de caracterizar al realismo y se percató que una de ellas era la conexión que tenía esta postura filosófica con respecto a la verdad, tanto en el aspecto de la evaluación de las teorías (tomarlas como si tuviesen valores de verdad), su progreso (aproximarse cada vez más a la verdad) o la explicación de su éxito (lo que mejor explica el éxito empírico de una teoría es su aproximación a la verdad). En esas instancias no se hizo mucho hincapié en qué significa "verdad" o qué se entiende por "verdadero", simplemente se limitó a mencionar que generalmente los realistas adoptan una postura correspondentista -incluso algunos la toman como la única posible para sus intereses - aunque otros defienden que no hay una teoría de la verdad que sea sustantiva del realismo científico, incluso se puede adoptar una postura deflacionista y seguir siendo un realista, como lo afirma Michael Devitt (1997).

Al inicio de este capítulo se presentó la noción de verdad aproximada de Smith y se mencionó que se encontraba enmarcada dentro de la postura deflacionista con respecto a la verdad (sin embargo, podría ser utilizada por un correspondentista haciendo los cambios necesarios) por lo cual surge la duda de si hay compatibilidad entre el realismo científico y el deflacionismo.

En el presente apartado se revisarán de manera breve algunas teorías de la verdad, específicamente la correspondentista y deflacionista, mostrando cuáles son las diferencias entre ellas. Después se presentará en específico la propuesta de Horwich y cómo resuelve diferentes cuestionamientos acerca de su postura y su relación con el realismo científico.

Cabe aclarar que no se pretende argumentar que el deflacionismo es mejor que la teoría correspondentista, simplemente se defenderá que en caso de tomar una postura deflacionista con respecto a la verdad (como lo hace Smith), uno puede seguir siendo un realista científico.

\subsection{La teoría de la verdad por correspondencia}

Horwich (2010, pág. 13) menciona que los enfoques tradicionales de la verdad sostienen tres presupuestos, el primero, que la verdad es una propiedad, la cual algunas creencias o afirmaciones la tienen y otras no; el segundo es que dicha propiedad es sustantiva, y que podemos razonablemente esperar 
un enfoque de que la verdad es su naturaleza subyacente; y, tercero, los enfoques deben proveer una explicación de varios asuntos importantes acerca de la verdad, como los métodos para su detección y por qué estos son los adecuados, es decir, cómo obtenemos creencias verdaderas.

Existen varias teorías de la verdad tales como las coherentistas, las pragmatistas, las epistémicas y las que plantean que la verdad es una cualidad inanalizable. La mayoría de ellas se escriben a lo que conocemos como el esquema de equivalencia $T$, el cual plantea que "p" es verdadero si, y sólo si, p, pero la diferencia consiste en cómo se toma el primer lado del bicondicional, es decir, qué queremos decir con que una oración, pensamiento, creencia o estado mental es verdadero.

Quizá la más popular es la teoría de la verdad por correspondencia, la cual afirma que la verdad de una oración o creencia consiste en algún tipo de correspondencia entre lo afirmado y el mundo, la explicación del enunciado debe recurrir a la realidad. El lado izquierdo del bicondicional se explica recurriendo a un tipo de propiedad representacional, por lo tanto, la afirmación "La nieve es blanca" es verdadera porque corresponde con la realidad de cierta forma.

Aquí se deben hacer algunas especificaciones como explicar en qué consiste dicha relación de correspondencia y cuáles son los correlatos requeridos en la realidad; a esto se le han dado varias respuestas que configuran las diferentes propuestas dentro de la teoría por correspondencia, como lo muestra Barrio (Cfr. 1998, págs. 25-28).

Por un lado, están los holistas quienes sostienen que la correspondencia se realiza entre las representaciones y los hechos, entonces la verdad de una oración se obtiene por la existencia del hecho que está siendo representado, tal es el caso de la teoría pictórica de Wittgentein. Por lo tanto, cuando alguien dice "la nieve es blanca" será verdadera porque corresponde con el hecho de que la nieve es blanca, mientras que "la nieve es azul" es falsa porque no hay ningún hecho con el que corresponda.

También están quienes se adhieren a un enfoque atomista donde la categoría de hechos se elimina, la verdad del todo oracional se construye directamente con las relaciones de denotación y cumplimiento entre sus partes y los objetos externos. Así la oración que hemos mencionado anteriormente será verdadera porque existe un objeto que es la nieve y tiene la condición o propiedad de ser blanca. En este caso la relación de denotación supone que existe una realidad subyacente que se compone de objetos los cuales tienen ciertas propiedades. Entre sus exponentes más conocidos están Devitt y Fodor quienes la afectan en términos causales o contrafácticos o Papineu y Milikan que lo hacen en términos teleológicos.

Para los correspondentistas, la verdad es una característica que las oraciones poseen aún y cuando no lo sepamos, y esta se obtiene gracias a una relación asimétrica que el mundo posee con el lenguaje, por ejemplo, alguien podría afirmar "en Neptuno hay vida" y ser verdadero aún y cuando no sepamos si 
efectivamente en Neptuno hay vida. Además: "La correspondencia, ya sea entre oraciones y hechos o ya sea entre palabras y objetos debe ser entendida como una conexión asimétrica de fundamentación que va de lo ontológico a lo lingüístico" (Barrio, 1998, pág. 26), de esta manera se está proponiendo que el lenguaje es exigido para que se adecue al mundo para lograr la verdad.

Asimismo, aquí también se niega que la verdad se defina únicamente para las oraciones que comprendemos y que la verdad sea independiente de la explicación del uso. Igualmente consideran que la corrección de los bicondicionales se encuentra sujeta a restricciones relacionadas con la explicación del significado de las expresiones para las cuales se define la verdad, es decir, dado que "la nieve es blanca” significa que la nieve es blanca es por lo que el bicondicional “(T) 'la nieve es blanca' es verdadero si, y sólo si, 'la nieve es blanca' es adecuado.

Podemos observar que intentan reconstruir la concepción clásica de la verdad, es decir, se proponen hacer una reconstrucción del significado del predicado que se está utilizando. Pretenden dar una definición analítica de un concepto que se usa dentro de una comunidad de hablantes, así, realizan la descomposición del concepto de verdad en sus componentes más básicos: “Al efectuar este análisis, se despliega la naturaleza de la verdad: aquella que nos muestra que ciertos aspectos específicos del mundo fundamentan la verdad de nuestras oraciones" (pág. 27).

En resumen, podemos ver que para la teoría de la correspondencia la tesis de equivalencia se sostiene porque las oraciones tienen una relación con el mundo que se determina por los hechos acerca de los usuarios del lenguaje y su ambiente. Se trata entonces de emparejar a las oraciones con situaciones, en algunos casos se utilizan términos metafóricos como "espejear" o "representar". Las afirmaciones tienen sus condiciones de verdad en virtud de sus estructuras y la referencia de sus partes. La verdad se toma como una propiedad sustantiva que todas las oraciones verdaderas comparten y es de la misma naturaleza ${ }^{102}$.

\subsection{La teoría deflacionista de la verdad}

Después de mucho tiempo intentando dilucidar qué era la verdad, hubo un grupo de autores que vieron en esa tarea una empresa fallida y como resultado de tal desilusión propusieron como alternativa lo que conocemos como teoría deflacionista de la verdad. Las nociones de sentido común como que la

\footnotetext{
102 One strategy along these lines (Wittgenstein, 1922) is to suppose that a statement as a whole depicts a fact whose constituents are referents of the statement's constituents, and that the statement is true if and only if such a fact exists. Another strategy (Austin, 1950; Tarski, 1958; Davidson, 1969) is to define truth in terms of reference and predicate-satisfaction without importing the notions of fact and structure. Either way, these correspondence theories further divide according to what is said about reference. For example, one might suppose, with Wittgenstein (1922), that it is simply indescribable; or, with Field (1972) and Devitt (1984), that reference is a naturalistic (causal) relation; or, with Quine (1970) and Leeds (1978), that it is merely a device for semantic ascent (Horwich, 1999, pág. 8).
} 
verdad era una especie de correspondencia con los hechos no terminaban de ser satisfactoria, resultaba ser más bien una intuición vaga. Las alternativas como el coherentismo, o las que proponían verificarla en condiciones ideales, o por su idoneidad como base para acción tampoco resultaron muy fructíferas.

Generalmente se pretendía explicar qué era la verdad como el significado de cuando alguien mencionaba que un enunciado era "verdadero", además de la conexión que se mantenía entre estos dos conceptos. Y esto se da por dos ideas equivocadas que están relacionadas; la primera, la creencia de que la verdad tiene alguna estructura oculta esperando a ser descubierta; la segunda, descubrir qué es la verdad nos permitirá explicar y resolver problemas filosóficos en las áreas de semántica, epistemología y lógica. Y esto en general surge porque cuando observamos que alguien es diabético es por la existencia de la diabetes, lo magnético lo es por el magnetismo, creemos que lo verdadero es de ese modo por la verdad (Cfr. Horwich, 1999, págs. 1-2).

Aquí el problema surge cuando damos el salto a preguntarnos ¿qué es la verdad? Lo cual parece injustificado y suele provocar que se causen pseudoproblemas, un ejemplo similar de este caso es el de la palabra "existe" que daría paso a la problemática de ¿qué es la existencia? El predicado "es verdadero", a diferencia de otros no se utiliza para atribuir a cierto tipo de entidades un cierto tipo de propiedad o característica cuya naturaleza subyacente se tome en cuenta por sus relaciones con los demás ingredientes de la realidad. Como consecuencia, cuando alguien dice "es verdadero" no debemos esperar que esté anclado en una teoría profunda de a qué se refiere, es decir, una que nos explique las condiciones generales de cómo se aplicará dicho predicado.

Los deflacionistas rechazan que la verdad pueda ser definida como una noción robusta o sustantiva, incluso que no es una propiedad genuina, sino simplemente un dispositivo formal o lógico de aserción que no asciende más allá de la obviedad de que "p" y “es verdadero que p" son equivalentes ${ }^{103}$. Es decir, el esquema queda solamente como "p" es verdadero si, y sólo si, p, el único candidato para el otro lado de la equivalencia es simplemente p. Así el esquema se vuelve trivial porque el lado izquierdo no nos dice mucho. Esto es muy similar a lo que alguna vez Frege había mencionado:

The thought expressed in [the] words "that sea-water is salt" coincides with the sense of the sentence "that sea-water is salt". So, the sense of the word "true" is such that it does not make any essential contribution to the thought. If I assert "It is true that sea-water is salt", I assert the same thing as if I assert "Seawater is salt". This enables us to recognize that the assertion is not to be found in the word 'true' but in the assertoric force with which the sentence is uttered. This may lead us to think that the word "true" has no sense at all. But in that case a sentence in which "true" occurred would have no sense either. All that one can say is: the word "true" has a sense that contributes nothing to the sense of the sentence in which it occurs as a predicate (Frege 1979: 251-2).

${ }^{103}$ El mencionado enfoque resulta atractivo al deflacionar lo que parece ser un oscuro problema metafísico, el problema de la naturaleza de la verdad, dejando abierta la posibilidad de dar una explicación de los aspectos semánticos del lenguaje sin esta carga teórica (Barrio, 1998, pág. 16). 
A esto es a lo que se le denomina como transparencia de los predicados de verdad, es decir: "p es verdadero", "es verdadero que p" y "p" significan lo mismo.

Aunque existen muchas teorías deflacionistas y con profundas diferencias entre ellas, Horwich (2010, págs. 14-16) sostiene que existen cuatro puntos en los cuales coinciden:

El primero (pragmático), la palabra “verdadero" tiene una función conceptual idiosincrática, un tipo especial de utilidad. Dicha función varía entre diferentes propuestas, unos la toman como un dispositivo de énfasis, de concesión, generalización o anáfora, pero el acuerdo reside en que el adverbio "verdadero" es diferente de otros como "rojo", "árbol” o "magnético", pues estos tienen la utilidad de la predicción y explicación causal.

El segundo (semántico), el rol no predictivo ni explicativo del predicado de verdad implica que su significado no es empírico ${ }^{104}$, su implementación no se basa en una regla que nos enseñe a aceptar: donde "f" articula algún contenido observable; tampoco se trata de abreviar una expresión compleja no empírica. Al contrario, el principio central que rige nuestro despliegue global del predicado de verdad es que cada declaración contiene las condiciones que son necesarias y suficientes para su propia verdad. Esto es algo por el principio básico de uso que ofrece el predicado de verdad con su significado distintivo y que capacita también para llevar a cabo su función distintiva ${ }^{105}$.

El tercer aspecto en el que coinciden es, dado que "verdadero" no tiene un papel constitutivo de un predicado empírico, entonces nos daremos cuenta que no habrá un análisis reductivo de la verdad a las propiedades empíricas. Además, podemos observar que los datos fundamentales de la verdad no serán leyes naturales que se relacionen con fenómenos empíricos. A lo mucho se puede esperar una sistematización mediante una lista de hechos superficiales con los cuales nos hemos comprometido por el significado del predicado de verdad. Esto es lo que se entiende al decir que la propiedad de la verdad no es "sustancial".

Por último, la verdad no es un concepto profundo y por ende no se le debe otorgar un papel central en la teorización filosófica. Su importancia real es centrarnos en lo que llama el "el principio de uso", es decir, lo que permite que esta función se cumpla: "Todo lo que un deflacionista aconseja hacer es fijar la

\footnotetext{
104 Así pues, el predicado "es verdadera" tiene una extensión (el conjunto de las oraciones verdaderas del lenguaje en el que se predica), pero no existe ninguna naturaleza subyacente a él que podamos encontrar mediante la especulación filosófica a la cual podamos atribuirles poderes explicativos. Los deflacionistas defienden un punto de vista eliminacionista respecto de la explicación de (ii):

(T.D.) No hay ninguna propiedad que se aplique a las oraciones (como por ejemplo 'César fue asesinado') que sirva para explicar por qué ellas son verdaderas (Barrio, 1998, pág. 16). (ii) es el lado izquierdo del condicional de la tesis de equivalencia.

105 ¿Por qué la oración ' César fue asesinado' es verdadera? Porque César fue asesinado, por el hecho obvio de que cada oración especifica su propia condición de verdad. Esto es lo que Tarski ha denominado "condición de adecuación material". Aún y cuando dos oraciones sean verdaedras no existe ninguna explicación común de por qué lo son (Barrio, 1998, pág. 16).
} 
extensión de la verdad, sin postular ninguna propiedad especial que supuestamente todas las oraciones verdaderas tendrían en común y que las falsas carecerían” (Barrio, 1998, pág. 5).

Una de las propuestas más conocidas dentro de las teorías deflacionistas es aquella que considera que los predicados veritativos únicamente tienen un rol desentrecomillador

The truth predicate is a device of disquotation. We may affirm the single sentence by just uttering it, unaided by quotation or by the truth predicate; but if we want to affirm some infinite lot of sentences that we can demarcate only by talking about the sentences, then the truth predicate has its use (Quine, 1970, pág. 12). Pero hay quienes piensan diferente, por ejemplo, el enfoque de Strawson (1950) se centra en su uso y esto lo toma como una mera expresión de acuerdo con en el enunciado, es decir, cuando Pedro dice "x" es verdadero, está afirmando que está de acuerdo con x. Por otro lado, Grover, Camp y Belnap (1975) afirman que es una pro-oración cuya referencia es anafórica a su antecedente oracional, es decir, es una expresión que hace referencia a oraciones antecedentes.

Otros deflacionismos se distinguen con su planteamiento acerca de la equivalencia de la verdad de una oración con ella misma. Para el deflacionismo semanticalista las instancias del esquema T son materialmente equivalentes, es decir, lo que está del lado derecho y lo que está del lado izquierdo tienen el mismo valor de verdad, tenemos como resultado la siguiente instancia ( $\mathrm{T}$ ) 'La nieve es blanca' es verdadera si, y sólo si, la nieve es blanca; esto vuelve que sea imposible que rechacemos uno de los dos lados y aceptemos el otro porque caeríamos en una contradicción. Aquí se está suponiendo nuestra comprensión actual de la afirmación 'la nieve es blanca' que significa que la nieve es de color blanco.

También existe el deflacionismo sintactista donde se defiende que cuando aplicamos el predicado veritativo este no depende de las propiedades semánticas del lenguaje, ni del uso de las expresiones de las que se predica, únicamente de las propiedades sintáctico-formales. En estos casos la equivalencia no es solamente material, también lo es lógica. Aunque Barrio atina a hacer una aclaración:

Las opciones con las que un deflacionista cuenta al interpretar la equivalencia entre lo que está a ambos lados de las oraciones con las cuales establecemos las condiciones de verdad no deben llevarnos a confusión. Los bicondicionales son siempre, para el deflacionismo, definiciones. No son meras conjeturas empíricas y en este sentido no describen hechos semánticos (Barrio, 1998, pág. 19).

Otra discrepancia que suele surgir entre deflacionismo es respecto al uso cotidiano del predicado de verdad, hay quienes defienden que las nociones de verdad y sus condiciones carecen de utilidad teórica y que debemos abandonar nuestro hablar cotidiano acerca de ella cuando formulamos una teoría dado que los predicados veritativos tienen un carácter redundante (se elimina); otros admiten que el hablar cotidiano acerca de la verdad sí tiene utilidad, aunque únicamente en ciertos usos "lógico-expresivos", a veces sirve para abreviar o para no repetir todo lo que alguien dijo: "todo lo que dijo el candidato es verdadero" en lugar de volver a hacer mención de cada una de sus enunciados; también cuando queremos expresar una creencia sobre algo que hemos olvidado o recordamos de manera imprecisa: "el teorema de 
Bernoulli es verdadero"; o para expresar una creencia que para poderla emitir hubiésemos necesitado un número muy grande o infinito de conjunciones o disyunciones: "todos los número enteros son múltiplos de 1 es verdadero" en lugar de decir: “1 es múltiplo de 1”, “2 es múltiplo de 1”, “3 es múltiplo de 1”...

En resumidas cuentas, dentro de esta teoría, cada oración especifica sus propias condiciones de verdad. Para ellos no existe una naturaleza subyacente al predicado veritativo, todo lo que se puede decir acerca de la verdad de un enunciado como 'La nieve es blanca' se expresa en la equivalencia 'la nieve es blanca' es verdadera si, y sólo si, la nieve es blanca; dichas equivalencias deben ser vistas como definiciones que fijan la extensión de la verdad, no son conjeturas empíricas acerca de hechos semánticos relacionados con los significados de las oraciones, puesto que la noción de verdad se aplica a las oraciones cuya comprensión está supuesta, ni tampoco análisis reconstructivos con el cual se logre iluminar la naturaleza del concepto intuitivo de verdad, dado que no se pretende descomponer el concepto en sus componentes básicos (Cfr. Barrio, 1998, págs. 22-23).

Las diferencias entre el deflacionismo y la correspondencia residen en su naturaleza y sus propósitos $^{106}$, aunque ambas son teorías no epistémicas de la verdad. Mientras que la segunda afirma que la verdad es una propiedad que las afirmaciones tienen en virtud de cierta relación con la realidad y, además -la verdad- tienen una naturaleza que requiere una explicación, esta puede encontrarse dentro de una teoría de la mente o del lenguaje. La explicación del significado y el rol de una afirmación puede ser que posee la propiedad de una cierta condición de verdad. Mientras que, para la primera, si pensamos que la verdad tiene o no una propiedad, ciertamente no debemos pensar en ella como una propiedad de alguna naturaleza que requiera explicación científica. En otras palabras, la verdad no tiene estructura oculta a expensas de que la encontremos. El interés no es la verdad, sino los términos de verdad porque ellos son importantes para la expresibilidad del lenguaje. De manera más resumida:

In sum, the deflationist has little to say about the metaphysics of truth but much to say about the linguistic role of 'true', whereas the correspondence theorist has a lot to say about the metaphysics of truth but little to say about the linguistics of 'true' (Devitt, 2001, pág. 580).

También discrepan en el significado de los términos de verdad, aunque concuerdan en que tienen un rol lógico, el deflacionista se queda únicamente con ese rol, pero no tienen "el rol descriptivo" de un predicado normal, mientras que para el correspondentista el término tiene un rol descriptivo sustancial en alguna teoría del mundo. Además, el correspondentista piensa que todas las afirmaciones verdaderas

\footnotetext{
106 The first problem is that the two theories have opposite focuses. Whereas the focus of the correspondence theory is on the nature and role of truth, the focus of the deflationary theory is on the nature and role of the truth term, for example, of 'true'. The former focus is metaphysical; the latter, linguistic. So an awful lot of what deflationists say does not bear directly on what the correspondence theorists say, and vice versa (Devitt, The Metaphysics of Truth, 2001, pág. 580).
} 
tienen algo en común, es decir su correspondencia con el mundo es lo que las hace verdaderas ${ }^{107}$; mientras que el deflacionista rechaza que haya tal explicación reductiva de la verdad ${ }^{108}$.

Otro aspecto en el que difieren es acerca del valor explicativo de la verdad, mientras que el correspondentista toma a la verdad como explicación del éxito o de los objetivos de la ciencia, el deflacionista diferirá en ello (lo cual se verá en un apartado más adelante) ${ }^{109}$.

\subsection{La teoría minimalista}

Una de las posturas más conocidas dentro del deflacionismo es la denominada como minimalista o minimalismo, una de las cuales fue desarrollada por Horwich en diversos textos (1999) (2001) (2004) (2005) (2010), quien considera que los predicados de verdad existen únicamente por una cierta necesidad lógica. A veces deseamos adoptar una actitud sobre alguna proposición (creer o desear, por ejemplo) sin saber qué es realmente esa proposición, quizá porque no se escucha claramente lo que alguien dijo o desconocemos la totalidad de lo que se menciona en un postulado. Es en esas situaciones cuando el concepto de verdad se vuelve valioso porque gracias a él se puede hacer la construcción de otra proposición íntimamente relacionada con la que no se puede identificar, la cual es perfectamente adecuada como alternativa a nuestra actitud.

Pone en consideración el siguiente ejemplo (cfr. Horwich, 1999, págs. 3-4): (1) Lo que Óscar dijo es verdadero; aquí tenemos algo de la forma (2) $x$ es $F$ cuyo significado es tal que; dado más información acerca de $x$ y dada una premisa adicional de la forma (3) $x=$ la proposición que $p$; entonces podemos inferir (4) $p$. Y esta es la propiedad inferencial que tienen las proposiciones sobre la verdad. Tomemos ahora como ejemplo la ley del tercero excluso: (5) Todo es rojo o no rojo, feliz o no feliz, barato o no barato, etc. entonces nuestra tarea es encontrar una sola proposición finita que pueda abarcar todos los casos de este tipo; y el concepto de verdad proveerá una solución. Ahora, por ejemplo, (6) Todo es rojo

\footnotetext{
${ }^{107}$ The difference between deflationism and the correspondence theory should emerge in proponents' responses to a demand for an explanation of the equivalence thesis. Let us take the most famous instance of the equivalence schema as our example: 'Snow is white' is true iff snow is white. In virtue of what is this so? The core of the correspondence theorist's answer is a reductive theory of the nature of true statements. This will be an account of what is common and peculiar to these statements and of the relation that true statements stand in to the world. When this theory is applied to 'Snow is white', it shows that this statement is related to the world in such a way that the statement is true iff snow is white. So, the theory of truth, together with facts about the statement 'Snow is white', explain why 'Snow is white' is true iff snow is white (Devitt, 2001, pág. 592) ${ }^{108}$ The deflationist, in contrast, cannot accept any appeal to a theory of the nature of truth in her explanation, because she dismisses the possibility of saying anything substantial about that nature. So, what explanation does she offer? Basically, none. She thinks that the demand for an explanation here is misguided: that 'Snow is white' is true iff snow is white is a "brute fact" needing no explanation. However, she has something further to say to make this provocative claim palatable: a diagnosis of the error of thinking that we need an explanation here. The diagnosis moves up to "the semantic level" to consider how the brute fact is expressed (Devitt, 2001, pág. 593).

${ }^{109}$ The contrast between the two theories should not be that the correspondence theory must offer a substantial explanation of why 'Snow is white' is true iff snow is white where the deflationary theory offers a trivial one appealing to the meaning of 'true'.19 The contrast should be that the correspondence theory must offer an explanation where the deflationary theory appeals to the meaning of 'true' to explain why no explanation is necessary (Devitt, 2001, pág. 593).
} 
o no rojo; es equivalente a (6*) La proposición que todo es rojo o no rojo es verdadera; lo cual funciona igual para los demás casos y podemos capturarlos en una afirmación universalmente cuantificada $\left(5^{*}\right)$ Toda proposición de la forma todo es fo no $f$ es verdadera, "It is in just this role, and not as the name of some baffling ingredient of nature, that the concept of truth figures so pervasively in philosophical reflection" (Horwich, 1999, pág. 4).

Así, lo que hace posible que la noción de verdad desempeñe ese rol es que, para cualquier oración declarativa (4) p, podemos ofrecer una afirmación equivalente (4*) La proposición que p es verdadera. Entonces la oración original la hemos convertido en un sintagma nominal. "La proposición que $p$ " es simplemente un "denominalizador". Para que el predicado de verdad cumpla su función se debe reconocer que

(MT) The proposition that quarks really exist is true if and only if quarks really exist, the proposition that lying is bad is true if and only if lying is bad, ... and so on, but nothing more about truth need be assumed (pág. 5).

Horwich considera que esto es todo lo que se puede decir acerca de la verdad y que la idea de que todas las proposiciones sobre lo verdadero deberían tener algo en común es simplemente un pseudo-problema. Además, considera que, a diferencia de otras propiedades, ser verdadero no es susceptible de un mayor análisis conceptual o científico.

El esquema de equivalencia de Horwich es el siguiente: “(E) It is true that p if and only if p” (pág. 6), adaptando nuestro esquema de aproximación quedaría de la siguiente manera: “(A) Es aproximadamente verdadero que $p$ si, y sólo si, $p "$.

Horwich (págs. 17-20) señala que los principios fundamentales de su teoría minimalista son los siguientes: los axiomas de la teoría son proposiciones como (i) [[La nieve es blanca] es verdadero si, y sólo si, la nieve es blanca] y (ii) [[Mentir es malo] es verdadero si, y sólo si, mentir es malo], que, es decir, todas las proposiciones cuya estructura es $\left(\mathrm{E}^{*}\right)[[p] \text { es verdadero si, y sólo si, } p]^{110}$. Para llegar a esta "estructura proposicional" podemos empezar con cualquiera de los axiomas y tomemos en cuenta que la afirmación expresada es divisible en dos componentes complejos. La primera parte es una oración que se repite, es decir (iii) 'La nieve es blanca' y el segundo es el remanente del llamado axioma, el esquema (E) '[ $p$ ] es verdadero si, sólo si, $p$ '. Ahora:

we assume that if a complex expression results from the application of a schema to a sequence of terms, then the meaning of the expression is the result of applying the meaning of the schema to the sequence of the terms' meanings (Horwich, 1999, pág. 18).

En el caso del ejemplo: ( $\left.i^{*}\right)$ '[La nieve es blanca] es verdadera si, sólo si, la nieve es blanca' que es el resultado de aplicar (E) a (iii), así la proposición que expresamos en (i*) resultan de aplicar lo que es

${ }^{110}$ Horwich restringe las instancias que puede tener el esquema de equivalencia para evitar con ello la paradoja del mentiroso (Truth, 1999, págs. 40-42) 
expresado por el esquema (E) a lo que es mencionado por (iii). Nos podemos dar cuenta que el axioma (i) es la consecuencia de emplear el axioma $\left(\mathrm{E}^{*}\right)$ a la proposición (iii*) [La nieve es blanca], lo mismo sucedería con (ii).

Así, para obtener los axiomas en la teoría minimalista (MT) es suficiente con aplicar el siguiente principio: "(5) For any object $x: x$ is an axiom of the minimal theory if and only if, for some $y$, when the function $\mathrm{E}^{*}$ is applied to $y$, its value is $x^{\prime}$ (pág. 19), o: “( $\left.5^{*}\right)(\mathrm{x})\left(\mathrm{x}\right.$ is an axiom of MT H $\left.(\exists \mathrm{y})\left(\mathrm{x}=\mathrm{E}^{*}(\mathrm{y})\right)\right)$ ” (pág. 20).

Cabe destacar que el minimalismo no nos dirá "qué es la verdad", es decir, no ofrece un principio como el siguiente $(\mathrm{x})(\mathrm{x}$ es verdadero si ... x ...) o lo que hace a una oración verdadera es que tenga las características $x$ o $y$, simplemente se centra en la parte semántica y del uso de las proposiciones veritativas.

En resumidas cuentas, de acuerdo con la concepción minimalista, la función de los predicados de verdad es permitir la formulación explícita de generalizaciones esquemáticas anteriormente analizadas. Nuestro entendimiento de la palabra está constituida por la práctica del uso cuando queremos realizar esa función, práctica cuya regularidad básica es una inclinación a aceptar las instancias del esquema de equivalencia de las cuales se compone la teoría de la verdad: "Thus, the minimal theory of truth will provide the basis for accounts of the meaning and function of the truth predicate, of our understanding it, of our grasp upon the concept of truth, and of the character of truth itself' (pág. 37).

\subsection{Realismo científico y deflacionismo}

Suele pensarse que adoptar el deflacionismo nos haría tomar ciertas posturas filosóficas en específico o sería inconsistente que eligiésemos otras que sí podrían ser defendidas con una teoría de la verdad que fuese más profunda, esto en los temas metafísicos, epistemológicos y semánticos donde la verdad suele jugar un papel central. Tal es el caso del realismo científico que se identifica normalmente con la teoría de la correspondencia, parece que por obvias razones si uno es correspondentista, entonces tendría que ser realista de esos elementos que uno piensa que tienen referente en nuestro enunciado, lo que aquí se intentará poner en duda es si ser realista necesariamente nos empuja a abrazar una teoría de la correspondencia o podemos adoptar la teoría minimalista de la verdad.

Este es un camino que han seguido Barrio (1988), Devitt (1991) (1997) (2014) y Horwich (1999) (2010) donde afirman que muchos de los problemas que han surgido en el debate realismo / anti-realismo se deben a una mala caracterización que pone en el centro a la semántica y no los constituyentes 
principales de dichas propuestas ${ }^{111}$. El realismo no implica ninguna doctrina de la verdad, incluso puede haber alguien que sea realista sin tener alguna teoría de la verdad y esto no causará inconsistencias.

Estos autores lo que consideran como el núcleo esencial del realismo son las tesis metafísica y la epistémica, es decir, que el mundo y los objetos existen de manera independiente de nosotros y que son cognoscibles, en el caso del realismo científico se referirá tanto a los objetos observables como a los inobservables, mientras que el anti-realista puede sostener que la realidad es construida, una proyección de la mente, que los inobservables son ficciones, o que no es cognoscible (o que sólo conocemos la parte observable). Hasta aquí, ninguno de los elementos hace mención de la palabra "verdad".

Aunque, como se mencionó, es común ligar a la teoría de la correspondencia con el realismo, hay una forma natural de sostener el realismo utilizando al deflacionismo esto de manera conveniente, elegante y no envuelve compromisos del tipo: "Realism* Most current common-sense, and scientific, physical existence statement are objectively and mind-independently (deflationary) true" (Devitt, 1997, pág. 41) Así da una ilustración del tipo de "ascenso semántico" que el deflacionismo hace posible, y conveniente, cualquiera que sea el sujeto de estudio. Dicho ascenso no hace a la doctrina semántica, en el sentido de ser parte de una teoría del significado; eso no cambia el caso de estudio.

Cuando Devitt se pregunta bajo qué condiciones podemos saber qué hace que una persona mantenga ciertos compromisos ontológicos se responde de la siguiente forma: una persona se compromete ontológicamente con la existencia de $a$ si al afirmar S, S dice algo que implica la existencia de $a_{s}$ así, basta con decir que los gatos existen para la afirmación "los gatos existen" sea verdadera. Considera que este criterio no exige el uso de ninguna teoría semántica, es suficiente con entender S. Conviene indicar, por supuesto, que Devitt propone mostrar con este argumento que el tipo de compromisos ontológicos adquiridos a la luz de su criterio se dan a nivel del lenguaje objeto y que no requieren, por lo tanto, que nos movamos hacia el metalenguaje (Cfr. Devitt, 1997, pág. 51).

Al momento de utilizar una teoría deflacionista dentro del realismo surgen una serie de dudas. Una de ellas podría ser si la verdad podrá mantener su rol explicativo cuando una teoría tiene éxito empírico, cuando decimos cosas como (a) La teoría especial hace predicciones exactas porque es

\footnotetext{
111. Realism is not about the semantic interpretation of existence claims. It is sometimes claimed that a person's realism about certain entities cannot be simply exemplified in a belief or claim that those entities exist. We must know how such a belief or claim is to be interpreted; realism about cats must come from a certain view of the reference of 'cat', for example." I have argued against this at length elsewhere. Briefly, we do not need to move into a metalanguage discussion of our object language claims to establish ontic commitment. Indeed, if commitment could never be established at the level of the object language it could never be established at all. The idea that talk about the world is unclear and in need of interpretation, yet talk about language and its relation to the world is straightforward on the face of it, reflects the damage of years of living under the linguistic turn (Devitt, 1991, pág. 53).
} 
(aproximadamente) verdadera o (b) Los microscopios de electrones funcionan bien porque las teorías en las que se basa son (aproximadamente) verdaderas.

Para acomodarlas en el axioma de equivalencia podemos considerar la situación en la cual conocemos explícitamente la teoría de la que estamos hablando y suponer que su formulación no es muy larga o complicada. Por ejemplo: (c) Nada va más rápido que la luz, en tal caso, en lugar de decir (d) La teoría de que nada va más rápido que la luz funciona bien es verdadera, nosotros diremos (e) La teoría que nada va más rápido que la luz funciona bien porque nada va más rápido que la luz. No se logra mayor profundidad explicativa poniendo el asunto en términos en verdad. Horwich reconoce que utilizar el predicado de verdad en este tipo de contextos a veces tiene una ventaja, pues nos da cierta economía de expresión y además podemos hacer dichas expresiones aún y cuando desconozcamos la teoría (también al generalizar), por ejemplo: (f) Las teorías (aproximadamente) verdaderas proveen predicciones exactas; aunque estas son las características de la verdad que son fundamentales para la concepción minimalista, por lo tanto no es necesario "ir más allá" (Cfr. Horwich, 1999, págs. 48-49).

Otra duda es al respecto de si el minamilismo nos llevaría necesariamente a un relativismo, lo cual se contrapondría al realismo. Esto se debe a una confusión, cuando alguien afirma que la verdad no es una propiedad compleja o naturalista, no está afirmando que las verdades son irreales, es decir, que ninguna afirmación o creencia son verdaderas. Lo último lo sostendría una persona que piense que la verdad es contextual o dependiente de la perspectiva, pero eso no está implicado por la teoría minimalista, sino que se oponen. Creer que los predicados de verdad tienen una propiedad sustancial es lo que lleva a la conclusión de que nada puede ser absolutamente verdadero. Por el contrario, el minimalista permite que sea fácil suponer que toda proposición o su negación es verdadera, esto hace que el relativismo sea insostenible (Cfr. Horwich, 1999, págs. 53): "Thus the 'insubstantiality' of truth is in no way tantamount to the nonexistence of truths" (pág. 53).

El término "realismo" es muy utilizado dentro de la filosofía, y uno puede sin duda inventar sentidos del mismo de tal manera que el enfoque minimalista pueda estar de parte del realista o del antirealista. La pregunta sustancial aquí concierne a la relación entre la concepción de la verdad y la justificación de creer en hechos que existen independientemente del pensamiento o de la experiencia. Para Horwich no hay tal relación. Al contrario, una fuente de confusión en los debates acerca del realismo científico es la tendencia de asumir que el problema de la verdad está envuelto fundamentalmente.

Si uno toma los anti-realismos más conocidos como el de Duhem y van Fraassen podemos observar que ninguno de ellos se afilia con la concepción minimalista porque ésta no da ninguna razón para pensar que las teorías son construidas fuera de los datos, y además está de acuerdo con la 
consideración holística que han tenido muchos filósofos para rechazar el positivismo lógico. Además, el minimalismo es consistente con la suposición de que el método científico nos provee con teorías de las que podemos creer que son aproximadamente verdaderas y no solamente adecuadas: "According to the deflationary picture, believing that a theory is true is a trivial step beyond believing the theory; and the justifiability of this attitude is certainly not precluded by minimalism" (pág. 57).

Horwich considera que la concepción minimalista no es la única que se mantiene neutral respecto a los dos aspectos centrales del realismo, sino que lo mismo sucede con las propuestas alternativas, por lo cual elegir una teoría de la verdad es "ortogonal" a las cuestiones relacionadas con el realismo. Las teorías de la verdad pueden no tener una implicación definitiva para los componentes epistemológicos y semánticos del problema (Cfr. págs. 58-60).

Una cuestión más es al respecto de la verdad como objetivo de la investigación, es decir, si la verdad no es una propiedad sustancial, ¿qué quiere decir que la verdad es el objetivo de la ciencia? En este sentido una afirmación como (g) El objetivo de la investigación $x$ es la verdad; donde la naturaleza de $x$ nos dirá qué es lo que se toma por verdad, por ejemplo; ( $\mathrm{g}^{*}$ ) El objetivo de la investigación del asesinato de Kennedy es la verdad es equivalente a decir ( $\mathrm{g}^{*}$ ') El objetivo de la investigación del asesinato de Kennedy es saber quién fue el asesino de Kennedy o en palabras de Devitt: "So, semantically descending, the view is that the aim of science is to discover what entities there are - observables and unobservables - and what they are like” (Devitt, 1991, pág. 57), es decir, cuando alguien afirma (g**) El objetivo de la investigación científica es la verdad es equivalente a ( $\mathrm{g}^{* *}$ ') El objetivo de la investigación científica es conocer la estructura del mundo.

De igual manera sucede con la idea de progreso científico tomado como una aproximación convergente hacia la verdad, en estos casos, lo que se está queriendo decir es que las teorías pasadas habían capturado algunas partes de la estructura del mundo, las actuales lo han hecho con otras más ${ }^{112}$ y se espera que en el futuro se acrecenté; claro esto no siempre de manera lineal, sino que a veces puede haber pérdidas (y revoluciones). En palabras de Horwich: "It suffices to imagine a temporal sequence of total theories $\mathrm{T}(1), \mathrm{T}(2), \ldots, \mathrm{T}(\mathrm{k}), \ldots, \mathrm{T}$ (final), becoming gradually (but not necessarily monotonically) more similar to $\mathrm{T}$ (final)-where $\mathrm{T}$ (final) is true. $\mathrm{T}$ (final) is a conjunction of unknown and presently inexpressible propositions" (1999, pág. 63).

Hasta el momento, lo que hemos probado es que la teoría minimalista de la verdad puede encajar bien dentro del realismo científico sin causarle más problemas de los que ya tiene, además de mostrar

112 Now any realist (who is not so radically eliminativist in her epistemology as to eschew talk of discovery) will believe that science already has discovered many of the entities there are and approximately what they are like (Devitt, 1991, pág. 57). 
que la teoría de la verdad elegida no juega un papel central en dicho debate, sino los aspectos metafísicos de existencia e independencia de la mente, por un lado, y los de posibilidad de conocimiento por el otro.

\section{6 ¿Cuál es nuestro realismo?}

Habrá quienes se pregunten qué tipo de realismo nos llevará a adoptar la teoría minimalista y el esquema de equivalencia [A] al respecto de la verdad aproximada; se cree que esto es un error, puesto que los debates sobre cuál realismo científico es más adecuado o mejor se deben librar en los aspectos ontológicos y epistémicos, después especificar cómo se aplica [A] dentro de su teoría, esto es algo que el mismo Smith había declarado.

Ahora, dado el ejemplo de Smith sobre las familias de modelos y las teorías caóticas, lo más adecuado sería, en su caso, centrarse en el realismo estructural propuesto por Jon Worral (1989), quien mencionó: "I should be understand that my realists claim only that we have grounds for holding that our present theories in mature science are approximately true" (pág. 143), aunque aclara que sólo utiliza la noción de verdad aproximada de manera intuitiva, ahora puede aplicarse [A] para aclarar en estos casos a qué se refiere.

En este sentido, cuando sustituimos en el esquema [A] su afirmación queda de la siguiente manera: [A*] "Nuestras teorías actuales en ciencias maduras" son aproximadamente verdaderas si, y sólo si, la realidad es aproximadamente como dicen nuestras teorías actuales en ciencias maduras, Worral deberá especificar a qué se refiere en este caso, a lo cual responderá que las estructuras postuladas en dichas teorías son aproximadamente a como son las de la realidad.

El argumento principal del realismo estructural, cuando menos en su inicio, es que para mantener el realismo y evitar la problemática de la inducción pesimista había que plantear que aquello que se mantenía en el cambio inter-teórico eran las estructuras, tal como lo mostró en el ejemplo de Fresnel y Maxwell donde cambian varios aspectos de la ontológico, en el primero se defendía la existencia de un éter y en el segundo a los campos electromagnéticos para resolver el mismo problema, pero hay algo que sí se conserva entre ellas:

There was an important element of continuity in the shift from Fresnel to Maxwell-and this was much more than a simple question of over the successful empirical content into the new theory. At the same time, it was rather less than a carrying over of the full theoretical content or full theoretical mechanisms (even in 'approximate' form). And what was carried over can be captured without making the very far-fetched assumption of Hardin and Rosenberg that Fresnel's theory was 'really' about the electromagnetic field all along. There was continuity or accumulation in the shift, but the continuity is one of form or structure, not of content. In fact, this claim was already made and defended by Poincare (pág. 157).

Esto lo lleva a afirmar que debemos comprometernos únicamente con la parte matemática o estructural de nuestras teorías. En este sentido, cuando un realista estructural habla de que la ciencia tiene como objetivo aproximarse cada vez más a la verdad, lo que está afirman es que las teorías científicas deberían 
aumentar la cantidad de estructuras que postulan dentro de sí (y que estas sean las que existen en el mundo). Cuando exclaman que una teoría T está más aproximada a la verdad que otra T', lo que está queriendo decir es que la teoría T captura una mayor cantidad de estructuras que la teoría T'.

Esto sería muy a grandes rasgos la propuesta aplicada al realismo estructural, la razón es porque se puede aplicar a distintos realismos y sólo es necesario que el autor especifique cuál es la forma en la que está utilizando el esquema [A].

Por último, habrá quien pida maneras de "reconocer" o "saber" cuándo hemos logrado conseguir la verdad, o unos criterios que permitan tener una creencia justificada en ella. Eso sería motivo de otra tesis. Hasta el momento, salvo el capítulo cuarto, nuestra Idónea Comunicación de Resultados se ha centrado en qué se quiere decir con aproximadamente verdadero o verosimilitud; y esto es lo que se ofrece al final. Aunque algunos de los mecanismos con los que esto puede ser defendido son el argumento de los no milagros, unificación, simplicidad, robustez y otras virtudes epistémicas.

\section{Conclusión}

En el primer capítulo de la ICR se comenzó hablando acerca del realismo científico donde principalmente se plantea la existencia de objetos observables e inobservables que son independientes de la mente y que somos (en ciertos casos) capaces de conocerlos por medio de la ciencia; además, de que las mejores teorías científicas actuales son aproximadamente verdaderas o verosímiles y que la noción de progreso consiste en acercarnos cada vez más a la verdad o aumentar la verosimilitud, esto debe entenderse como la tarea de obtener teorías y modelos científicos que postulen dentro de sí la estructura o componentes reales del mundo y que cada vez el conocimiento al respecto sea mayor; aunque se reconoció en diversas ocasiones que, dado que tomar en cuenta todos los elementos que participan en un fenómeno pueden ser muy grandes y eso complicaría sobremanera la posibilidad de tener un aparato matemático que sea tratable, es necesario que se realicen abstracciones e idealizaciones con la finalidad de tener una ciencia funcional, en este sentido un modelo que atrape la verdad completa sería demasiado complicado e innecesario (Teller, 2001) (Psillos, 1999), por ello una noción de verdad más manejable sería la verosimilitud o la verdad aproximada.

En varias ocasiones se mencionó a la verosimilitud o a la verdad aproximada como un elemento central del debate del realismo y que requería clarificación puesto que es utilizado en argumentos como el de los no milagros o el de la unificación; o en contra-argumentos como la subdeterminación empírica o la denominada como inducción pesimista; asimismo del reclamo anti-realista que dicha noción de verosimilitud era poco clara, incluso hay muchos realistas que deciden no adentrarse en el tema y utilizarlo de manera "intuitiva". 
No fue hasta 1962 que Karl Popper se avocó arduamente en realizar una propuesta formalizada, el tema del segundo capítulo, la cual prácticamente pasó desapercibida hasta una década después que surgieron algunas críticas por parte de Tichý (1974) y Miller (1974), fue precisamente en ese momento cuando este se convirtió en uno de los temas centrales del debate entre lo realistas, es decir, contestar la pregunta, ¿cuál es la función correcta de verosimilitud? para la cual se propusieron diferentes respuestas con autores como Oddie, Niiniluoto, Hilpinen y Kuipers, hasta la década de los 90's, mientras Tambolo, Cevolani, Kieseppa y Zwart han continuado con los esfuerzos de intentar dar una formalización y una métrica cuantitativa, sin embargo, todos ellos han sucumbido al denominado como problema de Miller. Mientras que otra corriente ha dejado de lado la búsqueda cuantitativa y formal para ofrecer una opción cualitativa, tal es el caso de Giere, Psillos y Aronson. Ello se revisó en el capítulo tercero.

El capítulo cuarto estuvo enfocado a aspectos sobre la utilidad epistémica de la verosimilitud dentro del proyecto realista, tanto como para ser útil como justificación para la verdad como para proveer ciertas reglas para la consecución de la misma. Aunque este no es precisamente el tema central de la ICR, se hizo para disipar algunas dudas.

En este último capítulo se mostró la propuesta que hizo Smith en 1998 sobre una noción de verdad aproximada que se enmarca dentro de una teoría deflacionista de la verdad, cuyo dispositivo desentrecomillador es el siguiente: [A] "P" es aproximadamente verdadero si, sólo si, aproximadamente P. Mediante diferentes ejemplos se expuso la aplicación del mismo, además que una de sus grandes ventajas es que exhibía que las cuestiones en comparación no son siempre las mismas, por lo tanto, no deberíamos esperar que lo que es útil en un caso, lo sea también en otro.

Considero que este es uno de los grandes beneficios que trae la propuesta de Smith aunada a la de Teller, puesto que deja de lado las problemáticas que había ocasionado la constante búsqueda de una noción cuya comparación fuese objetiva de manera general, dado que eso era imposible y tampoco se requería, sino que hay que establecer ciertos parámetros de interés para que esto se lleve a cabo y a partir de ello (intereses subjetivos) lograr objetividad. Esto no quiere decir que se caiga en un relativismo, aunque los elementos relevantes a comparar sean contextuales, la parte objetiva existe en el mundo. Aquí a lo que se renuncia es a la idea de que " $x$ es siempre más aproximado a $y$ que $z$ " pueda darse de una manera que aplique a todos los casos de interés. O como lo dice Niiniluoto:

To those readers who are worried that the similarity account of truthlikeness does not make verisimilitude completely 'objective' or purely "logical' I wish to cite my conclusion from Niiniluoto (1986b). If measures of verisimilitude always have a pragmatic dimension, by being dependent on our cognitive interests, this only shows that it has the same character as most of the interesting concepts in the philosophy of science such as theory, explanation, and confirmation. Science is a fallible and progressive enterprise which is run by historically developing scientific communities. Our tools for analysing science and its change should be 
flexible enough to take into account this richness of scientific practices. So, let us not try to make our theory of science more objective - or less objective - than science in fact is (Niiniluoto, 1987, pág. 473).

El ejemplo de Smith se encuentra enmarcado dentro de la visión semántica de las teorías que a veces tiene cierta tensión con el realismo, sin embargo, esta se desvanece cuando se afirma que en los modelos o en las estructuras se capturan o postulan también entidades no observables.

Quizá la problemática más grande de Smith no es su esquema de verdad aproximada, sino lo que él eligió para comparar en las teorías de modelado geométrico donde afirma que un modelo es más verosímil que otro si su cercanía geométrica es menor. Esto desde un principio provoca la sensación, y con justa razón, de que únicamente se está tratando de adecuación puesto que solamente se evalúa una cuestión que es el resultado de poner en marcha al modelo ${ }^{113}$; no dice nada sobre la ontología postulada que es fundamental para el realista científico. Además de provocar problemas indeseables como el de Ptolomeo.

La manera con la que se trató de solucionar este problema fue mediante las estrategias de Northcott y Chakravartty, con ello se podría resolver el problema de Ptolomeo; es decir, poner en comparación entre los modelos a las fuerzas causales que participan en ellos, además de sus grados de abstracción e idealización. Aunque esto podría parecer alentador, quizá cause otras dificultades al momento de evaluar dichos elementos, puesto que si se da más peso a la abstracción que a los otros elementos es posible que el modelo I sea mejor que el II, pero si damos prioridad a la idealización o a las fuerzas causales es posible que esto se revierta, no obstante, no cuento con un caso a la mano para demostrarlo, pero cae dentro de las posibilidades.

Al final hemos lidiado con una inquietud que podría incomodar a algunos realistas (a los exclusivamente correspondentistas) con respecto a utilizar una teoría de la verdad que fuese deflacionista puesto que ahí se enmarca la propuesta smitheana, de manera breve hemos mostrado por qué varias de las posibles objeciones no tendrían que ser de gran preocupación, bastaría con resaltar cuáles son los elementos centrales del realismo (existencia, independencia y cognoscibilidad) para mostrar que la teoría de la verdad no es central en dicho debate y que ciertos puntos se pueden reformular para que sigan funcionando. Sin embargo, y como el mismo Smith lo declara, si alguien desea seguir siendo correspondentista, el esquema [A] puede seguir siendo aplicado únicamente con respetar su explicación de derecha a izquierda del bicondicional.

\footnotetext{
${ }^{113}$ Aunque Smith hace la siguiente aclaración: "Hagamos hincapié en que no se trata de afirmar sin más que una teoría de la verdad sea solamente cuestión de precisión. La proposición es una proposición limitada, conectada con teorías MG de ambición modesta, que sólo pretenden decirnos cómo evolucionan en el tiempo ciertas cantidades. Sólo en ese caso basta el seguimiento próximo como criterio de verdad aproximada" (2001, pág. 94).
} 
Siendo este el caso, y la manera como ganará generalidad el esquema [A], es necesario que los realistas hagan uso del esquema [A] y expliquen cuál será la lectura que deberá darse en su caso favorecido. Los argumentos sobre la ontología y su justificación en cada caso corren por parte de lo que se está deseando defender ${ }^{114}$.

${ }^{114}$ Realists sometimes seem to suppose that a blanket invocation of the idea of approximate truth enables them to avoid some nasty objections (by e.g. taking the sting out of the Pessimistic Induction). Not so: when - as minimalists about truth - we are told by the optimistic realist that some favoured theory $\mathrm{T}$ is approximately true, our grasp of this will wait upon some explanation of how to construe approximately T. And there is no blanket, cover-all explanation available. All the hard work for the optimistic realist remains, then, as she is faced with explaining on a case by case basis, what work the 'approximately' is doing as applied to her various favoured cases (Smith, 1998b, pág. 127). 


\section{Bibliografía}

Alston, W. P. (2001). A Realist Conception of Truth. In M. P. Lynch, The Nature of Truth: Classic and Contemporary Perspectives (pp. 41-66). Massachusetts: Massachusetts Institute of Technology Press.

Andersson, G. (1982). El problema de la verosimilitud. En R. y. Anderson, Progreso y racionalidad en la ciencia (págs. 258-275). Madrid: Alianza.

Aronson, Harré y Way. (1994). Realism Rescued. London: Duckworth.

Aronson, J. L. (1990). Verisimilitude and Type Hierarchies. Philosophical Topics, 18, 5-28.

- (1997). Truth, Versimilitude and Natural Kinds. Philosophical Pappers, 26(1), 71-104.

Barnes, E. (1990). The Language Dependence of Accuracy. Synthese, 84, 59-95.

- (1991). Beyond Verisimilitude: A Linguistically Invariant Basis for Scientific Progress. Synthese, 88, 309-339.

Barrio, E. A. (1998). La verdad Desestructurada. Buenos Aires: Eudeba.

Belanger, C. A. (2015). On Philosophical Problems in the Foundations of Chaos theory. Toronto: Institute for the History and Philosophy of Science and Technology.

Ben-Menahem, Y. (2006). Conventionalism. Cambridge: Cambridge University Press.

Bird, A. (2002). Review. Ratio (New Series), XV(1), 104-107.

- (2007). What Is Scientific Progress? Noûs, 41(1), 64-89.

Boyd, R. (1984). The Current Status of Scientific Realism. In J. Leplin, Scientific Realism (pp. 41-82). Berkeley: University of California Press.

- (1985). Lex Orandi est Lex Credendi. In C. \&. Hooker, Images of Science: Essays on Realism and Empiricism (pp. 3-34). Chicago: The University of Chicago Press.

- (1990). "Realism, Approximate Truth, and Philosophical Method", en C. Wade Savage (comp.), Scientifical Theories, University of Minnesota, Press, Minneaoplis.

Brink, C. (1989). Verisimilitude: views and reviews. History and Philosophy of Logic, 10(2), 181-201.

- (2000). Verisimilitude. In W. Newton-Smith, A Companion to the Philosophy of Science (pp.

561-563). Massachusetts: Blackwell Publisher.

Bueno, O. (2001). Quest of Reality. Review Symposia, 360-366.

Bunge, M. (1963). The Myth of Simplicity. Englewood Cliffs: Prentice-Hall.

Bunnin, N., \& Yu, J. (2004). The Blackwell Dictionary of Western Philosophy. Oxford: Blackwell Publishing.

Carman, C. C. (2005). "Realismo científico" se dice de muchas maneras, al menos de 1111: una elucidación del término "realismo científico". Scientiae Studia, 3(1), 43-64.

Carnap, R. (1969). Fundamentación lógica de la Física. (N. Miguens, Trad.) Buenos Aires: Editorial Sudamericana.

Cartwright, N. (1983). How the Laws of Physics Lie. Oxford: Clarendon Press.

- (1999). The Dappled World: A Study of the Boundaries of Science. Cambridge: Cambridge University Press.

Casini, Alejandro. (1992). "Realismo epistemológico, referencia y verosimilitud, Crítica: Revista Hispanoamericana de Filosofía, vol. 24, no. 71, pp. 3-33.

— (2003). "Confirmación Hipotético-Deductiva y Confirmación Bayesiana", Análisis Filosófico, vol. 23, no. 1, mayo, 41-84.

Cevolani, G., \& Tambolo, L. (2013). Progress as Approximation to the Truth: A Defence of the Verisimilitudinarian Approach. Erkenntnis, 78, 921-935.

Chakravartty, A. (2001). The Semantic or Model-Theoretic View of Theories and Scientific Realism. Synthese, 127, 325-345.

- (2007). A Metaphysics for Scientific Realism: Knowing the Unobservable. Cambridge: Cambridge University Press. 
- (2010). Truth and Representation in Science: Two Inspirations from Art. In R. F. Hunter, Beyond Mimesis and Convention: Representantion: Representation in Art and Science (pp. 33-50). London: Springer Netherlands.

- (Fall 2015, Fall). Scientific Realism. In E. N. Zalta, The Stanford Encyclopedia of Philosophy. Retrieved from The Stanford Encyclopedia of Philosophy: http://plato.stanford.edu/archives/fall2015/entries/scientific-realism/

Chang, H. (2003). Preservative Realism and Its Discontents: Revisiting Caloric. Philosophy of Science, 70, 900-9012.

Churchland, P. S. (1986). Neurophilosophy. Cambridge: MIT Press.

Cohen, L. (1980). What has science to do with truth? Synthese, 45, 489-510.

- (1987). Verisimilitude and legisimilitude. In T. A. Kuipers, What is Closet-to-the-Truth? A parade of approaches to truthlikeness (Vol. 10, pp. 129-144). Amsterdam: Rodopi.

Devitt, M. (1991). Aberrations of the realism debate. Philosophical Studies, 61(1-2), 43-63.

- (1997). Realism and Truth. New Jersey: Princeton University Press.

- (2001). The Metaphysics of Truth. In M. P. Lynch, The Nature of Truth: Classic and Contemporary Perspectives (pp. 579-612). Massachusetts: Massachusetts Institute of Technology Press.

- (2014). Realism/Anti-realism. In M. Curd, \& S. Psillos, The Routledge Companion to Philosophy of Science (2nd ed., pp. 256-267). New York: Routledge.

Diéguez, A. (1998). Realismo cienfítico: una introducción al debate actual en la filosofía de la ciencia. Málaga: Universidad de Málaga.

Doppelt, G. (2007, January). Reconstructing Scientific Realism to Rebut the Pessimistic Meta-Induction. Philosophy of Science, 74, 96-118.

Dorato, M. (2000). Substantivalism, Relationism, and Structural Spacetime Realism. Foundations of Physics, 30(10), 1605-1628.

Dorothy L. Grover, J. L. (1975). A Prosentential Theory of Truth. Philosophical Studies: An International Journal for Philosophy in the Analytic, 27(2), 73-125.

Duadu, R. (2002). The Realism/Antirealism: The Debate on the Philosophy of Science. Konstanz: Tesis doctoral no publicada. Retrieved july 25, 2015, from http://citeseerx.ist.psu.edu/viewdoc/download?doi=10.1.1.138.4954\&rep=rep1\&type=pdf

Engel, P. (2002). Truth. Chesham: Acumen.

Festa, R. (1987). Theory of similarity, similarity of theories, and verisimilitude. In T. A. Kuipers, What is Closet-to-the-Truth? A parade of approaches to truthlikeness (Vol. 10, pp. 145-1776). Amsterdam: Rodipi.

Feyerabend, P. (1981). Realism, Rationalism \& Scientific Method. Philosophical Papers. (Vol. I). Cambridge: Cambridge University Press.

Field, H. (2001). Correspondence Truth, Disquotational Truth, and Deflationism. In M. P. Lynch, The Nature of Truth: Classic and Contemporary Perspectives (pp. 483-504). Massachusetts: Massachusetts Institue of Technology Press.

Fine, A. (1986). The Shaky Game. Chicago: The University of Chicago Press.

Flórez Quintero, D. T. (2012). ¿Exige el realismo científico un compromiso con la teoría correspondentista de la verdad? Praxis Filosófica, 34, 11-23.

Fodor, J., \& Lepore, E. (1992). Holism: A shopper's guide. Cambridge: Blackwell Publishers.

Forster, M. (2004, October 5). Verisimilitude and Likelihood. Madison, Wisconsin, United States of America: University of Wisconsin-Madison. Recuperado el 20 de November de 2015, de http://philosophy.wisc.edu/forster/920/Verisimilitude\&Likelihood.pdf

Frege, G. (1979). Posthumous Writings. (P. L. White, Trans.) Oxford: Blackwell.

French, S., \& Ladyman, J. (2011). In Defence of Ontic Structural Realism. In A. B. Bokulich, Boston Studies in the Philosophy and History of Science (Vol. 281, pp. 25-42). Dordrecht: Springer. 
García-Carpintero, M. (2010). Fictional Entities, Theoretical Models and Figurative Truth. In R. F. Hunter, Beyond Mimesis and Convention: Representation in Art and Science (pp. 139-168). London: Springer.

Gemes, K. (2007) "Verisimilitude and Content", Synthese, 154(2): 293-306.

Giere, R. (1988). Explaining Science: A Cognitive Approach. (D. L. Hull, Ed.) Chicago and London: The University of Chicago Press.

- (February de 1992). The Cognitive Construction of Scientific Knowledge (Response to Pickering). Social Studies of Science, 22(1), 95-107.

- (1999). Science Without Laws. (D. L. Hull, Ed.) Chicago and London: The University of Chicago Press.

- (2004). How Models Are Used to Represent Reality. Philosophy of Science, 71, 742-752.

Hacking, I. (1983). Representing and Intervening. Introductory topics in the philosophy of natural science. Cambridge: Cambridge University Press.

- (1985). Do We See through a Microscope? In C. \&. Hooker, Images of Science: Essays on Realism and Empiricism (pp. 132-152). Chicago: University of Chicago Press.

Harman, G. (1965). Inference to the Best Explanation. Philosophical Review, 74, 88-95.

Harris, J. (1974). "Popper's definition of "Verisimilitude", The British Journal for the Philosophy of Science, 25: 160-166.

Hasanoglu, K. (2006). Critiquing 'Approximate Truth'. Colorado: Master's Thesis Not Published. Retrieved April 10, 2015, from https://www.academia.edu/2278259/Critiquing_Approximate_Truth_

Hilpinen, R. (1968). Rules of Acceptance and Inductive Logic. Amsterdam: North Holland.

- (1976). Approximate Truth and Truthlikeness. En K. S. M. Przelecki, Formal methods in the methodology of the empirical sciences (págs. 19-42). Dordrecht: Reidel.

Hoefer, C., \& Rosenberg, A. (1994, December). Empirical Equivalence, Underdetermination, and Systems of the World. Philosophy of Science, 61(4), 592-607.

Holt, N. R. (1970). A Note On Wilhelm Ostwald's Energism. Isis, 61(3), 386-389.

Hooker, C. A. (1985). Surface Dazzle, Ghostly Depths: An Exposition and Critical Evaluation of Van Fraassen's Vindication of Empiricism againts Realism. In C. \&. Hooker, Images of Science: Essays on Realism and Empiricism (pp. 153-196). Chicago: The University of Chicago Press.

Horwich, P. (1999). Truth. New York: Oxford University Press.

- (2001). A Defense of Minimalism. In M. P. Lynch, The Nature of Truth: Classic and Contemporary

Perspectives (pp. 559-578). Massachusetts: Massachusetts Institute of Techonology.

- (2004). From a Deflationary Point of View. New York: Oxford University Press .

- (2005). A Minimalist Critique of Tarski on Truth. In J. B. Armour-Garb, Deflationism and Paradox

(pp. 75-84). Oxford: Oxford University Press.

- (2010). Truth-Meaning-Reality. New York: Oxford University Press Inc.

Kieseppä, I. A. (1996). Truthlikeness for Multidimensional Quantitative Cognitive Problems. Dordrecht: Springer.

— (1996). "Truthlikeness for Hypotheses Expressed in Terms of n Quantitative Variables", Journal of Philosophical Logic, 25: 109-134.

Kitcher, P. (1993). The Advancement of Science. Science without Legend, Objectivity without Illusions. New York: Oxford University Press.

Koperski, J. (2001). Has Chaos Been Explained? British Journal of Philosophy of Science, 52, 683-700. Kuipers, T. (1987). A structuralist approach to truthlikeness. In T. A. Kuipers, What is Closet-tothe-Truth? A parade of approaches to truthlikeness (Vol. 10, pp. 79-99). Amsterdam: Rodopi.

- (1987b). What is closer-to-the-truth?, Rodopi, Amsterdam.

— (1992). "Naive and refined truth approximation", Synthese, 93, 299-341. 
- (1996). 'Truth Approximation by the Hypothetico-Deductive Method', in W. Balzer and C. U. Moulines (eds.), Structuralist Theory of Science. Focal Issues, New Results, Walter de Gruyter, Berlin, pp. 83-113.

- (2000). From Instrumentalism to Constructive Realism: On Some Relations beteen Confirmation, Empirical Progress, and Truth Approximation. Dordrecht: Springer.

Kuhn, T. (1962). The Structure of Scientific Revolutions. Chicago: University of Chicago Press.

Kukla, A. (1998). Studies in Scientific Realism. Oxford: Oxford University Press.

Ladyman, J. (Spring 2014 Edition). Structural Realism. In E. N. Zalta, The Stanford Encyclopedia of Philosophy. Retrieved from http://plato.stanford.edu/archives/spr2014/entries/structural-realism/ Lange, M. (2002, October). Baseball, Pessimistic Inductions and the Turnover Fallacy. Analysis, 62(4), 281-285.

Laudan, L. (1981, March). A Confutation of Convergent Realism. Philosophy of Science, 48(1), 19-49.

Laudan, L., \& Leplin, J. (1991, september). Empirical Equivalence and Underdetermination. The Journal of Philosophy, 88(9), 449-472.

Leplin, J. (1984). Introduction. In J. Leplin, Scientific Realism (pp. 1-7). Los Angeles: University of California Press.

- (1997). A Novel Defence of Scientific Realism. New York: Oxford University Press.

- (2000). Realism and Instrumentalism. In W. H. Newton-Smith, A Companion to the Philosophy of Science (pp. 393-401). Oxford: Blackwell Publisher Ltd.

Lewis, D. (1973). Conterfactuals. Oxford: Blackwell Publishers Inc.

- (1986). On the Plurality of World, Oxford: Blackwell.

Lewis, P. J. (2001). Why the Pessimistic Induction is a Fallacy? Synthese, 129, 371-380.

Lipton, P. (1991). Infrence to the Best Explanation. London: Routledge.

Lloyd, T. (2014, September 2). Putting flesh on Stathis Psillos'skeleton. Retrieved May 20, 2015, from Critical Rationalism: http://liberalrationalism.blogspot.mx/2014/09/putting-flesh-on-stathispsillos.html

Lynch, M. P. (2001). Realism and the Correspondence Theory. In M. P. Lynch, The Nature of Truth: Classic and Contemporary Perspectives (pp. 7-16). Massachusetts: Massachusetts Institute of Technology.

Mach, E. (1895). On the Economical Nature of Physical Inquiry. In E. Mach, Popular Scientific Lectures (T. J. McCormack, Trans., pp. 186-213). Chicago: The Open Court Publishing Company.

McMullin, E. (1984). A Case for Scientific Realism. In J. Leplin, Scientific Realism (pp. 8-40). Berkeley: University California Press.

Miller, D. (1972). "The Truth-likeness of Truthlikeness", Analysis, 33(2): 50-55.

- (1974a). Popper's Qualitative Theory of Verisimilitude. The British Society for the Philosophy of Science, 25(2), 166-177.

- (1974b). On the Comparison of False Theories by Their Bases. The British Society for the Philosophy of Science, 25(2), 178-188.

- (1975). The Accuracy of Predictions. Synthese, 30, 159-191.

- (1979). On Distance From the Truth as a True Distance. En J. Hintikka, Essays on Mathematical and Philosophical Logic (Vol. 122, págs. 415-436). Dordrecht: Reidel Publishing Company.

- (2006). Out Of Error: Further Essays on Critical Rationalism. Aldershot: Ashgate.

Morganti, M. (2004). On the preferability of epistemic structural realism. Synthese, 142, 81-107.

Mormann, T. (2005). "Geometry of Logic and Truth Approximation", in Festa, R., et al. (eds.), Poznan Studies in the Philosophy of the Sciences and the Humanities: Confirmation, Empirical Progress and Truth Approximation, 83: 431-54.

- (2006). "Truthlikeness for Theories on Countable Languages", Jarvie, I. et al. (eds.) Karl Popper: A Centenary Assessment. Volume III: Science, Aldershot: Ashgate, 3-15. 
Mortensen, C. (Jun de 1983). Relevance and Verisimilitude. Synthese, 55(3), 353-364.

- (1983) "The Validity of Disjunctive Syllogism Is not So Easily Proved", Notre Dame Journal of Formal Logic, 24:35-40

Newton-Smith, W. (1981). The Rationality of Science. Boston: Routledge \& Kegan Paul.

- (1989). ""The Truth in Realism", Dialectica, no. 43, pp. 31-45.

Niiniluoto, I. (Dec of 1979a). Degrees of Truthlikeness: From Singular Sentences to Generalisations. The

British Journal for the Philosophy of Science, 30(4), 371-376.

- (1979b). Truthlikeness in First-Order Languages. En J. Hintikka, Essays on Mathematical and

Philosophical Logic (Vol. 122, págs. 437-458). Dordrecht: Reidel Publishing Company.

— (1980). "Scientific Progress", Synthése, no. 45, pp. 427-462

- (Sep of 1982). On Explicating Verisimilitude: A Reply to Oddie. Britis Journal for the Philosophy of

Science, 33(3), 290-296.

- (1987). Truthlikeness. Dordrecht: D. Reidel Publishing Company.

- (1987b). How to define verisimilitude. In T. A. 10., What is Closet-to-the-Truth? A parade of approaches to truthlikeness (Vol. 10, pp. 11-24). Amsterdam: Rodopi.

- (1987c). Verisimilitude with indefinite truth. In T. A. Kuipers, What is Closet-to-the-Truth? A parade

of approaches to truthlikeness (Vol. 10, pp. 187-196). Amsterdam: Rodopi.

- (1998). Verisimilitude: The Third Period. British Journal of Phililosophy of Science, 49, 1-29.

- (2014). Scientific progress as increasing verisimilitude. Studies in History and Philosophy of Science, 46, 73-77.

Northcott, R. D. (2004). Approximate truth and causal strength in science. Thesis. London, Unitad Kingdom: London School of Economics and Political Science.

Oddie, G. (Sep de 1981). Verisimilitude Reviewed. The British Journal for the Philosophy of Science, 32(3), 237-265.

- (1986). Likeness to Truth (Vol. 30). Dordrecht: D. Reidel Publishing Company.

- (1987). The picture theory of truthlikeness. In T. A. Kuipers, What is Closet-to-the-Truth? A parade of approaches to truthlikeness (Vol. 10, pp. 25-46). Amsterdam: Rodopi.

- (2008). "Truthlikeness and Value", in Festschrift for Ilkka Niiniluoto, College Publications: London, 225-40.

- (2013). "The content, consequence and likeness approaches to verisimilitude: compatibility, trivialization, and underdetermination", Synthese, 190: 1647-1687 [published online 28 May 2011, at DOI 10.1007/s11229-011-9930-8].

- (2014). Truthlikeness. En M. Curd, \& S. Psillos, The Routledge Companion to Philosophy of Science (2nd ed., págs. 541-551). New York: Routledge.

- (2016). Truthlikeness. En E. N. Zalta, The Stanford Encyclopedia of Philosophy (Spring 2016 ed.). Obtenido de http://plato.stanford.edu/archives/spr2016/entries/truthlikeness/

Park, S. (2011, May). A Confutation of the Pessimistic Induction. Journal for General Philosophy of Science, 42(1), 75-84.

Peirce, C. S. (1890-1913). Letters to Paul Carus. MS [L] 77.

- (1896 [c]). Lessons of the History of Science. MS [R]: 1288.

- (1897). Fallibilism, Continuity, and Evolution. MS [R] 955: Published, with deletions, as 1.141-175. See $\sup (1) \mathrm{G}-1892-0$.

- (1901). On the Logic of Drawing History from Ancient Documents Especially from Testimonies (Logic of History). MS [R] 690.

— (1931-35). Notes on Art. III. En C. H. Weiss, Collected Papers, (págs. vols. 1-6). Cambridge: Harvard University Press.

Popper, K. (1962). Conjetures and Refutations. The Growth of Scientific Knowledge. London: Basic Book. 
- (1972). Objective Knowledge. An Evolutionary Approach. Oxford: Cladrendon Press.

- (1976). A Note on Verisimilitude. The British Journal for the Philosophy of Science, 27(2), 147-159.

- (1983a). Conjeturas y Refutaciones: El desarrollo del conocimiento científico. (N. Míguez, Trad.)

Buenos Aires: Ediciones Paidos.

- (1983b). Realism and the Aim of Science. Post-Script to the logic of Scientific Discovery part I.

London: Huchinson.

- (2001). The Logic of Scientific Discovery (2nd ed.). London: Routledge.

Psillos, S. (1994). A Philosophical Study of the Transition from the Caloric Theory of Heat to Thermodynamics: Resisting the Pessimistic Meta-Induction. Studies in History and Philosophy of Science, 25(2), 159-190.

— (1996, September). Scientific Realism and the 'Pessimistic Induction'. Philosophy of Science, 63, S306-S314.

- (1999). Scientific realism: how science tracks truth. London: Routledge.

- (2000). The Present State of the Scientific Realism Debate. British Journal of Philosophy of Science, $51,705-728$.

- (2011). The Scope and Limits of the No Miracles Argument. In D. D. al, Explanation, Prediction, and Confirmation, The Philosophy of Science in a European Perspective (pp. 23-35). New York: Springer Science + Business Media.

Putnam, H. (1975). Mind, Language and Reality (Philosophical Pappers) (Vol. 2). Cambridge: Cambridge University Press.

- (1977, August). Realism and Reason. American Philosophical Association, 50(6), 483-498.

- (1978). Meaning and the Moral Sciences. London: Routledge \& Keagan Paul Ltd.

- (1981). Reason, Truth and History. Cambridge: Cambridge University Press.

Quine, W. V. (1951, January). Main Trends in Recent Philosophy: Two Dogmas of Empiricism. The Philosophical Review, 60(1), 20-43.

- (1960). Word and Object (2nd ed.). Massachusetts : Massachusetts Institute of Technology .

- (1963). From a Logical Point of View (2nd ed.). New York: Harper \& Row, Publishers.

- (1970). Philosophy of Logic (2nd ed.). London: Harvard University Press.

Quintanilla, M. A., 1982, "La verosimilitud de las teorías", en I Congreso de teoría y metodología de las ciencias, vol. I. Oviedo, pp. 473-489.

Restall, G. (2005). Minimalist about Truth Can (and Should ) Be Epistemicists, and it Helps if They Are Revision Theorists Too. In J. B. Armour-Garb, Deflationism and Paradox (pp. 97-106). Oxford: Oxford University Press.

Rivadulla, A. (2013). Inducción y verosimilitud. In C. U. Moulines, La ciencia: estructura y desarrollo (Enciclopedia Iberoamericana de Filosofía) (pp. 127-146). Madrid: Trotta.

Rodriguez-Pereyra, G. (2000). El problema metafísico de la verdad. Revista Latinoamericana de Filosofía, 26(2), 353-359.

Russell, B. (1920). Introduction to Mathematical Philosophy (2nd ed.). London: George Allen and Unwin.

Sanmartín, J. (1984). "A vueltas con el concepto de verosimilitud", Madrid.

Schwartz, R. J. (1990. "Approximate Truth, Idealization and Ontology", Southern Journal of Philosophy, no. 28, pp. 409-425.

Smith, P. (1998a). ApproximateTruth and Dynamical Theories. British Journal of Philosophy, 49, 253277.

- (1998b). Approximate Truth for Minimalists. Philosophical Papers, 27(2), 119-128.

- (2001). El caos: una explicación a la teoría. (A. R. Bevia, Trans.) Madrid: Cambridge University Press. 
Stanford, P. (2006). Exceeding Our Grasp: Science, History, and the Problem of Unconceived Alternatives. Oxford: Oxford University Press.

Strawson, P. (1950). Truth. Proceedings of Aristotelian Society, Supplementary Volume XXIV.

Suppe, F. (1989). The Semantic Conception of Theories and Scientific Realism, University of Illinois Press, Chicago.

Suppes, P. (1960). A comparison of the meaning and uses of models in mathematics and the empirical sciences. Synthese, 12, 287-391.

Swan, C. L. (2015). Science and Knowledge: A Post-Modern Approach to Empiricism. PM Thesis. Langley, Columbia Británica, Canada: Trinity Western University.

Tambolo, L. (2011). Scientific Progress, Verisimilitude, and Evidence. Logic and Philosophy of Science, IX(1), 561-567.

Tarski, A. (2001). The Semantic Conception of Truth and the Foundations of Semantics. In M. P. Lynch, The Nature of Truth: Classic and Contemporary Perspectives (pp. 331-364). Massachusetts: Massachusetts Institute of Technology Press.

Teller, P. (2001). Twilight of the Perfect Model Model. Erkenntnis, 55(3), 393-415.

Tichý, P. (1974). On Popper's Definitions of Verisimilitude. The British Society for the Philosophy of Science, 25(2), 155-160.

Urbach, P. (1983). Intimations of Similarity: The Shaky Basis of Verisimilitude. British Journal of Philosophy of Science, 34, 166-175.

van Fraassen, B. (1980). The Scientific Image. Oxford: Oxford University Press.

- (1985). Empiricism in the Philosophy of Science. In C. \&. Hooker, Images of Science: Essays on Realism and Empiricism (pp. 245-308). Chicago: University of Chicago Press.

Vázquez, J. (1991). "Progreso científico y verdad", Crítica, Revista Hispanoamericana De Filosofía, vol. XXIII, No. 69. Pp. 101-35.

Vision, G. (2004). Veritas: The Correspondence Theory and Its Critics. London: Massachusetts Institute of Technology Press.

Weston, T. S. (1988). Approximate truth and Łukasiewicz logic. Notre Dame Journal of Formal Logic, 29(2), 229-234.

Whewell, W. (1840). The Philosophy of the Inductive Sciences: Founded Upon their History. London: J. W. Parker.

Worral, J. (1989). Structural Realism: The Best of Both Worlds? Dialectica, 43, 99-124.

- (2007). Miracles and Models: Why Reports of the Death of Structural Realism May Be Exaggerated. Royal Institute of Philosophy Supplements, 82(61), 125-154.

- (2009). Miracles, Pessimism, and Scientific Realism. Philosophical Papers, 1-55.

Zamora Bonilla, J. (1992). Truthlikeness Without Truth: A Methodological Approach. Synthese, 93, 343-72.

- (1996). Mentiras a medias: Unas investigaciones sobre el programa de la verosimilitud. Madrid: Ediciones de la Universidad Autónoma de Madrid.

- (1996b). Verisimilitude, Structuralism and Scientific Progress. Erkenntnis, 44, 25-47.

- (2000). Trutlikeness, Rationality and Scientific Method. Synthese, 122, 321-335.

- (2002). Verisimilitude and the Dynamics of Scientific Research Programmes. Journal for the General Philosophy of Science, 33, 349-368.

- (2015). Realism versus anti-realism: philosophical problem or scientific concern? Synthese, 192, 117.

Zwart, S. D. (2001). Refined Verisimilitude (Vol. 307). Dordrecht: Springer. 


\section{Apéndice}

${ }^{\mathrm{i}}$ Las tesis realistas tienen por lo general cuando menos una contrapuesta anti-realista como se puede observar en el siguiente cuadro (Diéguez, 1998, pág. 79):

\begin{tabular}{|c|c|}
\hline $\begin{array}{l}\text { Pealismo ontológico: } \\
\text { Las entidades té́ricas postuladas por } \\
\text { las teorías clentificas bien establecidas } \\
\text { existen (aunque pueda haber excepcio. } \\
\text { nes). Los términos léricos tipicamen- } \\
\text { te refieren. }\end{array}$ & $\begin{array}{l}\text { Instrumentallsmo sobre entidades: } \\
\text { Las entidades téricas son meros re- } \\
\text { cursos predictivos y debe dejarse de } \\
\text { lado la cuestion do su existencia real. } \\
\text { Constructivlemo social: } \\
\text { Las entidades tedricas son construldas } \\
\text { socialmente. }\end{array}$ \\
\hline $\begin{array}{l}\text { Reallsmo epistemológlco: } \\
\text { Las teorias cientlficas nos proporcionan } \\
\text { un conocimiento adecuado (aunque } \\
\text { perfectible) de la realidad tal como éste } \\
\text { es con independencia de nuestros pro- } \\
\text { cesos cognithos. }\end{array}$ & $\begin{array}{l}\text { Fenomenismo: } \\
\text { Las teorias clentíficas sólo tratan de le- } \\
\text { nómenos observables. } \\
\text { ideallsmo epistemológico: } \\
\text { Las leorias cientificas versan scobre una } \\
\text { realidac hecha por la mente. }\end{array}$ \\
\hline $\begin{array}{l}\text { Realiemo teórico: } \\
\text { Las teorlas clertificas son susceptibles } \\
\text { de vordad o falsedad. }\end{array}$ & $\begin{array}{l}\text { Instrumentallsmo térico: } \\
\text { Las teorías clentificas son instrumen- } \\
\text { tos de calculo, útiles o Inútiles, empiri. } \\
\text { camente adecuadas o inadecuadas, } \\
\text { pero no verdaderas o falsas. }\end{array}$ \\
\hline $\begin{array}{l}\text { Realismo semántico: } \\
\text { Las teorías cientificas son verdaderas } \\
\text { ofalsas en función de su corresponden- } \\
\text { cia con la realidad. }\end{array}$ & $\begin{array}{l}\text { Pragmatismo: } \\
\text { La verdad o falsedad atribuibles a las } \\
\text { teorias cientilicas han de ser entendi- } \\
\text { das en relación con las actividedes cog. } \\
\text { nitivas humanas. } \\
\text { Coherentlamo: } \\
\text { La vordad o falsedad atrituibles a las } \\
\text { teorias no significa otra cosa que su co- } \\
\text { herencia con un sistema aceplado de } \\
\text { creencias, o con otras teorias. } \\
\text { Relativiemo: } \\
\text { La verdad o falsedad atrituibles a las } \\
\text { teorias clentiflcas son siempre relativas } \\
\text { a los contextos en que surgen. }\end{array}$ \\
\hline $\begin{array}{l}\text { Reallemo progresivo: } \\
\text { La ciencia progresa teniendo como } \\
\text { meta la verdad. Las nuevas teorias con- } \\
\text { tienen rnás verdad y/o menos falsedad } \\
\text { que las antoriores. }\end{array}$ & $\begin{array}{l}\text { Antirrealismo sobre el progreso: } \\
\text { El progreso en la ciencia no puede ser } \\
\text { establecido como un acercamiento cre- } \\
\text { ciente a la verdad. }\end{array}$ \\
\hline
\end{tabular}

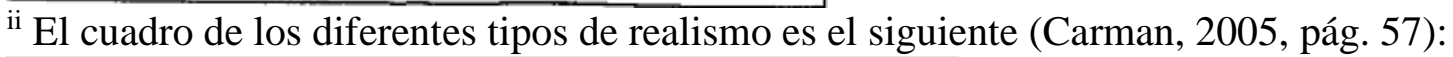

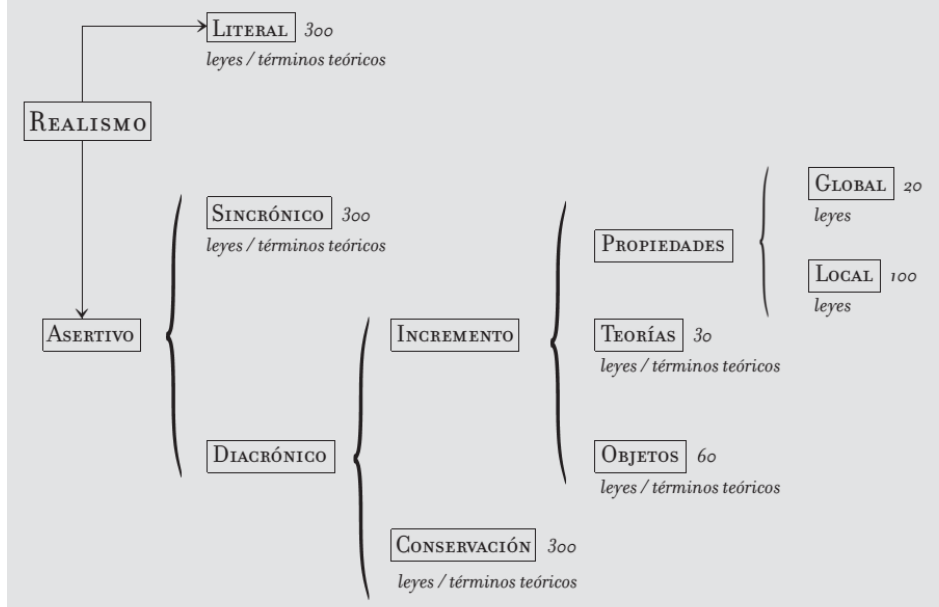


iii Diagrama que muestra la diferencia entre ignorancia, error e incertidumbre (Niiniluoto, 1987, pág. 159)

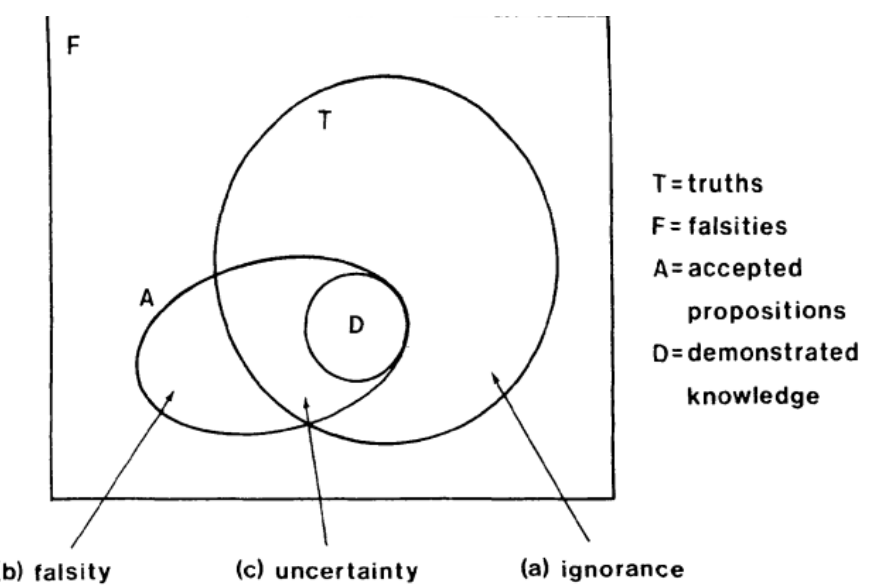

Fig. 1. Three kinds of errors.

iv Distinción entre parcialmente verdadero, totalmente verdadero o totalmente falso (Niiniluoto, 1987, pág. 175).

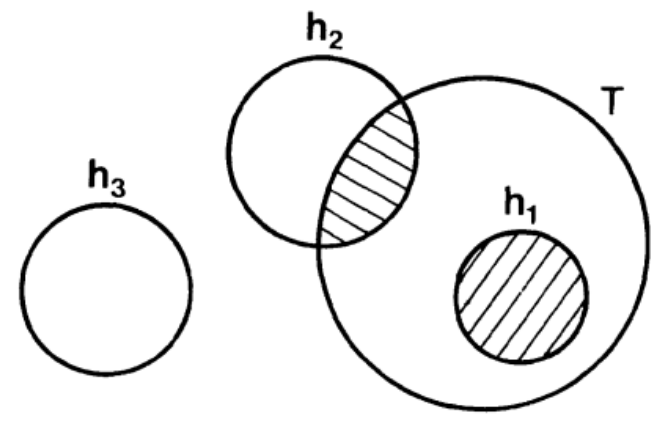

Fig. 3. $h_{1}$ is totally true, $h_{2}$ partly true, $h_{3}$ totally false.

${ }^{v}$ Máximo grado de verdad parcial (Niiniluoto, 1987, pág. 176).

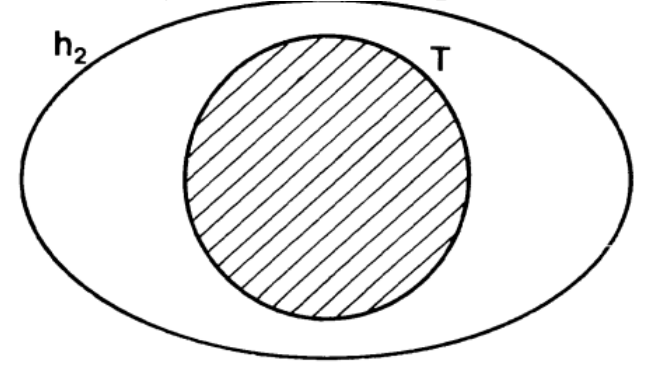

Fig. 5. $h_{2}$ has a maximal degree of partial truth. 


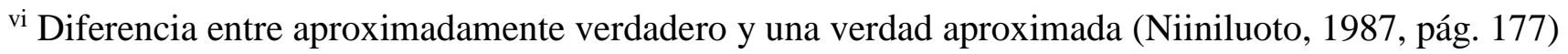

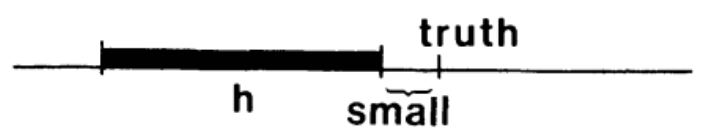

Fig. 6. $h$ is approximately true.

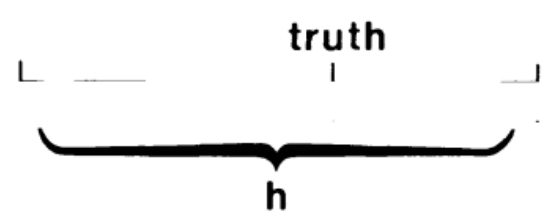

Fig. 7. $h$ is an approximate truth.

vii Comparación entre teorías verdaderas (Zamora, 1996, pág. 37).

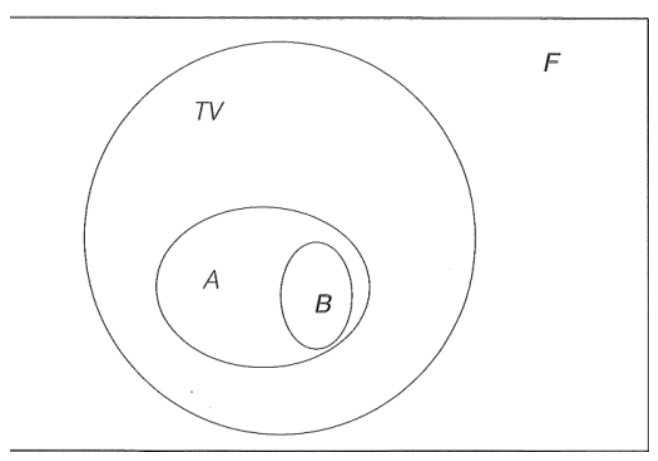

viii Comparación entre teorías falsas (Zamora, 1996, pág. 36)..

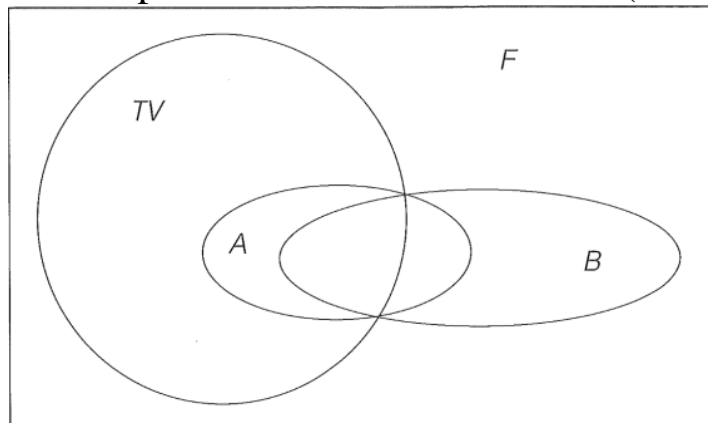

${ }^{i x}$ Dificultades para comparar teorías (Zamora, 1996, pág. 38).

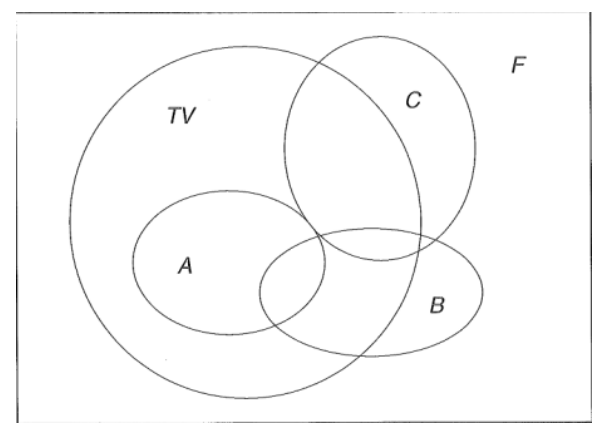


${ }^{\mathrm{x}}$ Podemos ver que Vs1 es igual a (iii) y Vs2=(VII) (Tichý, 1974, pág. 159).

$$
\sim p \cdot \sim q \quad p \cdot q \cdot \sim r \quad \sim p \cdot \sim q \cdot \sim r
$$

\begin{tabular}{lcll}
\hline$c t_{T}$ & $5 / 8$ & $6 / 8$ & $6 / 8$ \\
$c t_{F}$ & $\mathrm{I} / 3$ & $\mathrm{I} / 2$ & $\mathrm{I} / 2$ \\
$v s_{1}$ & $7 / 8$ & $2 / 8$ & $2 / 8$ \\
$v s_{2}$ & $2 \mathrm{I} / 25$ & $\mathrm{I} / 3$ & $\mathrm{I} / 3$
\end{tabular}

$\mathrm{xi}$

\begin{tabular}{|l|l|l|l|}
\hline W1 & H & R & W \\
\hline W2 & H & R & $\neg \mathrm{W}$ \\
\hline W3 & H & $\neg \mathrm{r}$ & W \\
\hline W4 & H & $\neg \mathrm{r}$ & $\neg \mathrm{W}$ \\
\hline W5 & $\neg \mathrm{h}$ & $\mathrm{R}$ & $\mathrm{W}$ \\
\hline W6 & $\neg \mathrm{h}$ & $\mathrm{R}$ & $\neg \mathrm{W}$ \\
\hline W7 & $\neg \mathrm{h}$ & $\neg \mathrm{r}$ & $\mathrm{W}$ \\
\hline W8 & $\neg \mathrm{h}$ & $\neg \mathrm{r}$ & $\neg \mathrm{W}$ \\
\hline
\end{tabular}

xii Distribución de los mundos (Oddie, Truthlikeness, 2016).

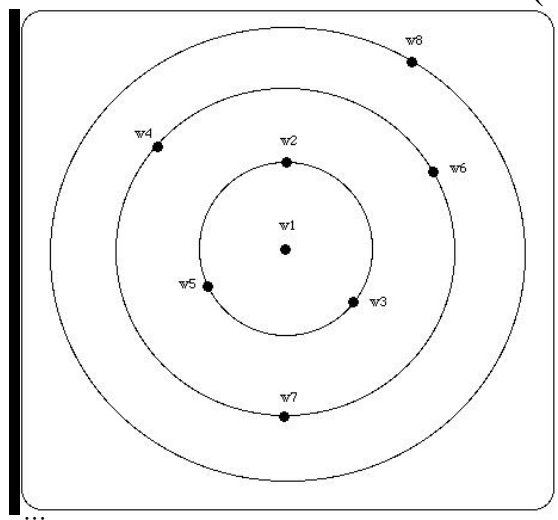

xiiiLa figura ilustra la idea de esferas anidadas en el mundo actual W, A es una proposición falsa representada por un subconjunto de espacio que no contiene a $\mathrm{W}$, las flechas nos marcan la medición de min(A) para su cercanía a la verdad y $\max (\mathrm{A})$ para su contenido de información (Oddie, 1986, pág. 52).

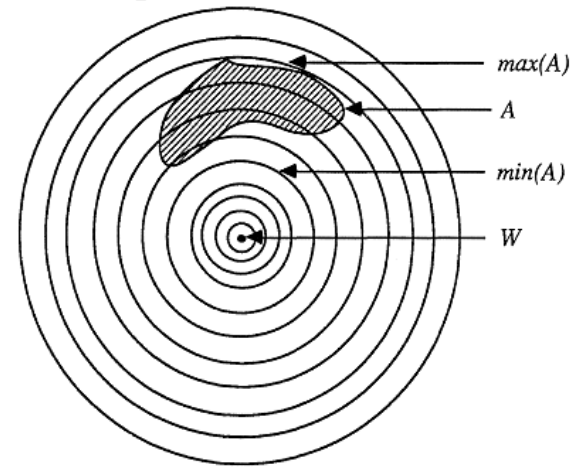


${ }^{\text {xiv }}$ Explicación de distancias entre teorías (Zamora, 1996, pág. 132).

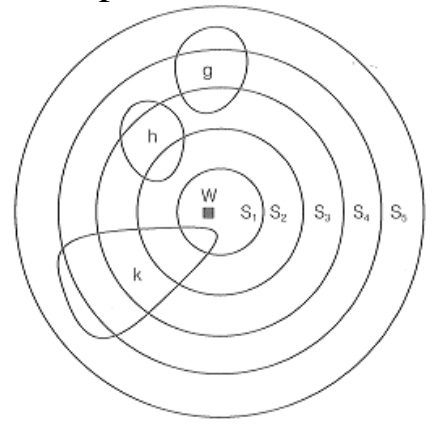

${ }^{x v}$ There is even no false theory that is more similar to $\mathrm{p}^{\wedge} \mathrm{q}$ than the tautology (Zwart, 2001, pág. 78).

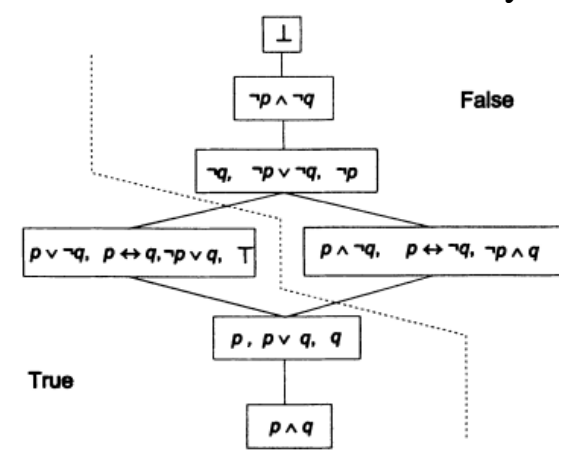

xvi

\begin{tabular}{|l|l|l|l|}
\hline A & Verdad(A) & $\operatorname{Min}(\mathrm{A})$ & $\operatorname{Max}(\mathrm{A})$ \\
\hline $\mathrm{h}^{\wedge} \mathrm{r}^{\wedge} \mathrm{W}$ & $\mathrm{V}$ & 0 & 0 \\
\hline $\mathrm{h}^{\wedge} \mathrm{r}$ & $\mathrm{V}$ & 0 & 0.33 \\
\hline $\mathrm{h}^{\wedge} \mathrm{r}^{\wedge} \neg \mathrm{W}$ & $\mathrm{F}$ & 0.33 & 0.33 \\
\hline $\mathrm{h}$ & $\mathrm{V}$ & 0 & 0.67 \\
\hline $\mathrm{h}^{\wedge} \neg \mathrm{r}$ & $\mathrm{F}$ & 0.33 & 0.67 \\
\hline$\neg \mathrm{r}$ & $\mathrm{F}$ & 0.33 & 1 \\
\hline$\neg \mathrm{h}^{\wedge} \neg \mathrm{r}^{\wedge} \mathrm{W}$ & $\mathrm{F}$ & 0.67 & 0.67 \\
\hline$\neg \mathrm{h}^{\wedge} \neg \mathrm{r}$ & $\mathrm{F}$ & 0.67 & 1 \\
\hline$\neg \mathrm{h}^{\wedge} \neg \mathrm{r}^{\wedge} \neg \mathrm{W}$ & $\mathrm{F}$ & 1 & 1 \\
\hline $\mathrm{h} \mathrm{V}^{\mathrm{h}}$ & $\mathrm{V}$ & 0 & 1 \\
\hline
\end{tabular}

xvii

\begin{tabular}{|l|l|l|}
\hline $\mathrm{A}$ & Verdad(A) & $\mathrm{mm}(\mathrm{A})$ \\
\hline $\mathrm{h}^{\wedge} \mathrm{r}^{\wedge} \mathrm{W}$ & $\mathrm{V}$ & 0 \\
\hline $\mathrm{h}^{\wedge} \mathrm{r}$ & $\mathrm{V}$ & 0.17 \\
\hline $\mathrm{h}^{\wedge} \mathrm{r}^{\wedge} \neg \mathrm{W}$ & $\mathrm{F}$ & 0.33 \\
\hline $\mathrm{h}$ & $\mathrm{V}$ & 0.33 \\
\hline $\mathrm{h}^{\wedge} \neg \mathrm{r}$ & $\mathrm{F}$ & 0.5 \\
\hline$\neg \mathrm{r}$ & $\mathrm{F}$ & 0.67 \\
\hline$\neg \mathrm{h}^{\wedge} \neg \mathrm{r}^{\wedge} \mathrm{W}$ & $\mathrm{F}$ & 0.67 \\
\hline$\neg \mathrm{h}^{\wedge} \neg \mathrm{r}$ & $\mathrm{F}$ & 0.83 \\
\hline$\neg \mathrm{h}^{\wedge} \neg \mathrm{r}^{\wedge} \neg \mathrm{W}$ & $\mathrm{F}$ & 1 \\
\hline $\mathrm{h} \neg_{\mathrm{h}}^{\mathrm{h}}$ & $\mathrm{V}$ & 0.5 \\
\hline $\mathrm{h} \mathrm{r}$ & $\mathrm{V}$ & 0.33 \\
\hline
\end{tabular}




\begin{tabular}{|c|c|c|}
\hline A & Verdad(A) & $\operatorname{av}(\mathrm{A})$ \\
\hline $\mathrm{h}^{\wedge} \mathrm{r}^{\wedge} \mathrm{W}$ & $\mathrm{V}$ & 0 \\
\hline $\mathrm{h}^{\wedge} \mathrm{r}$ & $\mathrm{V}$ & 0.17 \\
\hline $\mathrm{h}^{\wedge} \mathrm{r}^{\wedge} \neg \mathrm{W}$ & $\mathrm{F}$ & 0.33 \\
\hline $\mathrm{H}$ & $\mathrm{V}$ & 0.43 \\
\hline $\mathrm{h}^{\wedge} \neg \mathrm{r}$ & $\mathrm{F}$ & 0.5 \\
\hline$\neg \mathrm{r}$ & $\mathrm{F}$ & 0.56 \\
\hline$\neg \mathrm{h}^{\wedge} \neg \mathrm{r}^{\wedge} \mathrm{W}$ & $\mathrm{F}$ & 0.67 \\
\hline$\neg h^{\wedge} \neg \mathrm{r}$ & $\mathrm{F}$ & 0.83 \\
\hline$\neg \mathrm{h}^{\wedge} \neg \mathrm{r}^{\wedge} \neg \mathrm{W}$ & $\mathrm{F}$ & 1 \\
\hline hv $\neg$ rvw & $\mathrm{V}$ & 0.46 \\
\hline $\mathrm{hv \sim r}$ & $\mathrm{V}$ & 0.5 \\
\hline hv $\neg$ h & $\mathrm{V}$ & 0.5 \\
\hline
\end{tabular}

xix

\begin{tabular}{|l|l|l|}
\hline $\mathrm{A}$ & Verdad(A) & $\operatorname{sum}(\mathrm{A})$ \\
\hline $\mathrm{h}^{\wedge} \mathrm{r}^{\wedge} \mathrm{W}$ & $\mathrm{V}$ & 0 \\
\hline $\mathrm{h}^{\wedge} \mathrm{r}$ & $\mathrm{V}$ & 0.33 \\
\hline $\mathrm{h}^{\wedge} \mathrm{r}^{\wedge} \neg \mathrm{W}$ & F & 0.33 \\
\hline $\mathrm{H}$ & $\mathrm{V}$ & 1.33 \\
\hline $\mathrm{h}^{\wedge} \neg \mathrm{r}$ & F & 1 \\
\hline$\neg \mathrm{r}$ & F & 2.67 \\
\hline$\neg \mathrm{h}^{\wedge} \neg \mathrm{r}^{\wedge} \mathrm{W}$ & $\mathrm{F}$ & 0.67 \\
\hline$\neg \mathrm{h}^{\wedge} \neg \mathrm{r}$ & $\mathrm{F}$ & 1.67 \\
\hline$\neg \mathrm{h}^{\wedge} \neg \mathrm{r}^{\wedge} \neg \mathrm{W}$ & $\mathrm{F}$ & 1 \\
\hline
\end{tabular}

$\mathrm{xx}$

\begin{tabular}{|l|l|l|}
\hline $\mathrm{A}$ & Verdad(A) & min-sum-prom(A) \\
\hline $\mathrm{h}^{\wedge} \mathrm{r}^{\wedge} \mathrm{W}$ & $\mathrm{V}$ & 0 \\
\hline $\mathrm{h}^{\wedge} \mathrm{r}$ & $\mathrm{V}$ & 0.17 \\
\hline $\mathrm{h}^{\wedge} \mathrm{r}^{\wedge} \neg \mathrm{W}$ & $\mathrm{F}$ & 0.33 \\
\hline $\mathrm{h}$ & $\mathrm{V}$ & 0.67 \\
\hline $\mathrm{h}^{\wedge} \neg \mathrm{r}$ & $\mathrm{F}$ & 0.67 \\
\hline$\neg \mathrm{r}$ & $\mathrm{F}$ & 1.5 \\
\hline$\neg \mathrm{h}^{\wedge} \neg \mathrm{r}^{\wedge} \mathrm{W}$ & $\mathrm{F}$ & 0.67 \\
\hline$\neg \mathrm{h}^{\wedge} \neg \mathrm{r}$ & $\mathrm{F}$ & 1.16 \\
\hline$\neg \mathrm{h}^{\wedge} \neg \mathrm{r}^{\wedge} \neg \mathrm{W}$ & $\mathrm{F}$ & 1 \\
\hline
\end{tabular}

xxi

\begin{tabular}{|l|l|l|l|l|}
\hline & h-r-w & Distancia prom. & h-m-a & Distancia prom. \\
\hline T & $\mathrm{h}^{\wedge} \mathrm{r}^{\wedge} \mathrm{W}$ & 0 & $\mathrm{~h} \wedge \mathrm{m}^{\wedge} \mathrm{a}$ & 0 \\
\hline A & $\neg \mathrm{h}^{\wedge} \mathrm{r}^{\wedge} \mathrm{W}$ & 0.33 & $\neg \mathrm{h}^{\wedge} \neg \mathrm{m}^{\wedge} \neg \mathrm{a}$ & 1 \\
\hline B & $\neg \mathrm{h}^{\wedge} \neg \mathrm{r}^{\wedge} \mathrm{W}$ & 0.67 & $\neg \mathrm{h}^{\wedge} \mathrm{m}^{\wedge} \neg \mathrm{a}$ & 0.67 \\
\hline C & $\neg \mathrm{h}^{\wedge} \neg \mathrm{r}^{\wedge} \neg \mathrm{W}$ & 1 & $\neg \mathrm{h}^{\wedge} \mathrm{m}^{\wedge} \mathrm{a}$ & 0.33 \\
\hline
\end{tabular}


xxii Interacción entre el conjunto de afirmaciones y el modelo, a su del modelo con el mundo real (Psillos, 1999, p. 264).

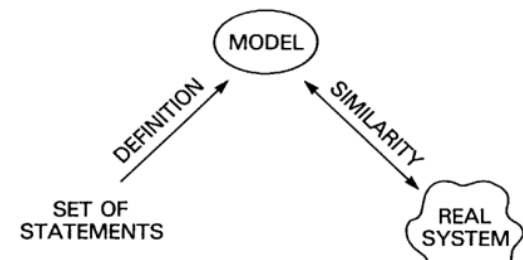

(Giere, 1988, p. 83).

xxiii Psillos lo reestructura de esta forma (Psillos, 1999, pág. 266)

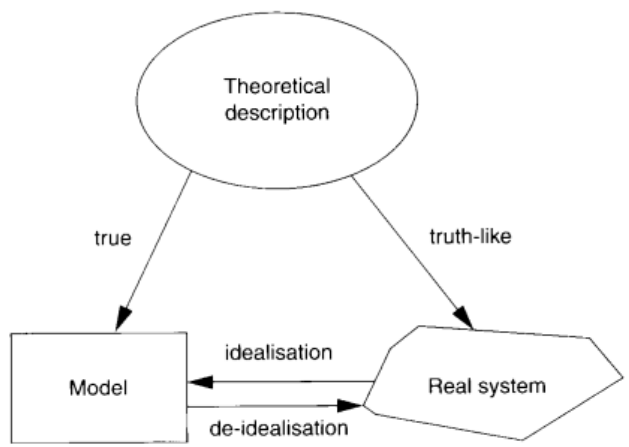

Figure 11.2 Theoretical descriptions of models are associated with idealised descriptions of real systems

xxiv Una de las representaciones de ordenamiento según Aronson (Aronson J. L., 1997, pág. 93):

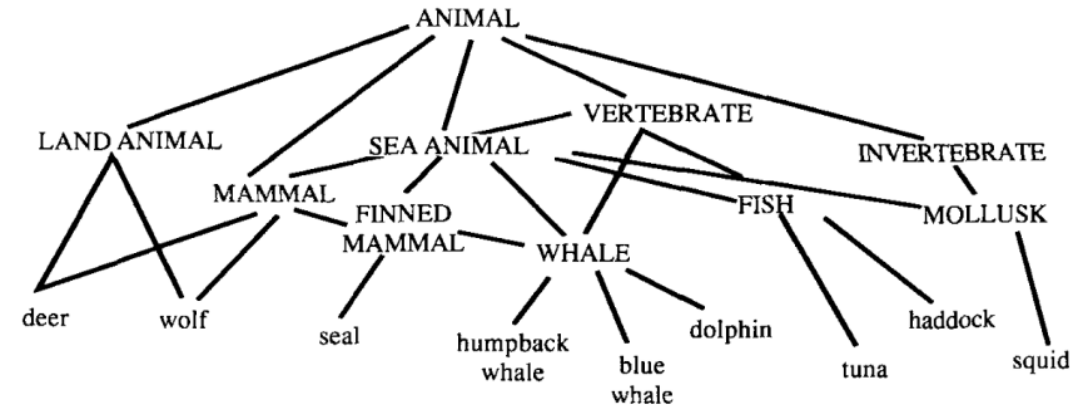

${ }^{x x v}$ Ordenamiento jerarquizado por su verosimilitud, (Aronson J. L., 1997, pág. 93).

BLUE WHALE $=7=$ TRUTH

HUMPBACK WHALE $=6$

DOLPHIN $=6$

SEAL $=5$

SHARK $=2$

MACKEREL $=2$

$\operatorname{BEAR}=2$

$\mathrm{DOG}=2$

GIANT SQUID $=0$ 
${ }^{\text {xxvi }}$ Esquema de similitud (Lloyd, 2014).

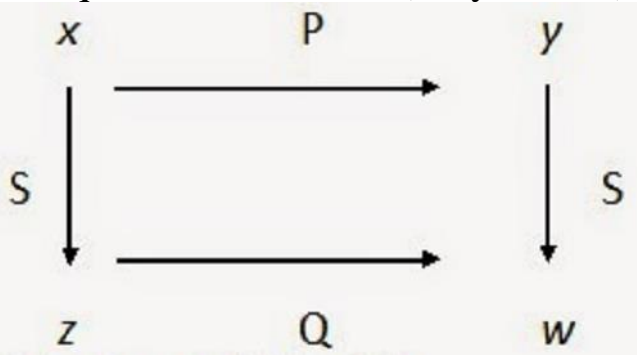

xxvii (Lloyd, 2014).

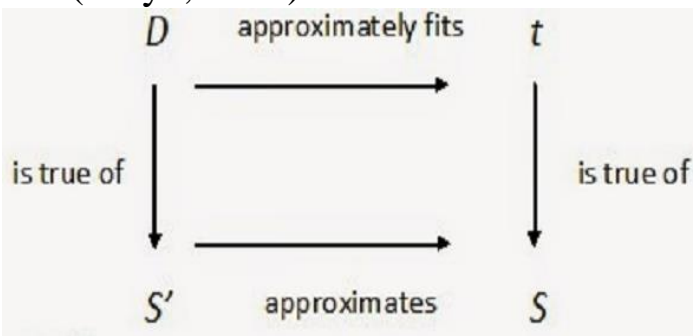

xxviii Esquema para saber qué está más aproximado a la verdad (Lloyd, 2014).

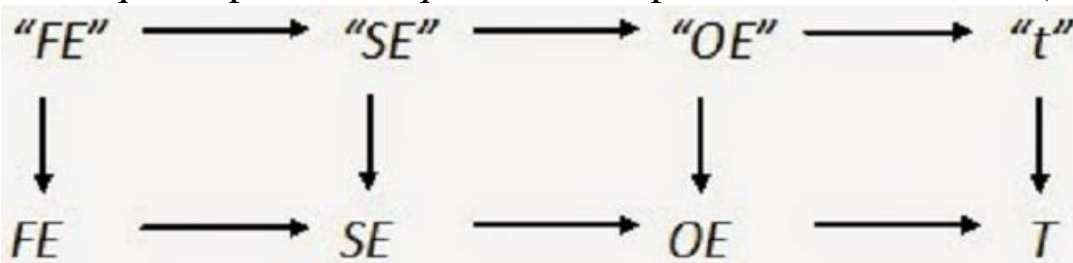

xxix Representación de "cantidad de errores" o falsedades de una teoría (Lloyd, 2014):

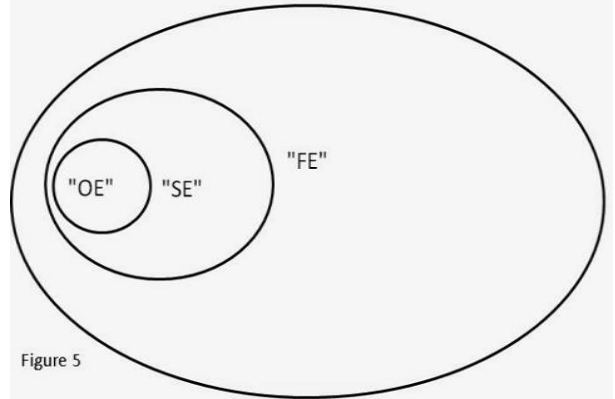

xxx Relación entre verosimilitud y exactitud según Oddie (Oddie, 1986, pág. 187).

$\begin{array}{llllllll}\text { Truthlikeness } & 1 & .75 & .67 & .50 & .33 & .25 & 0\end{array}$

Average overall

$\begin{array}{llllllll}\text { accuracy } & 1 & .81 & .73 & .66 & .57 & .56 & .49\end{array}$

Table 3

xxxi (Miller, 2006, pág. 213)

\begin{tabular}{l|cccl|l|l}
\hline & $x$ & $y$ & $x^{*}$ & $y^{*}$ & $y=f(x)$ & $y^{*}=f^{*}(x)$ \\
\hline $\mathbf{Z}$ & $5 t$ & $3 t$ & $t / 2$ & $-3 t / 4$ & $y=3 x / 5$ & $y^{*}=-3 x^{*} / 2$ \\
$\mathbf{X}$ & $4 t$ & $2 t$ & $t$ & $-t$ & $y=x / 2$ & $y^{*}=-x^{*}$ \\
$\mathbf{T}$ & $t$ & $t$ & $-t / 2$ & $t / 4$ & $y=x$ & $y^{*}=-x^{*} / 2$ \\
\hline
\end{tabular}


xxxii (Miller, 2006, pág. 219)

\section{GALILEI}

\section{LORENTZ}

$$
\begin{array}{ll}
x^{*}=x-v t & x^{*}=(x-v t) / \sqrt{ }\left(1-v^{2} / c^{2}\right) \\
t^{*}=t & t^{*}=\left(t-v x / c^{2}\right) / \sqrt{ }\left(1-v^{2} / c^{2}\right)
\end{array}
$$

xxxiii (Miller, 2006, pág. 218)

\begin{tabular}{l|cccc}
\hline & $\varphi$ & $\psi$ & $\eta$ & $\xi$ \\
\hline $\mathbf{Z}$ & $t$ & $5 m t$ & $t+25 a / 12$ & $5 m t^{2} / 2 a+5 m t$ \\
$\mathbf{X}$ & $t+a$ & $2 m t$ & $t+22 a / 12$ & $5 m t^{2} / 2 a+9 m t / 2$ \\
$\mathbf{T}$ & $t+2 a$ & $m t$ & $t+29 a / 12$ & $5 m t^{2} / 2 a+6 m t$ \\
\hline
\end{tabular}

xxxiv (Miller, 2006, pág. 227)

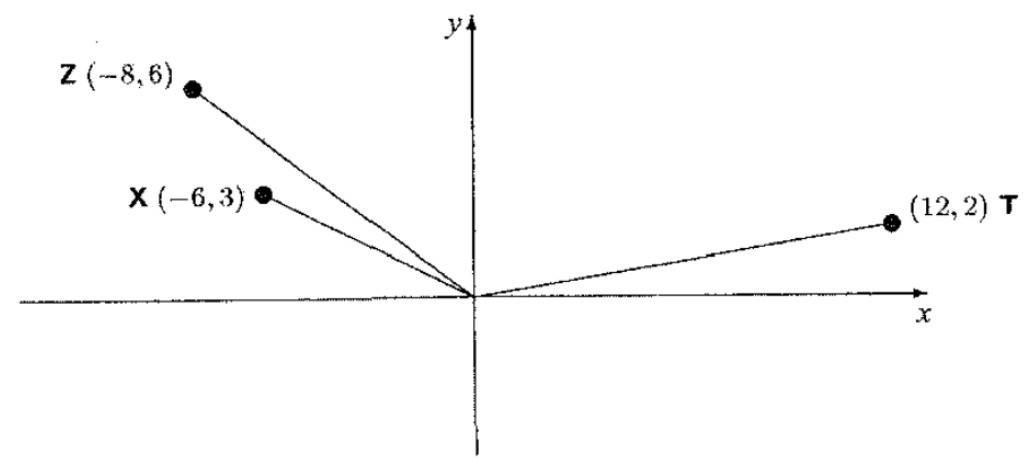

xxxv (Miller, 2006, pág. 228)

\begin{tabular}{l|rrrr} 
& $x$ & $y$ & \multicolumn{1}{c}{$r$} & $\vartheta$ \\
\hline $\mathbf{Z}$ & -8 & 6 & 10.00 & 2.50 \\
$\mathbf{X}$ & -6 & 3 & 6.71 & 2.68 \\
$\mathbf{T}$ & 12 & 2 & 12.17 & 1.03 \\
\hline
\end{tabular}

